\title{
The regulation of protein synthesis by mTOR signaling : a potential target for cancer treatment?
}

Citation for published version (APA):

Weppler, S. A. (2009). The regulation of protein synthesis by mTOR signaling : a potential target for cancer treatment? [Doctoral Thesis, Maastricht University]. Datawyse / Universitaire Pers Maastricht. https://doi.org/10.26481/dis.20091203sw

Document status and date:

Published: 01/01/2009

DOI:

10.26481/dis.20091203sw

Document Version:

Publisher's PDF, also known as Version of record

\section{Please check the document version of this publication:}

- A submitted manuscript is the version of the article upon submission and before peer-review. There can be important differences between the submitted version and the official published version of record.

People interested in the research are advised to contact the author for the final version of the publication, or visit the DOI to the publisher's website.

- The final author version and the galley proof are versions of the publication after peer review.

- The final published version features the final layout of the paper including the volume, issue and page numbers.

Link to publication

\footnotetext{
General rights rights.

- You may freely distribute the URL identifying the publication in the public portal. please follow below link for the End User Agreement:

www.umlib.nl/taverne-license

Take down policy

If you believe that this document breaches copyright please contact us at:

repository@maastrichtuniversity.nl

providing details and we will investigate your claim.
}

Copyright and moral rights for the publications made accessible in the public portal are retained by the authors and/or other copyright owners and it is a condition of accessing publications that users recognise and abide by the legal requirements associated with these

- Users may download and print one copy of any publication from the public portal for the purpose of private study or research.

- You may not further distribute the material or use it for any profit-making activity or commercial gain

If the publication is distributed under the terms of Article $25 \mathrm{fa}$ of the Dutch Copyright Act, indicated by the "Taverne" license above, 
The regulation of protein synthesis by $\mathrm{mTOR}$ signaling:

a potential target for cancer treatment? 
Printed by: Datawyse | Universitaire Pers Maastricht Cover design: Jodil Willems

(C) Sherry Weppler, Maastricht 2009 ISBN 9789052788890 


\title{
The regulation of protein synthesis by mTOR signaling: \\ a potential target for cancer treatment?
}

\author{
Dissertation \\ to obtain the degree of Doctor at Maastricht University, \\ on the authority of the Rector, Prof. dr. G.P.M.F. Mols \\ in accordance with the decision of the Board of Deans, \\ to be defended in public on \\ Thursday, December 3, 2009 at 12:00 p.m.
}

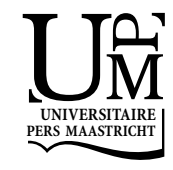




\section{Supervisors}

Prof. dr. B.G. Wouters

Prof. dr. P. Lambin

\section{Co-supervisors}

Dr. M.A.M. van Steensel

Dr. G. Lammering

\section{Assessment Committee}

Prof. dr. F.C.S. Ramaekers (chairman)

Dr. E.J. Bernhard (National Cancer Institute/NIH, USA)

Prof. dr. J.F.C. Glatz

Prof. dr. A.J. van der Kogel (Radboud University Nijmegen Medical Centre)

Prof. dr. P.M. Steijlen 


\section{CONTENTS}

$\begin{array}{lll}\text { Chapter } 1 \text { General introduction } & 9\end{array}$

Chapter 2 Hypoxia as a target for combined modality treatments

Chapter 3 Gene expression during acute and prolonged hypoxia is regulated by distinct mechanisms of translational control

Chapter 4 Expression of EGFR variant vIll promotes both radiation resistance and hypoxia tolerance

Chapter 5 Response of U87 glioma xenografts treated with concurrent rapamycin and fractionated radiotherapy: possible role for thrombosis

Chapter 6 Inhibition of 4E-BP1 phosphorylation and mRNA translation requires simultaneous blockade of mTORC1 and PI3K/Akt signaling

Chapter 7 Neuroendocrine carcinoma in Birt-Hogg-Dubé syndrome

Chapter 8 General discussion

Summary

Samenvatting

Acknowledgements

Curriculum vitae 


\section{ABBREVIATIONS}

\begin{tabular}{|c|c|}
\hline 4E-BP1 & elF4E binding protein 1 \\
\hline 4E-T & elF4E transporter \\
\hline AICAR & 5-aminoimidazole-4-carboxamide 1- $\beta$-D-ribonucleoside \\
\hline AMPK & 5' adenosine monophosphate-activated protein kinase \\
\hline ARCON & $\begin{array}{l}\text { accelerated radiotherapy combined with carbogen and } \\
\text { nicotinamide }\end{array}$ \\
\hline ATF4 & activating transcription factor 4 \\
\hline bFGF & basic fibroblast growth factor \\
\hline BHD & Birt-Hogg-Dubé \\
\hline BNIP3 & BCL2/adenovirus E1B 19kDa interacting protein 3 \\
\hline BrdU & bromodeoxyuridine \\
\hline CA-IX & carbonic anhydrase 9 \\
\hline $\mathrm{CHOP}$ & C/EBP homologous protein \\
\hline DMSO & dimethyl sulfoxide \\
\hline DTT & dithiothreitol \\
\hline ECM & extracellular matrix \\
\hline eEF & eukaryotic elongation factor \\
\hline EGF & epidermal growth factor \\
\hline EGFR & epidermal growth factor receptor \\
\hline EGFRvIII & epidermal growth factor receptor variant 3 \\
\hline elF & eukaryotic initiation factor \\
\hline EPO & erythropoietin \\
\hline ER & endoplasmic reticulum \\
\hline FGF-BP & fibroblast growth factor binding protein \\
\hline FKBP12 & FK506 binding protein $12 \mathrm{kDa}$ \\
\hline FLCN & folliculin \\
\hline FNIP & folliculin interacting protein \\
\hline FRB & FKBP12-rapamycin binding domain \\
\hline GADD34 & growth arrest and DNA damage inducible gene 34 \\
\hline GLUT & glucose transporter \\
\hline $\mathrm{Hb}$ & hemoglobin \\
\hline HIF & hypoxia inducible factor \\
\hline IGF & insulin-like growth factor \\
\hline IGF-BP & insulin-like growth factor binding protein \\
\hline IL & interleukin \\
\hline IRE & iron-responsive element \\
\hline IRES & internal ribosome entry site \\
\hline IRP1 & iron regulatory protein 1 \\
\hline IRS & insulin receptor substrate \\
\hline mAbs & monoclonal antibodies \\
\hline MAPK & mitogen activated protein kinase \\
\hline MEFs & mouse embryonic fibroblasts \\
\hline MMP & matrix metalloproteinase \\
\hline mTOR & mammalian target of rapamycin \\
\hline mTORC & mammalian target of rapamycin complex \\
\hline NF-kB & nuclear factor of kappa-light-chain-enhancer in activated B \\
\hline
\end{tabular}




$\begin{array}{ll}\text { NOS } & \text { nitric-oxide synthase } \\ \text { ODC } & \text { ornithine decarboxylase } \\ \text { ORF } & \text { open reading frame } \\ \text { p70S6K } & \text { ribosomal protein S6 kinase 70kDa } \\ \text { P bodies } & \text { processing bodies } \\ \text { PDGF } & \text { platelet derived growth factor } \\ \text { PDK1 } & \text { 3-phosphoinositide-dependent kinase 1 } \\ \text { PGK1 } & \text { phosphoglycerate kinase 1 } \\ \text { PI3K } & \text { phosphatidylinositol-3-kinase } \\ \text { PIP2 } & \text { phosphatidylinositol 4,5 bisphosphate } \\ \text { PIP3 } & \text { phosphatidylinositol 3,4,5 triphosphate } \\ \text { PKB } & \text { protein kinase B } \\ \text { PKCa } & \text { protein kinase C alpha } \\ \text { PK-M } & \text { pyruvate kinase M } \\ \text { PRAS40 } & \text { proline-rich Akt substrate of 40kDa } \\ \text { Protor } & \text { protein observed with Rictor } \\ \text { PTEN } & \text { phosphatase and tensin homolog } \\ \text { Raptor } & \text { regulatory associated protein of mTOR } \\ \text { REDD1 } & \text { regulated in development and DNA damage responses } \\ \text { Rheb } & \text { ras homolog enriched in brain } \\ \text { Rictor } & \text { rapamycin insensitive companion of mTOR } \\ \text { SIN1 } & \text { stress-activated protein kinase-interacting protein } \\ \text { TCD } 50 & \text { tumor control dose 50\% } \\ \text { TCP } & \text { tumor control probability } \\ \text { TIMP } & \text { tissue inhibitor of metalloproteinases } \\ \text { TNFa } & \text { tumor necrosis factor alpha } \\ \text { TKI } & \text { tyrosine kinase inhibitor } \\ \text { TOP } & \text { terminal oligopyrimidine } \\ \text { TORKinibs } & \text { mTOR kinase domain inhibitors } \\ \text { TOS } & \text { TOR signaling motif } \\ \text { TPZ } & \text { tirapazamine } \\ \text { TSC } & \text { tuberous sclerosis complex } \\ \text { UPA } & \text { urokinase-type plasminogen activator } \\ \text { uPAR } & \text { urokinase-type plasminogen activator receptor } \\ \text { UPR } & \text { unfolded protein response } \\ \text { UTR } & \text { untranslated region } \\ \text { VEGF } & \text { vascular endothelial growth factor } \\ \text { VEGFR } & \text { vascular endothelial growth factor receptor } \\ & \end{array}$



CHAPTER 1

General introduction 


\section{Introduction}

\section{mTOR in normal physiology and disease}

The mammalian target of rapamcyin (mTOR) is a central regulator of cell growth that has been highly conserved through evolution from yeast to mammals. mTOR responds to growth factors, nutrients and energy levels to promote protein synthesis and proliferation under replete conditions and to conserve energy and promote survival during periods of stress or starvation. The importance of TOR for development is clearly illustrated by the embryonic lethality of TOR mutants in Drosophila melanogaster, Caenorhabditis elegans, and Mus musculus. TOR knockout embryos die shortly after implantation due to impaired trophoblast differentiation and failure of embryonic stem cells to proliferate $(1,2)$. Dysfunction of mTOR signaling has also been implicated in a number of human diseases including obesity, type II diabetes, muscle atrophy, cardiac hypertrophy, neurodegenerative disorders such as Huntington's and Alzheimer's disease, and cancer (3). Current research efforts are investigating the therapeutic potential of modulating mTOR signaling in the management of these disorders.

\section{mTOR signaling complexes}

The mTOR kinase carries out its function within the context of two structurally distinct multi-protein complexes, mTORC1 and mTORC2 (Figure 1). mTORC1 consists of mTOR in association with LST8 and Raptor. LST8 and mTOR are the only common components present in both TOR complexes. LST8 binds constitutively to the catalytic domain of mTOR and stimulates its kinase activity (4). Raptor acts as a scaffolding protein to bring mTORC1 substrates such as p70S6K and 4E-BP1 within close proximity of the mTOR kinase domain. By phosphorylation of these substrates, mTORC1 plays a role in regulating the process of mRNA translation. A fourth partner of complex 1, PRAS40, binds mTORC1 under conditions of serum or nutrient deprivation and acts as a negative regulator of mTORC1 (5). Phosphorylation of PRAS40 by Akt or mTOR itself appears to release its inhibitory effect on mTORC1 (6).

mTORC2 contains mTOR, LST8, and Rictor in addition to the recently identified proteins SIN1 and PRR5/Protor $(7,8)$. Much less is known about the upstream regulation and function of this complex, although it is currently an area of active research. This complex has downstream substrates that are distinct from those of mTORC1, most likely as a consequence of the unique proteins present in this complex. Importantly, mTORC2 is responsible for 
phosphorylation of Akt at serine residue 473 (9) and is involved in the organization of the actin cytoskeleton via phosphorylation of protein kinase C-alpha (PKCa) (10).

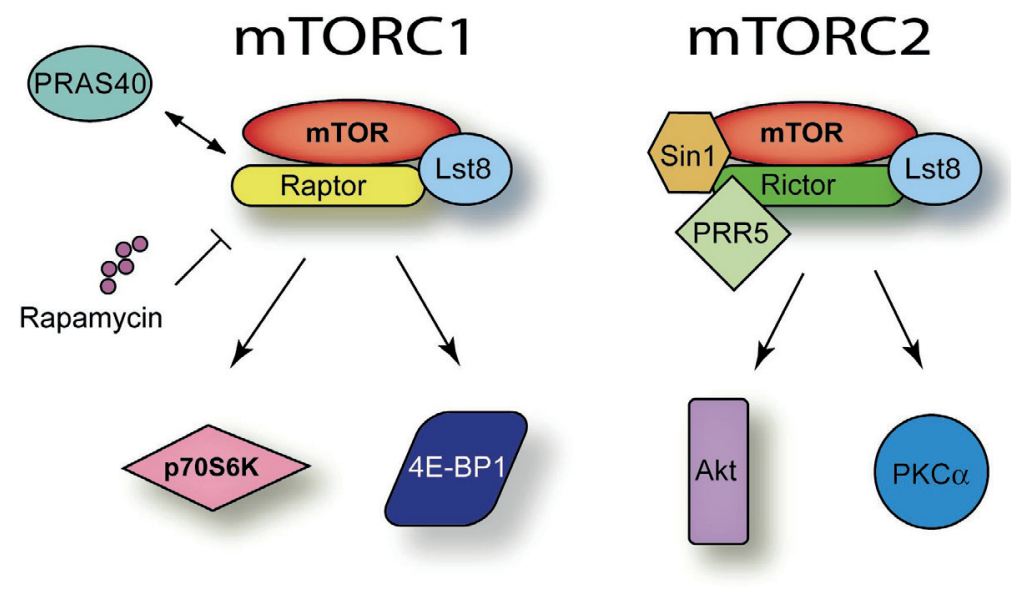

Figure 1. Members of the two multi-protein mTOR complexes. mTOR forms a part of two structurally and functionally distinct protein complexes termed mTORC1 and mTORC2. mTORC1 consists of mTOR in association with LST8 and Raptor. PRAS40 can bind to mTORC1 under certain conditions such as serum or nutrient starvation. mTORC1 regulates mRNA translation via its downstream targets p70S6K and 4E-BP1. mTORC2 comprises mTOR, LST8, and Rictor. Sin1 and PRR5 have also recently been found to associate with mTORC2. Akt and PKCa have been identified as mTORC2 substrates. Rapamycin, the small molecule inhibitor of mTOR, specifically targets mTORC1.

\section{Regulation of mTOR by growth factors}

mTORC1 is activated by the binding of various growth factors to their respective receptors located at the cell surface. Best described is the action of insulin and insulin-like growth factors which stimulate mTORC1 by way of the phosphatidylinositol-3-kinase (PI3K) pathway (Figure 2). There is some evidence that mTORC2 may also be activated by growth factors via PI3K, although little else is currently known about signaling upstream of mTORC2 (9). In addition to insulin, a number of other growth factors such as vascular endothelial growth factor (VEGF), platelet derived growth factor (PDGF), and epidermal growth factor (EGF) can also activate PI3K signaling.

Activation of the pathway begins by binding of the appropriate ligand to its receptor, which stimulates the kinase activity of the receptor to phosphorylate key tyrosine residues within the intracellular domain. Type 1a PI3K is then recruited to these phospho-tyrosine residues by direct binding of $\mathrm{SH} 2$ domains present in its p85 regulatory subunit. In some cases, the interaction 
between p85 and the receptor is indirect and occurs via substrate adaptor proteins such as the insulin receptor substrates IRS1 and IRS2 (11). Binding of PI3K has a dual function in that it releases the inhibitory function of $\mathrm{p} 85$ on the p110 catalytic subunit and also positions PI3K in close proximity to the plasma membrane where its substrate, phosphatidylinositol 4,5 bisphosphate (PIP2), resides. Phosphorylation of PIP2 by PI3K generates phosphatidylinositol 3,4,5 triphosphate (PIP3) which stimulates the recruitment of kinases such as PDK1 and Akt to the plasma membrane via interaction with their pleckstrin homology domains. PI3K signaling is controlled by the phosphatase PTEN, which can dephosphorylate PIP3 to PIP2 and limits further downstream activation of the pathway.

Akt activation requires phosphorylation on two residues; Thr308 which is phosphorylated by PDK1 when the two kinases are brought into close proximity at the plasma membrane by PIP3, and Ser473 which is phosphorylated by the mTORC2 complex $(9,12)$. Phospho-Akt has numerous direct downstream targets that promote survival and growth, one of which is tuberous sclerosis complex 2 (TSC2). TSC2 forms a complex with TSC1, and together this complex is an important negative regulator of mTORC1. Akt activation leads to inhibition of the TSC1/TSC2 complex and thus activation of mTORC1. When TSC2 is phosphorylated by Akt, it becomes bound by 14-33 proteins which sequester it to the cytosol and away from membrane-bound TSC1 (13). The TSC $1 / 2$ complex acts to downregulate mTORC1 activity by stimulating Rheb, a small Ras-like GTPase that interacts with mTORC1, to hydrolyze GTP to GDP. The activity of Rheb is determined by its guanine nucleotide binding state; Rheb in a GTP-bound form strongly stimulates mTORC1 activity while GDP-bound Rheb is inactive. Therefore, upon mitogen exposure, signaling through the PI3K/Akt pathway represses the function of TSC1/2, allowing GTP-bound Rheb to accumulate, and resulting in the activation of mTORC1. A recent report by Sato et al. has shed light on the mechanism of mTORC1 activation by Rheb-GTP (14). They show that Rheb does not induce autophosphorylation of mTOR (ie mTOR kinase activity) but that Rheb enhances the binding of substrates to mTORC1 by increasing their access to Raptor. 


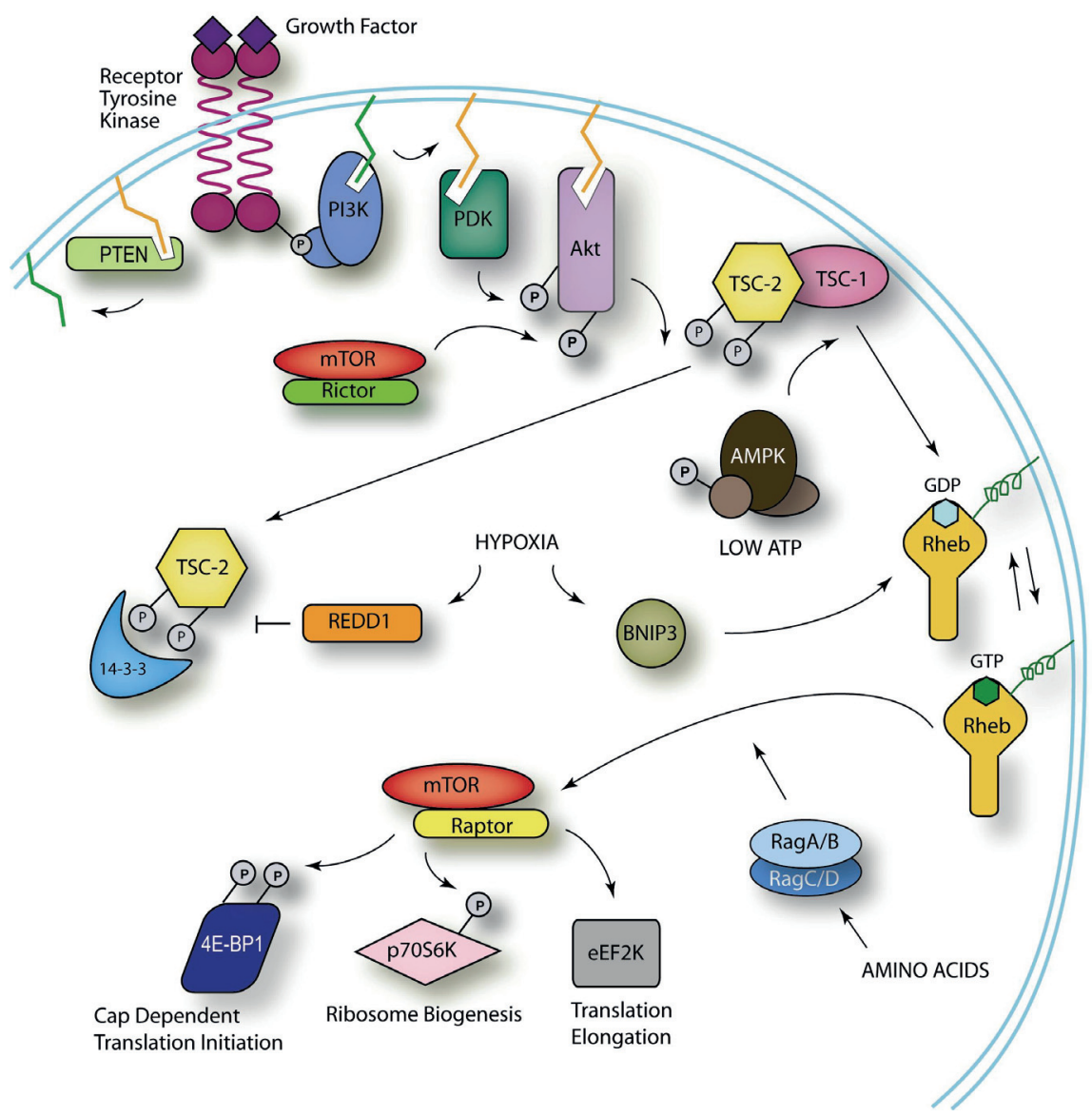

Figure 2. The mTOR signal transduction pathway. Activity of the mTOR-Raptor complex (mTORC1) is positively regulated by extracellular growth factors and by amino acids. Binding of growth factors to a cell surface receptor sets off a signaling cascade through the PI3K-PDK1Akt pathway to the TSC1/2 complex. For complete activation of Akt, phosphorylation of Ser473 by mTOR-Rictor (mTORC2) is required. Currently little is known about the upstream regulation of mTORC2. TSC is a major negative regulator of mTORC1 which is inactivated by Akt which promotes sequestration of TSC2 by 14-3-3 proteins. Hypoxia and low energy levels, on the other hand, can stimulate TSC2 via REDD1 and AMPK respectively. This stimulates the TSC1/2 complex to activate GTP hydrolysis by Rheb, leading to accumulation of GDP-bound Rheb and inhibition of mTORC1. Hypoxia can also promote Rheb-GDP in a TSC-independent manner via BNIP3. Accumulation of GTP-bound Rheb positively regulates activity of mTORC1. Amino acids, by activation of the Rag heterodimer, allow activation of mTORC1 by Rheb-GTP. Downstream targets of mTORC1 include 4E-BP1, p70-S6K and eEF2K which all function in some aspect of mRNA translation. 


\section{Deregulation of PI3K and $\mathrm{mTOR}$ in cancer}

In cancer, mutagenic events often occur in genes whose encoded proteins function in the PI3K signaling pathway, thus resulting in constitutive activation of mTOR and uncontrolled proliferation in the absence of mitogenic signals. Activating mutations in PI3K subunits, mutation or amplification of various growth factor receptors and loss of PTEN expression are common events reported in human malignancies that play a role in the deregulation of $\mathrm{PI} 3 \mathrm{~K}$ signaling. One such mutation involves the epidermal growth factor receptor (EGFR) whereby genomic deletion of exons 2-7 results in expression of a truncated form of the receptor called EGFRvIll. This EGFR variant lacks a portion of the extracellular ligand-binding domain and exhibits constitutively elevated kinase activity in the absence of ligand. EGFRvIll expression is reported in $50 \%$ of gliomas, and is also common in breast, prostate and nonsmall cell lung cancer, but is not found in normal tissue (15). Clinical studies have demonstrated a correlation between EGFRvIll expression and poor prognosis for patients with glioblastoma. Signaling downstream of EGFRvIII is also different compared to wild-type EGFR, with a preferential activation of the PI3K pathway and relatively less stimulation of the MAPK and STAT3 signaling pathways (16). Current interest lies in combining EGFR targeted therapies with mTOR inhibitors, as this treatment strategy seems to be particularly effective towards tumors which develop resistance against EGFR antagonists $(17,18)$.

\section{Regulation of mTOR by cellular energy levels}

Protein synthesis consumes a large proportion of the total cellular energy (estimated at $20-45 \%$ in mammalian cells), thus it is crucial that the rate of mRNA translation be linked to the ATP supply. Since mTOR is a key regulator of protein synthesis, it is not surprising that mTOR activity is coupled to cellular energy status. This connection is mediated by AMPK, a kinase that responds to changes in the ratio of AMP to ATP. It is important to note that the energy dependent regulation of mTOR signaling is dominant to other pathways such as insulin or amino acid stimulation, so that mTOR cannot be activated by other sources if energy levels are not permissive. AMPK becomes activated in a multi-step process that is initiated by the binding of two AMP molecules to the $\gamma$-subunit. This induces a conformational change that allows the subsequent phosphorylation of the $\alpha$-subunit on Thr172 by LKB1 (19). In contrast, under energy replete conditions when the ATP:AMP ratio is high, binding of ATP to AMPK inhibits its activation by preventing this phosphorylation event. Experiments utilizing the AMP mimetic 5-aminoimidazole4-carboxamide 1- $\beta$-D-ribonucleoside (AICAR) have shown that increased AMPK activity correlates with dephosphorylation of mTORC1 targets (20). 
The mechanism that mediates the repression of mTOR by AMPK involves the phosphorylation of TSC2 on multiple sites by AMPK. These phosphorylation events stimulate the inhibitory activity of TSC2 towards Rheb and mTOR (21), in contrast to the inactivating phosphorylation of TSC2 by Akt in response to growth factors. A possible second mechanism occurs by direct phosphorylation of mTOR by AMPK on Thr2446, however the consequence of this phosphorylation event on mTOR function is not clear (22). More recently, Gwinn et al. found that AMPK phosphorylates Raptor on 2 serine residues (Ser722 and Ser792) in response to energy stress (23). Cells with intact AMPK signaling normally undergo cell-cycle arrest during energy stress, however they found that cells unable to phosphorylate Raptor continue to proliferate and ultimately undergo apoptosis. This demonstrates the requirement of Raptor phosphorylation by AMPK for mTORC1 inhibition and cellcycle arrest induced by energy stress (23).

\section{Regulation of mTOR by amino acids}

Given that mTORC1 stimulates processes that use large amounts of amino acids, such as ribosome biogenesis and mRNA translation, it is physiologically advantageous for mTOR to respond to the availability of essential amino acids that mammalian cells are unable to synthesize themselves. Amino acids pay a key role in maintaining basal levels of mTOR signaling. In particular, the intracellular concentration of leucine, an essential branched-chain amino acid, positively regulates $\mathrm{mTORC} 1$ activity through a pathway parallel to the insulin signaling network (24). Leucine uptake is mediated by the SLC7A5-SLC3A2 amino acid antiporter which was recently shown to import leucine while exporting glutamine (25). Thus when cells are starved for glutamine, extracellular leucine cannot enter the cell and as a result, mTORC1 cannot be activated even in the presence of growth factors. The intracellular sensor of leucine or other amino acids which influence mTORC1 activity remains unknown, although it has been shown that the Rag family of small GTPases are involved in transmitting the amino acid input to mTORC1 $(26,27)$. Amino acids stimulate GTP loading of the Rags as well as their binding to Raptor. While this association does not stimulate mTOR kinase activity in vitro, there is evidence that it promotes $\mathrm{mTORC} 1$ relocation to vesicles that contain Rheb. Thus Rags may position mTORC1 at an optimal location to receive growth factor signals via Rheb when amino acids are present.

Vps34, a class 3 PI3K member, may also be involved in regulating mTORC1 under conditions of amino acid or glucose starvation, although the mechanism is currently unknown. Recent research provides evidence that Vps34 
acts at a point downstream of TSC2 and upstream of mTORC1 and shows that Vps34 is required for the insulin stimulation of mTORC1 targets $(28,29)$. However, the involvement of Vps34 in regulating TOR signaling has been brought into question as it was not found to hold true in a Drosophila model (30).

\section{Regulation of mTOR signaling by oxygen}

Oxygen is a crucial regulator of cellular metabolism. When oxygen levels become limiting, cells rapidly activate adaptive mechanisms to reduce energy expenditure by inhibiting energy-intensive processes such as mRNA translation (31). This effect occurs in part through inhibition of mTORC1 as can be seen upon exposure of cells to low oxygen (hypoxia) which reduces mTORC1 activity towards 4E-BP1 and p70S6K (32). Downregulation of mTOR signaling can thus be considered as a component of the cellular response to hypoxia.

A key aspect of the hypoxia response involves the hypoxia-inducible factor (HIF) family of transcription factors which orchestrate the transcriptional changes required for hypoxia tolerance. HIFs are rapidly activated by posttranscriptional mechanisms when oxygen levels drop below normal and subsequently promote the expression of genes whose products promote angiogenesis, anaerobic metabolism, cell motility and invasion. These processes function to improve tissue oxygenation and to maintain cellular ATP production in the absence of oxygen. BNIP3 and REDD1 are transcriptional targets of HIF which act to inhibit mTORC1 activity under hypoxia. REDD1 promotes the dissociation of TSC2 from 14-3-3 proteins, thereby restoring the inhibitory function of TSC2 towards Rheb and mTORC1 (33). BNIP3 acts downstream of TSC2 by interacting with Rheb directly and decreases the amount of active GTP-loaded Rheb (34).

Apart from the HIF-dependent regulation of mTORC1 there are also HIFindependent mechanisms which downregulate mTORC1 activity. For example PML, the promyelocytic leukemia tumor suppressor, also prevents the association of Rheb with mTORC1 but does so by co-localizing with mTOR in the nucleus under hypoxic conditions (35). Severe or long-term hypoxia also contributes to mTORC1 regulation indirectly by activating the energy stress pathway via AMPK as described in the previous section. Energy levels decrease under hypoxia since cells must rely on anaerobic glycolysis to generate ATP, a much less efficient method than the oxygen consuming process of oxidative phosphorylation. However, moderate hypoxia is able to activate AMPK very quickly (within 30 minutes) under serum-deplete conditions, 
which correlates with inhibition of mTORC1 (36). This appears to be a consequence of rapidly decreasing ATP levels under hypoxia when growth factors are not present.

The fact that hypoxia influences mTOR through multiple mechanisms suggests that it may be particularly important for adaptation to this stress.

\section{Possible link between folliculin and mTOR}

An interesting new connection has been made between mTORC1 signaling and folliculin, a protein of unknown function. Germline mutations in the gene encoding folliculin cause a rare genetic disease called Birt-Hogg-Dubé (BHD) syndrome. The characteristic features of BHD include benign skin tumors originating from the hair follicles (fibrofolliculomas) on the face and upper torso, lung cysts leading to spontaneous pneumothorax, and an increased risk of developing renal carcinoma (37). Mutations in the BHD gene are inherited in an autosomal dominant fashion and have been characterized in a number of families. The majority of reported human mutations are either frameshift or nonsense mutations that are predicted to cause protein truncation and result in haploinsufficiency (38). It is thought that folliculin acts as a typical tumor suppressor. Evidence to support this idea comes from renal tumors of BHD patients that have lost expression of the remaining wild-type allele, as well as loss-of-heterozygosity that has been reported at this locus in sporadic kidney tumors $(39,40)$. BHD syndrome displays phenotypic similarities with several familial hamartoma syndromes such as Peutz-Jeghers syndrome, Cowden syndrome and Tuberous Sclerosis Complex. These diseases are characterized by benign tumors that develop in multiple tissues and elevated risk of malignant cancer. Hamartoma syndromes all share a common upregulation of mTORC1 signaling, so it is a logical assumption that folliculin is also somehow connected to mTOR. The link between folliculin and mTORC1 has recently been confirmed in a kidney-specific BHD knock-out mouse where strong activation of Akt/mTORC1 and MAPK pathways was observed (41). How exactly folliculin is regulating mTORC1 is still not clear, although there is some evidence to suggest that folliculin associates with AMPK via two recently identified interacting proteins, FNIP1 and $2(42,43)$. Folliculin may therefore be involved in energy and/or nutrient sensing through the AMPK and mTOR pathways.

\section{Regulation of mRNA translation by $\mathrm{mTOR}$}

The result of stimulating mTORC1 activity is manifested in cellular changes such as increased cell growth (cell size and mass), increased proliferation, 


\section{Chapter 1}

angiogenesis, and increased survival (44). These downstream effects are all thought to be mediated by mTORC1's regulation of mRNA translation.

The process of mRNA translation involves the sequential decoding of mRNA by the ribosome into protein. Ribosomes are composed of 2 subunits, termed the 'small' 40S subunit and the 'large' 60S subunit, which together are comprised of 85-90 distinct proteins and four different ribosomal RNA molecules (45). The ribosome catalyzes the formation of peptide bonds between amino acids of the newly synthesized protein. Translation can be divided into three distinct stages: initiation, elongation, and termination. All stages require additional translation factors which transiently associate with the ribosome and allow separate regulation of the various stages. For most mRNAs, initiation begins by recruiting the $40 \mathrm{~S}$ ribosomal subunit to the $5^{\prime}$ cap structure of the mRNA (Figure 3). This occurs following formation of the elF4F complex consisting of elF4E (the cap-binding protein), elF4G (a large scaffolding protein which is crucial for binding of the ribosome), and elF4A (an RNA helicase) (46). As discussed later, mTOR plays an important role in regulating the availability of elF4E to participate in this complex. Together with the methionyl-tRNA and certain initiation factors, the $40 \mathrm{~S}$ subunit scans along the $5^{\prime}$ untranslated region (UTR) for the start codon. During elongation, the polypeptide chain is assembled in a stepwise fashion according to the reading frame of the mRNA.

Elongation requires two translation factors, eEF1 and eEF2. eEF2 is also regulated by $\mathrm{mTOR}$ and is required for translocation of the ribosome to the next codon in the mRNA (45). Termination occurs when the ribosome encounters a stop codon, resulting in the release of the polypeptide chain and ribosomal subunits. It is common for multiple ribosomes to initiate translation of an mRNA molecule in succession, which allows the simultaneous production of several peptides from a single mRNA. This structure is termed a 'polyribosome' or 'polysome' and can be isolated to determine which mRNAs are actively synthesizing protein at any given time or condition. 


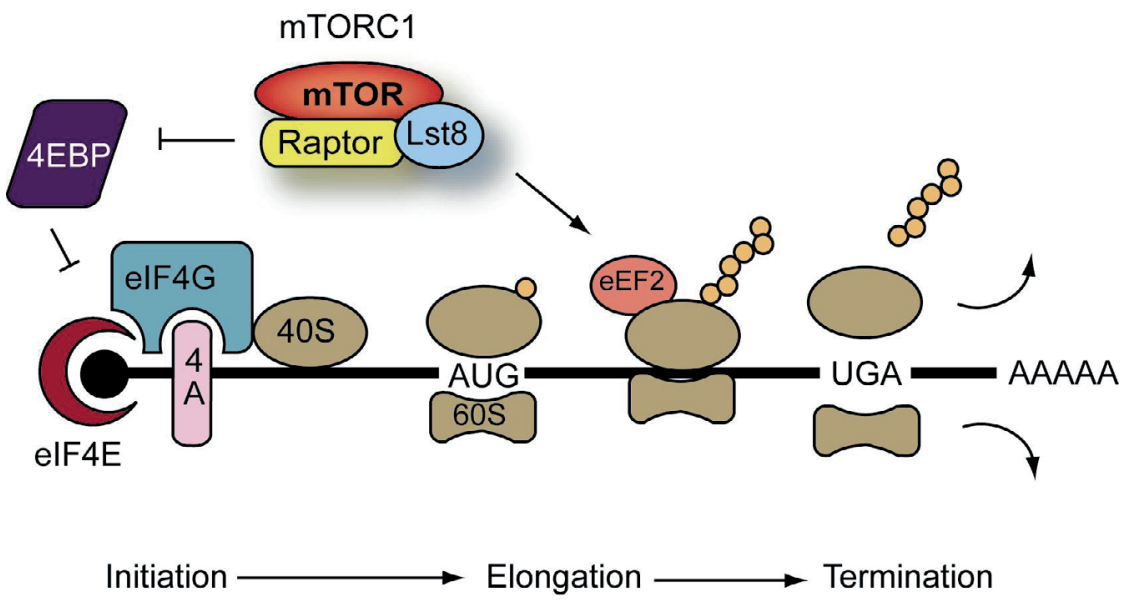

Figure 3. mTORC1 regulation of mRNA Translation. Initiation of translation begins by assembling the elF4E-elF4G-elF4A complex at the 5' cap of the mRNA. This process is stimulated by mTORC1 via inhibition of the elF4E binding protein (4EBP). This initiation complex recruits the $40 S$ ribosomal subunit which scans the 5' UTR for the AUG start codon where the 60S ribosomal subunit joins to form a functional ribosome. Elongation is also stimulated by mTORC1 by activation of the eEF2 elongation factor which is required for translocation of the ribosome along the mRNA. Upon encountering a stop codon, translation is terminated by releasing the nascent peptide and ribosomal subunits.

\section{Translational control and cancer}

There is increasing evidence that aberrant regulation of mRNA translation can contribute to cellular transformation and malignancy. In numerous cancers, general protein synthesis rates are significantly elevated in comparison to normal tissue $(47,48)$. In addition, many tumor suppressors and oncogenes have been identified which control protein synthesis. Finally, strong genetic support of this hypothesis comes from studies which show that experimental overexpression of elF4E can cause malignant transformation (49, 50 ) and from an animal model of B-cell lymphoma that demonstrates elF4E is tumorgenic in vivo $(51,52)$. How then might increased mRNA translation cause cancer? Not all mRNAs respond the same way to increases in translation initiation. Some mRNAs, many of which encode proteins influencing proliferation, apoptosis, angiogenesis, and metastasis, have long 5'UTRs with complex secondary structure and show much greater dependency on elF4E and other cap-dependent initiation factors for their translation. For example, c-Myc, cyclin D1, ornithine decarboxylase (ODC), matrix metalloproteinase-9 (MMP-9), and vascular endothelial growth factor (VEGF) all fall within this group of mRNAs whose translation rates respond to availability of the elF4F initiation complex and whose expression is linked to the defining hallmarks of cancer $(53,54)$. Therefore, prolonged upregulation of translation initiation can 
promote malignancy through the differential expression of mRNAs involved in transformation and tumor progression.

\section{Stress adaptation by translation regulation}

Eukaryotic cells possess a variety of mechanisms to dynamically regulate gene expression, so that appropriate proteins can be made available to cope with diverse cellular environments and to perform tissue-specific functions. These include epigenetic, transcriptional, post-transcriptional, translational, and post-translational processes which all play a role in determining the final proteome composition of a cell at any particular time. Under rapidly changing environmental conditions, translation regulation is particularly important as it allows cells to immediately adjust the production of particular proteins from the existing pool of mRNA transcripts. Transcriptional regulation, by comparison, takes much longer to implement changes at the level of protein expression, since mRNA must first be transcribed, processed and transported to the cytoplasm before new proteins can be synthesized. A simple analogy is to think of translational regulation like carrying an umbrella with you in case it should rain. At the first sign of inclement weather, by raising the umbrella you will stay relatively dry. Should conditions worsen or continue for longer periods of time, you may consider going home to get your raincoat (transcriptional regulation).

\section{Downstream effectors of TORC1 signaling}

The role of mTOR in the regulation of mRNA translation is brought about by the actions of three well described direct downstream effectors of mTORC1: $\mathrm{S} 6 \mathrm{~K}, 4 \mathrm{E}-\mathrm{BP}$, and eEF2 kinase.

\section{S6K}

In order for the S6 kinases (S6K1 and S6K2) to become activated they must be phosphorylated on multiple sites. mTORC1 associates with the S6 kinases through an interaction between Raptor and the TOR-signaling (TOS) motif located at the amino terminus of S6K. This interaction with TORC1 promotes the phosphorylation of S6K at Thr389 by mTOR (55). Phosphorylation at this site is required for subsequent phosphorylation by PDK1 at Thr229 located in the activation loop of the catalytic domain (56). Once phosphorylated at Thr229, S6K is fully activated and can phosphorylate its own downstream targets, such as ribosomal protein S6 (a part of the 40S ribosomal subunit). $\mathrm{S} 6$ phosphorylation correlates with increased protein synthesis and since S6 is located at the mRNA binding site of the ribosome, it is hypothesized to be involved in positively regulating translation $(57,58)$. However, there is little evidence that demonstrates that $\mathbf{S 6}$ phosphorylation actu- 
ally stimulates translation. One theory that has since been disproved is that S6K controls the translation of a subset of mRNAs that contain a 5' terminal oligopyrimidine (TOP) tract. 5' TOP mRNAs include a number of ribosomal proteins and translation elongation factors and the translation of these mRNAs correlates strongly with mTORC1 activity (59). However, S6K1/S6K2 knockout mice still retained translation of 5' TOP mRNAs which could be blocked using rapamycin, an mTORC1 inhibitor (60). Therefore, there appears to be another mTORC1-dependent protein involved in the regulation of 5' TOP translation other than the S6 kinases. However, recent evidence has shown that while TOP translation is dependent on mTOR, knock-down of either raptor or rictor has only a slight inhibitory effect, therefore suggesting that mTOR may regulate TOP translation through a novel pathway with only a minor contribution of mTORC1 (61). Nevertheless, the role of mTOR in 5' TOP translation is clear and demonstrates how mTOR signaling can stimulate ribosome biogenesis through increased production of ribosomal proteins.

Of course, functional ribosomes also require a rRNA component. mTOR is also able to control rDNA transcription by a link between S6K and the UBF rDNA transcription factor (62). Thus, mTORC1 signaling to S6K will ultimately increase the total translational capacity of the cell and lead to an increase in cell size and mass.

Not long ago, S6K1 was shown to phosphorylate elF4B and facilitate its recruitment into translation initiation complexes (63). This target of S6K may perhaps be physiologically more important than $\mathrm{S} 6$ in regulating translation. elF4B stimulates the RNA helicase activity of elF4A. Data suggest that phosphorylation enhances elF4B activity and promotes the translation of mRNAs containing secondary structure (64).

A negative feedback loop of the PI3K/Akt/TORC1 pathway has also been described which involves phosphorylation of the insulin-receptor substrates IRS1 and IRS2 by S6K (65). This serves to downregulate insulin stimulation of the PI3K pathway. However, if chronically activated, this negative feedback loop may contribute to insulin resistance and the onset of obesity or diabetes.

\section{E-BP}

The elF4E binding proteins (4E-BP1, 2 and 3 ) are a group of translational repressor proteins which compete with elF4G for an overlapping binding site on elF4E, so that when 4E-BP is bound to elF4E, it prevents formation of the elF4F complex and recruitment of the $40 \mathrm{~S}$ ribosome for translation initiation (46). In this way, 4E-BPs are important for the repression of cap-dependent translation by mTOR under sub-optimal growth or stress conditions. Trans- 
genic mice lacking 4E-BP1 and 4E-BP2 display elevated insulin resistance and sensitivity to diet-induced obesity, demonstrating a role for $4 \mathrm{E}-\mathrm{BPs}$ as "metabolic brakes" (66).

The interaction between 4E-BP and elF4E is regulated by a complex series of phosphorylation events. Hypo-phosphorylated 4E-BPs bind elF4E with high affinity, whereas hyper-phosphorylated 4E-BPs rapidly dissociate (67). The 4E-BPs also rely on a TOS motif for interaction with Raptor and mTORC1, just as the S6Ks. Evidence suggests that mTORC1 is responsible for phosphorylation of 4E-BP1 on Thr37 and Thr46 in response to nutrient signaling (68). Phosphorylation of 4E-BP1 occurs in a hierarchical manner such that phosphorylation of Thr37 and Thr46 is required to prime subsequent phosphorylation of Thr70, followed by Ser65 (69). Thr70 and Ser65 are responsive to insulin and growth factors and respond to inhibition by rapamycin. However, in vitro kinase assays do not confirm mTOR as the kinase that directly phosphorylates these residues (68). Therefore it seems likely that an mTORC1-associated or mTORC1-controlled kinase is required for phosphorylation of these sites.

\section{eEF2}

In addition to regulating translation initiation, mTORC1 also influences the elongation step of protein synthesis via eEF2. Association of eEF2 with the ribosome is controlled by phosphorylation of Thr56 in its GTP-binding domain (70). Phosphorylation of this residue is catalyzed by eEF2 kinase and inhibits the binding of eEF2 to the ribosome, thus impairing its activity. mTOR signaling negatively regulates eEF2 kinase activity by multiple inhibitory phosphorylation events. One of these sites (Ser 366) has been shown to be a direct target of S6K1 (71). Phosphorylation of two additional sites (Ser78 and Ser359) is also dependent upon mTORC1, although the kinase(s) directly responsible has yet to be identified (72). Therefore, by blocking the inhibitory effect of eEF2 kinase upon eE2F, mTOR can promote translation elongation.

\section{mTOR inhibitors in cancer therapy}

The mTOR kinase was discovered as the result of studies conducted in yeast investigating a macrolide compound with antifungal properties called rapamycin, what would later become known as the first mTOR inhibitor (73). Rapamycin was first isolated from the bacterium Streptomyces hygroscopicus obtained from a soil sample collected on Easter Island (Rapa Nui) in the early 1970s (74). Due to the immunosuppressant properties of rapamycin, its development as an antifungal agent was not pursued. However, this same property made rapamycin attractive for the treatment of graft rejection after organ transplanta- 
tion. As a laboratory tool, rapamycin enabled the elucidation of the mTOR pathway and has shed light on the potential of mTOR inhibitors for the treatment of a broad range of disorders including cancer, inflammatory and cardiovascular diseases. A number of rapamycin analogs with superior pharmacokinetic properties have been developed, for example RAD001 (Novartis), CCI779 (Wyeth) and AP23573 (Ariad), all of which are currently undergoing clinical testing for the treatment of various malignancies (44). FDA approval has been granted to mTOR inhibitors for use in solid organ transplants and in drug-eluting stents for cardiovascular disease.

The mechanism of rapamycin's inhibitory action is distinct from other smallmolecule kinase inhibitors and also contributes to its remarkable specificity. In order to be biologically active, rapamycin must bind initially to a cytoplasmic receptor protein, FKBP12. This complex then interacts with the FRB (FKBP12-rapamycin binding) domain of mTOR (Figure 4). Since the FRB domain lies outside of the catalytic domain, rapamycin-FKBP12 is not thought to function by direct inhibition mTOR catalytic activity but rather by means of steric hindrance whereby the association of mTOR with raptor is disrupted and thus substrate acquisition to mTORC1 is impaired (75). The FRB domain is unique to mTOR and is not found in similar kinases of the PI3K-related kinase family, therefore contributing to rapamycin's specificity. Another clinically relevant advantage is that the interaction between rapamycin-FKBP12 and mTOR is extremely stable, thus making the blockade of mTORC1 signaling essential irreversible once the complex has formed $(76,77)$. For reasons that are not clear, rapamycin-FKBP12 binds only to mTOR proteins that reside in mTORC1 (i.e. mTOR present within the mTORC2 complex is unable to bind rapamycin-FKBP12 directly). One possibility is that components of mTORC2 may physically block binding of rapamycin-FKBP12 to mTOR when in this complex. However, chronic treatment of cells with rapamycin can indirectly inhibit mTORC2 function by binding to newly synthesized mTOR protein and limiting the pool of mTOR molecules available for assembly into mTORC2 (78). 


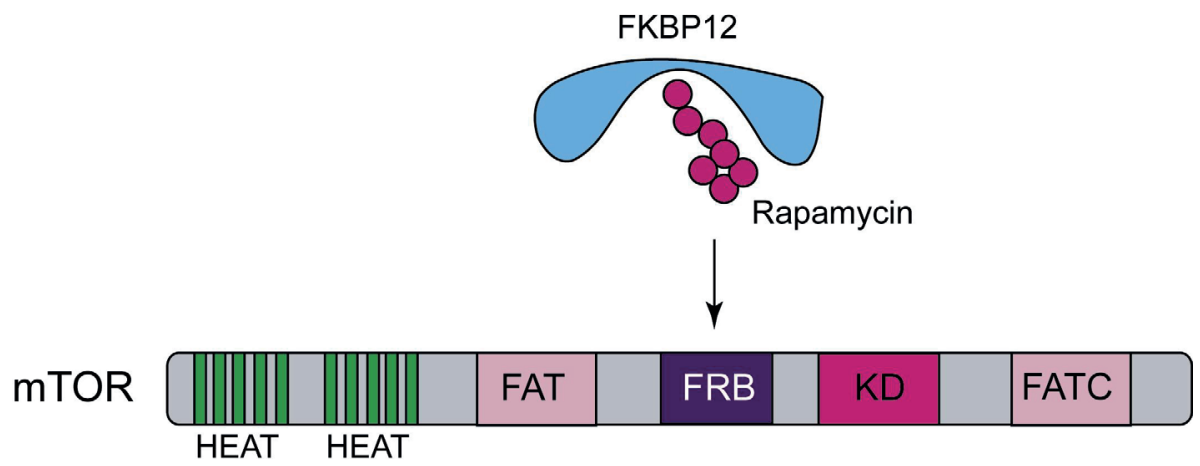

Figure 4. Inhibition of mTOR by rapamycin. The FRB domain of mTOR serves as the highaffinity binding site for the rapamycin-FKBP12 complex. Other important mTOR domains include the N-terminus HEAT domains which mediate protein-protein interactions and the kinase domain (KD) which harbors the catalytic site. The FAT and FATC domains are conserved regions found in protein which are members of the PI3K-like kinase (PIKK) family.

\section{Aims of this thesis}

In this thesis, I examine various aspects related to mTOR signaling in cancer with a focus on its role in the tumor microenvironment. The general aims of this thesis are to elucidate how mTOR signaling and the regulation of mRNA translation contribute to the response of tumor cells to microenvironmental stresses such as hypoxia or to cancer therapy, in order to exploit mTOR as a potential therapeutic target.

\section{Specific objectives}

Hypoxia is a common feature of solid tumors that contributes to mTOR regulation and modulates mRNA translation by both mTOR-dependent and independent mechanisms. Chapter 2 describes why hypoxia adversely affects patient prognosis and how we can exploit the unique properties of hypoxic tumors for cancer treatment. In chapter 3 , the mechanisms regulating mRNA translation inhibition under hypoxia are characterized. By examining cells cultured under hypoxic conditions, the dynamic changes in global mRNA translation, as well as several patterns of gene-specific changes in translation are quantified.

In chapter 4, we investigated the involvement of a signaling molecule upstream of mTOR (EGFRvIII) in tumor progression and response to therapy. A stable cell line model was generated and used to assess the impact of EGFRvIll on radiation sensitivity, in vivo tumor growth, and survival under hypoxia. 
Chapter $\mathbf{5}$ addresses the potential of mTOR as a therapeutic target in cancer using an animal model. In order to determine if mTOR inhibition could improve the local tumor control brought about by radiotherapy, rapamycin was given in combination with fractionated radiation to mice carrying glioblastoma xenografts.

In chapter 6 we characterized the regulation of mRNA translation initiation mediated by the mTORC1 target 4E-BP1. In this study, a parallel mTORC1independent pathway that signals to $4 \mathrm{E}-\mathrm{BP} 1$ is described.

A number of genetic syndromes that are characterized by benign hamartoma tumors, display overactive mTOR signaling. In chapter 7 , we present an interesting case of Birt-Hogg-Dubé syndrome in which we investigated the involvement of mTORC1 in tumor tissue from the patient. In addition, preliminary data suggesting the involvement of mTORC2 are presented in the discussion. 


\section{References}

1. Gangloff, Y. G., Mueller, M., Dann, S. G., Svoboda, P., Sticker, M., Spetz, J. F., Um, S. H., Brown, E. J., Cereghini, S., Thomas, G., and Kozma, S. C. Disruption of the mouse mTOR gene leads to early postimplantation lethality and prohibits embryonic stem cell development. Mol Cell Biol, 24: 9508-9516, 2004.

2. Murakami, M., Ichisaka, T., Maeda, M., Oshiro, N., Hara, K., Edenhofer, F., Kiyama, H., Yonezawa, K., and Yamanaka, S. mTOR is essential for growth and proliferation in early mouse embryos and embryonic stem cells. Mol Cell Biol, 24: 6710-6718, 2004.

3. Tsang, C. K., Qi, H., Liu, L. F., and Zheng, X. F. Targeting mammalian target of rapamycin (mTOR) for health and diseases. Drug Discov Today, 12: 112-124, 2007.

4. Kim, D. H., Sarbassov, D. D., Ali, S. M., Latek, R. R., Guntur, K. V., Erdjument-Bromage, H., Tempst, P., and Sabatini, D. M. GbetaL, a positive regulator of the rapamycin-sensitive pathway required for the nutrient-sensitive interaction between raptor and mTOR. Mol Cell, 11: 895-904, 2003.

5. Vander Haar, E., Lee, S. I., Bandhakavi, S., Griffin, T. J., and Kim, D. H. Insulin signalling to mTOR mediated by the Akt/PKB substrate PRAS40. Nat Cell Biol, 9: 316-323, 2007.

6. Oshiro, N., Takahashi, R., Yoshino, K., Tanimura, K., Nakashima, A., Eguchi, S., Miyamoto, T., Hara, K., Takehana, K., Avruch, J., Kikkawa, U., and Yonezawa, K. The proline-rich Akt substrate of $40 \mathrm{kDa}$ (PRAS40) is a physiological substrate of mammalian target of rapamycin complex 1. J Biol Chem, 282: 20329-20339, 2007.

7. Jacinto, E., Facchinetti, V., Liu, D., Soto, N., Wei, S., Jung, S. Y., Huang, Q., Qin, J., and $\mathrm{Su}, \mathrm{B}$. SIN1/MIP1 maintains rictor-mTOR complex integrity and regulates Akt phosphorylation and substrate specificity. Cell, 127: 125-137, 2006.

8. Pearce, L. R., Huang, X., Boudeau, J., Pawlowski, R., Wullschleger, S., Deak, M., Ibrahim, A. F., Gourlay, R., Magnuson, M. A., and Alessi, D. R. Identification of Protor as a novel Rictor-binding component of mTOR complex-2. Biochem J, 405: 513-522, 2007.

9. Sarbassov, D. D., Guertin, D. A., Ali, S. M., and Sabatini, D. M. Phosphorylation and regulation of Akt/PKB by the rictor-mTOR complex. Science, 307: 1098-1101, 2005.

10. Sarbassov, D. D., Ali, S. M., Kim, D. H., Guertin, D. A., Latek, R. R., Erdjument-Bromage, H., Tempst, P., and Sabatini, D. M. Rictor, a novel binding partner of mTOR, defines a rapamycin-insensitive and raptor-independent pathway that regulates the cytoskeleton. Curr Biol, 14: 1296-1302, 2004.

11. Vivanco, I. and Sawyers, C. L. The phosphatidylinositol 3-Kinase AKT pathway in human cancer. Nat Rev Cancer, 2: 489-501, 2002.

12. Flynn, P., Wongdagger, M., Zavar, M., Dean, N. M., and Stokoe, D. Inhibition of PDK-1 activity causes a reduction in cell proliferation and survival. Curr Biol, 10: 1439-1442, 2000.

13. Cai, S. L., Tee, A. R., Short, J. D., Bergeron, J. M., Kim, J., Shen, J., Guo, R., Johnson, C. L., Kiguchi, K., and Walker, C. L. Activity of TSC2 is inhibited by AKT-mediated phosphorylation and membrane partitioning. J Cell Biol, 173: 279-289, 2006.

14. Sato, T., Nakashima, A., Guo, L., and Tamanoi, F. Specific activation of mTORC1 by RHEB G-protein in vitro involves enhanced recruitment of its substrate protein. J Biol Chem, 2009.

15. Lammering, G. The Epidermal Growth Factor Receptor (EGFR)-Family Members as Targets to Improve the Radiosensitivity of Human Malignant Solid Tumors

Ph.D. Thesis, pp. 212. Maastricht: Maastricht University, 2004.

16. Huang, P. H., Mukasa, A., Bonavia, R., Flynn, R. A., Brewer, Z. E., Cavenee, W. K., Furnari, F. B., and White, F. M. Quantitative analysis of EGFRvIll cellular signaling networks reveals a combinatorial therapeutic strategy for glioblastoma. Proc Natl Acad Sci U S A, 104: 12867-12872, 2007.

17. Li, D., Shimamura, T., Ji, H., Chen, L., Haringsma, H. J., McNamara, K., Liang, M. C., Perera, S. A., Zaghlul, S., Borgman, C. L., Kubo, S., Takahashi, M., Sun, Y., Chirieac, L. R., Padera, R. F., Lindeman, N. I., Janne, P. A., Thomas, R. K., Meyerson, M. L., Eck, M. J., Engelman, J. A., Shapiro, G. I., and Wong, K. K. Bronchial and peripheral murine lung carcinomas induced by T790M-L858R mutant EGFR respond to HKI-272 and rapamycin combination therapy. Cancer Cell, 12: 81-93, 2007.

18. Bianco, R., Garofalo, S., Rosa, R., Damiano, V., Gelardi, T., Daniele, G., Marciano, R., Ciardiello, F., and Tortora, G. Inhibition of mTOR pathway by everolimus cooperates with EGFR inhibitors in human tumours sensitive and resistant to anti-EGFR drugs. Br J Cancer, 98: 923-930, 2008. 
19. Hawley, S. A., Boudeau, J., Reid, J. L., Mustard, K. J., Udd, L., Makela, T. P., Alessi, D. R., and Hardie, D. G. Complexes between the LKB1 tumor suppressor, STRAD alpha/beta and MO25 alpha/beta are upstream kinases in the AMP-activated protein kinase cascade. J Biol, 2: 28, 2003.

20. Bolster, D. R., Crozier, S. J., Kimball, S. R., and Jefferson, L. S. AMP-activated protein kinase suppresses protein synthesis in rat skeletal muscle through down-regulated mammalian target of rapamycin (mTOR) signaling. J Biol Chem, 277: 23977-23980, 2002.

21. Inoki, K., Zhu, T., and Guan, K. L. TSC2 mediates cellular energy response to control cell growth and survival. Cell, 115: 577-590, 2003.

22. Cheng, S. W., Fryer, L. G., Carling, D., and Shepherd, P. R. Thr2446 is a novel mammalian target of rapamycin (mTOR) phosphorylation site regulated by nutrient status. J Biol Chem, 279: 15719-15722, 2004.

23. Gwinn, D. M., Shackelford, D. B., Egan, D. F., Mihaylova, M. M., Mery, A., Vasquez, D. S., Turk, B. E., and Shaw, R. J. AMPK phosphorylation of raptor mediates a metabolic checkpoint. Mol Cell, 30: 214-226, 2008.

24. Avruch, J., Long, X., Ortiz-Vega, S., Rapley, J., Papageorgiou, A., and Dai, N. Amino Acid Regulation of TOR Complex 1. Am J Physiol Endocrinol Metab, 2008.

25. Nicklin, P., Bergman, P., Zhang, B., Triantafellow, E., Wang, H., Nyfeler, B., Yang, H., Hild, M., Kung, C., Wilson, C., Myer, V. E., MacKeigan, J. P., Porter, J. A., Wang, Y. K., Cantley, L. C., Finan, P. M., and Murphy, L. O. Bidirectional transport of amino acids regulates mTOR and autophagy. Cell, 136: 521-534, 2009.

26. Kim, E., Goraksha-Hicks, P., Li, L., Neufeld, T. P., and Guan, K. L. Regulation of TORC1 by Rag GTPases in nutrient response. Nat Cell Biol, 10: 935-945, 2008.

27. Sancak, Y., Peterson, T. R., Shaul, Y. D., Lindquist, R. A., Thoreen, C. C., Bar-Peled, L., and Sabatini, D. M. The Rag GTPases bind raptor and mediate amino acid signaling to mTORC1. Science, 320: 1496-1501, 2008.

28. Byfield, M. P., Murray, J. T., and Backer, J. M. hVps34 is a nutrient-regulated lipid kinase required for activation of p70 S6 kinase. J Biol Chem, 280: 33076-33082, 2005.

29. Nobukuni, T., Joaquin, M., Roccio, M., Dann, S. G., Kim, S. Y., Gulati, P., Byfield, M. P., Backer, J. M., Natt, F., Bos, J. L., Zwartkruis, F. J., and Thomas, G. Amino acids mediate mTOR/raptor signaling through activation of class 3 phosphatidylinositol $3 \mathrm{OH}$-kinase. Proc Natl Acad Sci U S A, 102: 14238-14243, 2005.

30. Juhasz, G., Hill, J. H., Yan, Y., Sass, M., Baehrecke, E. H., Backer, J. M., and Neufeld, T. $\mathrm{P}$. The class III $\mathrm{PI}(3) \mathrm{K}$ Vps34 promotes autophagy and endocytosis but not TOR signaling in Drosophila. J Cell Biol, 181: 655-666, 2008.

31. Wouters, B. G. and Koritzinsky, M. Hypoxia signalling through mTOR and the unfolded protein response in cancer. Nat Rev Cancer, 8: 851-864, 2008.

32. Arsham, A. M., Howell, J. J., and Simon, M. C. A novel hypoxia-inducible factorindependent hypoxic response regulating mammalian target of rapamycin and its targets. J Biol Chem, 278: 29655-29660, 2003.

33. DeYoung, M. P., Horak, P., Sofer, A., Sgroi, D., and Ellisen, L. W. Hypoxia regulates TSC1/2-mTOR signaling and tumor suppression through REDD1-mediated 14-3-3 shuttling. Genes Dev, 22: 239-251, 2008.

34. Li, Y., Wang, Y., Kim, E., Beemiller, P., Wang, C. Y., Swanson, J., You, M., and Guan, K. L. Bnip3 mediates the hypoxia-induced inhibition on mammalian target of rapamycin by interacting with Rheb. J Biol Chem, 282: 35803-35813, 2007.

35. Bernardi, R., Guernah, I., Jin, D., Grisendi, S., Alimonti, A., Teruya-Feldstein, J., CordonCardo, C., Simon, M. C., Rafii, S., and Pandolfi, P. P. PML inhibits HIF-1alpha translation and neoangiogenesis through repression of mTOR. Nature, 442: 779-785, 2006.

36. Liu, L., Cash, T. P., Jones, R. G., Keith, B., Thompson, C. B., and Simon, M. C. Hypoxiainduced energy stress regulates mRNA translation and cell growth. Mol Cell, 21: 521-531, 2006.

37. Nickerson, M. L., Warren, M. B., Toro, J. R., Matrosova, V., Glenn, G., Turner, M. L., Duray, P., Merino, M., Choyke, P., Pavlovich, C. P., Sharma, N., Walther, M., Munroe, D., Hill, R., Maher, E., Greenberg, C., Lerman, M. I., Linehan, W. M., Zbar, B., and Schmidt, L. S. Mutations in a novel gene lead to kidney tumors, lung wall defects, and benign tumors of the hair follicle in patients with the Birt-Hogg-Dube syndrome. Cancer Cell, 2: 157-164, 2002. 
38. Toro, J. R., Wei, M. H., Glenn, G. M., Weinreich, M., Toure, O., Vocke, C., Turner, M., Choyke, P., Merino, M. J., Pinto, P. A., Steinberg, S. M., Schmidt, L. S., and Linehan, W. M. BHD mutations, clinical and molecular genetic investigations of Birt-Hogg-Dube syndrome: a new series of 50 families and a review of published reports. J Med Genet, 45: 321-331, 2008.

39. Vocke, C. D., Yang, Y., Pavlovich, C. P., Schmidt, L. S., Nickerson, M. L., Torres-Cabala, C. A., Merino, M. J., Walther, M. M., Zbar, B., and Linehan, W. M. High frequency of somatic frameshift BHD gene mutations in Birt-Hogg-Dube-associated renal tumors. J Natl Cancer Inst, 97: 931-935, 2005.

40. Khoo, S. K., Kahnoski, K., Sugimura, J., Petillo, D., Chen, J., Shockley, K., Ludlow, J., Knapp, R., Giraud, S., Richard, S., Nordenskjold, M., and Teh, B. T. Inactivation of BHD in sporadic renal tumors. Cancer Res, 63: 4583-4587, 2003.

41. Baba, M., Furihata, M., Hong, S. B., Tessarollo, L., Haines, D. C., Southon, E., Patel, V., Igarashi, P., Alvord, W. G., Leighty, R., Yao, M., Bernardo, M., Ileva, L., Choyke, P., Warren, M. B., Zbar, B., Linehan, W. M., and Schmidt, L. S. Kidney-targeted Birt-Hogg-Dube gene inactivation in a mouse model: Erk1/2 and Akt-mTOR activation, cell hyperproliferation, and polycystic kidneys. J Natl Cancer Inst, 100: 140-154, 2008.

42. Baba, M., Hong, S. B., Sharma, N., Warren, M. B., Nickerson, M. L., Iwamatsu, A., Esposito, D., Gillette, W. K., Hopkins, R. F., 3rd, Hartley, J. L., Furihata, M., Oishi, S., Zhen, W., Burke, T. R., Jr., Linehan, W. M., Schmidt, L. S., and Zbar, B. Folliculin encoded by the BHD gene interacts with a binding protein, FNIP1, and AMPK, and is involved in AMPK and mTOR signaling. Proc Natl Acad Sci U S A, 103: 15552-15557, 2006.

43. Hasumi, H., Baba, M., Hong, S. B., Hasumi, Y., Huang, Y., Yao, M., Valera, V. A., Linehan, W. M., and Schmidt, L. S. Identification and characterization of a novel folliculin-interacting protein FNIP2. Gene, 415: 60-67, 2008.

44. Bjornsti, M. A. and Houghton, P. J. The TOR pathway: a target for cancer therapy. Nat Rev Cancer, 4: 335-348, 2004.

45. Wang, X. and Proud, C. G. The mTOR pathway in the control of protein synthesis. Physiology (Bethesda), 21: 362-369, 2006.

46. Gingras, A. C., Raught, B., and Sonenberg, N. elF4 initiation factors: effectors of mRNA recruitment to ribosomes and regulators of translation. Annu Rev Biochem, 68: 913-963, 1999.

47. Holland, E. C., Sonenberg, N., Pandolfi, P. P., and Thomas, G. Signaling control of mRNA translation in cancer pathogenesis. Oncogene, 23: 3138-3144, 2004.

48. Bader, A. G. and Vogt, P. K. An essential role for protein synthesis in oncogenic cellular transformation. Oncogene, 23: 3145-3150, 2004.

49. Smith, M. R., Jaramillo, M., Liu, Y. L., Dever, T. E., Merrick, W. C., Kung, H. F., and Sonenberg, N. Translation initiation factors induce DNA synthesis and transform NIH 3T3 cells. New Biol, 2: 648-654, 1990.

50. Lazaris-Karatzas, A., Smith, M. R., Frederickson, R. M., Jaramillo, M. L., Liu, Y. L., Kung, H. F., and Sonenberg, N. Ras mediates translation initiation factor 4E-induced malignant transformation. Genes Dev, 6: 1631-1642, 1992.

51. Ruggero, D., Montanaro, L., Ma, L., Xu, W., Londei, P., Cordon-Cardo, C., and Pandolfi, P. $P$. The translation factor elF-4E promotes tumor formation and cooperates with c-Myc in lymphomagenesis. Nat Med, 10: 484-486, 2004.

52. Wendel, H. G., Silva, R. L., Malina, A., Mills, J. R., Zhu, H., Ueda, T., Watanabe-Fukunaga, R., Fukunaga, R., Teruya-Feldstein, J., Pelletier, J., and Lowe, S. W. Dissecting elF4E action in tumorigenesis. Genes Dev, 21: 3232-3237, 2007.

53. Proud, C. G. Signalling to translation: how signal transduction pathways control the protein synthetic machinery. Biochem J, 403: 217-234, 2007.

54. Hanahan, D. and Weinberg, R. A. The hallmarks of cancer. Cell, 100: 57-70, 2000.

55. Schalm, S. S. and Blenis, J. Identification of a conserved motif required for $\mathrm{mTOR}$ signaling. Curr Biol, 12: 632-639, 2002.

56. Biondi, R. M., Kieloch, A., Currie, R. A., Deak, M., and Alessi, D. R. The PIF-binding pocket in PDK1 is essential for activation of S6K and SGK, but not PKB. Embo J, 20: 4380-4390, 2001.

57. Nielsen, P. J., Duncan, R., and McConkey, E. H. Phosphorylation of ribosomal protein S6. Relationship to protein synthesis in HeLa cells. Eur J Biochem, 120: 523-527, 1981.

58. Stewart, M. J. and Thomas, G. Mitogenesis and protein synthesis: a role for ribosomal protein S6 phosphorylation? Bioessays, 16: 809-815, 1994. 
59. Jefferies, H. B., Fumagalli, S., Dennis, P. B., Reinhard, C., Pearson, R. B., and Thomas, G. Rapamycin suppresses 5'TOP mRNA translation through inhibition of p70s6k. Embo J, 16: 3693-3704, 1997.

60. Pende, M., Um, S. H., Mieulet, V., Sticker, M., Goss, V. L., Mestan, J., Mueller, M., Fumagalli, S., Kozma, S. C., and Thomas, G. S6K1(-/-)/S6K2(-/-) mice exhibit perinatal lethality and rapamycin-sensitive 5'-terminal oligopyrimidine mRNA translation and reveal a mitogen-activated protein kinase-dependent S6 kinase pathway. Mol Cell Biol, 24: 3112-3124, 2004.

61. Patursky-Polischuk, I., Stolovich-Rain, M., Hausner-Hanochi, M., Kasir, J., Cybulski, N., Avruch, J., Ruegg, M. A., Hall, M. N., and Meyuhas, O. The TSC-mTOR pathway mediates translational activation of TOP mRNAs by insulin largely in a raptor- or rictor-independent manner. Mol Cell Biol, 29: 640-649, 2009.

62. Hannan, K. M., Brandenburger, Y., Jenkins, A., Sharkey, K., Cavanaugh, A., Rothblum, L., Moss, T., Poortinga, G., McArthur, G. A., Pearson, R. B., and Hannan, R. D. mTORdependent regulation of ribosomal gene transcription requires $\mathrm{S} 6 \mathrm{~K} 1$ and is mediated by phosphorylation of the carboxy-terminal activation domain of the nucleolar transcription factor UBF. Mol Cell Biol, 23: 8862-8877, 2003.

63. Holz, M. K., Ballif, B. A., Gygi, S. P., and Blenis, J. mTOR and S6K1 mediate assembly of the translation preinitiation complex through dynamic protein interchange and ordered phosphorylation events. Cell, 123: 569-580, 2005.

64. Raught, B., Peiretti, F., Gingras, A. C., Livingstone, M., Shahbazian, D., Mayeur, G. L., Polakiewicz, R. D., Sonenberg, N., and Hershey, J. W. Phosphorylation of eucaryotic translation initiation factor 4B Ser422 is modulated by S6 kinases. Embo J, 23: 1761-1769, 2004.

65. Harrington, L. S., Findlay, G. M., Gray, A., Tolkacheva, T., Wigfield, S., Rebholz, H., Barnett, J., Leslie, N. R., Cheng, S., Shepherd, P. R., Gout, I., Downes, C. P., and Lamb, R. F. The TSC1-2 tumor suppressor controls insulin-PI3K signaling via regulation of IRS proteins. J Cell Biol, 166: 213-223, 2004.

66. Le Bacquer, O., Petroulakis, E., Paglialunga, S., Poulin, F., Richard, D., Cianflone, K., and Sonenberg, N. Elevated sensitivity to diet-induced obesity and insulin resistance in mice lacking 4E-BP1 and 4E-BP2. J Clin Invest, 117: 387-396, 2007.

67. Gingras, A. C., Gygi, S. P., Raught, B., Polakiewicz, R. D., Abraham, R. T., Hoekstra, M. F., Aebersold, R., and Sonenberg, N. Regulation of 4E-BP1 phosphorylation: a novel two-step mechanism. Genes Dev, 13: 1422-1437, 1999.

68. Wang, X., Beugnet, A., Murakami, M., Yamanaka, S., and Proud, C. G. Distinct signaling events downstream of mTOR cooperate to mediate the effects of amino acids and insulin on initiation factor 4E-binding proteins. Mol Cell Biol, 25: 2558-2572, 2005.

69. Gingras, A. C., Raught, B., Gygi, S. P., Niedzwiecka, A., Miron, M., Burley, S. K., Polakiewicz, R. D., Wyslouch-Cieszynska, A., Aebersold, R., and Sonenberg, N. Hierarchical phosphorylation of the translation inhibitor 4E-BP1. Genes Dev, 15: 2852-2864, 2001.

70. Browne, G. J. and Proud, C. G. Regulation of peptide-chain elongation in mammalian cells. Eur J Biochem, 269: 5360-5368, 2002.

71. Wang, X., Li, W., Williams, M., Terada, N., Alessi, D. R., and Proud, C. G. Regulation of elongation factor 2 kinase by p90(RSK1) and p70 S6 kinase. Embo J, 20: 4370-4379, 2001.

72. Browne, G. J. and Proud, C. G. A novel mTOR-regulated phosphorylation site in elongation factor 2 kinase modulates the activity of the kinase and its binding to calmodulin. Mol Cell Biol, 24: 2986-2997, 2004.

73. Heitman, J., Movva, N. R., and Hall, M. N. Targets for cell cycle arrest by the immunosuppressant rapamycin in yeast. Science, 253: 905-909, 1991.

74. Vezina, C., Kudelski, A., and Sehgal, S. N. Rapamycin (AY-22,989), a new antifungal antibiotic. I. Taxonomy of the producing streptomycete and isolation of the active principle. J Antibiot (Tokyo), 28: 721-726, 1975.

75. Oshiro, N., Yoshino, K., Hidayat, S., Tokunaga, C., Hara, K., Eguchi, S., Avruch, J., and Yonezawa, K. Dissociation of raptor from mTOR is a mechanism of rapamycin-induced inhibition of mTOR function. Genes Cells, 9: 359-366, 2004.

76. Hosoi, H., Dilling, M. B., Shikata, T., Liu, L. N., Shu, L., Ashmun, R. A., Germain, G. S., Abraham, R. T., and Houghton, P. J. Rapamycin causes poorly reversible inhibition of mTOR and induces p53-independent apoptosis in human rhabdomyosarcoma cells. Cancer Res, 59: 886-894, 1999. 
77. Banaszynski, L. A., Liu, C. W., and Wandless, T. J. Characterization of the FKBP.rapamycin.FRB ternary complex. J Am Chem Soc, 127: 4715-4721, 2005.

78. Sarbassov, D. D., Ali, S. M., Sengupta, S., Sheen, J. H., Hsu, P. P., Bagley, A. F., Markhard, A. L., and Sabatini, D. M. Prolonged rapamycin treatment inhibits mTORC2 assembly and Akt/PKB. Mol Cell, 22: 159-168, 2006. 


\section{CHAPTER 2}

\section{Hypoxia as a target for combined modality treatments}

European Journal of Cancer. 2002; 38(2):240-257.

B.G. Wouters, S.A. Weppler, M. Koritzinsky, W. Landuyt, S. Nuyts, J. Theys, R.K. Chiu, P. Lambin 


\begin{abstract}
There is overwhelming evidence that solid human tumors grow within a unique microenvironment. This environment is characterized by an abnormal vasculature, which leads to an insufficient supply of oxygen and nutrients to the tumor cells. These characteristics of the environment limit the effectiveness of both radiotherapy and chemotherapy. Measurement of the oxygenation status of human tumors has unequivocally demonstrated the importance of this parameter on patient prognosis. Tumor hypoxia has been shown to be an independent prognostic indicator of poor outcome in prostate, head and neck and cervical cancers. Recent laboratory and clinical data have shown that hypoxia is also associated with a more malignant phenotype, affecting genomic stability, apoptosis, angiogenesis and metastasis. Several years ago, scientists realised that the unique properties within the tumor microenvironment could provide the basis for tumor-specific therapies. Efforts that are underway to develop therapies that exploit the tumor microenvironment can be categorised into three groups. The first includes agents that exploit the environmental changes that occur within the microenvironment such as hypoxia and reduced $\mathrm{pH}$. This includes bioreductive drugs that are specifically toxic to hypoxic cells, as well as hypoxia-specific gene delivery systems. The second category includes therapies designed to exploit the unique properties of the tumor vasculature and include both angiogenesis inhibitors and vascular targeting agents. The final category includes agents that exploit the molecular and cellular responses to hypoxia. For example, many genes are induced by hypoxia and promoter elements from these genes can be used for the selective expression of therapeutic proteins in hypoxic tumor cells. An overview of the various properties ascribed to tumor hypoxia and the current efforts underway to exploit hypoxia for improving cancer treatment will be discussed.
\end{abstract}




\section{Introduction}

\section{Hypoxia is present in solid human tumors}

During the past 10 years, it has become evident that solid human tumors very often contain regions that are deficient in oxygen. The presence of hypoxia has been demonstrated in cervical cancer [1,2], squamous cell carcinoma (SSC) of the head and neck [3,4], melanoma $[5,6]$, breast $[7,8]$ and more recently in prostate cancer [9]. The oxygen levels are typically very heterogeneous both among patients and within individual tumors. Oxygenation status has primarily been measured using either polarographic oxygen electrodes (Eppendorf) or biochemical techniques that rely upon the antibody detection of nitroimidazole-based adducts within hypoxic tissue (pimonidazole, EF5, $\mathrm{EF} 1$ ). Electrode $\mathrm{pO}_{2}$ data have been used extensively in clinical studies and are often referred to as the 'gold standard' for determining tumor oxygenation status. However, these electrodes show no discrimination of cell type or viability and thus will record readings from less significant (radiobiologically speaking) tissue. Since pimonidazole and EF5 are selectively reduced only in viable hypoxic cells, they have a theoretical advantage for determination of relevant hypoxia. This may also explain why Eppendorf $\mathrm{pO}_{2}$ values do not always correlate with the nitroimidazole-based hypoxia marker studies [1012]. Reliable methods of identifying patients with hypoxic tumors will be increasingly important in the coming years as therapies targeting this aspect of the microenvironment approach use in the clinic.

\section{Hypoxia is associated with poor prognosis}

The presence of hypoxic cells in human tumors is considered as one of the multifactorial causes of tumor treatment resistance. Experimental and clinical evidence suggest that the hypoxic fraction in solid tumors reduces sensitivity to conventional treatment modalities, influences growth, and may increase malignant progression. Importantly, tumor hypoxia has been clinically demonstrated to predict an adverse treatment outcome in the radiotherapeutic management of cancer of the head and neck, uterine cervix and soft-tissue sarcomas [2,4,13-16]. In head and neck cancer in particular, there is strong evidence that hypoxia is associated with poor outcome of radiotherapy in terms of locoregional control, disease-free survival and overall survival [13]. This poor prognosis due to hypoxia is independent of known prognostic parameters such as clinical stage. In some cases, the prognostic value of hypoxia was shown to be independent of the treatment modality. Patients with hypoxic tumors in one series had a worse prognosis when treated with sur- 
gery alone [2]. This result implies that hypoxia may be associated with more advanced or aggressive tumors.

\section{Mechanisms for worse prognosis}

\section{Treatment resistance}

For many years, the importance of hypoxia in solid tumors was linked solely to the fact that hypoxic cells are intrinsically more resistant to treatment. For ionizing radiation, the dose required to produce the same amount of cell killing is up to 3 times higher for hypoxic cells compared with well-oxygenated cells [17]. Chemotherapeutic drug resistance in hypoxic cells is also partially caused by reduced toxicity in the absence of molecular oxygen. Some agents, such as bleomycin, require free radicals in their mechanism of cell killing. Chemotherapeutic drug resistance can also be caused by the hypoxiainduced inhibition of cell cycle progression and proliferation, since a number of drugs specifically target highly proliferating cells. Proliferation decreases as a result of decreasing oxygen levels [18], and it has been shown that the drug toxicity falls off as a function of distance from blood vessels [19]. Furthermore, chemotherapeutic drug delivery to hypoxic areas is challenged since tumor hypoxia itself arises from insufficient and distorted vasculature. Thus the effective dose to hypoxic regions may be much less than to other parts of the tumor $[19,20]$.

\section{Increased malignancy}

Recently, data have suggested that conditions within the tumor microenvironment, most notably hypoxia, can influence patient prognosis by means other than treatment resistance. These data have come from both the laboratory and the clinic.

\section{Laboratory data}

There is a wealth of data from the laboratory that implicates hypoxia as a contributor to the malignant phenotype. Hypoxia has been implicated in promoting metastasis, angiogenesis, and selection of cells with a more malignant phenotype.

\section{Metastasis}

Several experimental models have shown that tumor hypoxia is associated with an increased ability to form metastases. Young and coworkers demonstrated many years ago that murine tumor cells exposed to severe hypoxia increased their metastatic potential [21]. Similarly, in the murine KHT-C fibrosarcoma model, hypoxic primary tumors exhibit a significant increase in 
pulmonary metastases [22]. Other in vitro experiments utilising the vasculosa area of early chick embryos to grow human glioblastoma cells demonstrated that microvessel density was significantly increased under hypoxia, and that migration of tumor cells outside of the main tumor mass occurred only under hypoxic conditions [23].

Hypoxia is able to promote tumor metastasis in two ways: (1) by inducing the expression of gene products involved in the metastatic cascade and (2) by providing selection pressure for a more aggressive phenotype (see next section). The initiation of metastasis is a multistep pathway that involves three major processes: degradation of the basement membrane and extracellular matrix (ECM), modulation of cell adhesion molecules, and cell migration. Hypoxia plays a role in influencing several of these areas, thereby making it an attractive target to control tumor progression.

The importance of matrix metalloproteinases (MMPs) in tumor invasion and metastasis is widely accepted. This family of enzymes is capable of degrading constituents of the basement membrane and ECM, including fibrillar collagen, but may also contribute to metastasis through interactions with cell adhesion molecules and migration through the ECM [24]. Several studies have shown that MMP expression is associated with poor prognosis and decreased overall survival [25-27]. Canning and co-workers have shown that MDA-MB-231, a highly metastatic breast carcinoma cell line, displays reduced secretion of tissue inhibitor of metalloproteinase-1 (TIMP-1) and increased expression of MMP-9 under hypoxic conditions in vitro [28]. In addition, the increased invasion of MDA-MB-231 cells through matrigel filters under hypoxia can be markedly reduced by addition of a MMP inhibitor. Similarly, in a rabbit model of myocardial infarction, cardiac myocytes show induced MMP-3 and MMP-9 expression, but downregulate TIMP-1 expression following infarction [29]. This pattern of MMP expression could be duplicated in vitro by culturing myocytes under hypoxic conditions, thus it seems that hypoxia is responsible for modulating MMP expression in several pathological conditions.

Activation of MMPs under hypoxia may be mediated by increased expression of urokinase-type plasminogen activator receptor (UPAR). UPAR is a cell surface receptor responsible for the binding and activation of urokinase-type plasminogen activator (UPA). Activated uPA is able to convert plasminogen into plasmin, which can then act directly in ECM degradation, and initiate the MMP activation cascade [24]. Cell surface associated UPAR is upregulated under hypoxia in vitro, and also contributes to invasiveness [30]. Hypoxia mediates this increased expression by increasing both transcription and sta- 
bility of UPAR RNA [31]. There is also evidence that the association of UPAR with its ligand is directly involved in migration, independent of uPA-mediated proteolysis, which in combination with ECM degradation can markedly enhance invasion [32].

Most research regarding the regulation of cell adhesion molecules by hypoxia has focused on endothelial cells with respect to angiogenesis, with relatively few studies having been conducted using tumor cells themselves. One such study revealed that cell surface integrins and other adhesion molecules, such as CD44 and N-CAM, were transiently downregulated upon exposure to hypoxia, leading to an associated decrease in adhesion to ECM components that returned to normal levels after reoxygenation [33]. If similar changes should occur in vivo, this could have a significant effect on the migration of malignant cells from a hypoxic environment to a new site of tumor growth.

In addition to its pro-inflammatory properties, interleukin-8 (IL-8) has been associated with the tumorigenicity, angiogenesis, and metastasis of numerous tumors including melanoma, prostate, bladder, pancreas and ovarian cancer. In vitro exposure of several different cell types to hypoxia leads to elevated levels of both $I L-8$ mRNA and protein [34,35]. The hypoxic regulation of $I L-8$ mRNA involves increases in both the stability and transcription of the message and is dependent upon the cooperation of the AP-1 and NF-B transcription factors. In vivo analysis by immunohistochemistry and in situ hybridisation of tumor sections has localised IL-8 expression adjacent to necrotic zones, lending even further evidence to the argument that IL-8 expression is regulated by hypoxia within the tumor micro-environment $[34,36]$. IL-8 expression is often correlated with an aggressive phenotype and has the ability to cause nonmetastatic cell lines transfected with $I L-8$ cDNA to become highly tumorigenic and invasive $[37,38]$. IL-8 transfected cells show upregulation of MMP-2 and MMP-9 mRNA, collagenase activity, and increased invasiveness through Matrigel-coated filters.

\section{Selection}

Hypoxia-mediated selection of tumor cells with a diminished apoptotic potential under hypoxic conditions has been suggested as an important biological mechanism for tumor progression [39]. Graeber and colleagues used embryonic fibroblasts derived from wt and p53-deficient mice to investigate the role of p53 in hypoxia-induced apoptosis and showed that oncogenic transformation predisposed cells to hypoxia-induced killing through an apoptotic pathway modulated by p53. They also demonstrated that apoptotic regions were more prevalent in $\mathrm{p} 53^{+/+}$tumors than in $\mathrm{p} 53^{-/-}$tumors and that apoptotic areas colocalised with hypoxic regions, distal to adjacent blood vessels. Based 
on the observation that in a mixture of transformed $\mathrm{p} 53^{-/-}$and $\mathrm{p} 53^{+/+}$cells in a 1 to 1000 ratio, $\mathrm{p} 53^{-/-}$cells had overtaken $\mathrm{p} 53^{+/+}$cells after multiple rounds of hypoxia and aerobic recovery, they concluded that hypoxia could also select for apoptosis-resistant cells. Drawn primarily from these experimental results, a mathematical model has recently been developed that describes the effects of alternating periods of hypoxia and normoxia on tumors that contain wildtype and mutant p53 cells [40]. Based on independent experimental results, the model can predict the time it takes for a subpopulation of mutant p53 tumor cells to become the dominant population within defined tumor regions, both in vitro and in vivo, and provides a qualitative insight into the behaviour of mixed populations of wild-type and mutant cells growing under normoxic and hypoxic conditions. By studying the role of the human papilloma virus (HPV) E6 and E7 genes in sensitising human cervical epithelial cells to hypoxia, Kim and colleagues [41] consolidated the results of Graeber and colleagues and extended the relevance of these observations made in genetically manipulated rodent cells to human neoplasia. Furthermore, studies using three-dimensional cultures of human multicell spheroids have also shown that tumor cells bearing mutant p53 are able to sustain longer periods of cellular proliferation in hypoxic conditions than those with the wild-type gene [42].

The selective pressure resulting from hypoxia is not limited to the selection of cells with reduced apoptotic potential. It has also been shown to provide a possible selection force for cells that have altered oncogenic pathways that result in a switch to a more angiogenic phenotype [43].

By promoting the clonal expansion of cells with reduced apoptosis and increased angiogenesis, hypoxia can contribute to the development and malignancy of tumors. Recent clinical results showing that hypoxic cervical cancers with a low apoptotic index are highly aggressive strongly support this basic experimental concept [44].

\section{Angiogenesis}

Tumor progression requires the formation of new blood vessels-the process of angiogenesis-in order to provide nutrients and remove catabolites from the expanding tumor mass. Angiogenesis is also essential for the efficient dissemination of primary tumor cells during metastasis. The early steps of angiogenesis and tumor metastasis are nearly identical, as both processes involve degradation of the ECM and directed migration of either vascular or neoplastic cells. In addition, angiogenesis requires proliferation of the migrating endothelial cells. Therefore, it is not surprising to find that many of the molecules that facilitate tumor cell invasion during metastasis are also in- 
volved in angiogenesis (i.e. MMPs, the uPA system and cell adhesion molecules), and may also be regulated by hypoxia in this function.

Initiation of angiogenesis begins when cells within the tumor microenvironment respond to hypoxia by the production of the vascular endothelial growth factor (VEGF) [45]. In vitro studies by Rofstad's group have shown that D-12 melanoma cells expressing low VEGF levels under aerobic conditions significantly increase VEGF secretion under hypoxia, and demonstrate increased angiogenesis and metastatic efficiency in mice [46]. In addition to VEGF, hypoxia is also responsible for inducing the expression of the VEGF receptors (VEGFR1 and VEGFR2) through HIF-1 mediated transcription [47]. Thus, it would seem that hypoxia efficiently promotes an angiogenic signal by regulating both the VEGF ligand and its receptors.

Basic fibroblast growth factor (bFGF), like VEGF, is a potent angiogenic factor, but its expression in endothelium does not appear to be directly regulated by hypoxia. bFGF binds with high affinity to heparan sulphate proteoglycans in the ECM where it remains sequestered in an inactive form until released by the FGF binding protein (FGF-BP). Upon mobilisation by FGF-BP, bFGF can exert its biological effects by signaling through one of its four receptor tyrosine kinases [48]. Hypoxia may play an indirect role in upregulating bFGF activity by inducing FGF-BP through the p38 signal transduction pathway [49, 50]. Hypoxia can also regulate the amount of extracellular bFGF available to stimulate endothelial cells by inducing its secretion, along with that of plateletderived growth factor, from macrophages that infiltrate the tumor microenvironment [51].

Integrins $\alpha v \beta 3$ and $\alpha v \beta 5$ are expressed on the angiogenic endothelium where they mediate adhesion with ECM components such as vitronectin. Human umbilical endothelial cells (HUVECs) exposed to $1 \%$ oxygen show increased expression of $\alpha v$ and $\beta 3$ subunits, while $\beta 5$ expression remained constant compared with aerobic controls [52]. A concomitant increase in the attachment to fibrinogen, an av $\beta 3$-mediated process, was also observed under hypoxia. There is evidence that this integrin regulates matrix degradation through the binding of proteolytically active MMP-2, which facilitates collagen degradation in vitro [53]. Cell-matrix interactions can augment VEGF signal transduction through complexes of $\alpha v \beta 3$ and VEGFR-2, whereby binding of vitronectin to its receptor results in increased VEGFR-2 kinase activity [54].

\section{Clinical data}

Several clinical studies support the association between hypoxia and malignancy. Data in primary uterine cervical carcinoma $[1,2,15,55]$, soft-tissue sar- 
coma $[4,56]$ and SSC of the head and neck $[3,13,14,57-61]$ showed that tumor hypoxia was prognostic for poorer outcome, irrespective of the treatment modality. Different end-points were evaluated, locoregional control, diseasefree survival, disease-specific survival or overall survival. In the study of Brizel and colleagues [13], 63 patients with head and neck cancer receiving primary radiotherapy underwent pre-treatment polarographic tumor oxygen measurement of the primary tumor or a metastatic neck lymph node. The median $\mathrm{pO}_{2}$ for the primary lesions was $4.8 \mathrm{~mm} \mathrm{Hg}$, and it was $4.3 \mathrm{~mm} \mathrm{Hg}$ for the cervical nodes. Hypoxia adversely affected 2 -year local control (30 versus $73 \%, P=0.01$ ), disease-free survival ( 26 versus $73 \%, P=0.005$ ), and survival (35 versus $83 \%, P=0.02$ ).

In general, tumor hypoxia does not depend on clinical tumor size, clinical stage, histological type, grade, extent of necrosis, or patient haemoglobin levels, and is therefore an independent predictor of outcome. Based on these results, it has been proposed that tumor hypoxia may directly influence malignancy and that the poor prognosis of hypoxic tumors is not simply a result of resistance to therapy $[2,14]$. Indeed, tumor hypoxia has been shown to promote lymph-vascular space involvement and parametrial infiltration in SCC of the uterine cervix [2]. Moreover, positive correlations between the lactate concentration of the primary tumor and the incidence of lymph node metastases have been demonstrated in cervical carcinoma [62] and in carcinoma of the head and neck [63]. High lactate level is indicative of extensive anaerobic metabolism and, hence, poor oxygenation in the tumor tissue [64].

There is substantial evidence that hypoxia is associated with clinical metastases and several mechanisms have been suggested. Nordsmark and colleagues demonstrated an inverse relationship between the tumor cell potential doubling time (Tpot) and the median tumor $\mathrm{pO}_{2}$ in human soft tissue sarcomas [56]. The authors suggested that a high proliferation rate was confined to more hypoxic tumors. In human cervical carcinoma, a low apoptotic index was associated with highly aggressive tumors [44]. Although experimental studies suggest that apoptotic cell kill is compromised in hypoxic tumors due to TP53 mutations [39], no association between mutant TP53 and hypoxia could be found in human soft-tissue sarcomas [16] or in cervical cancers [65]. In cervical cancers, a high incidence of metastases in squamous cell carcinoma of the uterine cervix is associated with poor oxygenation of the primary tumor and not with vascular density [66].

The exact mechanisms by which tumor hypoxia leads to distant metastases are still to be elucidated. Some suggestions for improving treatment strategies come from the study of Rofstad and colleagues in SCC of the uterine 
cervix treated with radiotherapy. The authors argue that treatment failure was primarily a result of hypoxia-induced radiation resistance rather than hypoxiainduced lymph-node metastasis, suggesting that novel treatment strategies aiming at improving tumor oxygenation or enhancing the radiation sensitivity of hypoxic tumor cells may prove beneficial to improve radiation therapy of advanced cervical carcinoma [67].

\section{Gene expression}

The multiple roles assigned to hypoxia, including the induction of angiogenesis, apoptosis and metastasis, likely result in large part from changes in gene expression that accompany hypoxia. A significant number and wide variety of hypoxia-induced genes have been described. Changes in the expression of many of these genes serve to counteract hypoxia and increase oxygenation, while others affect the cellular adaptation to decreased oxygen levels or mediate death signal pathways.

Upregulation of growth factors and hormones such as vascular endothelial growth factor (VEGF) [68], platelet-derived endothelial cell growth factor/thymidine phosphorylase (PDECGF/TP) [69] and erythropoietin (EPO) [70] results in endothelial cell proliferation and increased red blood cell production and serves to restore oxygen availability. Expression of the VEGF receptor Flt-1 is also induced in endothelial cells under hypoxic conditions [71]. Induction of the messenger molecule nitric oxide synthase (NOS) under hypoxia has been postulated as a mechanism to stimulate vasodilation resulting in increased blood flow [72].

As an adaptation to oxygen deprivation, cells need to shift their adenosine triphosphate (ATP) production from oxidative phosphorylation to anaerobic glycolysis. Thus, the activity of glycolytic enzymes such as phosphoglycerate kinase-1 (PGK-1) [73] and pyruvate kinase M (PK-M) [74] is increased during hypoxia, and the expression of glucose importer proteins (GLUTs) $[75,76]$ are also induced.

Several genes involved in regulating cell survival, metabolism and proliferation have been reported to be induced by hypoxia, including $c$-jun [77], insulin-like growth factor-2 (IGF-2), IGF-binding protein 1 and 3 (IGFBP-1 and IGFBP-3), transforming growth factor $\beta$ (TGF- $\beta$ ) [78], placental growth factor (P1GF) [79], urokinase receptor [80], tyrosine hydroxylase $(T H)$ [81], p27 $7^{K i p 1}$ [82] and $p 21^{\text {War1 }}[83]$. 
The regulation of gene expression under hypoxia has been shown to occur through many different mechanisms, including transcription, mRNA stability, translation and post-translational modifications. VEGF expression in particular is controlled at several levels by hypoxia, including increased transcription initiated by the transcription factor HIF-1 [84], enhancement of message stability by association with an RNA-binding protein HuR [85], and by increased production of a required chaperone protein ORP150 [86]. The 5'UTR of VEGF mRNA has also been shown to contain a functional internal ribosomal entry site (IRES), which facilitates cap-independent translation. This may serve as an advantage under hypoxic conditions where translation is low and competition for cap-dependent translation factors is high [87-89].

Cells exposed to hypoxia upregulate the expression of several transcription factors, including hypoxia-inducible factor (HIF-1) [90], p53 [91], AP-1 [92], C/EBP $\beta$ [93], early growth response 1 (Egr-1) [94] and nuclear factor $\mathrm{kB}$ (NFKB) [95]. Perhaps the most important within this group is HIF-1, which induces the expression of more than 30 known genes (for a review see Ref.[96]), including EPO [90,97], VEGF [98], NOS2 [99], Flt-1 [100], GLUT-1 and GLUT-3, PK-M [101] and IGF-2. The transcription of the HIF-1responsive genes is stimulated through the binding of HIF-1 and other transcriptional activators to a hypoxia responsive element (HRE) in the gene promoter [102-105].

The HIF-1 transcription factor itself, is regulated by a post-translational mechanism. HIF-1 is a heterodimer consisting of the two subunits, HIF-1 $\alpha$ and HIF-1 $\beta$ (identical to the aryl hydrocarbon receptor nuclear translocator (ARNT)) which are both ubiquitously expressed $[71,106]$. HIF-1 $\beta$ protein is stable, while HIF-1 $\alpha$ is targeted for ubiquitination by the von Hippel-Lindau tumor suppressor protein (VHL) and rapidly degraded by the proteasome under well-oxygenated conditions [107-109]. VHL recognises a hydroxylated prolyl residue (P564) in the HIF-1a protein, which remains unhydroxylated under hypoxic conditions [110,111]. Thus, HIF-1 $\alpha$ is stabilised during hypoxia and can dimerise with its partner HIF-1 $\beta$ to induce the transcription of HREresponsive genes.

\section{How do we combat hypoxia?}

The realisation that hypoxia is a common characteristic of human tumors that adversely effects patient prognosis suggests that targeting hypoxia will be an effective means of improving treatment. Scientists and clinicians alike are using two fundamentally different approaches to tackle the problems of hypoxia. The first approach is to improve or restore normal tumor oxygenation, 
and the second approach is to exploit the unique property of tumor hypoxia for targeting treatment to the tumor. The success of these two approaches will ultimately depend upon the relative importance of hypoxia in treatment resistance and malignancy.

\section{Improve oxygenation}

Attempts to increase the oxygen supply to the hypoxic yet potentially viable tumor cells has been a major goal of experimental and clinical research for over 40 years. Various strategies have been considered including hyperbaric or increased oxygen breathing, the administration of hypoxic cell sensitisers, and, more recently, erythropoietin to improve the haemoglobin level and to avoid repeated transfusions. Although most of the early attempts to overcome hypoxia have led to mixed results, in head and neck cancer a large meta-analysis of these trials has shown that oxygen modification results in a significant improvement in local control and disease-specific survival $[112,113]$.

\section{Erythropoietin (EPO)}

EPO is a glycoprotein hormone produced by the kidney in response to tissue hypoxia that stimulates red blood cell production in the bone marrow. Currently, there is active interest in using recombinant human EPO in patients with low haemoglobin $(\mathrm{Hb})$ levels in order to improve tumor oxygenation. The hypothesis is that some hypoxic tumors may result from low $\mathrm{Hb}$ levels in anaemic patients. $\mathrm{Hb}$ concentration has been shown to be an important prognostic factor for the outcome of various cancer types treated by radiotherapy. Most of the clinical studies published have shown better tumor control in patients with higher $\mathrm{Hb}$ levels than in patients with $\mathrm{Hb}$ in the lower part of - or below - the normal range. There seems to be a good documentation for the effect of $\mathrm{Hb}$ on radiation response in carcinoma of the uterine cervix [114-117], in head and neck cancer [118-122], in bronchogenic carcinoma [123-125], in bladder carcinoma [126-129] and prostate carcinoma [130]. Overall, patients with low haemoglobin levels have lower local control and survival. The only prospective study on the effect of transfusion on tumor control is a small study in carcinoma of the cervix [131]. Patients who were transfused to maintain their $\mathrm{Hb}$ level above $135 \mathrm{~g} / \mathrm{l}$ showed significantly improved local control rates.

Recombinant human EPO ( $r$-HuEPO) has been evaluated in normal subjects, as well as in subjects with various anaemic conditions. In oncology, EPO is known to increase the $\mathrm{Hb}$ level in cancer patients without interfering with their course of radiation therapy. In a study by Lavey and colleagues [132], the 40 
participating patients had a $\mathrm{Hb}$ value $<135 \mathrm{~g} / \mathrm{l}$ and a malignant tumor located above the diaphragm without evidence of distant metastasis for which they were scheduled to undergo a 5-8 week course of daily radiation therapy. Half the patients also received $150-300 \mathrm{mg} / \mathrm{kg}$ of EPO subcutaneously (s.c.) three times per week starting $0-10$ days prior to the first dose of radiation. The EPO and control groups did not differ significantly in patient age, gender, tumor type, initial $\mathrm{Hb}$, erythropoietin or iron bioavailability. The $\mathrm{Hb}$ level increased more than $6 \%$ during radiation therapy in all 20 of the EPO patients, but in only $2 / 20$ of the control patients $(P<0.001)$. The $\mathrm{Hb}$ rose from a mean \pm standard deviation (S.D.) of $119 \pm 13 \mathrm{~g} / \mathrm{l}$ to $>140 \mathrm{~g} / \mathrm{l}$ during radiation therapy in $80 \%$ of the EPO group compared with $5 \%$ of the control group $(P<0.001)$. The mean change in $\mathrm{Hb}$ concentration during radiation (an average rise of $5 \%$ per week) in the EPO group was significantly higher than in the control group $(P<0.001)$.

Abels and colleagues also showed that approximately $50-60 \%$ of anaemic cancer patients receiving chemotherapy responded with a $\mathrm{Hb}$ rise of at least $20 \mathrm{~g} / \mathrm{l}$ to EPO therapy given three times weekly at a dose of $150 \mathrm{I.U} . / \mathrm{kg}$ over a period of 12 weeks [133]. In a subsequent open-label dose titration study, doses up to $300 \mathrm{IU} / \mathrm{kg}$, were sometimes required, demonstrating the relative resistance to the effect of EPO in these patients. In another study, 60 anaemic patients treated with neoadjuvant radio-chemotherapy and EPO experienced more pathological responses compared with that of a historical control group (67\% versus $27 \%$ ) [134]. At the moment, several phase III trials are running to test the hypothesis that an increase of $\mathrm{Hb}$ with EPO during radioor chemo-therapy has the ability to improve outcome.

\section{ARCON}

The ARCON protocol (accelerated radiotherapy combined with carbogen and nicotinamide) is currently being evaluated in the clinic. Carbogen $(95 \%$ $\mathrm{O}_{2}+5 \% \mathrm{CO}_{2}$ ) is used to reduce diffusion limited or chronic hypoxia, and nicotinamide is added to reduce acute hypoxia resulting from temporary vasculature shutdown [135-140]. The use of these agents simultaneously has indeed been shown to increase the radiation damaging effect in a variety of rodent tumor models [141-145].

Increased oxygenation of tumors treated with carbogen and nicotinamide has been demonstrated in patients [140]. Promising results have been obtained in several non-randomised clinical studies using this combination in conjunction with accelerated irradiation. The Nijmegen radiotherapy group reported a significant beneficial effect for the treatment of stage T3-T4 SCC laryngeal tumors compared with historical conventional radiation therapy data, both in 
terms of locoregional control and survival $[146,147]$. Phase II clinical results obtained for bladder carcinoma also showed a significantly increased local control and overall survival from the triple combination treatment, when compared with previous experiences using standard radiotherapy [148].

However, these positive findings were not confirmed by a phase $1 / I I$ study of the European Organization for Research and Treatment of Cancer (EORTC) that involved head and neck SCC tumors of various localizations [149]. EORTC studies involving non-small cell lung cancer [150], and glioblastoma were also negative [151]. A randomised phase III clinical trial will be started shortly to ultimately determine the success of this protocol.

\section{Radiosensitisers}

Many years have been dedicated to the search and development of compounds that could substitute for oxygen at the time of radiotherapy. This approach was based on the concept that these compounds could mimic the effects of oxygen at the time of radiation delivery, thereby increasing DNA damage and restoring radiosensivity. However, most of the compounds developed could not be administered to patients at effective concentrations with acceptable toxicity. None the less, hypoxic sensitisers continue to be developed and used in some instances. Nimorazole, a 5-nitroimidazole derivative, has been widely used as an antimicrobial agent against Trichomonas vaginalis and other protozoa including Entamoeba histolytica and Giardia intestinalis with little reported toxicity. Similarly, significant or chronic toxicity has been absent from the phase I and II studies involving the use of nimorazole $[152,153]$. In a large double-blind randomised phase III trial in Denmark, nimorazole was reported to significantly improve the effect of radiotherapy of supraglottic and pharyngeal tumors, while the toxicity of the drug was mild [154]. This result was highly significant, and nimorazole has now been incorporated into the standard treatment of most head and neck cancer patients in Denmark.

\section{Exploit the microenvironment}

The second approach in combating hypoxia is fundamentally different from attempts to restore or replace oxygen. In this scenario, the unique property of tumor hypoxia is used as an advantage for targeting cancer treatment. There are three primary means by which this targeting is currently being attempted. The first is to target the lack of oxygen per se, for example by using bioreductive drugs that are only toxic in the absence of oxygen. The second is to exploit the unique features of the tumor vasculature that are both responsible 
for and a consequence of tumor hypoxia. Finally, one can target the known molecular and cellular biological responses to hypoxia.

\section{Exploit hypoxia per se}

\section{Bioreductive drugs}

Bioreductive drugs are compounds that are reduced by biological enzymes to their toxic, active metabolites. They are designed such that this metabolism occurs only or preferentially in the absence of oxygen. The use of these drugs in combination with traditional therapies has the potential to greatly improve treatment outcome by increasing cytotoxicity to the hypoxic fraction. Tirapazamine (TPZ) is the leading compound in this class of agents and has shown promising results in a number of clinical trials when used in combination with cisplatin and/or radiotherapy [155-157]. A wide number of cell lines are sensitive to TPZ, regardless of their p53 status, and require 50-150 times higher dose for the same toxicity under aerobic conditions [158]. The mechanism of this preferential toxicity is mediated by an enzymatically catalysed one-electron reduction of TPZ, which yields a highly reactive radical capable of causing cell death by producing various types of DNA damage [159]. In the presence of oxygen, the TPZ radical is rapidly oxidized back to the non-toxic parental compound, thus minimizing toxicity to well-oxygenated tissues. Preclinical in vitro testing has shown TPZ to have a synergistic effect on cell kill when given prior to cisplatin [160]. This synergism reflects the findings in animal studies $[158,161]$ and clinical trials $[162,163]$ showing that this combined chemotherapy potentiates the antitumor efficacy of cisplatin without increasing systemic toxicity. The mechanism of this synergism has yet to be elucidated, but has been postulated to involve the inhibition of cisplatininduced DNA cross-link repair [160,164].

Another promising bioreductive drug nearing clinical trial is AQ4N, a prodrug that is activated by reduction in hypoxic cells producing a stable product (AQ4) that intercalates within DNA and blocks topoisomerase II action. A key advantage to this drug is that the active AQ4 is stable, thus allowing diffusion to aerobic regions where it can act to produce a 'bystander' effect, or be effective in areas of transient/acute hypoxia [165]. In murine tumor models, AQ4N is not effective as a single agent, but shows substantial antitumor activity when combined with methods to increase the hypoxic fraction (physical clamping or hydralazine), radiation, or anticancer drugs [166,167].

\section{Gene therapy}

Poor prognosis for many cancer patients prescribed conventional drug or radiation treatments has increased interest in clinical protocols based on gene 
therapy. The aim is to transfer genetic material to the tumor cell or its microenvironment in quantities sufficient to obtain a therapeutic level of expression. However, strategies devised to date have limited efficiency, most notably due to deficiencies in the delivery systems employed. A recent approach to this problem employs the concept of targeting anaerobic bacteria to the hypoxic/necrotic areas of solid tumors. An association between bacteria and tumors dates back more than 100 years ago when William Coley found that certain patients who contracted bacterial infections recovered remarkably well from certain cancers. Currently, Clostridium spp. [168,169] and attenuated Salmonella typhimurium auxotrophs $[170,171]$ are being investigated at several research centres as systems to deliver anti-tumor compounds specifically to the tumor site. The latter strain grows under aerobic and anaerobic conditions, with selectivity for tumors reported as a consequence of its auxotrophic nature. The specificity of clostridia for tumors resides in its obligate requirement for anaerobic conditions, giving Clostridium an advantage over Salmonella. Intravenously (i.v.) injected spores of a non-pathogenic clostridial species have been shown to localise to, and germinate in, the hypoxic/necrotic regions of solid tumors. Although growth alone in the tumor is not sufficient for therapeutic efficacy, the possibility now exists to engineer Clostridium spp. to produce a variety of therapeutic proteins with anticancer properties. Clostridia can thus be used as highly selective in-situ cell factories able to produce and secrete antitumor therapeutics specifically at the tumor site. Moreover, it has been shown that the immune response does not hinder repeated administration of clostridial spores, that colonization can be improved using vascular targeting treatment using Combretastatin A4phosphate (CA-4P) (see next section) and that gene expression can be stopped at any time using suitable antibiotics [172]. We [173] and others $[174,175]$ demonstrated that it is possible to express therapeutic proteins, not only in vitro, but also in vivo after administration of the recombinant clostridia to tumor-bearing animals [176]. Moreover, the specificity of this gene delivery system can be further increased, by placing the therapeutic gene under the regulation of a radio-induced promoter, leading to spatial and temporal control of gene expression [177]. Taken together, these experiments demonstrate that the principle of using the Clostridium vector system, or other anaerobic bacteria such as Bifidobacterium [178], is feasible and holds considerable promise for tumor-specific therapy.

\section{Exploit tumor vasculature}

Abundant evidence has demonstrated that solid tumors require an expansion of the blood supply to provide their oxygen and nutritional requirements. Yet in tumors, this process of angiogenesis results in disproportional and inadequate vascular architecture, with vessels that are structurally and functionally 
different from those in normal tissues [179-181]. Consequently, this abnormal intra-tumoral vessel network, which elicits a high rate of endothelial cell proliferation [182], offers an ideal target for novel therapeutic strategies, such as anti-angiogenesis and vascular targeting.

\section{Anti-angiogenesis}

Angiogenesis is a complex biological process that offers potential therapeutic targets at many points [183]. The target population most often consists of actively dividing and migrating vascular endothelium from established normal host and tumor vessels. Many of the current strategies for therapeutic antiangiogenesis involve the blockade of angiogenic growth factors and the suppression of endothelial cell recruitment through small molecule receptor blockers, specific antibodies or the use of endogenous inhibitors. The five classes of angiogenesis antagonists in current clinical trials include molecules that block matrix breakdown, inhibit endothelial cells directly, block activators of angiogenesis, inhibit endothelial specific integrin/survival signalling and distinct mechanisms of action. Due to the large number of currently investigational anti-angiogenic approaches, we limit our discussion to a select number of drugs currently subject to clinical investigation.

The initial step in the angiogenic process is the degradation of the basement membrane surrounding the endothelial cells [184]. MMPs play a critical role in the degradative process [185]. Thus, inhibitors of MMPs are an obvious choice for anti-angiogenic strategies. Synthetic molecules such as marimastat, prinomastat, and BAY 12-9566 have been investigated as such agents. Unfortunately, phase III clinical trials using these inhibitors alone or in combination with chemotherapy have demonstrated no clinical efficacy [186]. The apparent explanation for this observation is that MMPs may be more important in the early stages of cancer and may not be required once the metastases have been established. Another method to target the enzymatic breakdown of the basement membrane and surrounding tissue is to disrupt the uPA system [187]. The urokinase inhibitor penicillamine is currently being tested in a phase II clinical trial for glioblastoma.

Molecules that inhibit endothelial cell migration and proliferation include the endogenous molecules angiostatin and endostatin [188], as well as the potent teratogen thalidomide. Angiostatin, a fragment of the precursor plasminogen was the first isolated tumor-derived angiogenesis inhibitor [189]. Treatment of experimental animals with angiostatin causes regression of the primary tumor, prevents angiogenesis and metastatic growth $[189,190]$. Endostatin is a C-terminal fragment of collagen type XVIII [191]. Interestingly, the activity of endostatin and angiostatin are synergistic when combined sug- 
gesting different molecular targets [192]. Both of these molecules are currently the subject of phase I clinical trials. Thalidomide has also been shown to have anti-angiogenic properties and in vitro data suggest that it also inhibits endothelial cell and tumor cell proliferation $[193,194]$. Recent reports from phase II clinical trials have shown encouraging results [195,196].

VEGF, its receptor and its signalling pathway are attractive targets for antiangiogenic strategies. A series of compounds that target this pathway including small molecule inhibitors of the VEGF-R, such as SU5416 [197], SU6668 [198], a ribozyme that degrades VEGF mRNA (angiozyme) [199] and antibodies directed against VEGF $[200,201]$ or VEGF-R (PTK-787/ ZK22584) [202] have been developed and are under clinical investigation.

Interactions between tumor cells and the ECM are vitally important for invasion and migration. In particular, $\alpha v \beta 3$ and $\alpha v \beta 5$ integrins, serve as major receptors for ECM-mediated cell adhesion and migration [203]. These integrin molecules have been demonstrated to be upregulated during repair, retinal neovascular-isation and tumor neo-angiogenesis [204-206]. This adhesion event is mediated by an arg-gly-asp (RGD) peptide motif and small peptides containing such a motif have been demonstrated to inhibit integrin function [207]. Angiogenesis is inhibited both by antibodies directed against these integrins and by peptide antagonists that block integrin-extracellular matrix interactions. A humanised monoclonal antibody directed against av $\beta 3$, designated Vitaxin [208,209] and a small molecule blocker of $\alpha \mathrm{v} \beta 3$, EMD121974 are currently the subject of clinical investigation.

A number of anti-angiogenic strategies work through mechanisms distinct from those described above. CAI is an inhibitor of calcium influx [210] currently in phase I studies in combination with paclitaxel against solid tumors. Interleukin-12 (IL-12) is a multifunctional cytokine determined to be antiangiogenic [211-213] by inducing interferon gamma and interferon-yinducible $10 \mathrm{kDa}$ protein (IP10) [214]. Furthermore, the group B streptococcus toxin, CM101 that selectively targets proliferating blood vessels has completed phase I trials with encouraging results [215].

\section{Vascular targeting}

The concept of 'vascular targeting' was championed many years ago $[181,216]$ and has recently become a very active area of research. This concept refers to the use of agents that exploit vasculature features that are unique within the tumor. Several advantages of targeting the vasculature have been presented including: (i) potential efficacy against any solid tumor since the main target is the endothelial cell lining, (ii) lack of treatment- 
induced resistance, since endothelial cells are genetically stable, (iii) accessibility of the drug and target, and (iv) indirect killing of many thousands of tumor cells from vessel damage and subsequent nutrient deprivation. This approach would also result in killing of those cells that are at intermediate levels of hypoxia, resistant to classical therapies [217]. Five different approaches to vascular targeting have been attempted in clinical settings (see Table 1).

The specificity of hyperthermia and photodynamic therapy for vasculature is somewhat limited as is the accessibility of these modalities for a variety of tumor sites. Flavone acetic acid (FAA) has been shown to be active in a variety of murine tumors [218-220]. This activity was accompanied by the induction of tumor necrosis factor a (TNFa), blood flow changes and the induction of haemorrhagic necrosis. However, changes in blood flow were not observed in patients and therefore this agent was ineffective in clinical trials $[221,222]$. Its structural analogue, the 5,6-dimethylxanthenone 4-acetic acid (DMXAA) compound, appears to induce TNFa more strongly in tumors than in normal tissues and to exert specific anti-tumor activity independently in humans $[223,224]$. DMXAA is presently being tested in a phase I trial both in the United Kingdom and New Zealand.

Various tubulin-interfering drugs have also been reported to provide antitumor activity through vasculature shutdown and the induction of haemorrhagic necrosis. This was demonstrated for the tubulin-binding drugs vincristine and vinblastine (both well known chemotherapeutics), colchicine, as well as the structurally similar compound homoharringtonine $[218,220,225]$. However, these effects were only observed at doses near the maximum systemically tolerable concentrations.

More recently, the combretastatin family of tubulin-binding compounds with more selective anti-tumor activity has been introduced [226]. CA-4P has been selected from this family for preclinical and clinical evaluation [219,227-232]. A single CA-4P dose of $1 / 3$ to $1 / 10$ of the maximum tolerable dose (rat or mouse experiments, respectively) results in rapid blood vessel damage, and subsequently tumor necrosis. The efficacy is somewhat tumor-dependentbeing more effective in the mouse KHT sarcoma [230] and the WAG/Rij rat rhabdomyosarcoma [232] models than the mouse $\mathrm{C} 3 \mathrm{H}$ mammary carcinoma [219]. Typically CA-4P results in central tumor necrosis, leaving a viable rim of cells on the edge of the tumor. CA-4P also appears to be much more effective in large tumors $\left(>7 \mathrm{~cm}^{3}\right)$ compared with small $\left(<1 \mathrm{~cm}^{3}\right)$ tumors [232]. The mechanism of action of CA-4P seems to result from a cell shape change that occurs in newly formed endothelial cells, resulting in blood vessel occlu- 
sion and total vascular shutdown $[229,233]$. Currently, a limited number of phase I clinical studies in the United States and the United Kingdom are examining the impact of CA-4P on tumor physiology, as well as general compliance and normal organ function.

Table 1 Vascular targeting strategies with demonstrated preclinical antitumor activity

\begin{tabular}{|c|c|c|}
\hline Hyperthermia & $\begin{array}{l}\text { Damage to endotherlial cells with subsequent al- } \\
\text { teration of micro-haemodynamics and vascular } \\
\text { stasis }\end{array}$ & $\begin{array}{l}\text { e.g. Refs. [246- } \\
\text { 248] }\end{array}$ \\
\hline $\begin{array}{l}\text { Photodynamic ther- } \\
\text { apy }\end{array}$ & $\begin{array}{l}\text { Aims to target directly the tumor cells, but also } \\
\text { induces tumor cell loss through the destruction of } \\
\text { intratumoral microvasculature }\end{array}$ & $\begin{array}{l}\text { e.g. Refs. } \\
{[249,250]}\end{array}$ \\
\hline $\begin{array}{l}\text { Tumor necrosis } \\
\text { factor } \alpha \\
\text { (TNF } \alpha)\end{array}$ & $\begin{array}{l}\text { Vascular damage and subsequent blood flow fail- } \\
\text { ure with acute haemorrhagic intratumoral necrosis; } \\
\text { also true for drugs that mediate their action through } \\
\text { TNFa induction, such as flavone acetic acid (FAA) } \\
\text { and its analogue DMXAA }\end{array}$ & $\begin{array}{l}\text { e.g. Refs. } \\
{[218,225,251]}\end{array}$ \\
\hline $\begin{array}{l}\text { Antibody-directed } \\
\text { Targeting }\end{array}$ & $\begin{array}{l}\text { Targeting tissue factor to initiate thrombosis within } \\
\text { the tumor with the formation of central necrosis }\end{array}$ & e.g. Refs. [252] \\
\hline $\begin{array}{l}\text { Tubulin interfering } \\
\text { Agents }\end{array}$ & $\begin{array}{l}\text { Acute endothelial cell collapse, vessel damage and } \\
\text { blood flow reduction with rapid major haemorrhagic } \\
\text { necrosis }\end{array}$ & $\begin{array}{l}\text { e.g. Refs. } \\
{[219,229,232,253]}\end{array}$ \\
\hline
\end{tabular}

DMXAA, 5,6-dimethylxanthenone 4-acetic acid.

\section{Exploit the biological responses to hypoxia}

The final strategy being pursued to target hypoxia is based on exploiting the recently understood biological responses to hypoxia. As described earlier, cells respond to hypoxia by modulating the expression of many genes. These changes in gene expression, in turn, cause a cellular and tissue response to hypoxia that affects both the cellular sensitivity to treatment and the processes of metastasis and angiogenesis. By targeting the early steps in the activation of these pathways, one may develop more specific and effective types of therapy.

Various biological responses to hypoxia can be viewed in a generalised sequence of four successive steps (see Fig. 1). The first step is carried out by an oxygen sensor-a protein that is capable of sensing and responding to reduced levels of oxygen. Activation of the sensor causes a molecular response consisting of the activation of downstream signalling pathways. This molecular response, in turn, leads to a cellular response, and finally a tissue or tumor response. In the past several years, we have learned much about 
one of the main hypoxic biological response pathways in mammalian cellsthat involving the HIF-1 transcription factor. This pathway serves as a good example of this general response sequence and for how this knowledge can be translated into new cancer therapies.

Two recent reports suggest that the oxygen sensor in the HIF-1 pathway is a prolyl hydroxlyase $[110,111]$. This enzyme, designated HIF-PH, requires oxygen for its activity (hydroxylation of proline residues). In this example, the molecular response to hypoxia is initiated as a result of reduced hydroxylation of a proline residue in the HIF-1 $\alpha$ subunit (P564). Reduced hydroxylation prevents the recognition of HIF- $1 \alpha$ by the VHL ubiquitin ligase, thereby preventing ubiquitination. As a result, HIF-1 is stabilised and can transactivate its many targets, such as EPO, VEGF and GLUT-1. These changes in gene expression lead to a cellular response that may consist of increased glycolysis in the tumor cells or activation of endothelial cell proliferation and migration by binding of VEGF to its receptor. Finally, this leads to a tumor or tissue response that consists of increased angiogenesis, and to increased survival of tumor cells resulting from a switch to anaerobic metabolism [234].

The important part of this illustration is that a detailed biological understanding of this pathway offers a plethora of options for targeting cancer treatment to the tumor. For example, an attractive molecular treatment would be one based on augmenting the activity of the oxygen sensor itself. Since the multiple cellular and tissue effects stem from this one initial protein, it provides a very specific and potent treatment target. There are already many examples of research directed against the second level of this pathway. Several compounds designed to alter the activity of HIF-1 [235,236], VHL [237], or the ubiquitin system itself [238-240] are being explored in cancer treatment. At the level of the cellular response, antibodies and inhibitors of both VEGF and its receptor Flk-1 have been developed (as discussed under the antiangiogenesis strategies). Recent reports suggest that inhibiting the ability of tumor cells to shift to glycolysis would also be advantageous [234,241]. Finally, targeting treatment to the cellular or tissue response of this pathway would consist of the more generalised anti-angiogenesis and hypoxiatargeted therapeutics (both discussed earlier). It is clear that as one moves downwards in this pathway from the oxygen sensor to the cellular and tissue responses, the targets become less specific in nature.

Elements of this pathway can be exploited as well as inhibited. For example, the DNA recognition sequence for the HIF-1 transcription factor is well described. This HRE can be inserted within gene therapy constructs, to limit the expression of therapeutic proteins to hypoxic areas of tumors [242-245]. 
Dachs and colleagues [243] established the potential for tumor hypoxia to be exploited for targeted gene expression by showing that the HRE from the mouse PGK-1 gene could be used to drive expression of heterologous genes within the mass of a solid tumor.

The HIF-1 pathway is relatively well understood and serves as a good example of how knowledge of the biological responses to hypoxia can translate into new therapies. However, there are numerous other molecular and cellular responses to hypoxia that are independent of HIF-1, perhaps each with unique oxygen sensors. Continued research into the basic molecular and cellular responses of hypoxia will undoubtedly contribute further to the development of novel hypoxia-based cancer therapies.

Figure 1. Biological responses to hypoxia can be viewed in terms of four successive steps. The HIF-1 pathway serves as an example of such a response. The first step is to sense that oxygen is limiting and in the HIF-1 pathway this is carried out by an oxygen-dependent prolyl hydroxylase. The second step is the initiation of a molecular response through the activation of downstream signalling pathways. In this example, this results in the activation of several classes of genes as a result of stabilisation of the HIF-1 $\alpha$ subunit. A cellular response occurs due to these changes in gene expression, in this case resulting in a switch to anaerobic metabolism and secretion of angiogenic factors. Finally, a tumor/tissue response occurs. In the HIF-1 pathway, this may be the induction of angiogenesis in the tumor micro-environment together with increased survival and proliferation of the tumor cells. Each of these steps in the biological response to hypoxia is an opportunity for targeting therapy as indicated below each box. 


\section{1) Sensors:}

activity of an oxygen

dependent prolyl hydroxylase

- target activity of hydroxylase

\section{2) Molecular response:}

reduced hydroxylation of HIF

reduced affinity for $\mathrm{VHL}$

gene transcription (VEGF, PGK etc)

- target activity of VHL

- ubiquitin pathway modification

- gene therapy - HRE

\section{3) Cellular response:}

secretion of VEGF

activation of VEGFR

anaerobic metabolism

- antibodies/inhibitors for VEGF

- antibodies/inhibitors for VEGFR

- inhibitors of glycolysis

\section{4) Tissue/tumour response: \\ angiogenesis}

proliferation/survival

- downstream angiogenesis inhibitors

- proliferation/survival modifying agents
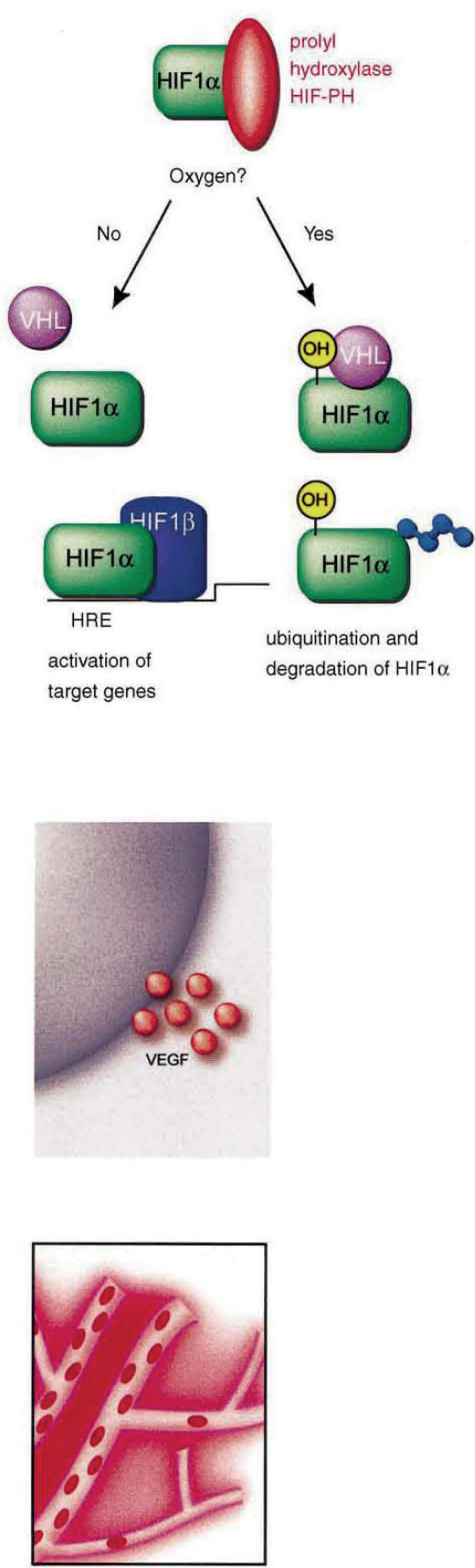


\section{References}

1. Knocke TH, Weitmann HD, Feldmann HJ, Selzer E, Potter R. Intratumoral pO2measurements as predictive assay in the treatment of carcinoma of the uterine cervix. Radiother Oncol 1999, 53, 99-104.

2. Hockel M, Schlenger K, Aral B, Mitze M, Schaffer U, Vaupel P. Association between tumor hypoxia and malignant progression in advanced cancer of the uterine cervix. Cancer Res 1996, 56, 4509-4515.

3. Nordsmark M, Overgaard M, Overgaard J. Pretreatment oxygenation predicts radiation response in advanced squamous cell carcinoma of the head and neck. Radiother Oncol 1996, 41, 31-39.

4. Brizel DM, Sibley GS, Prosnitz LR, Scher RL, Dewhirst MW. Tumor hypoxia adversely affects the prognosis of carcinoma of the head and neck. Int J Radiat Oncol Biol Phys 1997, 38, 285-289.

5. Lartigau E, Randrianarivelo $\mathrm{H}$, Avril MF, et al. Intratumoral oxygen tension in metastatic melanoma. Melanoma Res 1997, 7, 400-406.

6. Rofstad EK, Maseide K. Radiobiological and immunohistochemical assessment of hypoxia in human melanoma xenografts: acute and chronic hypoxia in individual tumours. Int J Radiat Biol 1999, 75, 1377-1393.

7. Vaupel P, Schlenger K, Knoop C, Hockel M. Oxygenation of human tumors: evaluation of tissue oxygen distribution in breast cancers by computerized $\mathrm{O} 2$ tension measurements. Cancer Res 1991, 51, 3316-3322.

8. Runkel S, Wischnik A, Teubner J, Kaven E, Gaa J, Melchert F. Oxygenation of mammary tumors as evaluated by ultrasound-guided computerized-pO2-histography. Adv Exp Med Biol 1994, 345, 451-458.

9. Movsas B, Chapman JD, Horwitz EM, et al. Hypoxic regions exist in human prostate carcinoma. Urology 1999, 53, 11-18.

10. Nordsmark M, Loncaster J, Chou SC, et al. Invasive oxygen measurements and pimonidazole labeling in human cervix carcinoma. Int J Radiat Oncol Biol Phys 2001, 49, 581-586.

11. Kavanagh MC, Tsang V, Chow $\mathrm{S}$, et al. A comparison in individual murine tumors of techniques for measuring oxygen levels. Int J Radiat Oncol Biol Phys 1999, 44, 1137-1146.

12. Lee J, Siemann DW, Koch CJ, Lord EM. Direct relationship between radiobiological hypoxia in tumors and monoclonal antibody detection of EF5 cellular adducts. Int $\mathrm{J}$ Cancer 1996, 67, 372-378.

13. Brizel DM, Dodge RK, Clough RW, Dewhirst MW. Oxygenation of head and neck cancer: changes during radiotherapy and impact on treatment outcome. Radiother Oncol 1999, 53, 113-117.

14. Brizel DM, Scully SP, Harrelson JM, et al. Tumor oxygenation predicts for the likelihood of distant metastases in human soft tissue sarcoma. Cancer Res 1996, 56, 941-943.

15. Fyles AW, Milosevic M, Wong $R$, et al. Oxygenation predicts radiation response and survival in patients with cervix cancer. Radiother Oncol 1998, 48, 149-156.

16. Nordsmark M, Alsner J, Keller J, et al. Hypoxia in human soft tissue sarcomas: adverse impact on survival and no association with p53 mutations. Br J Cancer 2001, 84, 10701075.

17. Gray LH, Conger AD, Ebert M, Hornsey S, Scott OC. Concentration of oxygen dissolved in tissues at the time of irradiation as a factor in radiotherapy. Br J Radiol 1953, 26, 638-648.

18. Bedford JS, Mitchell JB. The effect of hypoxia on the growth and radiation response of mammalian cells in culture. Br J Radiol 1974, 47, 687-696.

19. Durand RE. The influence of microenvironmental factors during cancer therapy. In Vivo 1994, 8, 691-702.

20. Baish JW, Gazit Y, Berk DA, Nozue M, Baxter LT, Jain RK. Role of tumor vascular architecture in nutrient and drug delivery: an invasion percolation-based network model. Microvasc Res 1996, 51, 327-346.

21. Young SD, Marshall RS, Hill RP. Hypoxia induces DNA overreplication and enhances metastatic potential of murine tumor cells. Proc Natl Acad Sci USA 1988, 85, 9533-9537.

22. De Jaeger K, Kavanagh MC, Hill RP. Relationship of hypoxia to metastatic ability in rodent tumours. Br J Cancer 2001, 84, 1280-1285.

23. Plasswilm L, Tannapfel A, Cordes $\mathrm{N}$, et al. Hypoxia-induced tumour cell migration in an in vivo chicken model. Pathobiology 2000, 68, 99-105. 
24. Curran S, Murray GI. Matrix metalloproteinases: molecular aspects of their roles in tumour invasion and metastasis. Eur J Cancer 2000, 36, 1621-1630.

25. Murray GI, Duncan ME, O'Neil P, McKay JA, Melvin WT, Fothergill JE. Matrix metalloproteinase-1 is associated with poor prognosis in oesophageal cancer. J Pathol 1998, 185, 256-261.

26. Murray GI, Duncan ME, O'Neil P, Melvin WT, Fothergill JE. Matrix metalloproteinase-1 is associated with poor prognosis in colorectal cancer. Nat Med 1996, 2, 461-462.

27. Sier CF, Kubben FJ, Ganesh S, et al. Tissue levels of matrix metalloproteinases MMP-2 and MMP-9 are related to the overall survival of patients with gastric carcinoma. $\mathrm{Br} \mathrm{J}$ Cancer 1996, 74, 413-417.

28. Canning MT, Postovit LM, Clarke SH, Graham CH. Oxygen mediated regulation of gelatinase and tissue inhibitor of metalloproteinases-1 expression by invasive cells. Exp Cell Res 2001, 367, 88-94.

29. Romanic AM, Burns-Kurtis CL, Gout B, Berrebi-Bertrand I, Ohlstein EH. Matrix metalloproteinase expression in cardiac myocytes following myocardial infarction in the rabbit. Life Sci 2001, 68, 799-814.

30. Graham CH, Forsdike J, Fitzgerald CJ, Macdonald-Goodfellow S. Hypoxia-mediated stimulation of carcinoma cell invasiveness via upregulation of urokinase receptor expression. Int $J$ Cancer 1999, 80, 617-623.

31. Maity A, Solomon D. Both increased stability and transcription contribute to the induction of the urokinase plasminogen activator receptor (uPAR) message by hypoxia. Exp Cell Res 2000, 255, 250-257.

32. MacDonald TJ, DeClerck YA, Laug WE. Urokinase induces receptor mediated brain tumor cell migration and invasion. J Neurooncol 1998, 40, 215-226.

33. Hasan NM, Adams GE, Joiner MC, Marshall JF, Hart IR. Hypoxia facilitates tumour cell detachment by reducing expression of surface adhesion molecules and adhesion to extracellular matrices without loss of cell viability. Br J Cancer 1998, 77, 1799-1805.

34. Xu L, Xie K, Mukaida N, Matsushima K, Fidler IJ. Hypoxiainduced elevation in interleukin-8 expression by human ovarian carcinoma cells. Cancer Res 1999, 59, 5822-5829.

35. Shi Q, Le X, Abbruzzese JL, et al. Cooperation between transcription factor AP-1 and NFkappaB in the induction of interleukin-8 in human pancreatic adenocarcinoma cells by hypoxia. J Interferon Cytokine Res 1999, 19, 1363-1371.

36. Kunz M, Hartmann A, Flory E, et al. Anoxia-induced up-regulation of interleukin-8 in human malignant melanoma. A potential mechanism for high tumor aggressiveness. Am J Pathol 1999, 155, 753-763.

37. Inoue K, Slaton JW, Kim SJ, et al. Interleukin 8 expression regulates tumorigenicity and metastasis in human bladder cancer. Cancer Res 2000, 60, 2290-2299.

38. Luca M, Huang S, Gershenwald JE. Expression of interleukin-8 by human melanoma cells up-regulates MMP-2 activity and increases tumor growth and metastasis. Am J Pathol 1997, 151, 1105-1113.

39. Graeber TG, Osmanian C, Jacks T, et al. Hypoxia-mediated selection of cells with diminished apoptotic potential in solid tumours. Nature 1996, 379, 88-91.

40. Gammack D, Byrne HM, Lewis CE. Estimating the selective advantage of mutant p53 tumour cells to repeated rounds of hypoxia. Bull Math Biol 2001, 63, 135-166.

41. Kim CY, Tsai MH, Osmanian C, et al. Selection of human cervical epithelial cells that possess reduced apoptotic potential to low-oxygen conditions. Cancer Res 1997, 57, 42004204.

42. Royds JA, Dower SK, Qwarnstrom EE, Lewis CE. Response of tumour cells to hypoxia: role of p53 and NFkB. Mol Pathol 1998, 51, 55-61.

43. Zundel W, Schindler C, Haas-Kogan D, et al. Loss of PTEN facilitates HIF-1-mediated gene expression. Genes Dev 2000, 14, 391-396.

44. Hockel M, Schlenger K, Hockel S, Vaupel P. Hypoxic cervical cancers with low apoptotic index are highly aggressive. Cancer Res 1999, 59, 4525-4528.

45. Semenza GL. Regulation of hypoxia-induced angiogenesis: a chaperone escorts VEGF to the dance. J Clin Invest 2001, 108, 39-40.

46. Rofstad EK, Danielsen T. Hypoxia-induced metastasis of human melanoma cells: involvement of vascular endothelial growth factor-mediated angiogenesis. $\mathrm{Br} \mathrm{J}$ Cancer 1999, 80, 1697-1707.

47. Veikkola T, Karkkainen M, Claesson-Welsh L, Alitalo K. Regulation of angiogenesis via vascular endothelial growth factor receptors. Cancer Res 2000, 60, 203-212. 
48. Aigner A, Butscheid M, Kunkel P, et al. An FGF-binding protein (FGF-BP) exerts its biological function by parallel paracrine stimulation of tumor cell and endothelial cell proliferation through FGF-2 release. Int J Cancer 2001, 92, 510-517.

49. Harris VK, Coticchia CM, Kagan BL, Ahmad S, Wellstein A, Riegel AT. Induction of the angiogenic modulator fibroblast growth factor-binding protein by epidermal growth factor is mediated through both MEK/ERK and p38 signal transduction pathways. J Biol Chem 2000, 275, 10802-10811.

50. Conrad PW, Rust RT, Han J, Millhorn DE, Beitner-Johnson D. Selective activation of p38alpha and p38gamma by hypoxia. Role in regulation of cyclin D1 by hypoxia in PC12 cells. J Biol Chem 1999, 274, 23570-23576.

51. Kuwabara K, Ogawa S, Matsumoto M, et al. Hypoxia-mediated induction of acidic/basic fibroblast growth factor and plateletderived growth factor in mononuclear phagocytes stimulates growth of hypoxic endothelial cells. Proc Natl Acad Sci USA 1995, 92, 4606-4610.

52. Walton HL, Corjay MH, Mohamed SN, Mousa SA, Santomenna LD, Reilly TM. Hypoxia induces differential expression of the integrin receptors alpha(vbeta3) and alpha(vbeta5) in cultured human endothelial cells. J Cell Biochem 2000, 78, 674-680.

53. Brooks PC, Stromblad S, Sanders LC, et al. Localization of matrix metalloproteinase MMP2 to the surface of invasive cells by interaction with integrin alpha v beta 3 . Cell 1996, 85, 683-693.

54. Soldi R, Mitola S, Strasly M, Defilippi P, Tarone G, Bussolino F. Role of alphavbeta3 integrin in the activation of vascular endothelial growth factor receptor-2. Embo J 1999, 18, 882-892.

55. Sundfor K, Lyng H, Trope CG, Rofstad EK. Treatment outcome in advanced squamous cell carcinoma of the uterine cervix: relationships to pretreatment tumor oxygenation and vascularization. Radiother Oncol 2000, 54, 101-107.

56. Nordsmark M, Hoyer M, Keller J, Nielsen OS, Jensen OM, Overgaard J. The relationship between tumor oxygenation and cell proliferation in human soft tissue sarcomas. Int J Radiat Oncol Biol Phys 1996, 35, 701-708.

57. Adam MF, Gabalski EC, Bloch DA, et al. Tissue oxygen distribution in head and neck cancer patients. Head Neck 1999, 21, 146-153.

58. Becker A, Hansgen G, Bloching M, Weigel C, Lautenschlager C, Dunst J. Oxygenation of squamous cell carcinoma of the head and neck: comparison of primary tumors, neck node metastases, and normal tissue. Int J Radiat Oncol Biol Phys 1998, 42, 35-41.

59. Nordsmark M, Overgaard J. A confirmatory prognostic study on oxygenation status and loco-regional control in advanced head and neck squamous cell carcinoma treated by radiation therapy. Radiother Oncol 2000, 57, 39-43.

60. Stadler P, Becker A, Feldmann HJ, et al. Influence of the hypoxic subvolume on the survival of patients with head and neck cancer. Int J Radiat Oncol Biol Phys 1999, 44, 749754.

61. Rudat V, Vanselow B, Wollensack $P$, et al. Repeatability and prognostic impact of the pretreatment $\mathrm{pO}(2)$ histography in patients with advanced head and neck cancer. Radiother Oncol 2000, 57, 31-37.

62. Schwickert G, Walenta S, Sundfor K, Rofstad EK, Mueller-Klieser W. Correlation of high lactate levels in human cervical cancer with incidence of metastasis. Cancer Res 1995, 55, 4757-4759.

63. Walenta S, Salameh A, Lyng H, et al. Correlation of high lactate levels in head and neck tumors with incidence of metastasis. Am J Pathol 1997, 150, 409-415.

64. Vaupel $P$, Kallinowski F, Okunieff $P$. Blood flow, oxygen and nutrient supply, and metabolic microenvironment of human tumors: a review. Cancer Res 1989, 49, 6449-6465.

65. Birner P, Schindl M, Obermair A, Plank C, Breitenecker G, Oberhuber G. Overexpression of hypoxia-inducible factor 1alpha is a marker for an unfavorable prognosis in early-stage invasive cervical cancer. Cancer Res 2000, 60, 4693-4696.

66. Sundfor K, Lyng H, Rofstad EK. Tumour hypoxia and vascular density as predictors of metastasis in squamous cell carcinoma of the uterine cervix. Br J Cancer 1998, 78, 822-827.

67. Rofstad EK, Sundfor K, Lyng H, Trope CG. Hypoxia-induced treatment failure in advanced squamous cell carcinoma of the uterine cervix is primarily due to hypoxia-induced radiation resistance rather than hypoxia-induced metastasis. Br J Cancer 2000, 83, 354-359.

68. Shweiki D, Itin A, Soffer D, Keshet E. Vascular endothelial growth factor induced by hypoxia may mediate hypoxia-initiated angiogenesis. Nature 1992, 359, 843-845. 
69. Kourembanas S, Hannan RL, Faller DV. Oxygen tension regulates the expression of the platelet-derived growth factor-B chain gene in human endothelial cells. J Clin Invest 1990, 86, 670-674.

70. Goldberg MA, Glass GA, Cunningham JM, Bunn HF. The regulated expression of erythropoietin by two human hepatoma cell lines. Proc Natl Acad Sci USA 1987, 84, 7972-7976.

71. Wang GL, Jiang BH, Rue EA, Semenza GL. Hypoxia-inducible factor 1 is a basic-helixloop-helix-PAS heterodimer regulated by cellular $\mathrm{O} 2$ tension. Proc Natl Acad Sci USA 1995, 92, 5510-5514.

72. McQuillan LP, Leung GK, Marsden PA, Kostyk SK, Kourembanas S. Hypoxia inhibits expression of eNOS via transcriptional and posttranscriptional mechanisms. Am J Physiol 1994, 267, H1921-H1927.

73. Firth JD, Ebert BL, Pugh CW, Ratcliffe PJ. Oxygen-regulated control elements in the phosphoglycerate kinase 1 and lactate dehydrogenase $A$ genes: similarities with the erythropoietin 30 enhancer. Proc Natl Acad Sci USA 1994, 91, 6496-6500.

74. Semenza GL, Roth PH, Fang HM, Wang GL. Transcriptional regulation of genes encoding glycolytic enzymes by hypoxiainducible factor 1. J Biol Chem 1994, 269, 23757-23763.

75. Sivitz WI, Lund DD, Yorek B, Grover-McKay M, Schmid PG. Pretranslational regulation of two cardiac glucose transporters in rats exposed to hypobaric hypoxia. Am J Physiol 1992, 263, E562-E569.

76. Ebert BL, Gleadle JM, O'Rourke JF, Bartlett SM, Poulton J, Ratcliffe PJ. Isoenzymespecific regulation of genes involved in energy metabolism by hypoxia: similarities with the regulation of erythropoietin. Biochem J 1996, 313, 809-814.

77. Ausserer WA, Bourrat-Floeck B, Green CJ, Laderoute KR, Sutherland RM. Regulation of Cjun expression during hypoxic and low-glucose stress. Mol Cell Biol 1994, 14, 5032-5042.

78. Santilli SM, Fiegel VD, Aldridge DE, Knighton DR. Rabbit aortic endothelial cell hypoxia induces secretion of transforming growth factor beta and augments macrophage adhesion in vitro. Ann Vasc Surg 1991, 5, 429-438.

79. Gleadle JM, Ebert BL, Firth JD, Ratcliffe PJ. Regulation of angiogenic growth factor expression by hypoxia, transition metals, and chelating agents. Am J Physiol 1995, 268, C1362-C1368.

80. Graham CH, Fitzpatrick TE, McCrae KR. Hypoxia stimulates urokinase receptor expression through a heme protein- dependent pathway. Blood 1998, 91, 3300-3307.

81. Czyzyk-Krzeska MF, Furnari BA, Lawson EE, Millhorn DE. Hypoxia increases rate of transcription and stability of tyrosine hydroxylase mRNA in pheochromocytoma (PC12) cells. J Biol Chem 1994, 269, 760-764.

82. Krtolica A, Krucher NA, Ludlow JW. Hypoxia-induced pRB hypophosphorylation results from downregulation of CDK and upregulation of PP1 activities. Oncogene 1998, 17, 22952304.

83. Carmeliet P, Dor Y, Herbert JM, et al. Role of HIF-1alpha in hypoxia-mediated apoptosis, cell proliferation and tumour angiogenesis. Nature 1998, 394, 485-490.

84. Forsythe JA, Jiang $\mathrm{BH}$, lyer NV, et al. Activation of vascular endothelial growth factor gene transcription by hypoxia-inducible factor 1 . Mol Cell Biol 1996, 16, 4604-4613.

85. Levy NS, Chung S, Furneaux H, Levy AP. Hypoxic stabilization of vascular endothelial growth factor mRNA by the RNAbinding protein HuR. J Biol Chem 1998, 273, 6417-6423.

86. Ozawa K, Kondo T, Hori O, et al. Expression of the oxygenregulated protein ORP150 accelerates wound healing by modulating intracellular VEGF transport. J Clin Invest 2001, 108, 41-50.

87. Stein I, Itin A, Einat P, Skaliter R, Grossman Z, Keshet E. Translation of vascular endothelial growth factor mRNA by internal ribosome entry: implications for translation under hypoxia. Mol Cell Biol 1998, 18, 3112-3119.

88. Akiri G, Nahari D, Finkelstein Y, Le SY, Elroy-Stein O, Levi BZ. Regulation of vascular endothelial growth factor (VEGF) expression is mediated by internal initiation of translation and alternative initiation of transcription. Oncogene 1998, 17, 227-236.

89. Miller DL, Dibbens JA, Damert A, Risau W, Vadas MA, Goodall GJ. The vascular endothelial growth factor mRNA contains an internal ribosome entry site. FEBS Lett 1998, 434, 417-420.

90. Semenza GL, Wang GL. A nuclear factor induced by hypoxia via de novo protein synthesis binds to the human erythropoietin gene enhancer at a site required for transcriptional activation. Mol Cell Biol 1992, 12, 5447-5454. 
91. Graeber TG, Peterson JF, Tsai M, Monica K, Fornace Jr AJ, Giaccia AJ. Hypoxia induces accumulation of p53 protein, but activation of a G1-phase checkpoint by low-oxygen conditions is independent of p53 status. Mol Cell Biol 1994, 14, 6264-6277.

92. Yao KS, Xanthoudakis S, Curran T, O'Dwyer PJ. Activation of AP-1 and of a nuclear redox factor, Ref-1, in the response of HT29 colon cancer cells to hypoxia. Mol Cell Biol 1994, 14, 5997-6003.

93. Yan SF, Zou YS, Mendelsohn M, et al. Nuclear factor interleukin 6 motifs mediate tissuespecific gene transcription in hypoxia. J Biol Chem 1997, 272, 4287-4294.

94. Yan SF, Lu J, Zou YS, Soh-Won J, et al. Hypoxia-associated induction of early growth response-1 gene expression. J Biol Chem 1999, 274, 15030-15040.

95. Koong AC, Chen EY, Giaccia AJ. Hypoxia causes the activation of nuclear factor kappa B through the phosphorylation of I kappa B alpha on tyrosine residues. Cancer Res 1994, 54, 1425-1430.

96. Semenza GL. Hypoxia-inducible factor 1: control of oxygen homeostasis in health and disease. Pediatr Res 2001, 49, 614-617.

97. Madan A, Curtin PT. A 24-base-pair sequence 30 to the human erythropoietin gene contains a hypoxia-responsive transcriptional enhancer. Proc Natl Acad Sci USA 1993, 90, 3928-3932.

98. Minchenko A, Salceda S, Bauer T, Caro J. Hypoxia regulatory elements of the human vascular endothelial growth factor gene. Cell Mol Biol Res 1994, 40, 35-39.

99. Melillo G, Musso T, Sica A, Taylor LS, Cox GW, Varesio L. A hypoxia-responsive element mediates a novel pathway of activation of the inducible nitric oxide synthase promoter. $J$ Exp Med 1995, 182, 1683-1693.

100. Gerber HP, Condorelli F, Park J, Ferrara N. Differential transcriptional regulation of the two vascular endothelial growth factor receptor genes. Flt-1, but not Flk-1/KDR, is up-regulated by hypoxia. J Biol Chem 1997, 272, 23659-23667.

101. Iyer NV, Kotch LE, Agani F, et al. Cellular and developmental control of O2 homeostasis by hypoxia-inducible factor 1 alpha. Genes Dev 1998, 12, 149-162.

102. Beck I, Weinmann R, Caro J. Characterization of hypoxiaresponsive enhancer in the human erythropoietin gene shows presence of hypoxia-inducible 120-Kd nuclear DNA-binding protein in erythropoietin-producing and nonproducing cells. Blood 1993, 82, 704-711.

103. Wang GL, Semenza GL. Characterization of hypoxia-inducible factor 1 and regulation of DNA binding activity by hypoxia. J Biol Chem 1993, 268, 21513-21518.

104. Ebert BL, Bunn HF. Regulation of transcription by hypoxia requires a multiprotein complex that includes hypoxia-inducible factor 1 , an adjacent transcription factor, and p300/CREB binding protein. Mol Cell Biol 1998, 18, 4089-4096.

105. Salceda S, Caro J. Hypoxia-inducible factor 1alpha (HIF-1alpha) protein is rapidly degraded by the ubiquitin-proteasome system under normoxic conditions. Its stabilization by hypoxia depends on redox-induced changes. J Biol Chem 1997, 272, 22642-22647.

106. Wiener CM, Booth G, Semenza GL. In vivo expression of mRNAs encoding hypoxiainducible factor 1. Biochem Biophys Res Commun 1996, 225, 485-488.

107. Maxwell PH, Wiesener MS, Chang GW, et al. The tumour suppressor protein VHLtargets hypoxia-inducible factors for oxygen-dependent proteolysis. Nature 1999, 399, 271-275.

108. Huang LE, Gu J, Schau M, Bunn HF. Regulation of hypoxiainducible factor 1alpha is mediated by an O2-dependent degradation domain via the ubiquitin-proteasome pathway. Proc Natl Acad Sci USA 1998, 95, 7987-7992.

109. Kallio PJ, Wilson WJ, O'Brien S, Makino Y, Poellinger L. Regulation of the hypoxiainducible transcription factor 1alpha by the ubiquitin-proteasome pathway. J Biol Chem 1999, 274, 6519-6525.

110. Jaakkola P, Mole DR, Tian YM, et al. Targeting of HIF-alpha to the von Hippel-Lindau ubiquitylation complex by O2-regulated prolyl hydroxylation. Science 2001, 292, 468-472.

111. Ivan $\mathrm{M}$, Kondo $\mathrm{K}$, Yang $\mathrm{H}$, et al. HIFalpha targeted for VHLmediated destruction by proline hydroxylation: implications for O2 sensing. Science 2001, 292, 464-468.

112. Overgaard J, Horsman MR. Modification of hypoxia-induced radioresistance in tumors by the use of oxygen and sensitizers. Semin Radiat Oncol 1996, 6, 10-21.

113. Saunders M, Dische S. Clinical results of hypoxic cell radiosensitisation from hyperbaric oxygen to accelerated radiotherapy, carbogen and nicotinamide. Br J Cancer Suppl 1996, 27, S271-S278.

114. Overgaard J. Sensitization of hypoxic tumour cells-clinical experience. Int J Radiat Biol 1989, 56, 801-811. 
115. Pedersen D, Sogaard H, Overgaard J, Bentzen SM. Prognostic value of pretreatment factors in patients with locally advanced carcinoma of the uterine cervix treated by radiotherapy alone. Acta Oncol 1995, 34, 787-795.

116. Girinski T, Pejovic-Lenfant MH, Bourhis J, et al. Prognostic value of hemoglobin concentrations and blood transfusions in advanced carcinoma of the cervix treated by radiation therapy: results of a retrospective study of 386 patients. Int J Radiat Oncol Biol Phys 1989, 16, 37-42.

117. Werner-Wasik M, Schmid CH, Bornstein L, Ball HG, Smith DM, Madoc-Jones H. Prognostic factors for local and distant recurrence in stage I and II cervical carcinoma. Int J Radiat Oncol Biol Phys 1995, 32, 1309-1317.

118. Fein DA, Lee WR, Hanlon AL, et al. Pretreatment hemoglobin level influences local control and survival of T1-T2 squamous cell carcinomas of the glottic larynx. J Clin Oncol 1995, 13, 2077-2083.

119. Lee WR, Berkey B, Marcial V, et al. Anemia is associated with decreased survival and increased locoregional failure in patients with locally advanced head and neck carcinoma: a secondary analysis of RTOG 85-27. Int J Radiat Oncol Biol Phys 1998, 42, 1069-1075.

120. van Acht MJ, Hermans J, Boks DE, Leer JW. The prognostic value of hemoglobin and a decrease in hemoglobin during radiotherapy in laryngeal carcinoma. Radiother Oncol 1992, 23, 229-235.

121. Warde P, O'Sullivan B, Bristow RG, et al. T1/T2 glottic cancer managed by external beam radiotherapy: the influence of pretreatment hemoglobin on local control. Int $\mathrm{J}$ Radiat Oncol Biol Phys 1998, 41, 347-353.

122. Dubray B, Mosseri V, Brunin F, et al. Anemia is associated with lower local-regional control and survival after radiation therapy for head and neck cancer: a prospective study. Radiology 1996, 201, 553-558.

123. Dische S, Warburton MF, Saunders MI. Radiation myelitis and survival in the radiotherapy of lung cancer. Int J Radiat Oncol Biol Phys 1988, 15, 75-81.

124. Macchiarini P, Silvano G, Janni A, Mussi A, Chella A, Angeletti CA. Results of treatment and lessons learned from pathologically staged T4 non-small cell lung cancer. J Surg Oncol 1991, 47, 209-214.

125. Sasai K, Ono K, Hiraoka M, et al. The effect of arterial oxygen content on the results of radiation therapy for epidermoid bronchogenic carcinoma. Int $\mathrm{J}$ Radiat Oncol Biol Phys 1989, 16, 1477-1481.

126. Cole CJ, Pollack A, Zagars GK, Dinney CP, Swanson DA, von Eschenbach AC. Local control of muscle-invasive bladder cancer: preoperative radiotherapy and cystectomy versus cystectomy alone. Int J Radiat Oncol Biol Phys 1995, 32, 331-340.

127. Hannisdal E, Fossa SD, Host H. Blood tests and prognosis in bladder carcinomas treated with definitive radiotherapy. Radiother Oncol 1993, 27, 117-122.

128. Wijkstrom $\mathrm{H}$, Nilsson B, Tribukait B. DNA analysis in predicting survival of irradiated patients with transitional cell carcinoma of bladder. Br J Urol 1992, 69, 49-55.

129. Greven KM, Solin LJ, Hanks GE. Prognostic factors in patients with bladder carcinoma treated with definitive irradiation. Cancer 1990, 65, 908-912.

130. Dunphy EP, Petersen IA, Cox RS, Bagshaw MA. The influence of initial hemoglobin and blood pressure levels on results of radiation therapy for carcinoma of the prostate. Int $\mathrm{J}$ Radiat Oncol Biol Phys 1989, 16, 1173-1178.

131. Bush RS. The significance of anemia in clinical radiation therapy. Int J Radiat Oncol Biol Phys 1986, 12, 2047-2050.

132. Lavey RS. Clinical trial experience using erythropoietin during radiation therapy. Strahlenther Onkol 1998, 174(Suppl. 4), 24-30.

133. Abels RI. Use of recombinant human erythropoietin in the treatment of anemia in patients who have cancer. Semin Oncol 1992, 19(Suppl. 8), 29-35.

134. Glaser CM, Millesi W, Kornek GV, et al. Impact of hemoglobin level and use of recombinant erythropoietin on efficacy of preoperative chemoradiation therapy for squamous cell carcinoma of the oral cavity and oropharynx. Int J Radiat Oncol Biol Phys 2001, 50, 705-715.

135. Rojas A, Joiner MC, Denekamp J. Extrapolations from laboratory and preclinical studies for the use of carbogen and nicotinamide in radiotherapy. Radiother Oncol 1992, 24, 123-124.

136. Chaplin DJ, Horsman MR, Trotter MJ. Effect of nicotinamide on the microregional heterogeneity of oxygen delivery within a murine tumor. J Natl Cancer Inst 1990, 82, 672-676.

137. Rojas A. Radiosensitization with normobaric oxygen and carbogen. Radiother Oncol 1991, 20(Suppl. 1), 65-70. 
138. Martin L, Lartigau E, Weeger $P$, et al. Changes in the oxygenation of head and neck tumors during carbogen breathing. Radiother Oncol 1993, 27, 123-130.

139. Horsman MR, Nordsmark M, Khalil AA, et al. Reducing acute and chronic hypoxia in tumours by combining nicotinamide with carbogen breathing. Acta Oncol 1994, 33, 371-376.

140. Laurence VM, Ward R, Dennis IF, Bleehen NM. Carbogen breathing with nicotinamide improves the oxygen status of tumours in patients. Br J Cancer 1995, 72, 198-205.

141. Siemann DW, Horsman MR, Chaplin DJ. The radiation response of KHT sarcomas following nicotinamide treatment and carbogen breathing. Radiother Oncol 1994, 31, 117-122.

142. Fenton BM. The effects of carbogen and nicotinamide on intravascular oxyhaemoglobin saturations in SCCVII and KHT murine tumours. Br J Cancer 1995, 71, 945-949.

143. Rojas A, Hirst VK, Calvert AS, Johns $H$. Carbogen and nicotinamide as radiosensitizers in a murine mammary carcinoma using conventional and accelerated radiotherapy. Int J Radiat Oncol Biol Phys 1996, 34, 357-365.

144. Denekamp J, Fowler JF. ARCON_current status: summary of a workshop on preclinical and clinical studies. Acta Oncol 1997, 36, 517-525.

145. Fenton BM, Lord EM, Paoni SF. Enhancement of tumor perfusion and oxygenation by carbogen and nicotinamide during single- and multifraction irradiation. Radiat Res 2000, 153, 75-83.

146. Kaanders JH, Pop LA, Marres HA, et al. Accelerated radiotherapy with carbogen and nicotinamide (ARCON) for laryngeal cancer. Radiother Oncol 1998, 48, 115-122.

147. Bussink J, Kaanders JH, Van der Kogel AJ. Clinical outcome and tumour microenvironmental effects of accelerated radiotherapy with carbogen and nicotinamide. Acta Oncol 1999, $38,875-882$.

148. Hoskin PJ, Saunders MI, Dische S. Hypoxic radiosensitizers in radical radiotherapy for patients with bladder carcinoma: hyperbaric oxygen, misonidazole, and accelerated radiotherapy, carbogen, and nicotinamide. Cancer 1999, 86, 1322-1328.

149. Bernier J, Denekamp J, Rojas A, et al. ARCON: accelerated radiotherapy with carbogen and nicotinamide in head and neck squamous cell carcinomas. The experience of the Cooperative group of radiotherapy of the European Organization for Research and Treatment of Cancer (EORTC). Radiother Oncol 2000, 55, 111-119.

150. Bernier J, Denekamp J, Rojas A, et al. ARCON: accelerated radiotherapy with carbogen and nicotinamide in non small cell lung cancer: a phase I/II study by the EORTC. Radiother Oncol 1999, 52, 149-156.

151. Miralbell R, Mornex F, Greiner R, et al. Accelerated radiotherapy, carbogen, and nicotinamide in glioblastoma multiforme: report of European Organization for Research and Treatment of Cancer trial 22933. J Clin Oncol 1999, 17, 3143-3149.

152. Overgaard J, Overgaard M, Timothy AR. Studies of the pharmacokinetic properties of nimorazole. Br J Cancer 1983, 48, 27-34.

153. Timothy AR, Overgaard J, Overgaard M. A phase I clinical study of Nimorazole as a hypoxic radiosensitizer. Int J Radiat Oncol Biol Phys 1984, 10, 1765-1768.

154. Overgaard J, Hansen HS, Overgaard M, et al. A randomized double-blind phase III study of nimorazole as a hypoxic radiosensitizer of primary radiotherapy in supraglottic larynx and pharynx carcinoma. Results of the Danish Head and Neck Cancer Study (DAHANCA) Protocol 5-85. Radiother Oncol 1998, 46, 135-146.

155. von Pawel J, von Roemeling R, Gatzemeier U, et al. Tirapazamine plus cisplatin versus cisplatin in advanced non-smallcell lung cancer: a report of the international CATAPULT I study group. Cisplatin and tirapazamine in subjects with advanced previously untreated non-small-cell lung tumors. J Clin Oncol 2000, 18, 1351-1359.

156. Rischin D, Peters L, Hicks R, et al. Phase I trial of concurrent tirapazamine, cisplatin, and radiotherapy in patients with advanced head and neck cancer. J Clin Oncol 2001, 19, 535542.

157. Craighead PS, Pearcey R, Stuart G. A phase I/II evaluation of tirapazamine administered intravenously concurrent with cisplatin and radiotherapy in women with locally advanced cervical cancer. Int J Radiat Oncol Biol Phys 2000, 48, 791-795.

158. Wouters BG, Wang LH, Brown JM. Tirapazamine: a new drug producing tumor specific enhancement of platinum-based chemotherapy in non-small-cell lung cancer. Ann Oncol 1999, 10(Suppl. 5), S29-S33.

159. Brown JM. SR 4233 (tirapazamine): a new anticancer drug exploiting hypoxia in solid tumours. Br J Cancer 1993, 67, 1163-1170. 
160. Kovacs MS, Hocking DJ, Evans JW, Siim BG, Wouters BG, Brown JM. Cisplatin antitumour potentiation by tirapazamine results from a hypoxia-dependent cellular sensitization to cisplatin. Br J Cancer 1999, 80, 1245-1251.

161. Siemann DW, Hinchman CA. Potentiation of cisplatin activity by the bioreductive agent tirapazamine. Radiother Oncol 1998, 47, 215-520.

162. Treat J, Johnson E, Langer C, et al. Tirapazamine with cisplatin in patients with advanced non-small-cell lung cancer: a phase II study. J Clin Oncol 1998, 16, 3524-3527.

163. Miller VA, Ng KK, Grant SC, et al. Phase II study of the combination of the novel bioreductive agent, tirapazamine, with cisplatin in patients with advanced non-small-cell lung cancer. Ann Oncol 1997, 8, 1269-1271.

164. Goldberg Z, Evans J, Birrell G, Brown JM. An investigation of the molecular basis for the synergistic interaction of tirapazamine and cisplatin. Int J Radiat Oncol Biol Phys 2001, 49, 175-182.

165. Patterson LH, McKeown SR. AQ4N: a new approach to hypoxia-activated cancer chemotherapy. Br J Cancer 2000, 83, 1589-1993.

166. Patterson LH, McKeown SR, Ruparelia K, et al. Enhancement of chemotherapy and radiotherapy of murine tumours by AQ4N, a bioreductively activated anti-tumour agent. $\mathrm{Br} \mathrm{J}$ Cancer 2000, 82, 1984-1990.

167. McKeown SR, Hejmadi MV, McIntyre IA, McAleer JJ, Patterson LH. AQ4N: an alkylaminoanthraquinone $\mathrm{N}$-oxide showing bioreductive potential and positive interaction with radiation in vivo. Br J Cancer 1995, 72, 76-81.

168. Minton NP, Mauchline ML, Lemmon MJ, et al. Chemotherapeutic tumour targeting using clostridial spores. FEMS Microbiol Rev 1995, 17, 357-364.

169. Lambin $\mathrm{P}$, Theys $\mathrm{J}$, Landuyt $\mathrm{W}$, et al. Colonisation of Clostridium in the body is restricted to hypoxic and necrotic areas of tumours. Anaerobe 1998, 4, 183-188.

170. Low KB, Ittensohn M, Le T, et al. Lipid A mutant Salmonella with suppressed virulence and TNFalpha induction retain tumor-targeting in vivo. Nat Biotechnol 1999, 17, 37-41.

171. Pawelek JM, Low KB, Bermudes D. Tumor-targeted Salmonella as a novel anticancer vector. Cancer Res 1997, 57, 4537-4544.

172. Theys J, Landuyt W, Nuyts S, et al. Improvement of Clostridium tumour targeting vectors evaluated in rat rhabdomyosarcomas. FEMS Immunol Med Microbiol 2001, 30, 37-41.

173. Theys J, Nuyts S, Landuyt W, et al. Stable Escherichia coli-Clostridium acetobutylicum shuttle vector for secretion of murine tumor necrosis factor alpha. Appl Environ Microbiol 1999, 65, 4295-4300.

174. Fox ME, Lemmon MJ, Mauchline ML, et al. Anaerobic bacteria as a delivery system for cancer gene therapy: in vitro activation of 5-fluorocytosine by genetically engineered clostridia. Gene Ther 1996, 3, 173-178.

175. Lemmon MJ, van Zijl P, Fox ME, et al. Anaerobic bacteria as a gene delivery system that is controlled by the tumor microenvironment. Gene Ther 1997, 4, 791-796.

176. Theys J, Landuyt W, Nuyts S, et al. Specific targeting of cytosine deaminase to solid tumors by engineered Clostridium acetobutylicum. Cancer Gene Ther 2001, 8, 294-297.

177. Nuyts S, Van Mellaert L, Theys J, Landuyt W, Lambin P, Anne J. The use of radiationinduced bacterial promoters in anaerobic conditions: a means to control gene expression in clostridiummediated therapy for cancer. Radiat Res 2001, 155, 716-723.

178. Yazawa K, Fujimori M, Amano J, Kano Y, Taniguchi S. Bifidobacterium longum as a delivery system for cancer gene therapy: selective localization and growth in hypoxic tumors. Cancer Gene Ther 2000, 7, 269-274.

179. Konerding MA, Malkusch W, Klapthor B, et al. Evidence for characteristic vascular patterns in solid tumours: quantitative studies using corrosion casts. $\mathrm{Br} \mathrm{J}$ Cancer 1999, 80, 724-732.

180. Konerding MA, Miodonski AJ, Lametschwandtner A. Microvascular corrosion casting in the study of tumor vascularity: a review. Scanning Microsc 1995, 9, 1233-1243.

181. Denekamp J. Vascular attack as a therapeutic strategy for cancer. Cancer Metastasis Rev 1990, 9, 267-282.

182. Denekamp J, Hobson B. Endothelial-cell proliferation in experimental tumours. Br J Cancer 1982, 46, 711-720.

183. Folkman J. Tumor angiogenesis: therapeutic implications. N Engl J Med 1971, 285, 1182 1186.

184. Hanahan D, Folkman J. Patterns and emerging mechanisms of the angiogenic switch during tumorigenesis. Cell 1996, 86, 353-364. 
185. Hiraoka N, Allen E, Apel IJ, Gyetko MR, Weiss SJ. Matrix metalloproteinases regulate neovascularization by acting as pericellular fibrinolysins. Cell 1998, 95, 365-377.

186. Zucker S, Cao J, Chen WT. Critical appraisal of the use of matrix metalloproteinase inhibitors in cancer treatment. Oncogene 2000, 19, 6642-6650.

187. Towle MJ, Lee A, Maduakor EC, Schwartz CE, Bridges AJ, Littlefield BA. Inhibition of urokinase by 4-substituted benzo[b]thiophene-2- carboxamidines: an important new class of selective synthetic urokinase inhibitor. Cancer Res 1993, 53, 2553-2559.

188. Marshall E. The power of the front page of The New York Times. Science 1998, 280, 996997.

189. O'Reilly MS, Holmgren L, Shing Y, et al. Angiostatin: a novel angiogenesis inhibitor that mediates the suppression of metastases by a Lewis lung carcinoma. Cell 1994, 79, 315328.

190. Holmgren L, O'Reilly MS, Folkman J. Dormancy of micrometastases: balanced proliferation and apoptosis in the presence of angiogenesis suppression. Nat Med 1995, 1, 149-153.

191. O'Reilly MS, Boehm T, Shing Y, et al. Endostatin: an endogenous inhibitor of angiogenesis and tumor growth. Cell 1997, 88, 277-285.

192. Yokoyama Y, Dhanabal M, Griffioen AW, Sukhatme VP, Ramakrishnan S. Synergy between angiostatin and endostatin: inhibition of ovarian cancer growth. Cancer Res 2000, 60, 2190-2196.

193. D'Amato RJ, Loughnan MS, Flynn E, Folkman J. Thalidomide is an inhibitor of angiogenesis. Proc Natl Acad Sci USA 1994, 91, 4082-4085.

194. Minchinton Al, Fryer KH, Wendt KR, Clow KA, Hayes MM. The effect of thalidomide on experimental tumors and metastases. Anticancer Drugs 1996, 7, 339-343.

195. Figg WD, Dahut W, Duray P, et al. A randomized phase II trial of thalidomide, an angiogenesis inhibitor, in patients with androgen-independent prostate cancer. Clin Cancer Res 2001, 7, 1888-1893.

196. Fine HA, Figg WD, Jaeckle K, et al. Phase II trial of the antiangiogenic agent thalidomide in patients with recurrent highgrade gliomas. J Clin Oncol 2000, 18, 708-715.

197. Fong TA, Shawver LK, Sun L, et al. SU5416 is a potent and selective inhibitor of the vascular endothelial growth factor receptor (Flk-1/KDR) that inhibits tyrosine kinase catalysis, tumor vascularization, and growth of multiple tumor types. Cancer Res 1999, 59, 99-106.

198. Lair AD, Vajkoczy $P$, Shawver LK, et al. SU6668 is a potent antiangiogenic and antitumor agent that induces regression of established tumors. Cancer Res 2000, 60, 4152-4160.

199. Usman N, Blatt LM. Nuclease-resistant synthetic ribozymes: developing a new class of therapeutics. J Clin Invest 2000, 106, 1197-1202.

200. Asano M, Yukita A, Matsumoto T, Hanatani M, Suzuki H. An anti-human VEGF monoclonal antibody, MV833, that exhibits potent anti-tumor activity in vivo. Hybridoma 1998, 17, 185190.

201. Rubenstein JL, Kim J, Ozawa T, et al. Anti-VEGF antibody treatment of glioblastoma prolongs survival but results in increased vascular cooption. Neoplasia 2000, 2, 306-314.

202. Wood JM, Bold G, Buchdunger E, et al. PTK787/ZK 222584, a novel and potent inhibitor of vascular endothelial growth factor receptor tyrosine kinases, impairs vascular endothelial growth factor-induced responses and tumor growth after oral administration. Cancer Res 2000, 60, 2178-2189.

203. Friedlander M, Brooks PC, Shaffer RW, Kincaid CM, Varner JA, Cheresh DA. Definition of two angiogenic pathways by distinct alpha $v$ integrins. Science 1995, 270, 1500-1502.

204. Brooks PC, Clark RA, Cheresh DA. Requirement of vascular integrin alpha $v$ beta 3 for angiogenesis. Science 1994, 264, 569-571.

205. Brooks PC,Montgomery AM, RosenfeldM, et al. Integrin alpha v beta 3 antagonists promote tumor regression by inducing apoptosis of angiogenic blood vessels. Cell 1994, 97, 11571164.

206. Brooks PC, Stromblad S, Klemke R, Visscher D, Sarkar FH, Cheresh DA. Antiintegrin alpha $v$ beta 3 blocks human breast cancer growth and angiogenesis in human skin. J Clin Invest 1995, 96, 1815-1822.

207. Pasqualini R, Koivunen E, Ruoslahti E. Alpha v integrins as receptors for tumor targeting by circulating ligands. Nat Biotechnol 1997, 15, 542-546.

208. Wu H, Beuerlein G, Nie Y, et al. Stepwise in vitro affinity maturation of Vitaxin, an alphav beta3- specific humanized mAb. Proc Natl Acad Sci USA 1998, 95, 6037-6042. 
209. Gutheil JC, Campbell TN, Pierce PR, et al. Targeted antiangiogenic therapy for cancer using Vitaxin: a humanized monoclonal antibody to the integrin alphavbeta3. Clin Cancer Res 2000, 6, 3056-3061.

210. Kohn EC, Felder CC, Jacobs W, et al. Structure-function analysis of signal and growth inhibition by carboxyamido-triazole, CAI. Cancer Res 1994, 54, 935-942.

211. Cavallo F, Di Carlo E, Butera M, et al. Immune events associated with the cure of established tumors and spontaneous metastases by local and systemic interleukin 12. Cancer Res 1999, 59, 414-421.

212. Voest EE, Kenyon BM, O'Reilly MS, Truitt G, D’Amato RJ, Folkman J. Inhibition of angiogenesis in vivo by interleukin 12. J Natl Cancer Inst 1995, 87, 581-586.

213. Coughlin CM, Salhany KE, Wysocka M, et al. Interleukin-12 and interleukin-18 synergistically induce murine tumor regression which involves inhibition of angiogenesis. J Clin Invest 1998, 101, 1441-1452.

214. Haicheur N, Escudier B, Dorval T, et al. Cytokines and soluble cytokine receptor induction after IL-12 administration in cancer patients. Clin Exp Immunol 2000, 119, 28-37.

215. DeVore RF, Hellerqvist CG, Wakefield GB, et al. Phase I study of the antineovascularization drug CM101. Clin Cancer Res 1997, 3, 365-372.

216. Denekamp J. Vascular endothelium as the vulnerable element in tumours. Acta Radiol Oncol 1984, 23, 217-225.

217. Wouters BG, Brown JM. Cells at intermediate oxygen levels can be more important than the "hypoxic fraction" in determining tumor response to fractionated radiotherapy. Radiat Res 1997, 147, 541-550.

218. Hill SA, Lonergan SJ, Denekamp J, Chaplin DJ. Vinca alkaloids: anti-vascular effects in a murine tumour. Eur J Cancer 1993, 9, 1320-1324.

219. Horsman MR, Ehrnrooth E, Ladekarl M, Overgaard J. The effect of combretastatin A-4 disodium phosphate in a $\mathrm{C} 3 \mathrm{H}$ mouse mammary carcinoma and a variety of murine spontaneous tumors. Int J Radiat Oncol Biol Phys 1998, 42, 895-898.

220. Zwi LJ, Baguley BC, Gavin JB, Wilson WR. The use of vascularised spheroids to investigate the action of flavone acetic acid on tumour blood vessels. Br J Cancer 1990, 62, 231237.

221. Mahadevan V, Malik ST, Meager A, Fiers W, Lewis GP, Hart IR. Role of tumor necrosis factor in flavone acetic acid-induced tumor vasculature shutdown. Cancer Res 1990, 50, 5537-5542.

222. Futami H, Eader LA, Komschlies KL, et al. Flavone acetic acid directly induces expression of cytokine genes in mouse splenic leukocytes but not in human peripheral blood leukocytes. Cancer Res 1991, 51, 6596-6602.

223. Joseph WR, Cao Z, Mountjoy KG, Marshall ES, Baguley BC, Ching LM. Stimulation of tumors to synthesize tumor necrosis factor-alpha in situ using 5,6-dimethylxanthenone-4acetic acid: a novel approach to cancer therapy. Cancer Res 1999, 59, 633-638.

224. Ching LM, Joseph WR, Crosier KE, Baguley BC. Induction of tumor necrosis factor-alpha messenger RNA in human and murine cells by the flavone acetic acid analogue 5,6dimethylxanthenone-4-acetic acid (NSC 640488). Cancer Res 1994, 54, 870-872.

225. Baguley BC, Holdaway KM, Thomsen LL, Zhuang L, Zwi LJ. Inhibition of growth of colon 38 adenocarcinoma by vinblastine and colchicine: evidence for a vascular mechanism. Eur $\mathrm{J}$ Cancer 1991, 27, 482-487.

226. Pettit GR, Singh SB, Boyd MR, et al. Antineoplastic agents. 291. Isolation and synthesis of combretastatins A-4, A-5, and A-6(1a). J Med Chem 1995, 38, 1666-1672.

227. Pettit GR, Singh SB, Hamel E, Lin CM, Alberts DS, Garcia-Kendall D. Isolation and structure of the strong cell growth and tubulin inhibitor combretastatin A-4. Experientia 1989, 45, 209-211.

228. Pettit GR, Temple Jr C, Narayanan VL, et al. Antineoplastic agents 322. synthesis of combretastatin A-4 prodrugs. Anticancer Drug Des 1995, 10, 299-309.

229. Dark GG, Hill SA, Prise VE, Tozer GM, Pettit GR, Chaplin DJ. Combretastatin A-4, an agent that displays potent and selective toxicity toward tumor vasculature. Cancer Res 1997, 57, 1829-1834.

230. Li L, Rojiani A, Siemann DW. Targeting the tumor vasculature with combretastatin A-4 disodium phosphate: effects on radiation therapy. Int J Radiat Oncol Biol Phys 1998, 42, 899-903. 
231. Tozer GM, Prise VE, Wilson J, et al. Combretastatin A-4 phosphate as a tumor vasculartargeting agent: early effects in tumors and normal tissues. Cancer Res 1999, 59, 16261634.

232. Landuyt W, Verdoes O, Darius DO, et al. Vascular targeting of solid tumours: a major 'inverse' volume-response relationship following combretastatin A-4 phosphate treatment of rat rhabdomyosarcomas. Eur J Cancer 2000, 36, 1833-1843.

233. Galbraith SM, Chaplin DJ, Lee F, et al. Effects of combretastatin A4 phosphate on endothelial cell morphology in vitro and relationship to tumour vascular targeting activity in vivo. Anticancer Res 2001, 21, 93-102.

234. Seagroves TN, Ryan HE, Lu H, et al. Transcription factor hif-1 is a necessary mediator of the pasteur effect in mammalian cells. Mol Cell Biol 2001, 21, 3436-3444.

235. Sun X, Kanwar JR, Leung E, Lehnert K, Wang D, Krissansen GW. Gene transfer of antisense hypoxia inducible factor- 1 alpha enhances the therapeutic efficacy of cancer immunotherapy. Gene Ther 2001, 8, 638-645.

236. Kung AL, Wang S, KIco JM, Kaelin WG, Livingston DM. Suppression of tumor growth through disruption of hypoxia-inducible transcription. Nat Med 2000, 6, 1335-1340.

237. Kim MS, Kwon HJ, Lee YM, et al. Histone deacetylases induce angiogenesis by negative regulation of tumor suppressor genes. Nat Med 2001, 7, 437-443.

238. Cusack Jr JC, Liu R, Houston M, et al. Enhanced chemosensitivity to CPT-11 with proteasome inhibitor PS-341: implications for systemic nuclear factor-kappaB inhibition. Cancer Res 2001, 61, 3535-3540.

239. Russo SM, Tepper JE, Baldwin Jr AS, et al. Enhancement of radiosensitivity by proteasome inhibition: implications for a role of NF-kappaB. Int J Radiat Oncol Biol Phys 2001, 50, 183-193.

240. Adams J, Palombella VJ, Elliott PJ. Proteasome inhibition: a new strategy in cancer treatment. Invest New Drugs 2000, 18, 109-121.

241. Ryan HE, Poloni M, McNulty W, et al. Hypoxia-inducible factor-1alpha is a positive factor in solid tumor growth. Cancer Res 2000, 60, 4010-4015.

242. Dachs GU, Tozer GM. Hypoxia modulated gene expression: angiogenesis, metastasis and therapeutic exploitation. Eur J Cancer 2000, 36, 1649-1660.

243. Dachs GU, Patterson AV, Firth JD, et al. Targeting gene expression to hypoxic tumor cells. Nat Med 1997, 3, 515-520.

244. Shibata T, Akiyama N, Noda M, Sasai K, Hiraoka M. Enhancement of gene expression under hypoxic conditions using fragments of the human vascular endothelial growth factor and the erythropoietin genes. Int J Radiat Oncol Biol Phys 1998, 42, 913-916.

245. Shibata T, Giaccia AJ, Brown JM. Development of a hypoxia-responsive vector for tumorspecific gene therapy. Gene Ther 2000, 7, 493-498.

246. Song CW. Effect of local hyperthermia on blood flow and microenvironment: a review. Cancer Res 1984, 44(Suppl.), 4721s-4730s.

247. Reinhold HS, Endrich B. Tumour microcirculation as a target for hyperthermia. Int J Hyperthermia 1986, 2, 111-137.

248. Dewhirst MW, Prosnitz L, Thrall D, et al. Hyperthermic treatment of malignant diseases: current status and a view toward the future. Semin Oncol 1997, 24, 616-625.

249. Dougherty TJ, Gomer CJ, Henderson BW, et al. Photodynamic therapy. J Natl Cancer Inst 1998, 90, 889-905.

250. Pass HI. Photodynamic therapy in oncology: mechanisms and clinical use. J Natl Cancer Inst 1993, 85, 443-456.

251. Watanabe N, Niitsu $\mathrm{Y}$, Umeno $\mathrm{H}$, et al. Toxic effect of tumor necrosis factor on tumor vasculature in mice. Cancer Res 1988, 48, 2179-2183.

252. Huang X, Molema G, King S, Watkins L, Edgington TS, Thorpe PE. Tumor infarction in mice by antibody-directed targeting of tissue factor to tumor vasculature. Science 1997, 275, 547-550.

253. Chaplin DJ, Pettit GR, Parkins CS, Hill SA. Antivascular approaches to solid tumour therapy: evaluation of tubulin binding agents. Br J Cancer 1996, 27(Suppl.), S86-S88. 


\section{CHAPTER 3}

Gene expression during acute and prolonged hypoxia is regulated by distinct mechanisms of translational control

EMBO J. 2006 Mar 8;25(5):1114-25.

Marianne Koritzinsky, Michaël G Magagnin, Twan van den Beucken, Renaud Seigneuric, Kim Savelkouls, Josée Dostie, Stéphane Pyronnet, Randal J Kaufman, Sherry A Weppler, Jan Willem Voncken, Philippe Lambin, Constantinos Koumenis, Nahum Sonenberg and Bradly G Wouters 


\title{
Chapter 3
}

\begin{abstract}
Hypoxia has recently been shown to activate the endoplasmic reticulum kinase PERK, leading to phosphorylation of elF2 $\alpha$ and inhibition of mRNA translation initiation. Using a quantitative assay, we show that this inhibition exhibits a biphasic response mediated through two distinct pathways. The first occurs rapidly, reaching a maximum at $1-2 \mathrm{~h}$ and is due to phosphorylation of elF2 $\alpha$. Continued hypoxic exposure activates a second, elF2 $\alpha$ independent pathway that maintains repression of translation. This phase is characterized by disruption of elF4F and sequestration of elF4E by its inhibitor 4E-BP1 and transporter 4E-T. Quantitative RT-PCR analysis of polysomal RNA indicates that the translation efficiency of individual genes varies widely during hypoxia. Furthermore, the translation efficiency of individual genes is dynamic, changing dramatically during hypoxic exposure due to the initial phosphorylation and subsequent dephosphorylation of elF2 $\alpha$. Together, our data indicate that acute and prolonged hypoxia regulates mRNA translation through distinct mechanisms, each with important contributions to hypoxic gene expression.
\end{abstract}




\section{Introduction}

The presence of hypoxic and anoxic areas in human tumors is well documented, and is prognostic for poor outcome (reviewed in Harris, 2002; Wouters et al, 2002). The clinical importance of tumor hypoxia results from its ability to protect cells against both radiation and chemotherapy and from the fact that it can provide a selection pressure for apoptotically resistant cells (Graeber et al, 1996). Furthermore, the cellular response to hypoxia causes important changes in gene expression that affect cell behavior and influence patient prognosis. There has been particular focus on changes mediated through the family of hypoxia-inducible transcription factors (HIFs). HIF-1 and HIF-2 promote transcription of more than 60 putative downstream genes (for a review see Semenza, 2003) that affect hypoxia tolerance, energy homeostasis, angiogenesis and tumor growth. Although the transcriptional response to hypoxia is clearly very important (Ryan et al, 1998; Tang et al, 2004; Leek et al, 2005), tumor cells also experience short, transient exposures to hypoxia and/or anoxia that occur over time frames too fast for an effective transcriptional response. Transient changes in oxygenation occur owing to the abnormal vasculature found in most tumors, characterized by immature, leaky and improperly formed vessels. Perfusion of these vessels can change dynamically in time, leading to rapid but transient episodes of severe hypoxia in the tumor cells dependent upon them (Bennewith and Durand, 2004; Cardenas-Navia et al, 2004). Consequently, post-transcriptional responses are presumably important for adaptation to cycling oxygenation in tumors.

Control of mRNA translation during hypoxia is emerging as an important cellular response to hypoxia (Koumenis et al, 2002; Koritzinsky et al, 2005; Wouters et al, 2005). As protein synthesis is energy costly, inhibition of mRNA translation may represent an active response to prevent loss of energy homeostasis during hypoxia. Indeed, it has been shown that overall mRNA translation is severely but reversibly inhibited during hypoxia (Koumenis et al, 2002; Erler et al, 2004; Bi et al, 2005) with kinetics that precede ATP depletion (Lefebvre et al, 1993). Furthermore, regulation of mRNA translation can have a significant and rapid impact on individual gene expression. This is because the sensitivity of individual genes to changes in overall translation varies widely and in a manner that reflects the molecular mechanisms responsible for controlling translation (Johannes et al, 1999; Harding et al, 2000). Regulation of gene expression through control of mRNA translation is important during various pathologies including cancer (Holland et al, 2004). The mechanisms responsible for inhibiting translation during hypoxia are not yet fully understood. 
We have previously investigated the involvement of the endoplasmic reticulum (ER) kinase PERK in the hypoxia-induced downregulation of protein synthesis (Koumenis et al, 2002). PERK is activated as part of the evolutionarily conserved unfolded protein response (UPR) (reviewed in Schroder and Kaufman, 2005). It phosphorylates elF2 $\alpha$, a subunit of elF2, which in its GTPbound form recruits the aminoacylated tRNA to the 40S ribosomal subunit. The exchange of GDP for GTP is mediated by the guanine nucleotide exchange factor elF2B. Ser51-phosphorylated elF2 $\alpha$ inhibits elF2B, resulting in inhibition of translation initiation. elF2 $\alpha$ phosphorylation results in a set of molecular events collectively termed the integrated stress response. These include the inhibition of global mRNA translation in conjunction with induced expression of the transcription factor ATF4 and its downstream target genes (Harding et al, 2003). We showed that hypoxia rapidly activated PERK, which led to reversible phosphorylation of elF2 $\alpha$ (Koumenis et al, 2002). Hypoxiainduced inhibition of protein synthesis was severely attenuated in cells without functional PERK. After prolonged periods of hypoxia, PERK-deficient cells did show partial inhibition, suggesting that protein synthesis is regulated through additional mechanisms.

Another candidate mechanism for inhibiting translation during hypoxia is disruption of the cap-binding protein complex elF4F, which consists of elF4E, elF4A and elF4G (for recent reviews see Gebauer and Hentze, 2004; Holcik and Sonenberg, 2005). elF4E participates in a protein bridge between the mRNA and the ribosome by its simultaneous interaction with the mRNA $5^{\prime}$ cap structure and the large scaffolding protein elF4G, which in turn interacts with elF3 that is bound to the 40S ribosomal subunit. elF4E is regulated through a set of binding proteins (4E-BPs) that bind reversibly to elF4E in their hypophosphorylated form, and this obstructs the interaction between elF4E and elF4G. The 4E-BP1 protein becomes hyperphosphorylated in response to a number of stimuli, such as insulin, hormones, growth factors, mitogens and cytokines, as a result of activation of the PI3-kinase/Akt/mTOR pathway (Hay and Sonenberg, 2004).

It remains unclear to what degree the lack of elF4F assembly contributes to inhibition of translation during tumor hypoxia. Several studies have investigated the combined consequences of ischemia/reperfusion on elF4F-related proteins in rat brains (reviewed in DeGracia et al, 2002). Proteolysis of elF4G was reported during ischemia and reperfusion in vivo (Neumar et al, 1998; Martin de la Vega et al, 2001), but not in neuronal cells cultured in vitro (NGF differentiated PC12 cells) (Martin et al, 2000). The reports addressing the expression and phosphorylation status of elF4E during ischemia are conflicting, but 4E-BP1 dephosphorylation has been demonstrated both in vivo and 
in vitro (Martin et al, 2000; Martin de la Vega et al, 2001). The acuteness and complexity of ischemia/reperfusion stress and the high sensitivity of neurons to deprivation and reconstitution of both oxygen and nutrients are distinct properties of this model system and thus difficult to extrapolate to tumor hypoxia. In rat hepatocytes, 4E-BP1 becomes dephosphorylated and associates with elF4E rapidly (15-60 min) upon mild hypoxia, but this could not explain the observed down-regulation of protein synthesis (Tinton and BucCalderon, 1999). More recently, it was reported that hypoxia could influence 4E-BP1 phosphorylation by affecting the activity of mTOR (Arsham et al, 2003). Serum-starved and hypoxic human embryonic kidney cells failed to activate mTOR, phosphorylate 4E-BP1 and dissociate 4E-BP1 from elF4E in response to insulin treatment. Nonetheless, it remains unknown whether hypoxia alone is sufficient to disrupt the elF4F complex and to what extent this influences overall translation during hypoxia. Here we show that hypoxia induces a biphasic inhibition of mRNA translation characterized by transient phosphorylation of elF2 $\alpha$ and subsequent dissociation of elF4F. These two mechanisms operate independently of each other and both have important consequences for gene expression during hypoxia

\section{Materials and methods}

\section{Cell culture}

Exponentially growing cervical carcinoma HeLa cells (American Type Culture Collection CCL-2), lung adenocarcinoma A549 cells, normal human fibroblasts (AG1522) or MEFs that were WT or had a homozygous knock-in mutation for elF2 $\alpha$ (S51A) (Scheuner et al, 2001) were grown on glass dishes or chamber slides in DMEM media supplemented with $10 \%$ fetal calf serum. The MEF media also contained MEM nonessential amino acids and $55 \mu \mathrm{M} 2-$ mercaptoethanol (all Sigma-Aldrich). For preparation of extracts and viability assessments, see Supplementary data.

\section{Hypoxic conditions}

Cells were transferred to a hypoxic culture chamber (MACS VA500 microaerophilic workstation, Don Whitley Scientific). The composition of the atmosphere in the chamber consisted of $5 \% \mathrm{H}_{2}, 5 \% \mathrm{CO}_{2}, 0.0 \% \mathrm{O}_{2}$ and residual $\mathrm{N}_{2}$. 


\section{$\mathbf{m}^{7}$ GTP resin precipitation}

A $1 \mathrm{mg}$ portion of HeLa extract was incubated with $25 \mu \mathrm{l}$ of $\mathrm{m}^{7}$ GTP sepharose resin (Amersham Biosciences) for $3 \mathrm{~h}$ at $4^{\circ} \mathrm{C}$. The resin was washed, boiled in Laemmli buffer and the polypeptides were resolved by SDS-PAGE.

\section{Western blotting}

Cell extracts were boiled in Laemmli buffer and polypeptides were resolved by SDS-PAGE and transferred onto $0.2 \mu \mathrm{m}$ nitrocellulose membranes (Amersham Corp.). For primary antibodies, see Supplementary data. Detection of peroxidase-coupled secondary antibodies was performed with Enhanced Chemiluminescence (Amersham Corp.).

\section{Immunofluorescence}

Cells were fixed with $4 \%$ paraformaldehyde and permeabilized in $4 \%$ paraformaldehyde and $0.1 \%$ Triton X-100. For antibodies, see Supplementary data. Cells were mounted in the ProLong ${ }^{\mathrm{TM}}$ Antifade Kit (Molecular Probes) and analyzed with a Zeiss inverted LSM 410 laser scan confocal microscope.

\section{Polysomal fractionation and analysis}

Polysomal fractionation and analysis were performed as described previously (Koritzinsky et al, 2005); see Supplementary data.

\section{RNA isolation and reverse transcription}

RNA isolation and reverse transcription were performed as described previously (Koritzinsky et al, 2005); see Supplementary data.

\section{Quantitative PCR analysis}

Real-time PCR was performed in either ABI 7700 or ABI 7500 (Applied Biosystems). For primers and probes, see Supplementary data. Unfractionated samples were normalized by $18 \mathrm{~S}$ rRNA signal. Samples from polysome fractions were normalized by $18 \mathrm{~S}$ rRNA measured by PCR divided by $18 \mathrm{~S}$ rRNA measured by spectrometry during fractionation, corrected for loading. This facilitated correction for any differences in RNA isolation or reverse transcriptase efficiency between samples. The abundance of every gene was calculated relative to a master reference using standard curves.

\section{Supplementary data}

Supplementary data are available online at www.embojournal.org. 


\section{Results}

\section{Kinetics of translation inhibition}

To determine the effects of hypoxia on mRNA translation initiation in HeLa cells, we examined the association of ribosomes with mRNA at various time points. In this assay, the number of ribosomes found within the 'polysomal' fraction of mRNA (mRNA containing two or more ribosomes) is a reflection of de novo protein synthesis. This technique is advantageous to other methods such as ${ }^{35} \mathrm{~S}$ incorporation, which requires prior amino-acid starvation, a procedure that can itself influence translation initiation (Kimball and Jefferson, 2000). Figure $1 \mathrm{~A}$ shows that at all time points examined, hypoxia causes a large decrease in polysomal mRNA and a corresponding increase in free ribosomes and ribosomal subunits. The reduction in translation is not influenced by cell death, as cell viability remains above $90 \%$ following $16 \mathrm{~h}$ of hypoxia (data not shown). Furthermore, the inhibition of translation is completely reversible upon reoxygenation (data not shown).

To assess quantitatively overall mRNA translation from the polysome profiles, we calculated the percentage of rRNA participating in polysomes and defined this as the overall translation efficiency. This value is reduced from 62 to $24 \%$ after $1 \mathrm{~h}$ of hypoxia, and then recovers somewhat stabilizing at $\sim 30 \%$ (Figure 1B). The drop in translation reproducibly exhibited this biphasic response with maximum inhibition after 1-2 $\mathrm{h}$, followed by a small recovery. The magnitude of inhibition is comparable to that observed following complete disruption of the cellular redox environment with $1 \mathrm{mM}$ dithiothreitol (DTT) (17\%) (data not shown).

Analysis of the polysome profiles in Figure $1 \mathrm{~A}$ shows that hypoxia also causes a change in the distribution of the polysomal mRNA, with proportionally less signal in the higher molecular weight fractions. This indicates that the average number of ribosomes per mRNA transcript is also decreased during hypoxia, reflecting a reduction in translation initiation efficiency even for those transcripts that remain translated. From the polysome profiles, we calculated the average number of ribosomes per translated transcript (i.e. mRNAs containing two or more ribosomes) at different time points during hypoxia (Figure 1C). The kinetics of this parameter follow in large part that of the overall translation. 

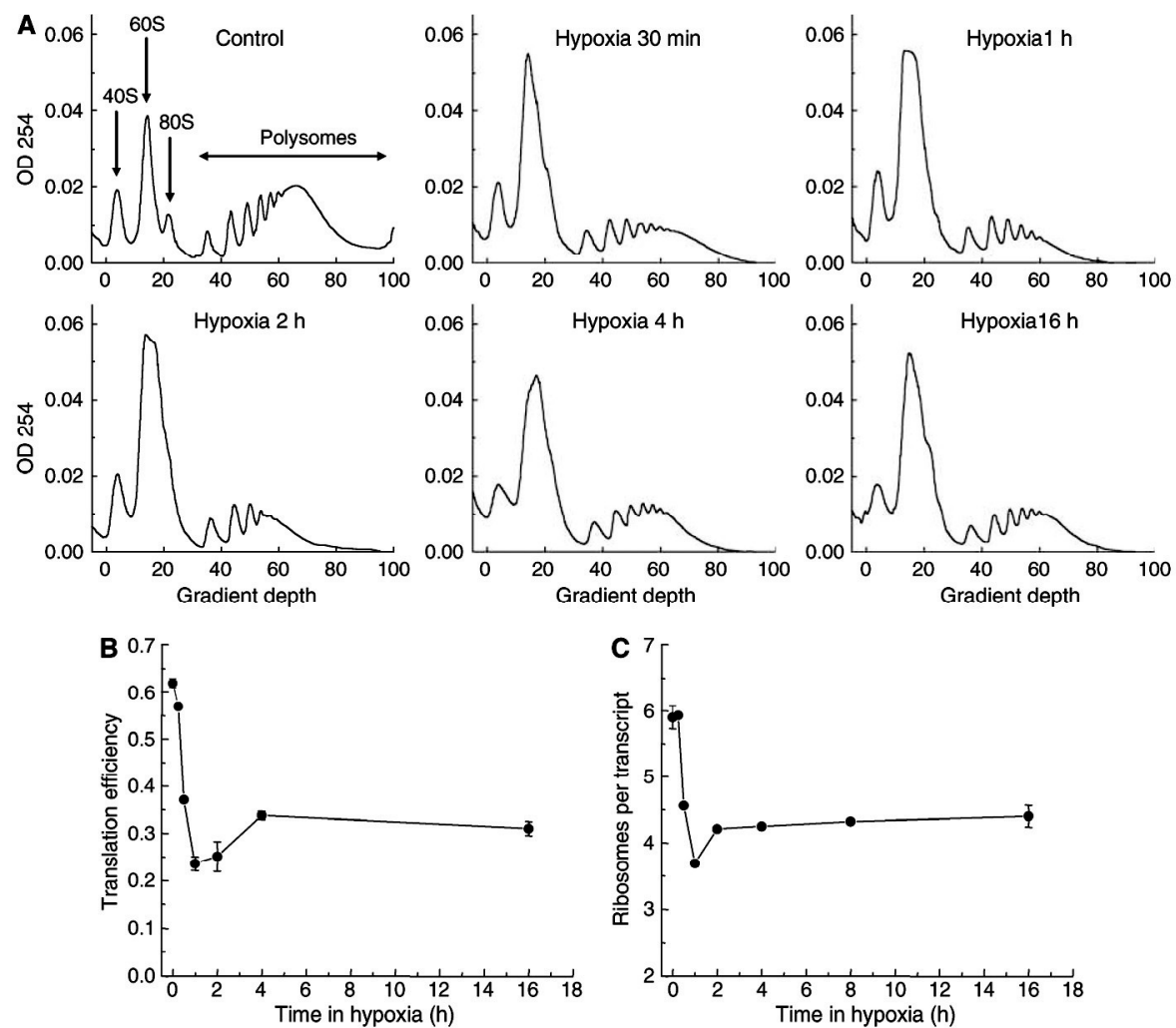

Figure 1. Hypoxia inhibits mRNA translation. HeLa cells were exposed to $0.0 \% \mathrm{O}_{2}$ for $0-16 \mathrm{~h}$ and cell lysates were separated on a sucrose gradient. (A) The optical density (OD) at $254 \mathrm{~nm}$ is shown as a function of gradient depth for each time point. Actively translated mRNA is associated with high-molecular-weight polysomes deep in the gradient. (B) Translation efficiency in HeLa cells as a function of time in $0.0 \% \mathrm{O}_{2}$. As a measure of overall translation efficiency, the relative amount of rRNA participating in polysomes was estimated. This fraction is proportional to the integrated area under the curve containing polysomes, as marked in (A). (C) The average number of ribosomes per mRNA in the polysomes as a function of time in $0.0 \% \mathrm{O}_{2}$. This was calculated by differential integration of the profiles in (A).

\section{elF $2 \alpha$ regulates translation during acute hypoxia}

The elF2 $\alpha$ kinase PERK is at least partly responsible for protein synthesis inhibition during acute hypoxia, as measured by radioactive labeling of newly synthesized proteins (Koumenis et al, 2002). Thus, we hypothesized that the rapid inhibition and subsequent partial recovery in translation is due to changes in elF2 $\alpha$ phosphorylation. Indeed, we found that the phosphorylation of elF2 $\alpha$ is greatest after 1-2 $\mathrm{h}$ and then decreases by $8 \mathrm{~h}$ of hypoxia in several cell lines (Figure 2A). ATF4 protein levels also increase and then decrease during hypoxia in a manner that mirrors elF2 $\alpha$ phosphorylation. The 
dynamics of elF2 $\alpha$ phosphorylation and ATF4 protein induction thus correlate with the initial inhibition of translation and its subsequent recovery.

To assess the requirement of elF2 $\alpha$ phosphorylation for translation inhibition during hypoxia we examined the response of mouse embryo fibroblasts (MEFs) derived from elF2 $\alpha$ knock-in mice containing an S51A mutation (Scheuner et al, 2001). As expected, these cells were defective in phosphorylation of elF2 $\alpha$ during hypoxia (Figure 2B). The translation efficiency in wildtype (WT) MEFs is similar to that in HeLa cells, with a rapid drop during acute hypoxia followed by a partial recovery (Figure $2 \mathrm{C}$ ). In contrast, S51A MEFs display a substantial defect in their ability to inhibit translation during the initial phase. Nonetheless, after $16 \mathrm{~h}$ of hypoxia, both cell lines show a similar loss in translation efficiency. These data indicate that elF $2 \alpha$ phosphorylation is indeed necessary for inhibition of translation during acute hypoxia, but not at later times.

When the polysome profiles are analyzed in terms of the average number of ribosomes per translated transcript, S51A MEFs exhibit an even stronger defect in their response during acute hypoxia. Despite a small but detectable drop in translation efficiency during the first $4 \mathrm{~h}$ of hypoxia (Figure $2 \mathrm{C}$ ), S51A MEFs show no decrease in the average number of ribosomes per translated transcript (Figure 2D). The same result was found in cells treated with DTT, a known activator of PERK that causes elF2 $\alpha$ phosphorylation. In contrast, WT MEFs show a strong reduction in average ribosomes per transcript during both acute hypoxia and DTT treatment. Interestingly, after $8 \mathrm{~h}$ of hypoxia, the average number of ribosomes per translated transcript increases again toward normal levels in WT cells and is equivalent to that in S51A MEFs by 16 $\mathrm{h}$. These data provide further evidence that the inhibition of translation that occurs after acute and prolonged hypoxia is mechanistically distinct. 


\section{Chapter 3}
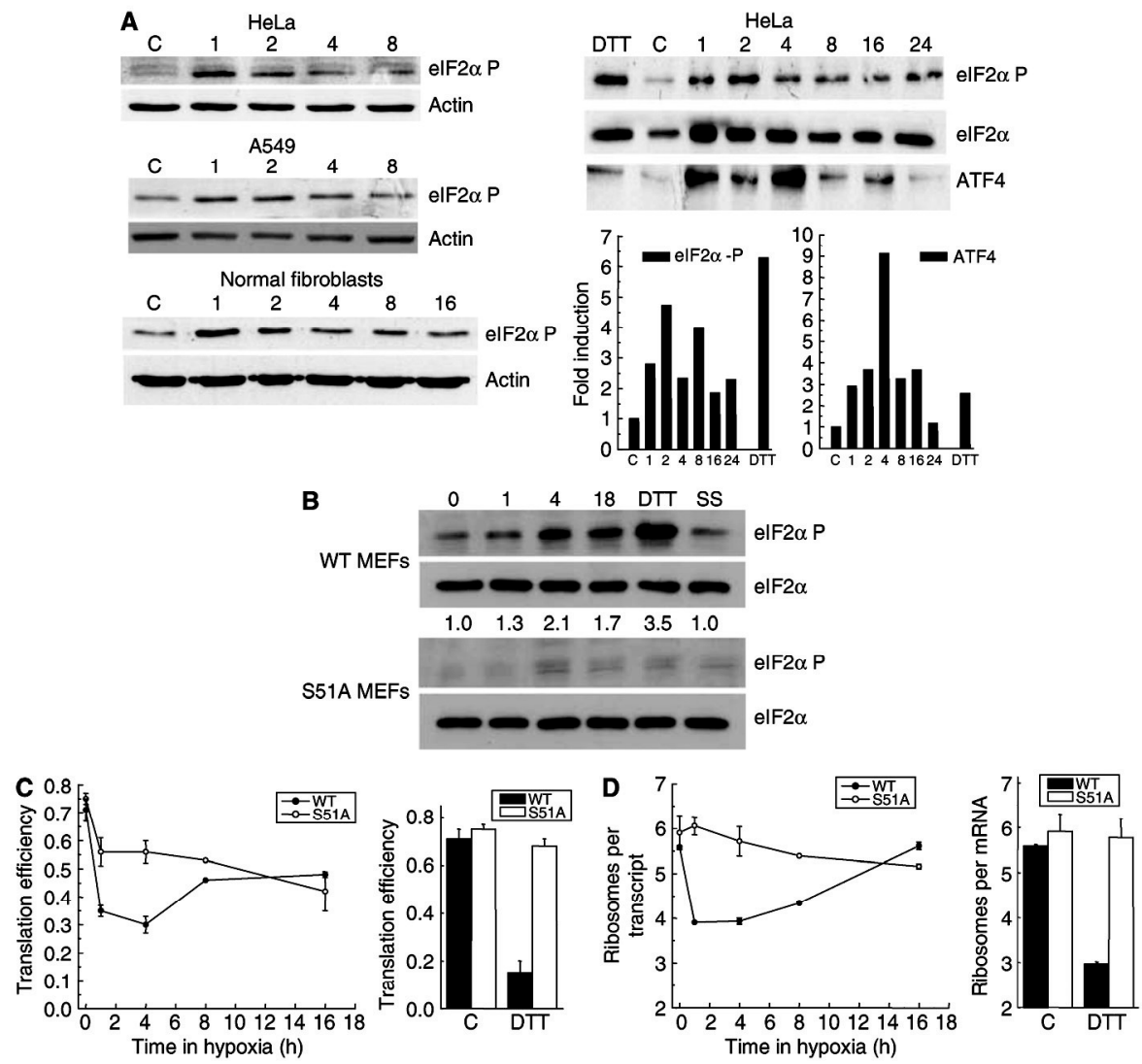

Figure 2. Inhibition of translation during acute hypoxia is dependent on elF2 $\alpha$. HeLa cells, A549 cells, human normal fibroblasts (NF) and WT or S51A MEFs were exposed to $0.0 \% \mathrm{O}_{2}$ for $0-16$ h, $1 \mathrm{mM}$ DTT or serum starvation (SS) for $1 \mathrm{~h}$. Cell lysates were separated by SDS-PAGE. Immunoblots for (A) HeLa, A549 and NF or (B) MEFs were performed using antibodies against total or phosphorylated elF2 $\alpha$, ATF4 and $\beta$-actin. In (A), optical densitometry for phosphorylated elF2 $\alpha$ or ATF 4 normalized by total elF2 $\alpha$ is also shown. Total elF2 $\alpha$ expression has previously been shown to be constant during hypoxia (Koumenis et al, 2002). (C) Cell lysates were separated on a sucrose gradient, and OD at $254 \mathrm{~nm}$ was recorded. Translation efficiency as a function of time in $0.0 \% \mathrm{O}_{2}$ in WT and S51A MEFs was estimated as in Figure 1. (D) Average number of ribosomes per mRNA in the polysomes in WT and S51A MEFs as a function of time in $0.0 \% \mathrm{O}_{2}$ was calculated as in Figure 1 . 


\section{Disruption of the elF4F complex during hypoxia}

The assembly of the cap-binding complex elF4F is a common control point for translation initiation and was thus a likely candidate for maintaining low rates of translation during prolonged hypoxia. We examined the levels of elF4E and proteins that associate with it as an active complex (elF4GI) or as an inactive complex (4E-BP1). Figure $3 \mathrm{~A}$ shows that the levels of elF4E do not change during hypoxia. In contrast, 4E-BP1 (Figure 3B) shows both a small induction at $8 \mathrm{~h}$ and a strong dephosphorylation after $16 \mathrm{~h}$ of hypoxia. This protein runs as different migrating bands representing different phosphorylation levels (Pause et al, 1994). The fastest migrating band is substantially increased after $16 \mathrm{~h}$ of hypoxia, and represents the hypophosphorylated 4E$\mathrm{BP} 1$, which is known to have a higher affinity for elF4E. A small decrease in the abundance of the scaffold protein elF4GI (Figure 3C) was observed after 8 $\mathrm{h}$, consistent with a decrease in its rate of synthesis measured in a microarray study using polysomal RNA (unpublished data). Overexposure of the blots indicated no reproducible changes in the cleavage of elF4G. The influence of hypoxia on 4E-BP1 phosphorylation appears to be largely independent of elF2 $\alpha$ phosphorylation, as it is not differentially affected in the WTand S51A MEFs (unpublished data). However, until the relative contributions of various upstream signaling pathways to 4E-BP phosphorylation under hypoxia are better understood, it is premature to conclude that no connection between elF2 $\alpha$ and elF4F exists.

To more strictly assess the influence of hypoxia on elF4F, we investigated the association of elF4E with elF4GI and elF4GII as well as with its inhibitor 4EBP1 in HeLa cells. During aerobic conditions where translation is efficient, elF4E is associated with large amounts of both elF4GI and elF4GII, and only a small amount of 4E-BP1 (cap lanes in Figure 4A and B). Cap-associated elF4G migrated somewhat slower than the overall pool of elF4G, suggesting a possible modification of this phospho-protein when bound to the cap. In contrast, after 4 or $16 \mathrm{~h}$ of hypoxia, there is a dramatic loss in binding to both elF4GI and elF4GII, indicating dissociation of the elF4F complex. At $16 \mathrm{~h}$, this dissociation correlates with a large increase in binding between elF4E and 4E$\mathrm{BP} 1$, consistent with the increase in the hypo-phosphorylated levels of 4E-BP1 at this time. It also correlated with decreased phosphorylation of elF4E (Supplementary Figure S1) at $16 \mathrm{~h}$, but the physiological significance of this remains unclear. However, although dissociation of elF4G and elF4E is complete after $4 \mathrm{~h}$ of hypoxia, a corresponding change in elF4E phosphorylation or elF4E/4E-BP1 association is not seen at this time point. This suggests that a mechanism distinct from 4E-BP1 dephosphorylation may also inhibit elF4F during hypoxia. 


\section{Chapter 3}
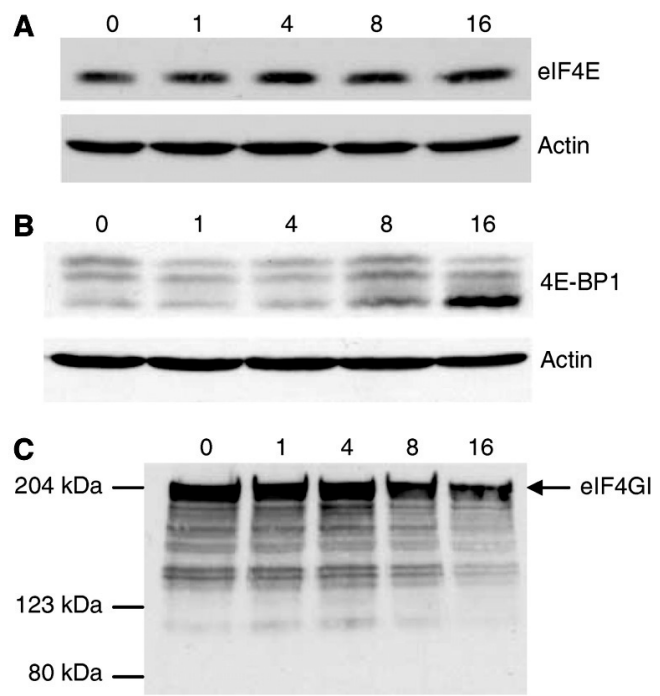

Figure 3. Expression of elF4E, 4E-BP1 and elF4GI during hypoxia. HeLa cells were exposed to $0.0 \% \mathrm{O}_{2}$ for $0-16 \mathrm{~h}$ and cell lysates separated by SDS-PAGE. Immunoblots were performed using antibodies against actin, (A) elF4E, (B) 4E-BP1 and (C) elF4GI. The phosphorylation forms of $4 \mathrm{E}-\mathrm{BP} 1$ have different electrophoretic mobilities and are represented by several bands on the immunoblot. Full-length elF4GI runs at about $220 \mathrm{kDa}$; the blot is overexposed to detect cleavage products.

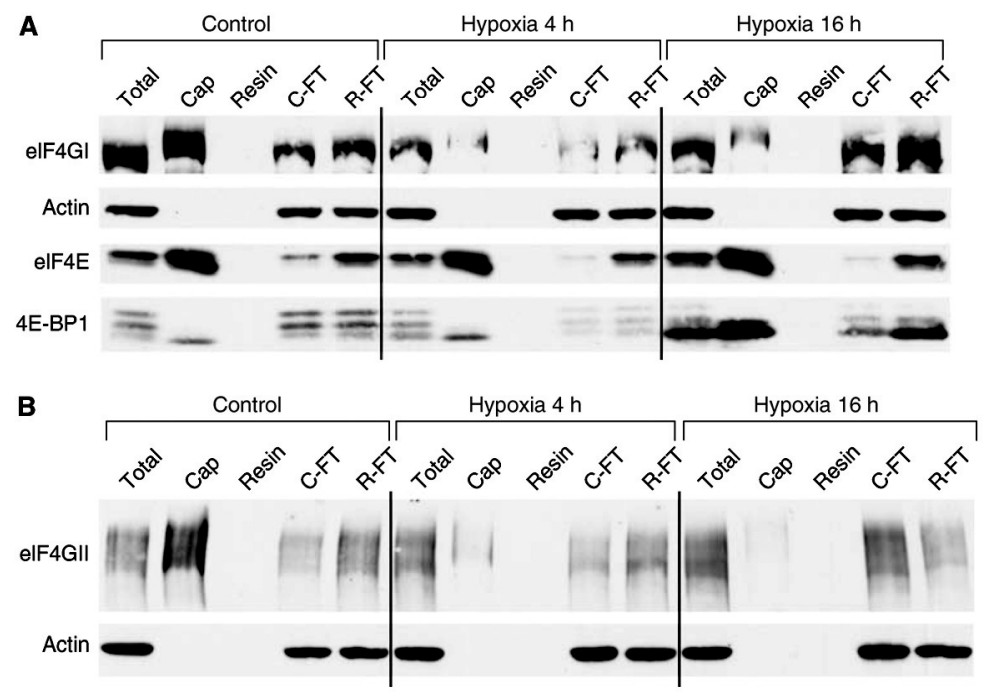

Figure 4. elF4F is disrupted during prolonged hypoxia. HeLa cells were exposed to $0.0 \% \mathrm{O}_{2}$ for $0-16 \mathrm{~h}$ and cell lysates probed for the presence of various elF4E complexes. Lysates were incubated with an $\mathrm{m}^{7}$-cap analogue ('Cap') or uncapped resin as a negative control. Immunoblots were performed with antibodies against actin, (A) elF4GI, elF4E, 4E-BP1 and (B) elF4GII. 'Cap': proteins bound to the capped resin; 'Resin': proteins bound to the uncapped resin; 'C-FT': unbound fraction after incubation with capped resin; 'R-FT': unbound fraction after incubation with uncapped resin. 


\section{Translocation of elF4E by $4 \mathrm{E}-\mathrm{T}$}

A potential cause of elF4F disruption that has not been well characterized is the translocation of elF4E to the nucleus or to cytoplasmic bodies of mRNA processing (P-bodies). A 5-20\% fraction of elF4E is known to localize to the cell nucleus (Lejbkowicz et al, 1992). The shuttling protein 4E-T is the only known regulator of elF4E localization and is capable of binding and transporting it to the cell nucleus (Dostie et al, 2000). elF4E also colocalizes with 4E-T in P-bodies, where mRNA is degraded or stored (Andrei et al, 2005). Hypoxia caused a redistribution of both elF4E and 4E-T from predominantly cytoplasmic staining under aerobic conditions to substantial nuclear staining during hypoxia (Figure $5 \mathrm{~A}-\mathrm{C}$ ). This redistribution occurred progressively over time in hypoxic conditions, correlating with the gradual dephosphorylation of 4E-T (Figure 5D). In addition, hypoxic cells exhibit significant elF4E and 4E-T staining in the perinuclear area, which may be associated with the nuclear envelope or the ER. Interestingly, hypoxia also increased the number of 4E-T speckles, which have been described as P-bodies (Ferraiuolo et al, 2005).

\section{Gene-specific regulation of translation}

As translation efficiency is highly gene specific, we anticipated that individual genes would show different patterns of translation efficiency during acute and prolonged hypoxia. To investigate this, we fractionated polysomal mRNA and subsequently measured the mRNA abundance of individual genes by quantitative RT-PCR (Figure 6A). We first confirmed that concomitant with an increase in polysome association, the non/subpolysomal abundance decreased (Supplementary Figure S2). Subsequently, we quantified both the transcript recruitment and distribution within the polysomes (expressed as the relative fraction of translated transcripts and the average number of ribosomes per translated transcript, respectively).

We first measured the translational profile of the housekeeping gene $\beta$-actin (Figure 6B). In aerobic cells, it is efficiently translated with a majority of the mRNA in polysome fractions 5 and 6 . After $1 \mathrm{~h}$ of hypoxia, there is a marked reduction in translation, as evidenced by a shift toward the lower polysome fractions, which recovers considerably by $16 \mathrm{~h}$. The drop in translation efficiency at $1 \mathrm{~h}$ is due to reductions in the relative fraction of translated mRNA and in the average number of ribosomes per translated transcript (Figure 6B). At later time points, only the average number of ribosomes per transcript remained low. The kinetic changes in translation efficiency for $\beta$-actin are similar to those observed for overall translation efficiency. 
A
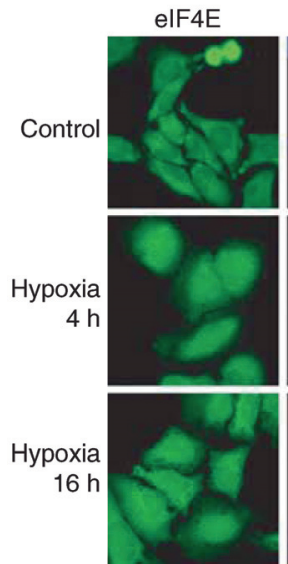

B

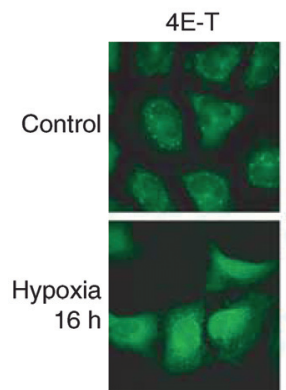

DAPI
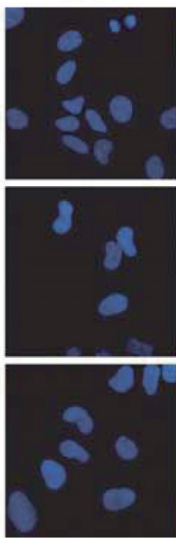

DAPI
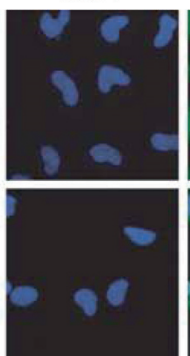

C
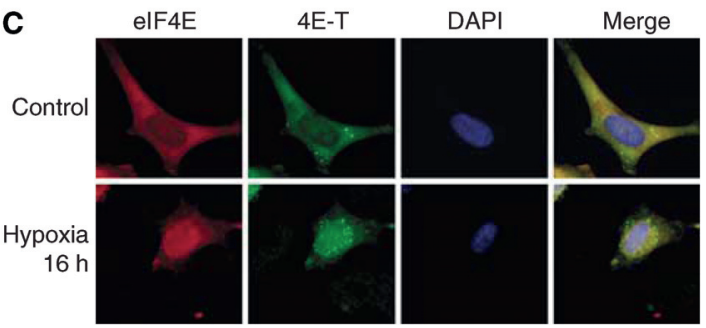

D

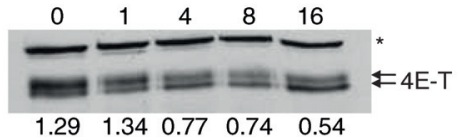

Merge
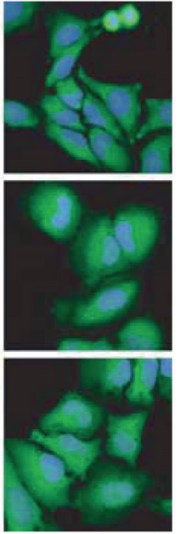

Merge
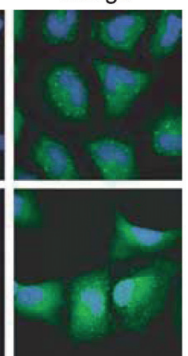

$\operatorname{los}$

$\sqrt{4}$$$
\text { . }
$$

Figure 5. 4E-T and elF4E relocalize during hypoxia. HeLa cells were treated with $0.0 \% \mathrm{O}_{2}$ for $0-16$ h. Cells were stained with DAPI and (A) a polyclonal antibody against elF4E, (B) a polyclonal antibody against 4E-T or (C) a monoclonal antibody against elF4E and a polyclonal antibody against 4E-T. Cells were visualized by confocal microscopy and individual pictures merged to determine colocalization. (D) Cell lysates were separated by SDSPAGE and immunoblots performed using antibodies against $4 \mathrm{E}-\mathrm{T}$. The ratio of the individual bands was quantified with optical densitometry. A cross-reacting band is indicated $\left({ }^{*}\right)$. 
A
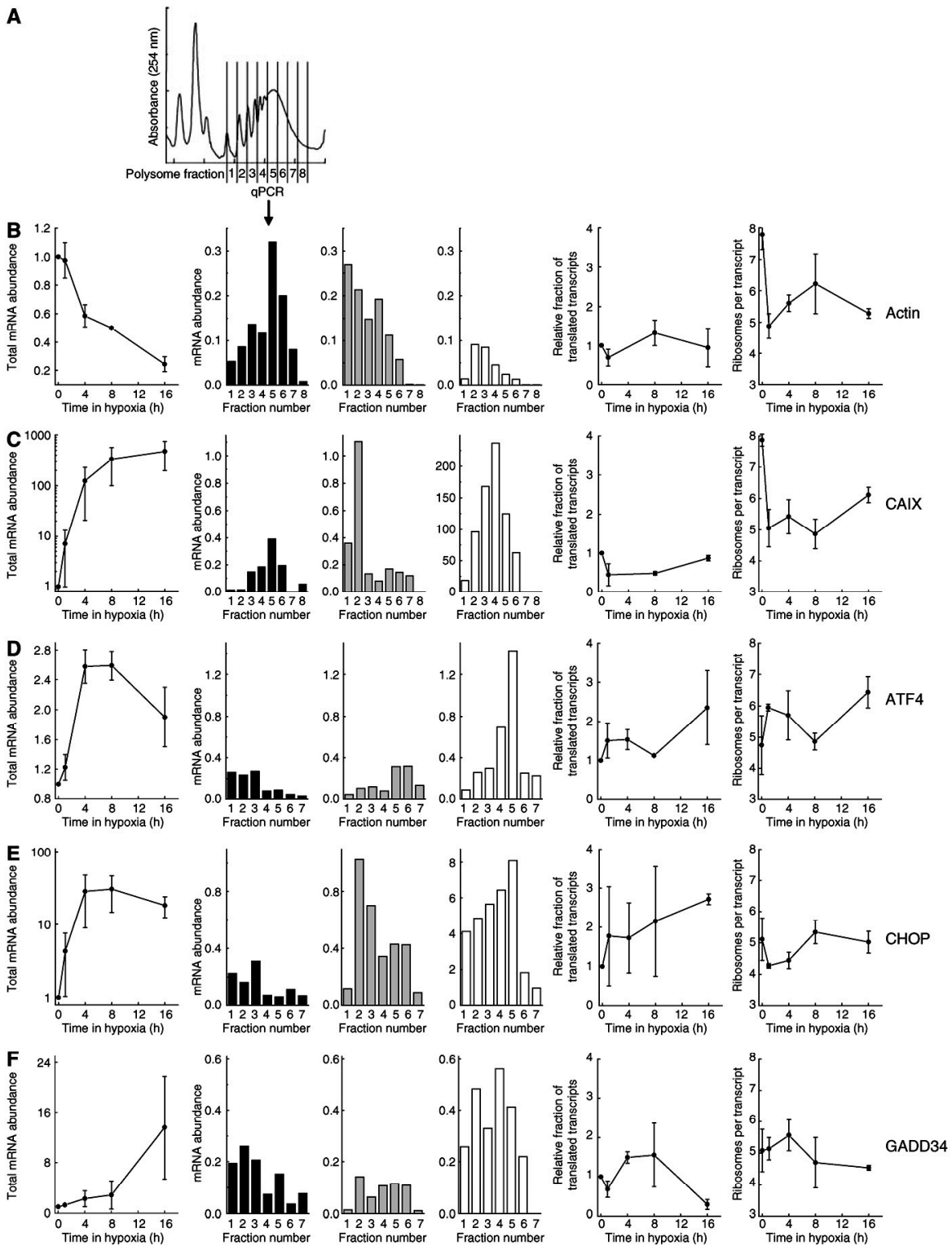

Figure 6. Gene-specific regulation of translation during hypoxia. HeLa cells were exposed to $0.0 \% \mathrm{O}_{2}$ for $0-16 \mathrm{~h}$ and cell lysates were separated on sucrose gradients. (A) Fractions were collected as indicated, RNA was isolated and reverse transcribed. Thereafter, the total mRNA abundance of (B) $\beta$-actin, (C) CAIX, (D) ATF4, (E) CHOP and (F) GADD34 was determined using real-time quantitative PCR. The left panel shows total mRNA levels from unfractionated samples, normalized by $18 \mathrm{~S}$ rRNA signal. The following three panels use black, gray and white bars to represent the gene abundance in polysome fractions following 0,1 or $16 \mathrm{~h}$ hypoxia, respectively. The last two graphs show components of translation efficiency. This includes the relative fraction of transcripts in polysomes (i.e. corrected for total mRNA abundance) and the average number of ribosomes per mRNA. Graphs show the average from two independent experiments, and the histograms show the results from one representative experiment. 
Many proteins are induced at the transcriptional level by hypoxia and we suspected that these genes might be preferentially translated during hypoxia. We investigated the translation of the HIF-1 target gene carbonic anhydrase IX (CAIX), which is important for tumor cell growth and survival during hypoxia (Robertson et al, 2004). Figure 6C shows an $\sim 500$-fold transcriptional induction of CAIX during hypoxia. Polysome analysis indicates that, similar to $\beta$-actin, CAIX is initially efficiently translated but severely inhibited after $1 \mathrm{~h}$ of hypoxia. A significant restoration of the polysome distribution occurs after 16 $\mathrm{h}$ and thus ensures protein synthesis at this time where there is also significantly more cellular mRNA. As for $\beta$-actin, the initial inhibition of CAIX translation is due to a drop in the recruitment of the mRNA into polysomes and in the number of ribosomes per transcript. However, during prolonged hypoxia, the mRNA recruitment recovers and lower translation efficiency is attributed only to a small reduction in the average number of ribosomes per transcript.

ATF4 is a central transcription factor mediating the UPR following ER stress. Both thapsigargin (which causes ER stress) and $16 \mathrm{~h}$ of hypoxia result in elF2 $\alpha$ phosphorylation and translational induction of ATF4 in a PERKdependent manner (Harding et al, 2000; Blais et al, 2004; Bi et al, 2005). Under normal conditions, the translation efficiency of this gene is low, with most of the mRNA found in fractions 1-3 (Figure 6D). In direct contrast to $\beta$-actin and CAIX, its translation is substantially increased during acute hypoxia, due to increased recruitment into the polysomes and an increase in the average number of ribosomes per transcript. In agreement with Blais et al (2004), we also observed a further increase in ATF4 translation efficiency during prolonged hypoxia.

An important transcriptional target of ATF4 is the C/EBP transcription factor CHOP (Fawcett et al, 1999), which induces cell cycle arrest and apoptosis during ER stress. Figure $6 \mathrm{E}$ shows that $\mathrm{CHOP}$ is regulated both transcriptionally and translationally by hypoxia. Translation is only moderately inhibited during acute hypoxia, as shown by a drop in the average number of ribosomes per transcript. However, this reduction is much smaller than average overall reduction (Figure $1 \mathrm{C}$ ) and the reductions observed for both $\beta$ actin and CAIX. After $16 \mathrm{~h}$ of hypoxia, translation of CHOP is stimulated, as indicated by a recovery in the number of ribosomes per transcript and a marked increase in the fraction of translated mRNA.

Recovery from ER stress requires the GADD34 gene, which is induced in a PERK-dependent (Novoa et al, 2001) and CHOP-dependent (Marciniak et al, 2004) manner. GADD34 stimulates the activity of PP1c to dephosphorylate elF2 $\alpha$. We found that, like CHOP, GADD34 is regulated both transcriptionally 
and translationally during hypoxia. Interestingly, its translation efficiency is highest after $4 \mathrm{~h}$ of hypoxia, which coincides with the start of recovery from elF2 $\alpha$ phosphorylation and overall translation inhibition (Figure 6F). In contrast, GADD34 mRNA is unable to completely bypass the translation inhibition after $16 \mathrm{~h}$.

\section{Gene-specific regulation of translation-dependence upon elF2 $\alpha$}

The gene-specific changes in translation noted above likely reflect the underlying elF2 $\alpha$-and elF4F-dependent mechanisms of translation control during hypoxia. We thus analyzed gene-specific translation in WT and S51A MEFs to establish the dependence of individual genes on elF2 $\alpha$ regulation (Figure 7). In contrast to WT MEFs, S51A MEFs show no loss in translation efficiency of $\beta$-actin or CAIX during acute hypoxia (Figure 7A and B). The loss in translation efficiency for these genes in the WT cells is similar to that observed in HeLa cells and is due primarily to a reduction in the average number of ribosomes per transcript. For both these genes, S51A MEFs show virtually no reduction in this parameter during the acute phase of hypoxia. However, in contrast to acute hypoxia, the translation efficiency during prolonged hypoxia is similar for these two genes in both cell lines.

For ATF4 (Supplementary Figure S2), CHOP (data not shown) and GADD34 (Figure 7C), acute hypoxia causes a stimulation of translation in WT MEFs that is similar to HeLa cells. However, the translational induction is entirely absent in S51A MEFs. The increase in translation efficiency for GADD34 in WT MEFs during acute hypoxia results mainly from an increase in the average number of ribosomes per transcript (Figure $7 \mathrm{C}$ ). Cells that are defective in elF2 $\alpha$ phosphorylation show impaired regulation of this parameter. Thus, for all genes examined, the observed changes in translation efficiency during acute hypoxia are dependent on elF2 $\alpha$ phosphorylation. 
A
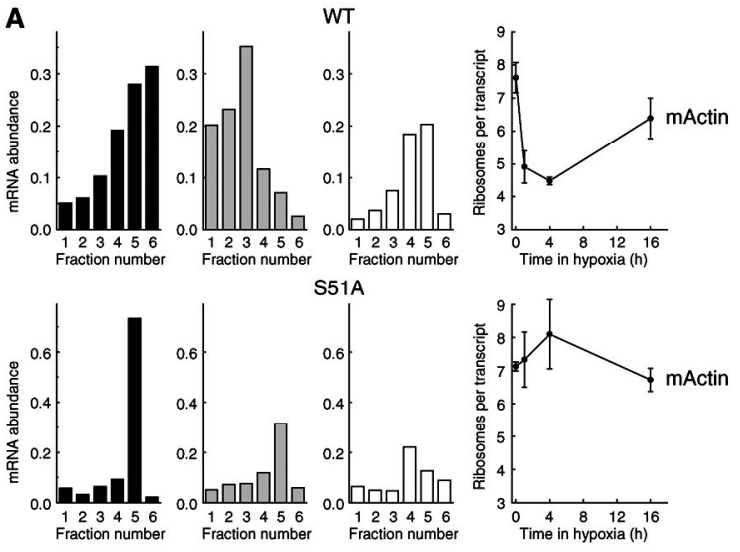

S51A
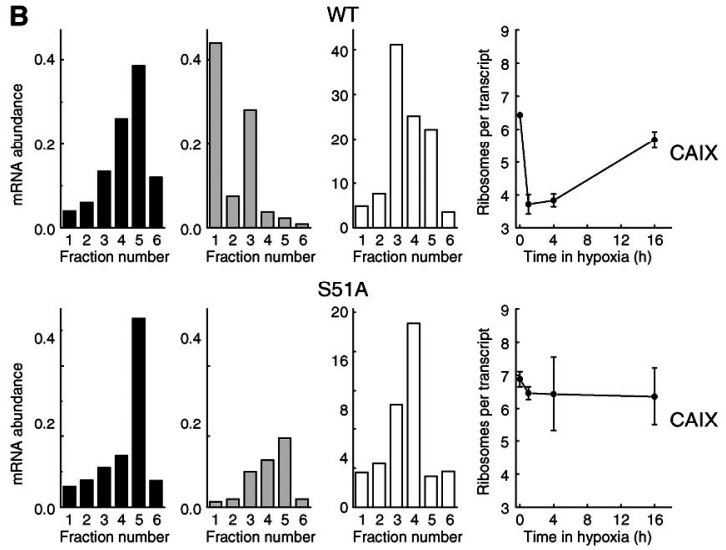

S51A
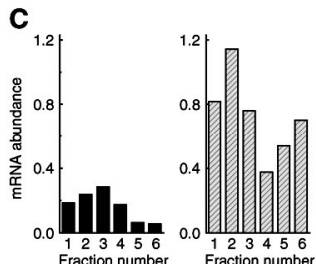

WT
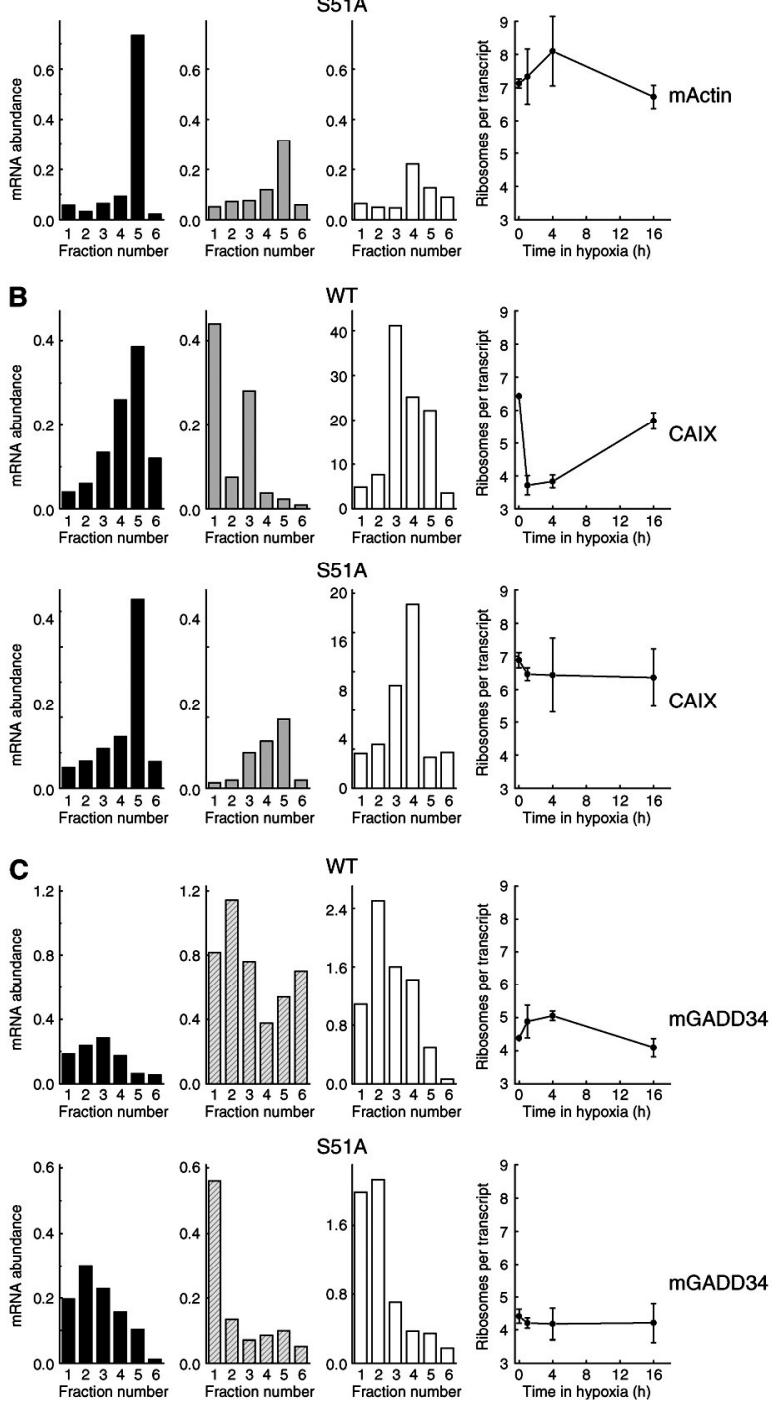

S51A
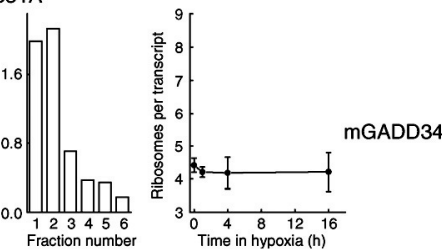

Figure 7. Dependence on elF2 $\alpha-P$ for gene-specific translational regulation. WT and S51A MEFs were exposed to $0.0 \% \mathrm{O}_{2}$ for $0-16 \mathrm{~h}$ and cell lysates were separated on sucrose gradients. RNA was isolated from polysome fractions and reverse transcribed. Thereafter, the abundance of (A) $\beta$-actin, (B) CAIX and (C) GADD34 was determined using realtime quantitative PCR. The first three panels use black, solid grey, hatched grey and white bars to represent the gene abundance in polysome fractions following 0 , 1,4 or $16 \mathrm{~h}$ hypoxia, respectively. The following graph depicts one component of translation efficiency, that is, the average number of ribosomes per mRNA. 


\section{Discussion}

Rapid and persistent downregulation of protein synthesis is thought to be a means of energy preservation and to protect against the lethal effects of hypoxia (Koumenis et al, 2002; Wouters et al, 2005). Here we show that the inhibition of global mRNA translation during hypoxia exhibits a biphasic response (Figure 8). The initial rapid inhibition (i.e. $15 \mathrm{~min}-4 \mathrm{~h}$ ) is primarily dependent on elF2 $\alpha$ phosphorylation, whereas inhibition during prolonged hypoxia is independent of elF2 $\alpha$. Phosphorylation of elF2 $\alpha$ under conditions of anoxia is extremely rapid, occurring almost as quickly as we can establish hypoxia in our system (15-30 $\mathrm{min}$ ). We have previously shown that elF2 $\alpha$ is also phosphorylated under more moderate hypoxic conditions, although to a smaller degree and after longer times (Koumenis et al, 2002). We speculate that this rapid anoxic response may be especially important during the acute exposures to hypoxia/anoxia that frequently occur in tumors due to the transient opening and closing of blood vessels. This rapid response may explain the importance of elF2 $\alpha$ and ATF4 in the tolerance of cells to oxidative stress, which also occurs during hypoxia/reoxygenation cycles (Harding et al, 2003). This hypothesis is supported by a recent study by Bi et al (2005), who showed that activation of the PERK-elF2 $\alpha$ pathway during hypoxia contributes to overall tumor growth. Human tumor cells expressing a dominantnegative PERK allele as well as MEFs lacking PERK or expressing the S51A elF2 $\alpha$ produce smaller tumors with increased cell death in hypoxic areas than their WT counterparts ( $\mathrm{Bi}$ et al, 2005). Thus, although activation of elF2a phosphorylation in response to hypoxia is transient, this response appears critical for long-term cell survival within hypoxic regions of tumors.

Inhibition of translation during prolonged anoxia is associated with disruption of the mRNA cap-binding complex elF4F and sequestration of elF4E by both dephosphorylated 4E-BP1 and 4E-T. To our knowledge, this report is the first to show a physiological stress-induced regulation of the localization of elF4E and its transporter 4E-T. Accumulation of elF4E in the cell nucleus or Pbodies renders it unavailable for cytoplasmic translation. Relocalization of elF4E may have additional roles apart from reducing cap-dependent protein translation, including effects on mRNA processing, transport and degradation. Moderate hypoxia (1\%) has also been shown to affect the elF4F complex through inhibition of mTOR (Arsham et al, 2003). However, the kinetics and relative contribution of the elF4F pathway on inhibition of global and gene-specific translation during more moderate hypoxia remain to be determined (see below). 


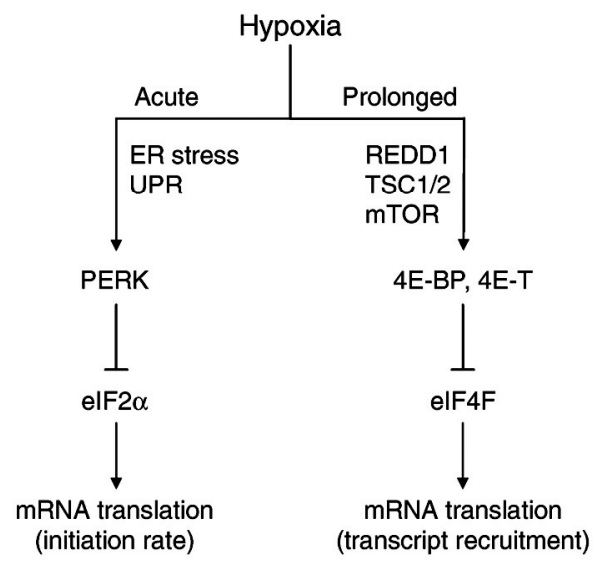

Figure 8. Model of the effects of hypoxia on overall mRNA translation. Acute hypoxia causes transient elF2 $\alpha$ phosphorylation due to PERK activation as a part of the UPR. This results in inhibition of the rate of translation initiation. Following prolonged hypoxic conditions, activation of $4 \mathrm{E}-\mathrm{BP}$ and $4 \mathrm{E}-\mathrm{T}$ causes disruption of elF4F, which inhibits the recruitment of mRNA to polysomes. Both molecular mechanisms affect specific mRNAs to varying degrees, resulting in differential gene expression.

Analysis of mRNA distribution within polysomes at different times also revealed interesting mechanistic differences during acute and prolonged hypoxia. Acute hypoxia caused a substantial drop in the average number of ribosomes per translated transcript. This presumably results from a reduction in the rate at which ribosomal subunits can be loaded onto mRNA, as each subunit requires a new nonphosphorylated elF2 $\alpha$ molecule. Inhibition of translation during prolonged hypoxia via elF4F did not show this effect. Instead, translation was suppressed mainly by reducing the fraction of mRNA found within the polysomes. These results are consistent with a model in which the elF4F cap-binding complex remains bound to the mRNA allowing sequential rounds of initiation by available elF2a complexes. When translation is inhibited via elF4F, many transcripts will lack this cap-binding complex and hence will not be competent to initiate translation. However, those transcripts that do contain elF4F will be translated normally (Figure 8). A similar phenomenon has been observed for a subpopulation of mRNAs that contain 5 ' terminal oligopyrimidine tracts (5'TOPs), which alternate between translationally repressed and active states in response to various stimuli (reviewed in Meyuhas and Hornstein, 2000). It is thus conceivable that the overall reduction in mRNA translation observed during prolonged hypoxia affects a subset of genes, such as those with 5'TOPs, to a greater degree than others.

An important issue that arises from our study is the nature of the oxygensensing pathways upstream of elF2 $\alpha$ and elF4F. Substantial evidence suggests that the oxygen sensors are largely independent of the HIF oxygensensing pathway (Jaakkola et al, 2001; Koumenis et al, 2002). In the case of elF2 $\alpha$, its phosphorylation occurs in an HIF-independent manner. Instead, it requires PERK activation (Koumenis et al, 2002) and is associated with acti- 
vation of the UPR in response to ER stress (Romero-Ramirez et al, 2004; Bi et al, 2005). The upstream signaling that leads to elF4F disruption is less clear, with perhaps both HIF-dependent and -independent components. Hypoxia has been shown to prevent insulin stimulation of mTOR and phosphorylation of its substrate 4E-BP1 during conditions of moderate hypoxia and serum starvation (Arsham et al, 2003). Similarly, Brugarolas et al (2004) showed that induction of REDD1 during hypoxia resulted in activation of the mTOR inhibitory complex TSC1/TSC2. As we also observe a decrease in the phosphorylation of 4E-BP1 after prolonged hypoxia, the elF4F-dependent changes in translation reported here may also be due in part to inhibition of mTOR via REDD1 and TSC1/2. However, it is unlikely that this accounts entirely for elF4F disruption and translation inhibition during hypoxia. REDD1 is a HIF-dependent gene and both mTOR inhibition and translation inhibition during hypoxia occur in HIF1a-knockout cells (Koumenis et al, 2002; Arsham et al, 2003). Furthermore, our data indicate that elF4F disruption occurs before substantial binding of elF4E to 4E-BP1. Here we have identified redistribution of elF4E into the cell nucleus via $4 \mathrm{E}-\mathrm{T}$ as an additional mechanism for elF4F disruption during hypoxia. Further work will be needed to establish to what degree inhibition of translation is due to suppression of mTOR/4E-BP1 phosphorylation and 4E-T activation, as well as to the requirements of HIF in both of these pathways.

The fact that both elF2 $\alpha$ and elF4F independently affect translation during hypoxia has important implications for the regulation of gene expression. mRNAs preferentially translated during acute hypoxia must be less dependent on elF2 $\alpha$ availability, whereas mRNAs that are actively translated during prolonged hypoxia must be less dependent on elF4F. The translation of ATF4, which contains two upstream open reading frames (uORFs) in its $5^{\prime} \mathrm{UTR}$, is perhaps the best example of a mammalian gene that displays this type of preferential translation (Harding et al, 2000). When elF2 $\alpha$ availability is high, translation begins at the $5^{\prime}$ most uORF and re-initiation occurs efficiently at the subsequent $\mathrm{UORF}$, preventing translation from the correct start codon of ATF4. When elF2 $\alpha$ is phosphorylated, there is a higher probability of skipping the second uORF and re-initiating at the bona fide start codon (Lu et al, 2004). Here, we found that in addition to ATF4, the downstream genes CHOP and GADD34 are also translationally induced during acute hypoxia. The S51A MEFs, which are unable to phosphorylate elF2 $\alpha$, are defective in this translational regulation. This result is consistent with a report showing that ER stress-induced expression of GADD34 protein can be prevented by keeping elF2 $\alpha$ dephosphorylated (Novoa et al, 2003). The bypass of translation inhibition may thus facilitate the ability of GADD34 to dephosphorylate elF2 $\alpha$ and promote recovery from ER stress. 
Our results predict that during prolonged hypoxia, gene transcripts with lower dependency on elF4F should be preferentially translated. The translation of ATF4 and CHOP was in fact stimulated in HeLa cells after $16 \mathrm{~h}$ of hypoxia when the elF4F complex was disrupted. Preferential translation under conditions of limiting cap-binding complex activity can occur through a higher than average affinity for elF4F (Lawson et al, 1988). Another group of mRNAs that can be translated independently of the elF4F complex are those that contain an internal ribosomal entry site (IRES) in their 5'UTR (Carter et al, 2000; Holcik and Sonenberg, 2005). The presence of an IRES enables translation initiation under conditions where elF4F-dependent translation is inhibited. Importantly, both mouse HIF-1 $\alpha$ and VEGF have been shown to contain functional IRESs within their 5'UTR (Stein et al, 1998; Lang et al, 2002), although their biological importance is not yet firmly established. This provides a mechanism to ensure their translation during prolonged hypoxia where elF4F is disrupted. The mechanism responsible for the selective translation of ATF4 and $\mathrm{CHOP}$ during prolonged hypoxia remains to be identified.

In conclusion, we have shown that mRNA translation is inhibited through multiple independent pathways with differing activation kinetics during hypoxia. These distinct modes of translational control influence the translation of individual genes to varying degrees and consequently can influence hypoxiaregulated protein expression in complex ways. An important finding is that inhibition of translation via elF2 $\alpha$ is transient, leading to dynamic changes in the translation efficiency of genes over the first $8 \mathrm{~h}$ of hypoxia. Our selected analysis of gene translation during hypoxia suggests that many genes may be differentially regulated by hypoxia. A complete survey of the genome for differentially translated genes during various exposures to hypoxia and their dependence of elF2 $\alpha$ is possible and will undoubtedly identify novel and important hypoxia-regulated proteins (Koritzinsky et al, 2005).

\section{Acknowledgements}

This work was financially supported by Netherlands Organization for Scientific Research (NWO), the Dutch Cancer Society (KWF Kankerbestrijding) and the Euroxy grant from the 6th framework of the EU to BGW, from the Norwegian Research Council to MK and from grant CA94214 from the National Institutes of Health (NIH) to CK. 


\section{References}

Andrei MA, Ingelfinger D, Heintzmann R, Achsel T, Rivera-Pomar R, Luhrmann R (2005) A role for elF4E and elF4E-transporter in targeting mRNPs to mammalian processing bodies. RNA 11: 717-727

Arsham AM, Howell JJ, Simon MC (2003) A novel hypoxia-inducible factor-independent hypoxic response regulating mammalian target of rapamycin and its targets. J Biol Chem 278: 29655-29660

Bennewith KL, Durand RE (2004) Quantifying transient hypoxia in human tumor xenografts by flow cytometry. Cancer Res 64: 6183-6189

Bi M, Naczki C, Koritzinsky M, Fels D, Blais J, Hu N, Harding H, Novoa I, Varia M, Raleigh J, Scheuner D, Kaufman RJ, Bell J, Ron D, Wouters BG, Koumenis C (2005) ER stressregulated translation increases tolerance to extreme hypoxia and promotes tumor growth. EMBO J 24: 3470-3481

Blais JD, Filipenko V, Bi M, Harding HP, Ron D, Koumenis C, Wouters BG, Bell JC (2004) Activating transcription factor 4 is translationally regulated by hypoxic stress. Mol Cell Biol 24: 7469-7482

Brugarolas J, Lei K, Hurley RL, Manning BD, Reiling JH, Hafen E, Witters LA, Ellisen LW, Kaelin Jr WG (2004) Regulation of mTOR function in response to hypoxia by REDD1 and the TSC1/TSC2 tumor suppressor complex. Genes Dev 18: 2893-2904

Cardenas-Navia LI, Yu D, Braun RD, Brizel DM, Secomb TW, Dewhirst MW (2004) Tumordependent kinetics of partial pressure of oxygen fluctuations during air and oxygen breathing.

Cancer Res 64: 6010-6017

Carter MS, Kuhn KM, Sarnow P (2000) Cellular internal ribosome entry site elements and the use of cDNA microarrays in their investigation. In Translational Control of Gene Expression, Sonenberg N, Hershey JW, Mathews MB (eds) pp 615-636. Cold Spring Harbor, NY: Cold Spring Harbor Laboratory Press

DeGracia DJ, Kumar R, Owen CR, Krause GS, White BC (2002) Molecular pathways of protein synthesis inhibition during brain reperfusion: implications for neuronal survival or death. $J$ Cereb Blood Flow Metab 22: 127-141

Dostie J, Ferraiuolo M, Pause A, Adam SA, Sonenberg N (2000) A novel shuttling protein, 4E-T, mediates the nuclear import of the mRNA 50 cap-binding protein, elF4E. EMBO J 19: 3142-3156

Erler JT, Cawthorne CJ, Williams KJ, Koritzinsky M, Wouters BG, Wilson C, Miller C, Demonacos C, Stratford IJ, Dive C (2004) Hypoxia-mediated down-regulation of Bid and Bax in tumors occurs via hypoxia-inducible factor 1-dependent and -independent mechanisms and contributes to drug resistance. Mol Cell Biol 24: 2875-2889

Fawcett TW, Martindale JL, Guyton KZ, Hai T, Holbrook NJ (1999) Complexes containing activating transcription factor (ATF)/CAMP-responsive-element-binding protein (CREB) interact with the CCAAT/enhancer-binding protein (C/EBP)-ATF composite site to regulate Gadd153 expression during the stress response. Biochem J 339 (Part 1): 135-141

Ferraiuolo MA, Basak S, Dostie J, Murray EL, Schoenberg DR, Sonenberg N (2005) A role for the elF4E-binding protein 4E-T in P-body formation and mRNA decay. J Cell Biol 170: 913924

Gebauer F, Hentze MW (2004) Molecular mechanisms of translational control. Nat Rev Mol Cell Biol 5: 827-835

Graeber TG, Osmanian C, Jacks T, Housman DE, Koch CJ, Lowe SW, Giaccia AJ (1996) Hypoxia-mediated selection of cells with diminished apoptotic potential in solid tumours. Nature 379: 88-91

Harding HP, Novoa I, Zhang Y, Zeng H, Wek R, Schapira M, Ron D (2000) Regulated translation initiation controls stress-induced gene expression in mammalian cells. Mol Cell 6: 10991108

Harding HP, Zhang Y, Zeng H, Novoa I, Lu PD, Calfon M, Sadri N, Yun C, Popko B, Paules R, Stojdl DF, Bell JC, Hettmann T, Leiden JM, Ron D (2003) An integrated stress response regulates amino acid metabolism and resistance to oxidative stress. Mol Cell 11: 619-633

Harris AL (2002) Hypoxia-a key regulatory factor in tumour growth. Nat Rev Cancer 2: 38-47 Hay N, Sonenberg N (2004) Upstream and downstream of mTOR. Genes Dev 18: 1926-1945

Holcik M, Sonenberg N (2005) Translational control in stress and apoptosis. Nat Rev Mol Cell Biol 6: 318-327 
Holland EC, Sonenberg N, Pandolfi PP, Thomas G (2004) Signaling control of mRNA translation in cancer pathogenesis. Oncogene23: 3138-3144

Jaakkola P, Mole DR, Tian YM, Wilson MI, Gielbert J, Gaskell SJ, Kriegsheim A, Hebestreit HF, Mukherji M, Schofield CJ, Maxwell PH, Pugh CW, Ratcliffe PJ (2001) Targeting of HIFalpha to the von Hippel-Lindau ubiquitylation complex by O2-regulated prolyl hydroxylation. Science 292: 468-472

Johannes G, Carter MS, Eisen MB, Brown PO, Sarnow P (1999) Identification of eukaryotic mRNAs that are translated at reduced cap binding complex elF4F concentrations using a cDNA microarray. Proc Natl Acad Sci USA 96: 13118-13123

Kimball SR, Jefferson LS (2000) Regulation of translation initiation in mammalian cells by amino acids. In Translational Control of Gene Expression, Sonenberg N, Hershey JW, Mathews MB (eds) pp 561-579. Cold Spring Harbor, NY: Cold Spring Harbor Laboratory Press

Koritzinsky M, Seigneuric R, Magagnin MG, Beucken T, Lambin P, Wouters BG (2005) The hypoxic proteome is influenced by gene-specific changes in mRNA translation. Radiother Oncol 76: 177-186

Koumenis C, Naczki C, Koritzinsky M, Rastani S, Diehl A, Sonenberg N, Koromilas A, Wouters BG (2002) Regulation of protein synthesis by hypoxia via activation of the endoplasmic reticulum kinase PERK and phosphorylation of the translation initiation factor elF2alpha. Mol Cell Biol 22: 7405-7416

Lang KJ, Kappel A, Goodall GJ (2002) Hypoxia-inducible factor-1alpha mRNA contains an internal ribosome entry site that allows efficient translation during normoxia and hypoxia. Mol Biol Cell 13: 1792-1801

Lawson TG, Cladaras MH, Ray BK, Lee KA, Abramson RD, Merrick WC, Thach RE (1988) Discriminatory interaction of purified eukaryotic initiation factors $4 \mathrm{~F}$ plus $4 \mathrm{~A}$ with the 50 ends of reovirus messenger RNAs. J Biol Chem 263: 7266-7276

Leek RD, Stratford I, Harris AL (2005) The role of hypoxia-inducible factor-1 in three-dimensional tumor growth, apoptosis, and regulation by the insulin-signaling pathway. Cancer Res 65: 4147-4152

Lefebvre VH, Van Steenbrugge M, Beckers V, Roberfroid M, Buc-Calderon P (1993) Adenine nucleotides and inhibition of protein synthesis in isolated hepatocytes incubated under different pO2 levels. Arch Biochem Biophys 304: 322-331

Lejbkowicz F, Goyer C, Darveau A, Neron S, Lemieux R, Sonenberg N (1992) A fraction of the mRNA 50 cap-binding protein, eukaryotic initiation factor $4 \mathrm{E}$, localizes to the nucleus. Proc Natl Acad Sci USA 89: 9612-9616

Lu PD, Harding HP, Ron D (2004) Translation reinitiation at alternative open reading frames regulates gene expression in an integrated stress response. J Cell Biol 167: 27-33

Marciniak SJ, Yun CY, Oyadomari S, Novoa I, Zhang Y, Jungreis R, Nagata K, Harding HP, Ron $\mathrm{D}(2004)$ CHOP induces death by promoting protein synthesis and oxidation in the stressed endoplasmic reticulum. Genes Dev 18: 3066-3077

Martin de la Vega C, Burda J, Nemethova M, Quevedo C, Alcazar A, Martin ME, Danielisova V, Fando JL, Salinas M (2001) Possible mechanisms involved in the down-regulation of translation during transient global ischaemia in the rat brain. Biochem J 357: 819-826

Martin ME, Munoz FM, Salinas M, Fando JL (2000) Ischaemia induces changes in the association of the binding protein 4E-BP1 and eukaryotic initiation factor (elF) 4G to elF4E in differentiated PC12 cells. Biochem J 351 (Part 2): 327-334

Meyuhas O, Hornstein E (2000) Translational control of TOP mRNAs. In Translational Control of Gene Expression, Sonenberg N, Hershey JW, Mathews MB (eds) pp 671-694. Cold Spring Harbor, NY: Cold Spring Harbor Laboratory Press

Neumar RW, DeGracia DJ, Konkoly LL, Khoury JI, White BC, Krause GS (1998) Calpain mediates eukaryotic initiation factor $4 \mathrm{G}$ degradation during global brain ischemia. J Cereb Blood Flow Metab 18: 876-881

Novoa I, Zeng H, Harding HP, Ron D (2001) Feedback inhibition of the unfolded protein response by GADD34-mediated dephosphorylation of elF2alpha. J Cell Biol 153: 1011-1022

Novoa I, Zhang Y, Zeng H, Jungreis R, Harding HP, Ron D (2003) Stress-induced gene expression requires programmed recovery from translational repression. EMBO J 22: 1180-1187

Pause A, Belsham GJ, Gingras AC, Donze O, Lin TA, Lawrence Jr JC, Sonenberg N (1994) Insulin-dependent stimulation of protein synthesis by phosphorylation of a regulator of 50 cap function. Nature 371: 762-767

Robertson N, Potter C, Harris AL (2004) Role of carbonic anhydrase IX in human tumor cell growth, survival, and invasion. Cancer Res 64: 6160-6165 
Romero-Ramirez L, Cao H, Nelson D, Hammond E, Lee AH, Yoshida H, Mori K, Glimcher LH, Denko NC, Giaccia AJ, Le QT, Koong AC (2004) XBP1 is essential for survival under hypoxic conditions and is required for tumor growth. Cancer Res 64: 5943-5947

Ryan HE, Lo J, Johnson RS (1998) HIF-1 alpha is required for solid tumor formation and embryonic vascularization. EMBO J 17: 3005-3015

Scheuner D, Song B, McEwen E, Liu C, Laybutt R, Gillespie P, Saunders T, Bonner-Weir S, Kaufman RJ (2001) Translational control is required for the unfolded protein response and in vivo glucose homeostasis. Mol Cell 7: 1165-1176

Schroder M, Kaufman RJ (2005) The mammalian unfolded protein response. Annu Rev Biochem 74: 739-789

Semenza GL (2003) Targeting HIF-1 for cancer therapy. Nat Rev Cancer 3: 721-732

Stein I, Itin A, Einat P, Skaliter R, Grossman Z, Keshet E (1998) Translation of vascular endothelial growth factor mRNA by internal ribosome entry: implications for translation under hypoxia. Mol Cell Biol 18: 3112-3119

Tang N, Wang L, Esko J, Giordano FJ, Huang Y, Gerber HP, Ferrara N, Johnson RS (2004) Loss of HIF-1alpha in endothelial cells disrupts a hypoxia-driven VEGF autocrine loop necessary for tumorigenesis. Cancer Cell 6: 485-495

Tinton SA, Buc-Calderon PM (1999) Hypoxia increases the association of 4E-binding protein 1 with the initiation factor $4 \mathrm{E}$ in isolated rat hepatocytes. FEBS Lett 446: 55-59

Wouters BG, van den Beucken T, Magagnin MG, Koritzinsky M, Fels D, Koumenis C (2005) Control of the hypoxic response through regulation of mRNA translation. Semin Cell Dev Biol 16: 487-501

Wouters BG, Weppler SA, Koritzinsky M, Landuyt W, Nuyts S, Theys J, Chiu RK, Lambin P (2002) Hypoxia as a target for combined modality treatments. Eur J Cancer 38: 240-257 



\section{CHAPTER 4}

\section{Expression of EGFR variant vIll promotes both radiation resistance and hypoxia tolerance}

Radiotherapy and Oncology. 2007; 83(3):333-9.

Sherry A. Weppler*, Younan Li*, Ludwig Dubois, Natasja Lieuwes, Barry Jutten, Philippe Lambin, Bradly G. Wouters, Guido Lammering.

* These authors contributed equally to the manuscript 


\title{
Chapter 4
}

\begin{abstract}
Background and purpose: EGFRvIll has been described to function as an oncoprotein with constitutive activation promoting neoplastic transformation and tumorigenicity. The present study was undertaken to test whether EGFRvIll also contributes to hypoxia tolerance.
\end{abstract}

Material and methods: The human glioma cell line U373 was genetically modified to stably express EGFRvIll. Western blotting and immunohistochemistry verified the expression of EGFRvIll. Tumor xenografts were produced by injecting U373 control and EGFRvIll positive cells subcutaneously into the lateral flank of recipient mice. Colony formation assays were performed after ionizing radiation at $4 \mathrm{~Gy}$ and after exposure to anoxia for 1-4 days.

Results: EGFRvIII accelerated tumor growth leading to a 3.5-fold increase in tumor size compared to control tumors at 40 days after cell injection. EGFRvIII promoted clonogenic survival by almost 2-fold and 4-fold after $4 \mathrm{~Gy}$ and 4 days of anoxia, respectively. EGFRvIll was also associated with a substantially bigger colony size after anoxic treatment.

Conclusions: EGFRvIll expression stimulates the growth of tumor xenografts and strongly promotes survival after irradiation and under hypoxic stress. 


\section{Introduction}

The epidermal growth factor receptor (EGFR) is a well characterized protooncogene that is expressed in multiple cancers where it has been shown to promote tumor progression and therapy resistance [1, 3, 12, 19]. EGFR targeted strategies are actively under investigation and EGFR-specific tyrosine kinase inhibitors (TKI) and monoclonal antibodies (mAb) have shown great promise $[4,6-8,17]$. This is illustrated by the high number of currently running clinical trials investigating anti-EGFR strategies in cancer treatment. However, some of the first clinical reports failed to corroborate the promising antitumor effects seen in preclinical studies, implicating persistent growth pathways despite blockade of wild-type EGFR [5, 21]. The presence of naturally occurring mutations of EGFR may account for the limited clinical response to EGFR-targeted therapies [10, 13, 18]. A commonly described variant harbors an in-frame deletion of exons 2-7 resulting in a truncated version of the receptor which lacks a portion of the extracellular ligand binding domain. This variant, called EGFRvIII, has not been detected in normal tissue, but is found in many malignancies, such as glioblastoma, non-small lung cell carcinoma, breast cancer, prostate cancer and just recently also in head and neck cancer $[15,16,20]$. Ligand-independent activation of EGFRvIII may explain the relative inability of blocking $m A$ bs to downregulate the receptor $[2,26]$. The present study was undertaken to test the hypothesis that EGFRvIII expressing tumor cells not only contribute to therapy resistance but also to hypoxia tolerance. This would have important implications for our understanding of the tumor microenvironment and for the optimization of EGFR-targeted strategies in cancer therapy.

\section{Materials and methods}

\section{Generation of a stable EGFRvIll expressing cell line}

U373 human glioma cells were obtained from the American Type Culture Collection (Manassas, VA, USA) and cultured in MEMa medium (Invitrogen, Breda, NL) supplemented with $10 \%$ fetal calf serum (FCS). The phßAc.EGFRvIll plasmid, a generous gift from D.Bigner (Duke University, NC, USA), was transfected into U373 cells using PolyFect (Qiagen, Venlo, $\mathrm{NL}$ ) according to the manufacturer's directions. Forty-eight hours after transfection, cells were trypsinized and seeded at low density for selection in 300 $\mu \mathrm{g} / \mathrm{ml}$ Geneticin (Invitrogen, Breda, NL). The plates were incubated for two weeks to allow formation of resistant colonies. Several colonies were chosen for expansion and labeled U373-vllI clones A-G. 


\section{Immunoblotting}

The cell pellet obtained from a $6 \mathrm{~cm}$ plate was lysed in $50 \mu$ RIPA buffer (150 $\mathrm{mM} \mathrm{NaCl}, 1 \% \mathrm{NP}-40,0.5 \%$ sodium deoxycholate, $0.1 \%$ SDS, $50 \mathrm{mM}$ Tris$\mathrm{HCl}, \mathrm{pH} 7.5$, 1x protease inhibitor cocktail) and incubated on ice for $30 \mathrm{~min}$. Cell debris was removed by centrifugation at $10,000 \mathrm{~g}$ for $15 \mathrm{~min}$. The protein concentration in the supernatant was determined using the DC Assay (BioRad, Veenendaal, NL). Forty micrograms of each sample was resolved on an $8 \%$ SDS-PAGE gel and blotted onto a Hybond ECL nitrocellulose membrane (GE Healthcare, Deigem, BE) by electrotransfer. The membrane was blocked with $5 \%$ milk-TBST (20 mM Tris- $\mathrm{HCl}, \mathrm{pH} 7.6,140 \mathrm{mM} \mathrm{NaCl}, 0.1 \%$ Tween 20) and incubated overnight in a 1:1000 dilution of EGFR (15F8) rabbit monoclonal antibody (Cell Signaling Technology, Danvers, MA, USA). The membrane was washed with TBST and incubated for $1 \mathrm{~h}$ with a goat anti-rabbit secondary antibody (Cell Signaling Technology) at 1:3000 dilution. Immobilized proteins were detected using SuperSignal West Pico chemiluminescent substrate (Perbio, Etten-Leur, NL) and by exposing the blot to X-ray film.

\section{Immunohistochemistry}

Cells grown in chamber slides in vitro were fixed with $10 \%$ formalin and stained for EGFR using a 1:200 dilution of EGFR (sc-03) rabbit polyclonal antibody (Santa Cruz Biotechnology, Heidelberg, DE). The primary antibody was detected by an EnVision peroxidase-linked secondary antibody (DAKO, Heverlee, BE) used in combination with $\mathrm{DAB}+$ chromogen and substrate (DAKO, Heverlee, BE). Slides were counterstained with hematoxylin and mounted in DPX medium (Brunschwig chemie, Amsterdam, NL).

Seven micrometer thick tumor sections were stained using the same primary antibody as above at 1:100 dilution. A biotinylated goat anti-rabbit secondary (DAKO) was used at a 1:200 dilution followed by Vectastain ABC solution (Brunschwig chemie) and detection with DAB.

\section{Radiation of cells}

Cells were seeded in $6 \mathrm{~cm}$ dishes in order to reach $\sim 80 \%$ confluence at the time of irradiation. Growth medium containing $0.5 \%$ FCS was added to cells $16 \mathrm{~h}$ before irradiation. During irradiation, dishes were placed in a Plexiglas jig filled with water at $37^{\circ} \mathrm{C}$. Cells were irradiated using an MCN 225 industrial X-ray tube (Philips, Eindhoven, NL) operated at $225 \mathrm{kV}$ and $10 \mathrm{~mA}$ to deliver a dose of $4 \mathrm{~Gy}$ at a rate of $0.85 \mathrm{~Gy} / \mathrm{min}$. Immediately following irradiation, cells were returned to the incubator for $24 \mathrm{~h}$ at which time they were plated in MEMa $+10 \%$ FCS for the clonogenic survival assay. 


\section{Clonogenic survival assay}

Cells were counted using a Coulter Z Series particle counter (Beckman Coulter, Mijdrecht, NL) and seeded in triplicate $6 \mathrm{~cm}$ dishes. For hypoxia experiments, cells were seeded for clonogenic survival prior to hypoxic exposure at $0 \%$ oxygen for 1-4 days. After the hypoxic treatment, the plates were removed from the hypoxic chamber (a MACS VA500 microaerophilic workstation supplied by Don Whitley Scientific, Shipley, UK) and incubated under standard culture conditions until colonies formed ( 14 days in total). Colonies were fixed and stained with $2 \%$ bromophenol blue in $70 \%$ ethanol. Plating efficiency was determined by counting colonies consisting of $\geq 50$ cells and correcting for the number of cells seeded.

\section{Tumor xenograft growth}

Animal experiments were performed using adult NMRI (nu/nu) female mice $(28-32 \mathrm{~g})$ from the animal facility of the Catholic University of Leuven in Belgium. The animal facilities and experiments were in accordance with local institutional guidelines for animal welfare and were approved by the Animal Ethics Committee of the university. Three million U373 and U373-vllI(+) cells were resuspended in $100 \mu \mathrm{l}$ growth medium and injected subcutaneously into the lateral flank of recipient mice. Tumors were measured with callipers in three orthogonal diameters and used to calculate tumor volume based on the formula $\mathrm{A} \times \mathrm{B} \times \mathrm{C} \times \pi / 6$. Animals were followed until the ethically allowed tumor burden was reached, at which time tumors were excised, fixed in $1-4 \%$ formaldehyde, and embedded in paraffin. Mean tumor volumes were calculated for each group.

\section{In vitro growth under aerobic and hypoxic conditions}

For growth under aerobic conditions, $10^{5}$ cells were seeded in triplicate on 6 $\mathrm{cm}$ dishes. The plates were incubated under normal culture conditions in a $5 \% \mathrm{CO}_{2}$ incubator for 1-6 days. To monitor growth under hypoxia, $5 \times 10^{5}$ cells were seeded in $10 \mathrm{~cm}$ dishes. The following day (day 0), dishes were placed in the hypoxic chamber for 1-4 days. Plates were harvested by washing two times with phosphate-buffered saline followed by trypsinization. Total cell numbers were enumerated using a Coulter $Z$ Series particle counter (Beckman Coulter, Mijdrecht, NL). Cell numbers were normalized to the amount of cells present on day 0 . Doubling times were calculated from the slope of the best-fit line during the exponential phase of growth. 


\section{Statistics}

Statistical analysis was carried out using the program SPSS 12.0.1 for Windows (SPSS Inc., 2003, Chicago, IL, USA). A non-parametric Mann-Whitney $\mathrm{U}$ test was used to assess differences in xenograft tumor growth. A Student's $t$-test was used to assess differences in radiation survival and a one-way ANOVA was used to determine differences in growth under hypoxia. $P$ values $<0.05$ were considered to be significant.

\section{Results}

\section{Generation of a stable EGFRvIII model}

U373 glioma cells were transfected with an EGFRvIll expression plasmid in which EGFRvIll transcription is driven from a human $\beta$-actin promoter. Several clones with stable integration of the plasmid were selected and screened for EGFRvIII protein expression. Clones A, D, and $F$ have high expression of EGFRvIll as seen by the presence of two bands corresponding to different glycosylated forms of the mutant receptor (Fig. 1a). In contrast, clones B, C, $\mathrm{E}$, and $\mathrm{G}$ express only wild-type EGFR similar to the parental U373 cells despite displaying Geneticin resistance. We selected clone D as an EGFR-vIII positive cell line and clone $B$ as an EGFR-vlll negative control for use in further experiments. We will refer to clones B and D as U373-vIII(-) and U373$\mathrm{vlll}(+)$, respectively. Immunohistochemical staining was performed using an antibody that recognizes both wild-type and variant forms of EGFR. The parental U373 and U373-vIII(-) cell lines show low EGFR expression which is localized mainly to the plasma membrane (Fig. 1b). In contrast, U373-vllI(+) show higher expression in both the cytoplasm and at the plasma membrane with some cells also demonstrating strong nuclear staining.

\section{Intrinsic radiation resistance imparted by EGFRvIII}

Previous studies have demonstrated a role for EGFRvIII in radiation resistance $[10,11]$. We confirmed that our cell line model is also protected from radiation induced killing when EGFR-vIll is expressed (Fig. 2). In a clonogenic survival assay, U373-vIII(+) showed an almost 2-fold increase in survival after irradiation with $4 \mathrm{~Gy}(P=0.005)$, suggesting that EGFR-vlll is functional in our model and able to activate downstream survival pathways. 


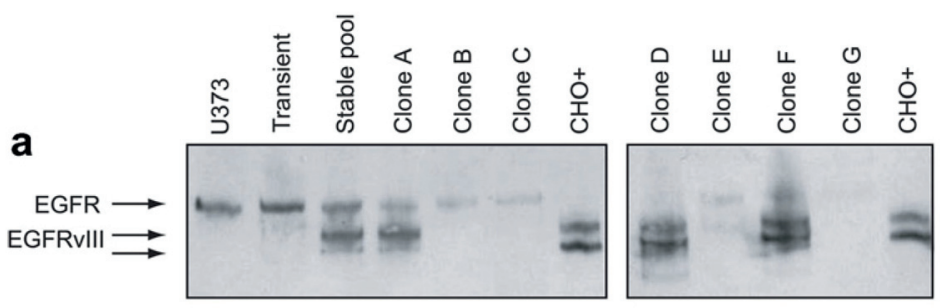

b

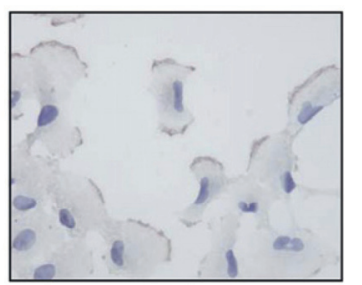

U373

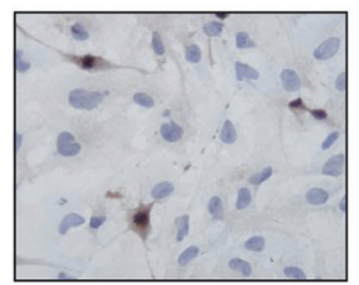

U373-vIII(-)

Clone B

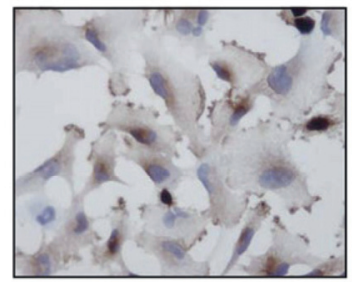

U373-vIII(+)

Clone D

Figure 1. Stable expression of EGFRvIII in selected U373 clones. U373 cells were transfected with phßAc.EGFRvill and stable integration of the plasmid was selected by growth in Geneticin. (a) Untransfected U373 cells, as well as transfected cells, either before (transient) or after selection (stable pool and individual clones), were screened for expression of EGFRvIll by immunoblot analysis. $\mathrm{CHO}+$ indicates lysate from Chinese hamster ovary cells which have been engineered to express EGFRvIII and serve as a positive control. Arrows indicate bands at the appropriate molecular weight for wild type EGFR and EGFRvIII. (b) EGFR expression was detected by immunohistochemical staining of U373, U373-vIII(-) and U373-vIII(+) cells grown in vitro. 


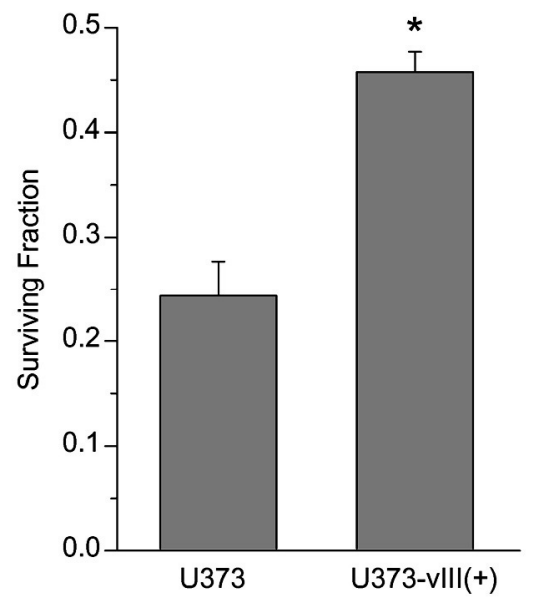

Figure 2. EGFRvIll increases the intrinsic radioresistance of U373 cells. Clonogenic survival assays were performed to determine the radiosensitivity of U373 and U373-vIII(+) cells. Cells were irradiated with $4 \mathrm{~Gy}$ and plated for colony formation $24 \mathrm{~h}$ later. The mean values of 3 independent experiments are shown. Error bars indicate standard error of the mean. ${ }^{*} P=0.005$.

\section{EGFRvIll induces growth advantage in vivo}

We established tumor xenografts from U373 and U373-vIII(+) cells to investigate the influence of EGFRvIll on growth in vivo. Both EGFRvIII positive and negative cell lines established tumors at a similar rate with palpable tumors becoming visible around day 10 after injection (data not shown). Despite growing at similar rates under normal culture conditions in vitro (Fig. 4a), U373-vIII(+) stimulated the growth of tumor xenografts. On day 40 the average U373-vIII(+) tumor volume was $948 \mathrm{~mm}^{3}$, a 3.5 -fold increase compared to the parental U373 tumors $(P=0.011)$ (Fig. 3a). U373 tumors took an average of 88 days to reach a similar volume (Fig. $3 b$ ). Sections from these tumors that were stained for EGFR expression showed a similar heterogeneous staining pattern in both tumor types, however U373-vllI(+) displayed a clear increase in the intensity of EGFR staining (Fig. $3 c$ and d). Since the antibody used for immunohistochemistry recognizes both wild-type EGFR and EGFRvIll, we conducted immunoblot analysis of ex vivo tumor lysates to confirm that the elevated staining seen in Fig. 3d was due to increased EGFRvIII expression. Two individual U373-vIII(+) tumors showed dramatically higher expression of EGFRvIII than wild-type EGFR compared to U373 tumors which displayed variable levels of the wild-type protein (Fig. 3e). Therefore, these results show that our cell model retains a high and stable level of EGFRvIll expression during tumor growth in vivo. 

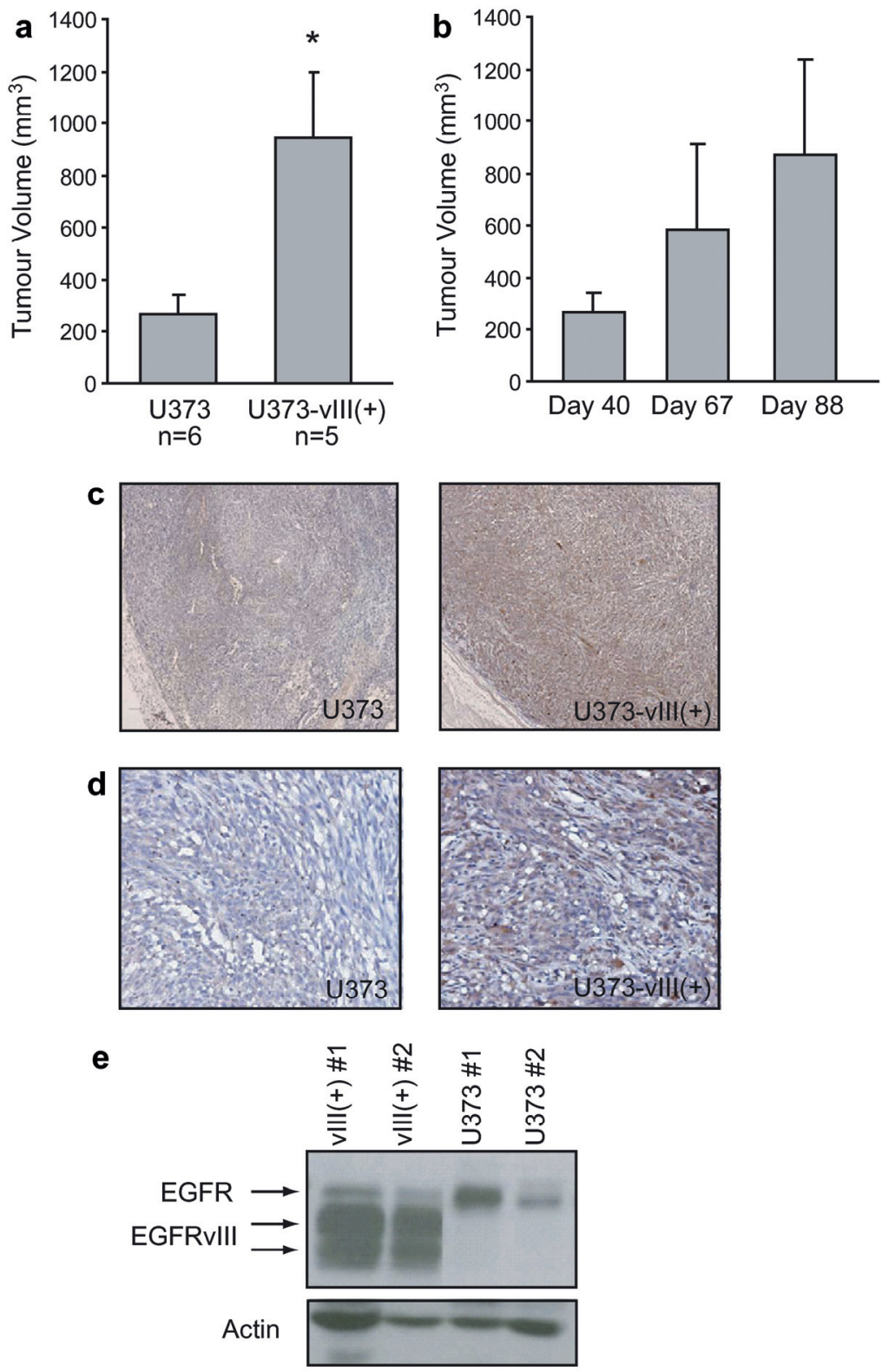

Figure 3. EGFRvIll promotes tumor growth in vivo. Tumor xenografts were established in nude mice using U373 and U373-vIII(+) cells. (a)Columns indicate the mean tumor volume \pm standard deviation at day forty after injection. ${ }^{*} P=0.011$. (b) Mean tumor volumes \pm standard deviation of U373 xenografts at time points after day 40 . Tumors were excised and processed for immunohistochemical staining of EGFR. Representative sections from U373 tumors (left column) and U373-vllI(+) tumors (right column) are shown at $4 \mathrm{X}$ (c) and $20 \mathrm{X}$ (d) magnification. (e) Immunoblot analysis of ex vivo tumor lysates from two individual U373 or U373-vIII(+) tumors was conducted using antibodies recognizing EGFR and $\beta$-actin. 


\section{Hypoxia tolerance of EGFRvill expressing cells}

Due to the growth advantage displayed by EGFRvIll expressing tumors, we hypothesized that EGFRvIll may help cells to tolerate the stress of the tumor microenvironment. We began by assessing cell growth under both normoxic and hypoxic conditions. No significant difference in doubling time was observed between the three cell lines under normoxic conditions (Fig. 4a). The doubling time was calculated to be $\sim 23 \mathrm{~h}$. Under a low oxygen environment, all cell lines displayed decreased growth; however during the first $48 \mathrm{~h}$, U373-vllI(+) cells grew more quickly than the cell lines lacking EGFRvIll expression (Fig. 4b). During this time U373-vlll(+) cells had a significantly faster doubling time of 34 $\mathrm{h}$ compared to $47 \mathrm{~h}$ for $\mathrm{U} 373(P<0.002)$. A decrease in total cell number in all cell lines after 2 days of hypoxic exposure indicates that the rate of cell death exceeded the rate of proliferation at this time.
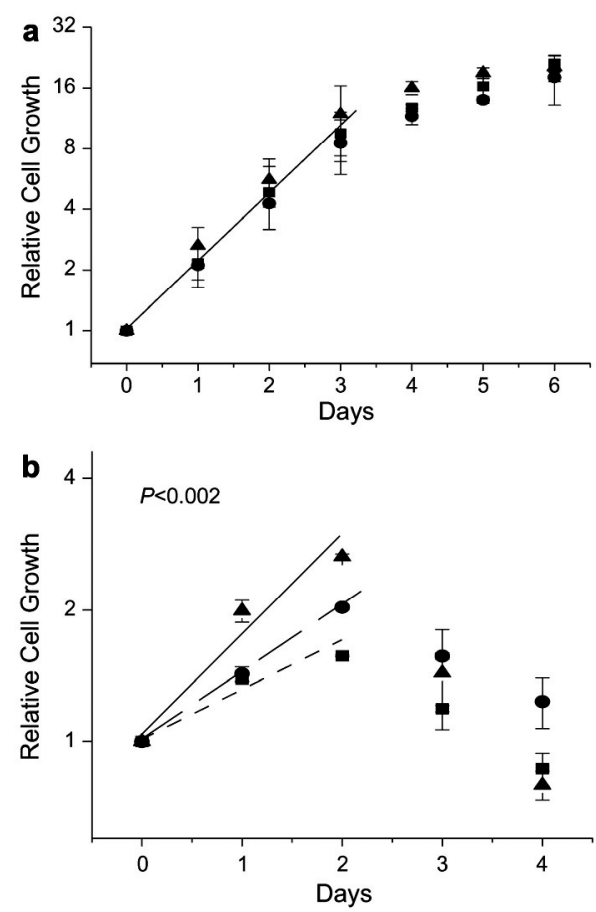

Figure 4. EGFRvIII influences growth under hypoxia. The influence of EGFRvIll on cell growth was evaluated by counting total cell numbers of U373 (घ), U373-vIII(-) (•), and U373-vllI(+) ( $\Delta$ ) after incubation under normoxic (a) or hypoxic (b) conditions. The mean cell number relative to day 0 is shown. Error bars indicate standard deviation of triplicate measurements. (b) The slopes of all three curves are significantly different from each other during the first two days $(P<$ 0.002 , one-way ANOVA).

In order to assess if EGFRvIll could influence the long-term effects of hypoxia on cell killing, we performed a clonogenic survival assay. U373-vlll(+) cells were more resistant to hypoxia-induced death than parental U373 or U373vIll(-) cells after 3-4 days of exposure to $0 \%$ oxygen (Fig. 5). Together, these results demonstrate that EGFRvIII promotes tolerance of tumor cells to hypoxic stress. 


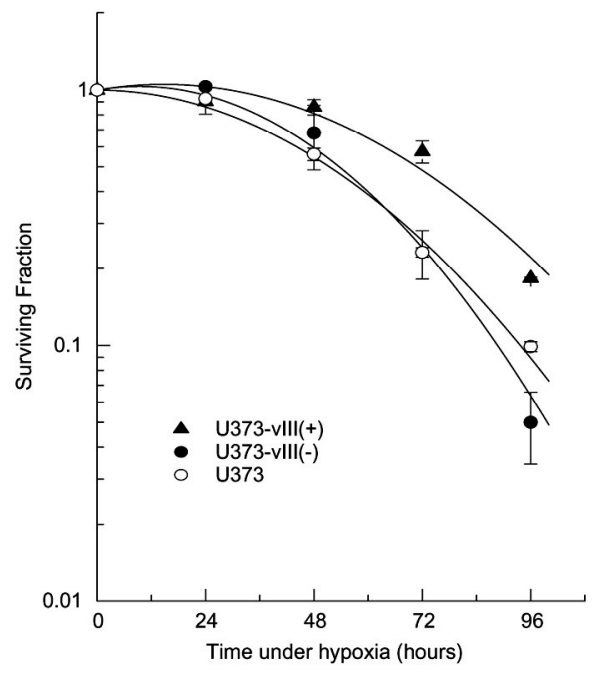

Figure 5. EGFRvIll improves clonogenic survival under hypoxia. Hypoxia tolerance was determined by clonogenic survival of U373, U373-vIII(-) and U373-vIII(+) after exposure to $0 \%$ oxygen for 24-96 $\mathrm{h}$. The mean surviving fraction \pm standard error of two independent experiments are shown.

\section{Discussion}

In the present report we describe the development of a useful cellular model with which to study the contribution of EGFRvIll to tumor growth, response to therapy and hypoxia. We confirmed that this cell line displays increased radioresistance relative to the parental cell line (Fig. 2), as expected based on previous studies which emphasize the importance of EGFRvIll as a clinical target and mediator of radiation induced survival signaling [9,10]. EGFRvIII expression in our model also promotes tumor growth in vivo (Fig. 3a) and growth in vitro under hypoxic conditions (Fig. 4b). Thus, under conditions where nutrients may be limited or cell stress is apparent, EGFRvIll may impart a growth or survival advantage. Supporting this hypothesis, we have made the observation that indeed, U373-vIII(+) cells show increased survival after hypoxic stress (Fig. 5).

Our results suggest that the growth advantage of EGFRvIll expressing cells in xenograft tumors may be related to the EGFRvIll induced proliferation and survival observed under hypoxia. Furthermore, the clones derived from the EGFRvIll positive cell line were significantly bigger than the controls in the colony formation assays presented (Fig. 5; data not shown), which also suggests an induced proliferation under hypoxic conditions. The mechanisms underlying the enhanced survival after ionizing radiation and hypoxia are not fully understood and warrant further evaluation. We have previously shown that EGFRvIII, although constitutively phosphorylated at relatively low levels, 
responds to ionizing radiation with an immediate activation after clinically relevant doses of ionizing radiation [9]. This radiation induced activation preferentially stimulates PI3K-Akt signaling, which is known to be involved in cellular proliferation and apoptosis $[9,14,24,25]$. Whether this can explain the difference in clonogenic survival of almost 2- and 4-fold after $4 \mathrm{~Gy}$ and 4 days of anoxia, respectively (Fig. 2-5), remains unclear. Despite its role in proliferation and antiapoptosis, EGFRvIII may alter the capacity for DNA repair via activation of the Akt-mammalian target of rapamycin (mTOR) pathway and the subsequent upregulation of translation of DNA repair proteins $[19,22,23]$.

Our results might also indicate a possible selection of EGFRvIll expressing tumor cells under hypoxic conditions in growing tumors, which would lead to an accumulation of EGFRvIll positive cancer cells in hypoxic areas of the tumor. This might, however, impair on the effectiveness of targeted antiEGFR drugs due to the biodistribution properties of the drugs in solid tumors.

In summary, we have implicated EGFRvIll as a contributor to cell survival under conditions of radiotherapy as well as hypoxic stress. This finding improves our understanding of the contribution of hypoxia on the negative influence of radiosensitivity in tumor cells. It also highlights the need for monitoring the expression of EGFRvIII in human tumors in order to individualize and optimize molecular targeted therapies. The mechanisms underlying these vlll-dependent phenotypical changes warrant further investigation.

\section{Acknowledgements}

We acknowledge financial support from the Association for International Cancer Research (AICR Grant 05-277 awarded to G.L., P.L. and B.W.), the Dutch Cancer Society (KWF Grant 2006-3519 awarded to G.L., P.L. and B.W.) and the EU 6th framework programme (EUROXY Grant LSCH-CT2003-502932 awarded to P.L. and B.W.). 


\section{References}

[1] Ang KK, Berkey BA, Tu X, et al. Impact of epidermal growth factor receptor expression on survival and pattern of relapse in patients with advanced head and neck carcinoma. Cancer Res 2002;62:7350-6.

[2] Batra SK, Castelino-Prabhu S, Wikstrand CJ, et al. Epidermal growth factor ligandindependent, unregulated, cell-transforming potential of a naturally occurring human mutant EGFRvIII gene. Cell Growth Differ 1995;6:1251-9.

[3] Baumann M, Krause M. Targeting the epidermal growth factor receptor in radiotherapy: radiobiological mechanisms, preclinical and clinical results. Radiother Oncol 2004;72:25766.

[4] Bonner JA, Harari PM, Giralt J, et al. Radiotherapy plus cetuximab for squamous-cell carcinoma of the head and neck. N Engl J Med 2006;354:567-78.

[5] Cohen EE, Rosen F, Stadler WM, et al. Phase II trial of ZD1839 in recurrent or metastatic squamous cell carcinoma of the head and neck. J Clin Oncol 2003;21:1980-7.

[6] Heimberger AB, Learn CA, Archer GE, et al. Brain tumors in mice are susceptible to blockade of epidermal growth factor receptor (EGFR) with the oral, specific, EGFR-tyrosine kinase inhibitor ZD1839 (iressa). Clin Cancer Res 2002;8:3496-502.

[7] Krause M, Ostermann G, Petersen C, et al. Decreased repopulation as well as increased reoxygenation contribute to the improvement in local control after targeting of the EGFR by C225 during fractionated irradiation. Radiother Oncol 2005;76:162-7.

[8] Krause M, Schutze C, Petersen C, et al. Different classes of EGFR inhibitors may have different potential to improve local tumour control after fractionated irradiation: a study on C225 in FaDu hSCC. Radiother Oncol 2005;74:109-15.

[9] Lammering G, Hewit TH, Valerie K, et al. EGFRvIII-mediated radioresistance through a strong cytoprotective response. Oncogene 2003;22:5545-53.

[10] Lammering G, Hewit TH, Holmes M, et al. Inhibition of the type III epidermal growth factor receptor variant mutant receptor by dominant-negative EGFR-CD533 enhances malignant glioma cell radiosensitivity. Clin Cancer Res 2004;10:6732-43.

[11] Lammering G, Valerie K, Lin PS, Hewit TH, Schmidt-Ullrich RK. Radiation-induced activation of a common variant of EGFR confers enhanced radioresistance. Radiother Oncol 2004;72:267-73.

[12] Lammering G. Molecular predictor and promising target: will EGFR now become a star in radiotherapy? Radiother Oncol 2005;74:89-91.

[13] Lynch TJ, Bell DW, Sordella R, et al. Activating mutations in the epidermal growth factor receptor underlying responsiveness of non-small-cell lung cancer to gefitinib. N Engl J Med 2004;350:2129-39.

[14] Mellinghoff IK, Wang MY, Vivanco I, et al. Molecular determinants of the response of glioblastomas to EGFR kinase inhibitors. N Engl J Med 2005;353:2012-24.

[15] Moscatello DK, Holgado-Madruga M, Godwin AK, et al. Frequent expression of a mutant epidermal growth factor receptor in multiple human tumors. Cancer Res 1995;55:5536-9.

[16] Okamoto I, Kenyon LC, Emlet DR, et al. Expression of constitutively activated EGFRvIII in non-small cell lung cancer. Cancer Sci 2003;94:50-6.

[17] Ono M, Kuwano M. Molecular mechanisms of epidermal growth factor receptor (EGFR) activation and response to gefitinib and other EGFR-targeting drugs. Clin Cancer Res 2006;12:7242-51.

[18] Paez JG, Janne PA, Lee JC, et al. EGFR mutations in lung cancer: correlation with clinical response to gefitinib therapy. Science 2004;304:1497-500.

[19] Schmidt-Ullrich RK, Contessa JN, Lammering G, Amorino G, Lin PS. ERBB receptor tyrosine kinases and cellular radiation responses. Oncogene 2003;22:5855-65.

[20] Sok JC, Coppelli FM, Thomas SM, et al. Mutant epidermal growth factor receptor (EGFRvIII) contributes to head and neck cancer growth and resistance to EGFR targeting. Clin Cancer Res 2006;12:5064-73.

[21] Soulieres D, Senzer NN, Vokes EE, Hidalgo M, Agarwala SS, Siu LL. Multicenter phase II study of erlotinib, an oral epidermal growth factor receptor tyrosine kinase inhibitor, in patients with recurrent or metastatic squamous cell cancer of the head and neck. $J$ Clin Oncol 2004;22:77-85.

[22] Sunavala-Dossabhoy G, Fowler M, De Benedetti A. Translation of the radioresistance kinase TLK1B is induced by gammairradiation through activation of mTOR and phosphorylation of 4E-BP1. BMC Mol Biol 2004;5:1. 


\section{Chapter 4}

[23] Sunavala-Dossabhoy G, Balakrishnan SK, Sen S, Nuthalapaty S, De Benedetti A. The radioresistance kinase TLK1B protects the cells by promoting repair of double strand breaks. BMC Mol Biol 2005;6:19.

[24] Toulany M, Dittmann K, Baumann M, Rodemann HP. Radiosensitization of Ras-mutated human tumor cells in vitro by the specific EGF receptor antagonist BIBX1382BS. Radiother Oncol 2005;74:117-29.

[25] Toulany M, Dittmann K, Kruger M, Baumann M, Rodemann HP. Radioresistance of K-Ras mutated human tumor cells is mediated through EGFR-dependent activation of PI3K-AKT pathway. Radiother Oncol 2005;76:143-50.

[26] Wikstrand CJ, McLendon RE, Friedman AH, Bigner DD. Cell surface localization and density of the tumor-associated variant of the epidermal growth factor receptor, EGFRvIII. Cancer Res 1997;57:4130-40. 


\section{CHAPTER 5}

\section{Response of U87 glioma xenografts}

treated with concurrent rapamycin and fractionated radiotherapy: Possible role for thrombosis

Radiotherapy and Oncology. 2007; 82(1):96-104.

Sherry A. Weppler, Mechthild Krause, Agnieszka Zyromska, Philippe Lambin, Michael Baumann, and Bradly G. Wouters. 


\title{
Chapter 5
}

\begin{abstract}
Background and purpose: Rapamycin, a highly specific mTOR inhibitor, has shown anti-proliferative and anti-angiogenic properties, as well as an enhancement in tumor growth delay when used in combination with radiation in mouse xenograft models. Our goal was to determine if rapamycin can also have a positive effect on the local tumor control achieved by radiotherapy.
\end{abstract}

Materials and methods: Nude mice bearing U87 glioblastoma xenografts were treated with concomitant rapamycin and radiotherapy over a 5 day fractionation schedule. Animals received graded total doses ranging from 24 to $100 \mathrm{~Gy}$. Experimental endpoints were tumor growth delay and local tumor control. In addition, histological evaluation of tumor sections was performed to examine changes occurring within the tumor microenvironment as a result of treatment. Analysis of proliferation, mTOR signalling, hypoxia, and vessel thrombosis was conducted.

Results: As a single agent, rapamycin reduced the in vitro growth of U87 cells by $70 \%$ and caused a 4 day growth delay of tumor xenografts. In combination with radiation, no further increase in tumor growth delay was observed when compared to radiation alone. The tumor control dose $50 \%\left(\mathrm{TCD}_{50}\right)$ was 46.8 Gy $(95 \% \mathrm{Cl} 41 ; 53 \mathrm{~Gy})$ in tumors treated with radiation alone and was slightly but not significantly lower at $42.8 \mathrm{~Gy}(95 \% \mathrm{Cl} 36 ; 49 \mathrm{~Gy})$ after simultaneous treatment with rapamycin. Histological evaluation revealed evidence of elevated hypoxia following rapamycin treatment that may be due to vessel thrombosis.

Conclusions: The influence of rapamycin on thrombosis and tumor hypoxia may be a confounding factor limiting its effectiveness in combination with radiotherapy. 


\section{Introduction}

The mammalian target of rapamycin (mTOR) kinase has been identified as an attractive molecular target for cancer therapy and a number of mTOR inhibitors are currently under evaluation in clinical trials [1,2]. mTOR is a key component of the PI3K/Akt signal transduction pathway which is stimulated by various growth factors upon binding to their respective receptors [3]. In addition, mTOR also plays a role in adapting cellular responses to nutrient availability and cellular energy levels [3]. When activated, mTOR integrates these environmental inputs by phosphorylating two major targets, p70S6K and $4 \mathrm{E}-\mathrm{BP} 1$, which regulate the translation of mRNA into protein thus leading to the differential expression of genes that are controlled at the translational level [4].

mTOR activity is frequently upregulated in a wide spectrum of human cancers often occurring as a consequence of mutations in PI3K, loss of PTEN expression, or overexpression of Akt [5-7]. These genetic alterations promote proliferation and survival when mitogenic factors and nutrients are limiting, as is often the case within the tumor microenvironment. Many tumor cell lines with known mutations within the PI3K/Akt/mTOR pathway are sensitive to the growth inhibitory effects of rapamycin, a highly specific mTOR inhibitor $[8,9]$. The anti-proliferative effects of rapamycin are mediated in part by arresting cells in G1 phase of the cell-cycle due to modulation of cyclin D1 [10] and p27 levels [11]. In addition, mTOR inhibition may also lead directly to apoptosis [12-14] or autophagy (another form of programmed cell death) [15] depending upon the genetic make-up of the cell.

Besides its direct action on tumor cells, rapamycin has also been shown to have several anti-vascular effects. Guba et al. have demonstrated potent anti-angiogenic activity of rapamycin which was attributed to two factors: (1) reduced VEGF production by tumor cells and (2) the inhibition of VEGFinduced proliferation in endothelial cells [16]. Blood vessel function can also be impaired by rapamycin via the stimulation of thrombosis within tumor microvasculature [17]. Thirdly, rapamycin can radiosensitize endothelial cells resulting in reduced vascularity and perfusion in glioma xenografts [18].

These data suggest that mTOR inhibitors may be promising agents in combination with radiotherapy. Indeed, rapamycin has previously been shown to prolong the growth delay of glioma xenografts treated with fractionated radiotherapy; an effect which was proposed to be caused by inhibition of tumor cell repopulation [19]. One might hypothesize that rapamycin could also improve local tumor control by contributing to vascular damage and preventing 
angiogenesis during radiotherapy. Furthermore, rapamycin may prevent activation of radiation-induced survival signals that are generated by stimulation of the PI3K pathway [20-22]. As a cytostatic drug already used in the clinic for the treatment of graft rejection, rapamycin is well tolerated and is not anticipated to complicate normal tissue toxicity.

In the present study we tested the efficacy of combining rapamycin with fractionated radiotherapy on tumor cure using a glioblastoma xenograft model. We designed our experiment so as to minimize the effects of rapamycin on repopulation and to investigate if there is an additional direct contribution to cytotoxicity and tumor cure. We demonstrate variability in the response of tumors to the combined therapy, despite being sensitive to rapamycin as a single agent. Elevated vessel thrombosis and hypoxia were also observed in several rapamycin treated animals. We propose that thrombosis of tumor vasculature is playing a role in determining outcome to the combined therapy.

\section{Materials and methods}

\section{Rapamycin}

Rapamycin was purchased from LC Laboratories (Woburn, MA, USA) and stored protected from light at $-20^{\circ} \mathrm{C}$. For in vitro experiments, a $1 \mathrm{mg} / \mathrm{ml}$ stock solution was made using dimethyl sulfoxide (DMSO). For in vivo experiments, rapamycin was dissolved in ethanol to yield a $10 \mathrm{mg} / \mathrm{ml}$ stock solution. Prior to injection, the stock solution was diluted to yield a final concentration of 0.4 $\mathrm{mg} / \mathrm{ml}$ rapamycin in 5\% PEG400, 5\% Tween 80 and $4 \%$ ethanol. Rapamycin was delivered by intraperitoneal (i.p.) injection at a dose of $1 \mathrm{mg} / \mathrm{kg}$ bodyweight with control animals receiving vehicle alone.

\section{In vitro growth inhibition}

HeLa (cervix adenocarcinoma, ATCC), MDAMB231 and MCF7 (breast adenocarcinoma, gift from V. Castronovo, Liège University), U251, U118, and U87 (glioblastoma, gift from J. Sarkaria, Mayo Clinic), and A549 (lung carcinoma, gift from J.M. Brown, Stanford University) cell lines were maintained in Dulbecco's modified Eagle's medium containing 10\% fetal calf serum and incubated in a humidified $5 \% \mathrm{CO}_{2}$ chamber at $37^{\circ} \mathrm{C}$. Cells were seeded at an appropriate density so as to maintain exponential growth during the course of the experiment. 1.5-3.5 $\times 10^{4}$ cells were seeded onto 24-well plates in triplicate. The following day, serial dilutions of rapamycin were added to the plates. Control wells were treated with an equal volume of DMSO. After 5 days of incubation, cells were harvested by trypsinization and counted using 
a Coulter Z Series particle counter (Beckman Coulter, Mijdrecht, NL). The relative growth inhibition was calculated by normalizing the average cell number in the rapamycin treated wells by the DMSO control.

\section{Animals}

Animal experiments were performed using 7- to 14-week-old NMRI (nu/nu) mice from the specific pathogen-free animal breeding facility of the Experimental Centre of the Medical Faculty of the University of Dresden. The animal facilities and the experiments were approved according to the German animal welfare regulations. To minimize the residual immune response, all animals received 4 Gy whole-body irradiation 1-2 days before tumor transplantation.

\section{Tumor xenograft model}

U87 cells were established as a tumor xenograft as described previously [23]. Stock tumors were maintained by serial passage to the back of nude mice. For the experiments, source tumors were excised, cleared of necrotic tissue, cut into small pieces $\left(\sim 1 \mathrm{~mm}^{3}\right)$, and transplanted subcutaneously into the right hind leg of the recipient mice. Tumor diameters were measured twice per week and used to calculate tumor volume based on the formula of a rotational ellipsoid $\pi / 6 \times a \times b^{2}$, where $a$ is the longer and $b$ is the perpendicular shorter tumor axis. Treatment was initiated when tumors reached a volume of $100 \mathrm{~mm}^{3}$.

\section{Tumor irradiation}

Animals received injections of rapamycin beginning one day before irradiation and continuing daily throughout the fractionation schedule. Irradiation was delivered under ambient conditions, without anaesthesia, $2 \mathrm{~h}$ after injection with rapamycin or vehicle $(200 \mathrm{kV}$ X-rays, $0.5 \mathrm{~mm} \mathrm{Cu}$, at a dose rate of $\sim 1$ $\mathrm{Gy} / \mathrm{min}$ ). Animals were immobilized in jigs specially designed to hold the tumor-bearing leg in the irradiation field. Five equal fractions were delivered over five consecutive days to total doses of $24,32,40,50,60,72.5,85$, and 100 Gy. Animals were randomized into control or rapamycin treatment groups, aiming for a total of sixteen animals per dose level.

\section{Animal follow-up, determination of tumor growth delay and $T C D_{50}$}

Animals were observed until the tumor diameter reached 12-15 $\mathrm{mm}$, until death, or until day 150 after the end of treatment. Median tumor volumes were calculated for each treatment arm and dose level as a function of time after start of treatment. Regrowth delay was calculated for the dose groups in 
which less than $50 \%$ of tumors were cured (i.e., 24,32 , and $40 \mathrm{~Gy}$ ). The time for tumors to reach 5 times the initial volume was determined for each animal and this value was used to calculate the median regrowth time for the treatment group. Regrowth delay was calculated as the difference in median regrowth time for any pair of treatments. Recurrences were scored when the tumor volume increased for at least three consecutive measurements after passing a nadir. Tumor control frequency at day 120 after end of irradiation was calculated for each dose group using correction for censored animals according to the method given by Walker and Suit [24]. Animals were monitored for an additional 30 days to ensure no further recurrences. A binary (cure/failure) model was used to fit the individual tumor control data. As reported in previous investigations [25], animals censored later than day 20 after end of treatment were counted as local controls. Animals censored before day 20 were omitted from analysis $(n=21)$. The tumor-control probability (TCP) was modeled using the logit model

$\mathrm{TCP}=1 /[1+\exp (-f(x, \beta)]$

where $x$ is the vector of covariates that define the treatment, $\beta$ is the vector of parameters describing radiosensitivity of the tumors, and $f$ is a (possibly nonlinear) function of these. Parameters were estimated using maximum likelihood as implemented in STATA 7.0 software (STATA Corporation, College Station, TX). Quoted confidence limits are asymptotic estimates from the results of the likelihood fits. Comparison of maximum likelihood fits was performed using the likelihood ratio test [26]. $T C D_{50}$ at day 120 after end of irradiation and associated dose-response curve were determined from:

$f(D, \beta)=\beta_{1}\left(1-D / \beta_{2}\right)$ where $\beta 1$ is a constant and $T C D_{50}=\beta_{2}$.

\section{Immunohistochemistry}

Mice with implanted U87 xenografts were treated with $1 \mathrm{mg} / \mathrm{kg}$ rapamycin or vehicle alone for 2 days. On the second day, mice in the radiation treatment group were irradiated with a single dose of $4.8 \mathrm{~Gy}$ (to simulate the treatment of the animals in the $24 \mathrm{~Gy}$ total dose group of the $\mathrm{TCD}_{50}$ assay). Twenty-four hours after irradiation the tumors were excised. Prior to excision, tumors were labelled for $1 \mathrm{~h}$ with pimonidazole (Natural Pharmacia International Inc., Research Triangle Park, NC, USA), administered i.p. at $0.1 \mathrm{mg} / \mathrm{g}$ body weight and followed by $3.75 \mathrm{mg}$ bromodeoxyuridine (BrdU) (Serva, Heidelberg, DE) for $15 \mathrm{~min}$. Tumors were fixed overnight in $4 \%$ neutral buffered formalin and embedded in paraffin. Three micrometer thick sections were stained for BrdU using monoclonal antibody clone Bu20a (DAKO, Hamburg, DE). The Hypoxyprobe- $1^{\mathrm{TM}}$ kit (Chemicon International, Hampshire, UK) was used to detect pimonidazole and phospho-S6 ribosomal protein (Ser235/236) was recognized by a rabbit polyclonal antibody from Cell Signaling Technology 
(Frankfurt am Main, DE). Staining of tissue sections for thrombosis was performed using the Martius Yellow-Brilliant Crystal Scarlet-Soluble Blue (MSB) kit (HD Supplies, UK) according to the method of Lendrum et al. [27].

\section{Statistics}

Statistical analysis was carried out using the program GraphPad Prism 4.02 (GraphPad Software Inc., San Diego, USA). A two-tailed $t$-test was used to assess differences in BrdU labelling. The Kruskal-Wallis analysis of variance test was used in combination with Dunn's multiple comparison post-test to establish significance for pimonidazole and MSB staining. Ninety-five percent confidence intervals of median values were determined as given by Sachs [28]. $P$ values $<0.05$ were considered to be significant.

\section{Results}

\section{Anti-proliferative effect of rapamycin in vitro}

We tested the in vitro growth of seven tumor cell lines representing a variety of tissue types in response to increasing concentrations of rapamycin. As seen in Fig. 1, HeLa and MDAMB231 were resistant to rapamycin with less than $30 \%$ growth inhibition and an $\mathrm{IC}_{50}$ of $>1 \mu \mathrm{g} / \mathrm{ml}$. In contrast, all other cell lines tested showed a marked reduction in growth at very low concentrations of rapamycin. The most sensitive cell line in our assay was U87, derived from a PTEN-null glioblastoma. U87 displayed a $74 \%$ inhibition of growth at 1 $\mathrm{ng} / \mathrm{ml}$ rapamycin. Based on these results we selected U87 as a model to further study the effects of rapamycin in vivo. 


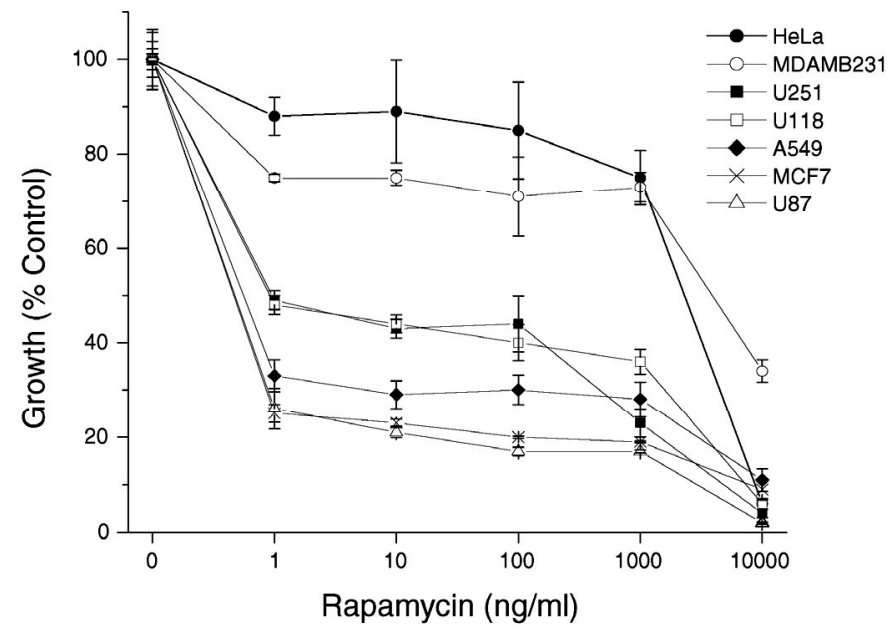

Figure 1. In vitro growth inhibition of tumor cell lines by rapamycin. Cells were seeded in 24-well plates and treated the following day with vehicle or increasing concentrations of rapamycin. After 5 days, cells were counted and the growth of rapamycin-treated cells was normalized to that of vehicle-treated cells. Results shown are means \pm standard deviation of triplicate samples.

\section{Rapamycin inhibits mTOR signalling and growth of U87 xeno- grafts}

The ability of rapamycin to inhibit mTOR signalling in U87 xenografts was assessed by immunohistochemical staining for S6, a ribosomal subunit protein that is phosphorylated downstream of mTOR and has been previously validated as a marker of mTOR activity [12,29]. After 2 days of treatment with $1 \mathrm{mg} / \mathrm{kg}$ rapamycin, the intensity of phospho-S6 staining was decreased (Fig. $2 \mathrm{~B})$. The proportion of cells with high (+++) phospho-S6 staining decreased by $\sim 50 \%$ with a corresponding increase in low (+) intensity staining (Fig. 2A). This suggests that rapamycin was able to reduce the activation of mTOR targets in vivo.

Next we investigated the influence of rapamycin on proliferation. Twenty-four hours after the last dose of rapamycin, tumors were labelled with BrdU for 15 min before excision. As seen in Fig. 2C, significantly fewer cells incorporated BrdU into replicating DNA when tumors were treated with rapamycin $(P=$ 0.006). This is consistent with studies that demonstrate an accumulation of cells in $\mathrm{G}_{0}-\mathrm{G}_{1}$ phase of the cell cycle after rapamycin treatment [19]. Taken together these results indicate that our dosing regimen was sufficient to block mTOR signalling and reduce proliferation in vivo. This was confirmed when we followed the growth of tumors treated daily with rapamycin for 6 days. Compared to controls, rapamycin treated tumors grew more slowly and on 
average required 4 additional days in order to reach the same relative tumor volume (Fig. 2D).
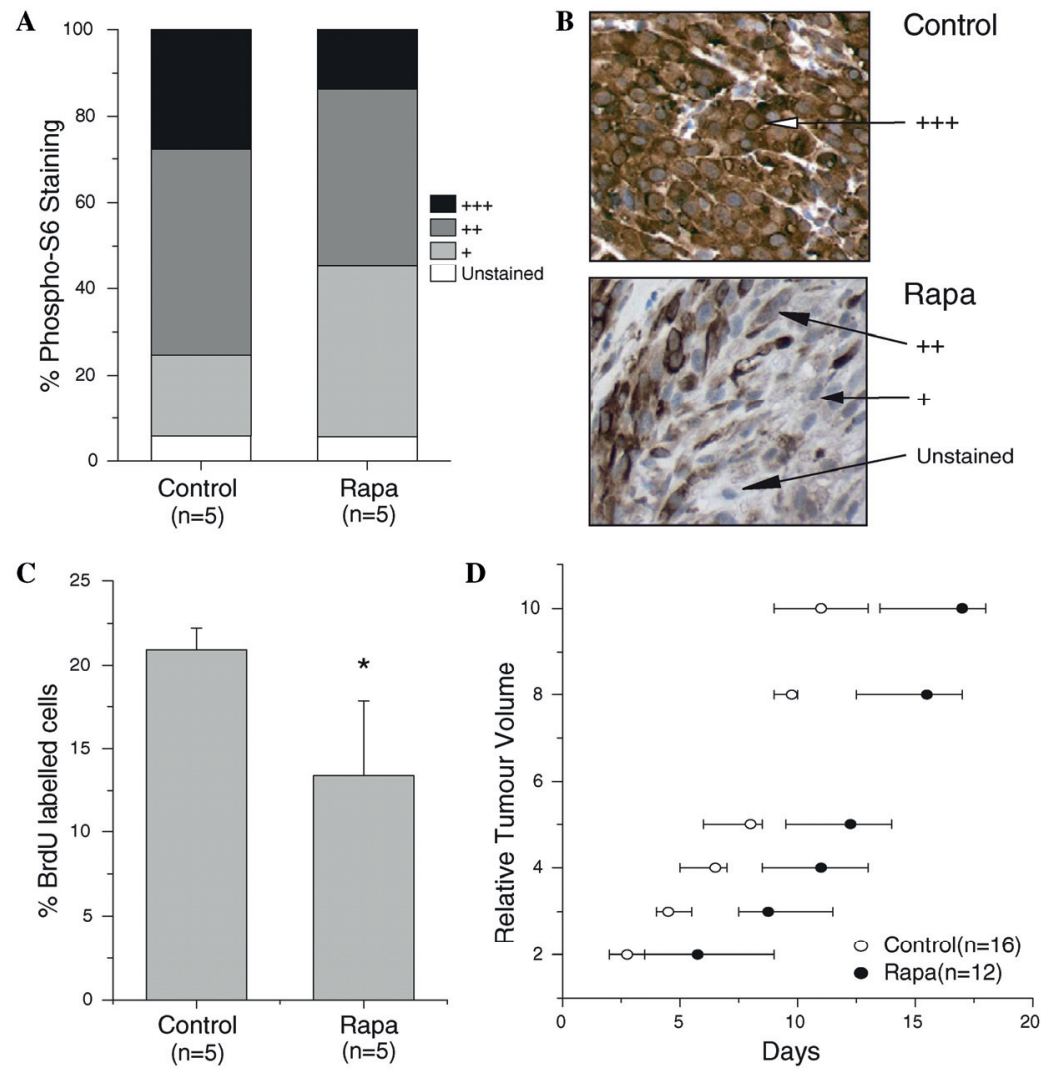

Figure 2. Rapamycin inhibits mTOR signalling and proliferation in vivo. Nude mice bearing subcutaneous U87 xenografts were treated with $1 \mathrm{mg} / \mathrm{kg}$ rapamycin for 2 days. Control animals received vehicle alone. On day 3 , animals were injected with BrdU and euthanized. Tumors were excised and processed for immunohistochemical staining. (A) Phosphorylation of ribosomal protein S6 was used as a marker of mTOR activity. Staining intensity was scored on a scale from zero to +++ in sections from 5 mice per group. (B) Phospho-S6 staining in representative control and rapamycin treated tumors. Arrows indicate the various levels of staining intensity. (C) BrdU uptake of cells in S-phase. Columns represent the mean labelling index \pm standard deviation from 5 mice per group. ${ }^{\star} P=0.006$. (D) Tumor growth delay of animals treated with vehicle (control) or rapamycin for 6 days. Data points represent the median number of days to reach a fixed tumor volume and error bars represent $95 \%$ confidence intervals. 


\section{Tumor growth delay with combination therapy}

We next determined if rapamycin could delay tumor regrowth if used in combination with fractionated radiotherapy. Rapamycin was given for 6 days along with equal fractions of radiation on days 2-6. In the lowest dose group of $24 \mathrm{~Gy}$, we observed a 26 day growth delay for tumors to reach 5 times the starting volume, however there was no additional effect of rapamycin (Fig. $3 A)$. Tumors treated with the combination therapy began to regress sooner but tumor regrowth began at approximately the same time as the tumors receiving radiation alone. The higher dose groups showed a similar pattern with no enhancement of growth delay (data not shown). Interestingly, we observed a large variation in the response of tumors within the rapa + RT treatment arm which accounts for the large error bars in Fig. 3A. To illustrate this variability, the growth of individual tumors is plotted in Fig. 3B. In the upper graph, the majority of tumors treated with 24 Gy alone responded in a similar fashion with regrowth beginning around day 25 . In contrast, the group receiving concurrent rapamycin had 4 out of 8 tumors that behaved similar to the radiation only controls, one that had a delayed regrowth, and 3 tumors that were cured. The data suggest that some tumors receiving the combined treatment may have responded better although the group as a whole did not show an improvement in growth delay.

\section{Local tumor control}

Animals were treated with fractionated radiotherapy as described above for the growth delay experiment. A total of eight different doses ranging from 24 to $100 \mathrm{~Gy}$ were given in five equal fractions and the animals were observed long-term for local tumor recurrence. Fig. 4 depicts the rate of tumor cure (data points) and the predicted probability of tumor control (fitted curves). The $\mathrm{TCD}_{50}$ for the control group was calculated to be $46.8 \mathrm{~Gy}(95 \% \mathrm{Cl} 41 ; 53)$. Concurrent rapamycin treatment shifted the dose-response curve towards increased radiosensitivity with a reduction of the $\mathrm{TCD}_{50}$ to $42.8 \mathrm{~Gy}(95 \% \mathrm{Cl}$ 36 ; 49), although this value did not reach significance when compared to radiation alone. 

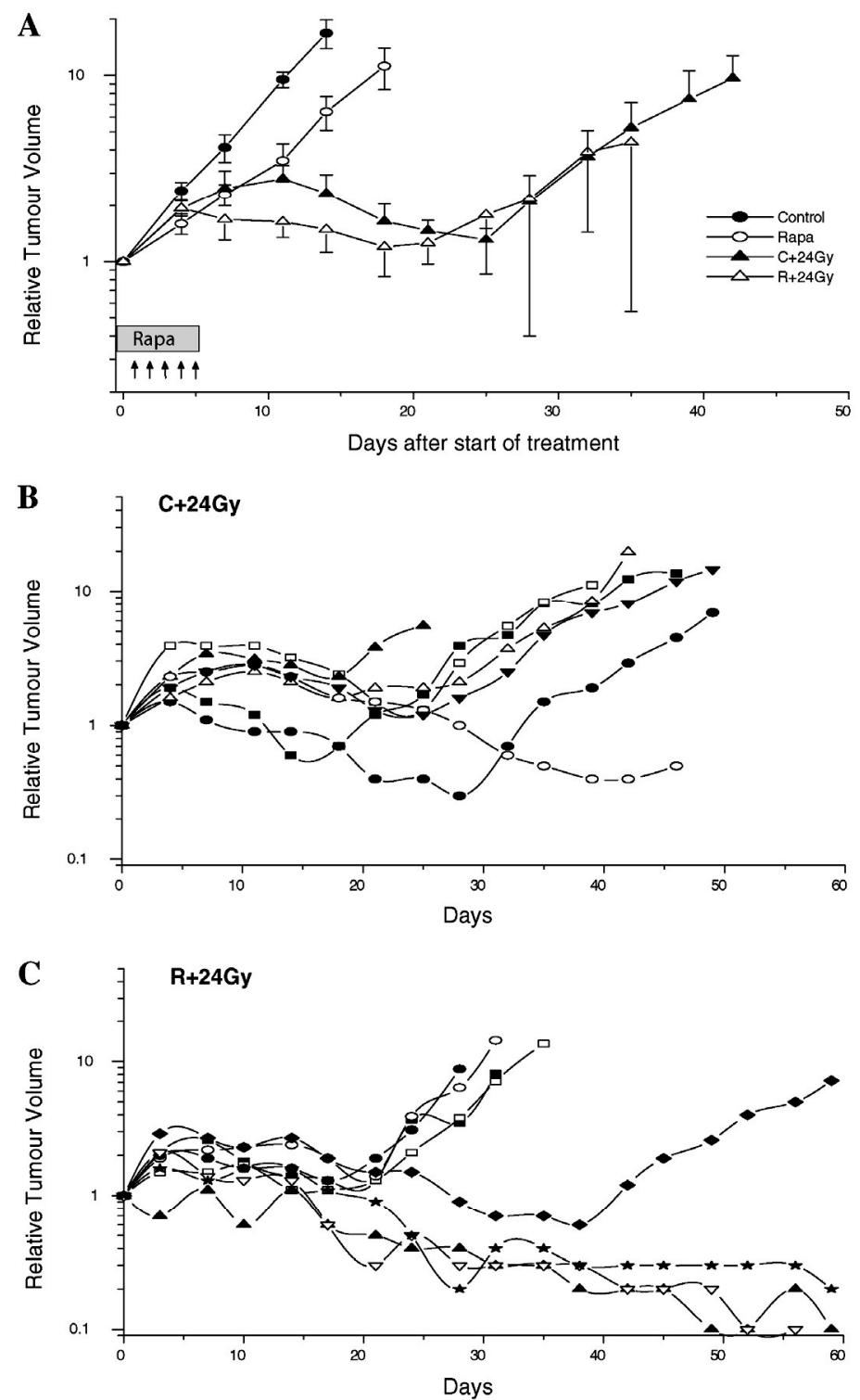

Figure 3. Rapamycin increases heterogeneity of response to radiation. Mice with established U87 tumors received injections of vehicle or $1 \mathrm{mg} / \mathrm{kg}$ rapamycin for 6 days, either with or without 5 fractions of $4.8 \mathrm{~Gy}$. Drug or vehicle was started one day before the fractionation schedule. (A) Median tumor volume for each of the four treatment arms is depicted. Arrows indicate time of irradiation and the filled bar depicts the period over which rapamycin was delivered. Error bars represent standard error. (B) Tumor volume measurements for individual animals treated with vehicle plus 5 x $4.8 \mathrm{~Gy}$ (upper graph) or rapamycin plus $5 \times 4.8 \mathrm{~Gy}$ (lower graph). 


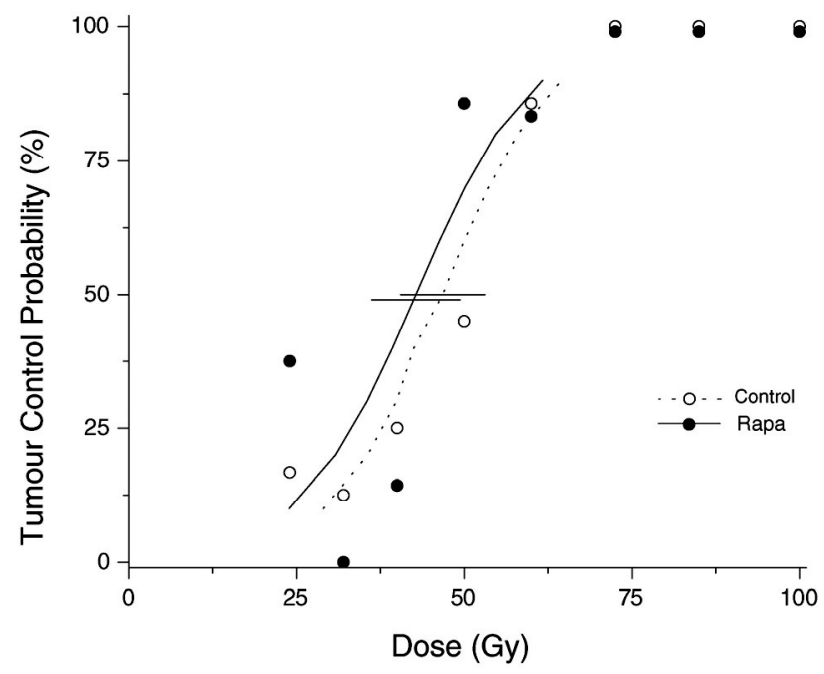

Figure 4. Local control of U87 xenografts treated with rapamycin and radiotherapy. Rate of local control (data points) and calculated tumor control probabilities (curves) of U87 tumors irradiated with 5 fractions over 5 days with total doses between 24 and $100 \mathrm{~Gy}$. Rapamycin or vehicle was administered beginning one day before irradiation and daily $2 \mathrm{~h}$ before each fraction. Error bars indicate $95 \%$ confidence interval of the $\mathrm{TCD}_{50}$ values.

\section{Hypoxia and thrombosis}

We hypothesized that the heterogeneous response of rapamycin treated tumors irradiated with subcurative doses might be a result of differences within the tumor microenvironment. In order to assess treatment induced changes, we examined tumors after receiving 2 doses of rapamycin either with or without a single $4.8 \mathrm{~Gy}$ fraction, thus simulating the conditions on day 3 of the $\mathrm{TCD}_{50}$ experiment. Pimonidazole was injected prior to tumor excision in order to evaluate the extent of hypoxia. Fig. $5 \mathrm{~A}$ shows the pimonidazole staining pattern observed in representative control and rapamycin treated tumors. Control tumors and those receiving radiation alone were typically well oxygenated, with the exception of one tumor within the control group that had a large hypoxic core. The mean hypoxic fractions were $2.8 \%$ and $2.2 \%$ for the control and RT groups, respectively (Fig. 5B). These data are consistent with the highly vascularized nature of glioblastomas [30]. The groups receiving rapamycin (both with and without radiation) showed significantly increased levels of pimonidazole labelling when compared to control $(P<0.05)$ or RT alone $(P<0.01)$. 
A
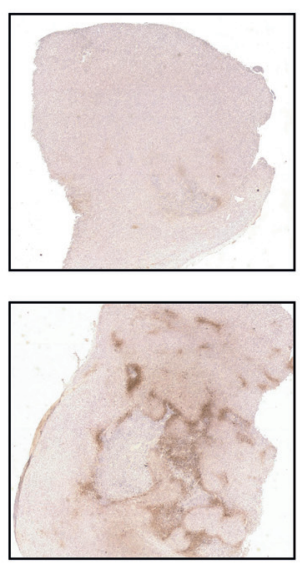

Rapa
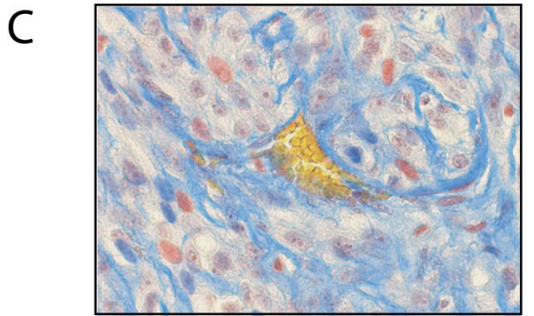

Perfused Vessel

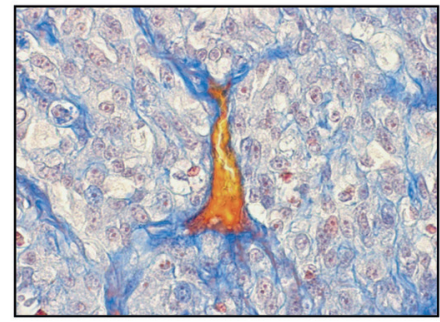

\section{Thrombotic Vessel}

B

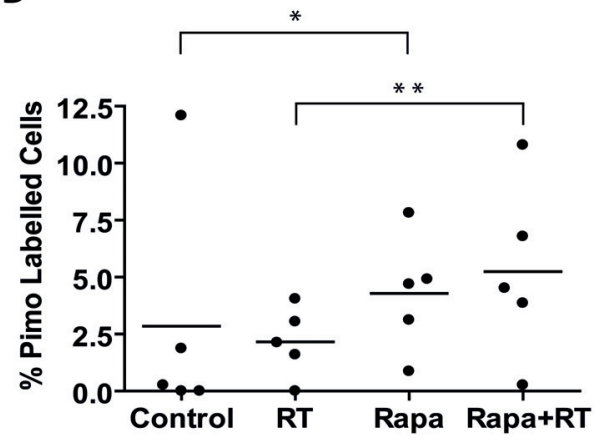

D

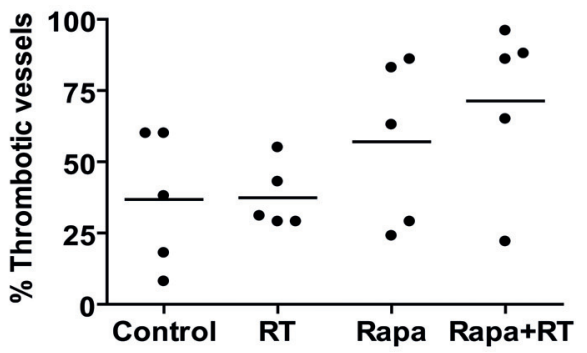

Figure 5. Rapamycin influences hypoxia and vessel thrombosis. Mice bearing established U87 xenografts were treated with vehicle (control) or rapamycin for 2 days either with or without a single $4.8 \mathrm{~Gy}$ fraction on day 2. Pimonidazole was injected the following day and tumors were excised $1 \mathrm{~h}$ later. (A) Pimonidazole staining in representative control and rapamycin treated tumors. (B) Percentage of pimonidazole labeled cells was determined from tumor sections. Column bars represent the mean of 5 tumors. ${ }^{*} P<0.05$. ${ }^{* *} P<0.01$. (C) MSB staining of a rapamycin treated tumor was used to identify thrombotic vessels. Representative fields show an open vessel containing yellow erythrocytes (upper figure) and a thrombotic vessel which is occluded by a red fibrin deposit (lower figure). (D) The number of both partially and fully occluded vessels as a percentage of the total vessel number was calculated. Column bars represent the mean of 5 tumors. 
Initial observations of the pimonidazole sections indicated that changes to the tumor vasculature might be occurring in the rapamycin treated groups. Several recent reports have suggested that rapamycin treatment may influence vessel thrombosis. This led us to perform MSB staining on the tissue sections in order to easily detect vessels containing fibrin occlusions. Fig. $5 \mathrm{C}$ shows an MSB stained tumor section from an animal treated with rapamycin with both a normal perfused vessel containing yellow erythrocytes (top) and a vessel that is almost entirely occluded by a red thrombus (bottom). No differences were found in total vessel numbers between the experimental arms (data not shown) indicating that rapamycin was not affecting vessel density at this early time point. The control group had a high basal level of thrombosis with an average of $37 \%$ thrombotic vessels (Fig. 5D). This is not unusual since intravascular thrombosis is a frequent finding in glioblastoma tissue and is observed histologically in over $90 \%$ of cases [30]. In both groups receiving rapamycin, there was an increasing trend in the percentage of thrombotic vessels (Fig. 5D). Again, it is interesting to note that some of the rapamycin treated tumors show similar levels of thrombosis as controls, but that the heterogeneity in thrombosis mirrors the differences seen in both hypoxia and tumor response to radiotherapy.

\section{Discussion}

Rapamycin analogues CCl-779 (Wyeth-Ayest), RAD001 (Novartis), and AP23573 (Ariad) are currently in different phases of clinical trials to assess toxicity profiles and antitumor activity. $\mathrm{CCl}-779$ is the most advanced compound in development and has shown partial responses in recurrent breast and renal cell carcinoma [31,32]. Most interest currently lies in combining these mTOR inhibitors with other cytotoxic modalities. Numerous reports have demonstrated that rapamycin can sensitize tumor cells to apoptosisinducing agents in vitro [33,34]. This has stimulated pre-clinical evaluation of CCl-779 in combination with gemcitabine in pancreatic cancer [35]. In our study we investigated the combination of rapamycin with a short course of fractionated radiotherapy so as to minimize the anti-proliferative effect of rapamycin and thus evaluate its potential to contribute to the direct cytotoxic effect of radiation. We find that rapamycin does not significantly improve radiation response as assessed by either growth delay or $\mathrm{TCD}_{50}$. However we found that rapamycin did increase variability in tumor response to radiotherapy, with several individual tumors showing large increases in growth delay. This may be a consequence of statistical probability, however these data may also suggest that rapamycin provides a benefit to radiation treatment in individual tumor cases. If this is the case, then it will be important to determine 
the biological factors that mediate this differential response in order to potentially identify patients that may benefit from combination treatment.

Differences in the pharmacokinetics of rapamycin have been observed in clinical trials [36] and would help to explain a lack of enhancement of radiotherapy if delivery of rapamycin to the tumor was impaired. Although we cannot rule out this possibility entirely, it seems unlikely to play a major role since animals receiving rapamycin alone responded in a homogeneous manner with respect to proliferation and growth delay (Fig. $2 \mathrm{C}$ and D).

Our studies point toward changes in the microenvironment as a potential contributing factor in the response to the combination of rapamycin and radiation. We found that rapamycin treated animals showed increased amounts of thrombosis and also an increase in the hypoxic fraction measured by pimonidazole binding. However, similar to the results observed in individual tumor response, these microenvironmental changes after rapamycin treatment were also variable amongst the individual tumors examined. It is tempting to speculate that the increase in both vessel thrombosis and resulting hypoxia in a subset of rapamycin treated tumors may explain the variation in their response to radiotherapy. The complete or partial restriction to blood flow by thrombotic vessels would produce local areas of acute hypoxia causing an increase in radioresistance. If this is the case, then administration of rapamycin prior to radiotherapy, as was done in our study, may decrease radiosensitivity due to transient increases in acute hypoxia and thus offset any potential increase in toxicity of the combination treatment. This hypothesis is supported by the finding that the combination treatment showed a substantial gain in the group of animals which received the lowest dose per fraction (24 Gy group). It is well known that the influence of hypoxia on overall response in fractionated therapy increases with increasing dose per fraction. It would be interesting to test this hypothesis by administering rapamycin in an adjuvant setting and/or further reducing the dose per fraction so as to minimize the consequences of (acute) hypoxia. It should be pointed out however, that at this time we cannot rule out the possibility that rapamycin-induced thrombosis may be beneficial if the additional vascular damage translates into increased cytotoxicity to tumor cells, as has been documented using vasculartargeting agents in combination with radiotherapy $[37,38]$.

Our analysis of vessel thrombosis was conducted after the initial investigation of tumor hypoxia. In hindsight, the hypoxic fraction may have been underestimated in our experiment if you take into account the possible inhibitory effect of thrombosis on pimonidazole delivery to the tumor. Intrinsic markers of hypoxia or oxygen probe measurements would be useful to determine if 
this is in fact occurring in our system. In addition, sequential measurements of hypoxia over time would shed light on the relative effect of rapamycin on hypoxia in individual tumors.

The ability of rapamycin to contribute to response through its effects on the vasculature may also be influenced by tumor type. Glioblastomas are characterized by frequent thrombosis and areas of necrosis and in addition, these patients are at high risk for developing deep-vein thrombosis and pulmonary embolism suggesting a systemic dysfunction of coagulation [30]. Therefore, a fraction of these tumors may already have high levels of thrombosis making it difficult to observe additional thrombosis induced by rapamycin. Previous studies documenting rapamycin-induced thrombosis were conducted using pancreatic and colon adenocarcinoma models and did not find evidence of thrombosis in control tumors $[17,39]$. It would thus be interesting to evaluate rapamycin in combination with radiation in other tumor types showing less intrinsic vasculature occlusion. Subsequent studies should also consider including tumor lines which are less sensitive than U87 to rapamycin as a single agent since the magnitude of this response may mask interactions with radiation.

Any variability we observed in tumor response may simply reflect the stochastic nature of thrombus formation and its consequences. Impaired perfusion in a single vessel due to thrombus formation can potentially affect thousands or millions of individual tumor cells and thus have a large impact on tumor response. The fact that the hypoxic fraction can vary tremendously amongst individual untreated tumors derived from the same cell line and grown in the same host supports a role for the stochastic nature of blood vessel formation and/or function in determining hypoxia and radiosensitivity of individual tumors [40].

Finally, there is also some recent evidence suggesting that pre-treatment levels of hypoxia could contribute to the ability of rapamycin to affect tumor response. As described previously, the activity of mTOR is regulated by numerous upstream pathways that monitor growth factors, nutrients, and energy metabolism. Recently hypoxia was also implicated in the regulation of mTOR signalling through two different pathways. Hypoxia causes activation of the TSC1/2 complex, which functions to inhibit mTOR. This can occur both via induction of the HIF-dependent gene REDD1, and/or through activation of AMPK $[41,42]$. This leads us to speculate that rapamycin may be less effective in hypoxic regions of tumors since mTOR may already be at least partially inactivated by TSC. Thus the amount of hypoxia present at the start of treatment may play a part in determining sensitivity to rapamycin in vivo. 
Whether this is relevant in our model is subject to debate since Kaper et al. argue that hypoxia's ability to inhibit mTOR is diminished in tumors where mTOR activity has been highly upregulated by mutation of the PI3K pathway [43].

It is clear that additional preclinical work is needed to establish the degree and consequences of vascular thrombosis and hypoxia on both tumors and normal tissues treated with rapamycin and irradiation. It would be interesting to monitor perfusion during the course of therapy via in vivo imaging techniques such as DCE-MRI and to compare this with treatment outcome. Also, alternative sequencing and timing of rapamycin and radiation delivery should be investigated in order to determine if there is an optimal therapeutic window. Our results suggest that it will be important to consider the effects of rapamycin on tumor oxygenation and thrombosis and to use caution in the design of future clinical trials combining mTOR inhibitors with radiotherapy.

\section{Acknowledgements}

This work was supported in part by a grant from the Nederlands Vereniging voor Oncologie awarded to S.A.W. and by Grant Ba 1433-4 by the Deutsche Forschungsgemeinschaft to M.B. The authors thank Ms. D. Pfitzmann, Ms. K. Schumann, and Ms. E. Lootze for their excellent technical assistance with the animal experiments conducted in Dresden. We also thank Mrs. S. Balschukat (Dresden), and Mrs. Hanna Andrusewicz and Dr. Jan Sir (Department of Pathology in Bydgoszcz) for their help with the histological assessments. 


\section{References}

[1] Dancey JE. Inhibitors of the mammalian target of rapamycin. Expert Opin Investig Drugs 2005;14:313-28.

[2] Rubio-Viqueira B, Hidalgo M. Targeting mTOR for cancer treatment. Curr Opin Investig Drugs 2006;7:501-12.

[3] Avruch J, Lin Y, Long X, Murthy S, Ortiz-Vega S. Recent advances in the regulation of the TOR pathway by insulin and nutrients. Curr Opin Clin Nutr Metab Care 2005;8:67-72.

[4] Petroulakis E, Mamane Y, Le Bacquer O, Shahbazian D, Sonenberg N. mTOR signaling: implications for cancer and anticancer therapy. Br J Cancer 2006;94:195-9.

[5] Vivanco I, Sawyers CL. The phosphatidylinositol 3-Kinase AKT pathway in human cancer. Nat Rev Cancer 2002;2:489-501.

[6] Choe G, Horvath S, Cloughesy TF, et al. Analysis of the phosphatidylinositol 30-kinase signaling pathway in glioblastoma patients in vivo. Cancer Res 2003;63:2742-6.

[7] Kang S, Bader AG, Zhao L, Vogt PK. Mutated PI 3-kinases: cancer targets on a silver platter. Cell Cycle 2005;4:578-81.

[8] Guertin DA, Sabatini DM. An expanding role for mTOR in cancer. Trends Mol Med 2005;11:353-61.

[9] Yu K, Toral-Barza L, Discafani C, et al. mTOR, a novel target in breast cancer: the effect of $\mathrm{CCl}-779$, an mTOR inhibitor, in preclinical models of breast cancer. Endocr Relat Cancer 2001;8:249-58.

[10] Hashemolhosseini S, Nagamine Y, Morley SJ, Desrivieres S, Mercep L, Ferrari S. Rapamycin inhibition of the G1 to $S$ transition is mediated by effects on cyclin D1 mRNA and protein stability. J Biol Chem 1998;273:14424-9.

[11] Kawamata S, Sakaida H, Hori T, Maeda M, Uchiyama T. The upregulation of p27Kip1 by rapamycin results in G1 arrest in exponentially growing T-cell lines. Blood 1998;91:561-9.

[12] Teachey DT, Obzut DA, Cooperman J, Fang J, Carroll M, Choi JK, Houghton PJ, Brown VI, Grupp SA. The mTOR inhibitor CCl-779 induces apoptosis and inhibits growth in preclinical models of primary adult human ALL. Blood 2006;107:1149-55.

[13] Huang S, Bjornsti MA, Houghton PJ. Rapamycins: mechanism of action and cellular resistance. Cancer Biol Ther 2003;2:222-32.

[14] Hosoi H, Dilling MB, Shikata T, et al. Rapamycin causes poorly reversible inhibition of mTOR and induces p53-independent apoptosis in human rhabdomyosarcoma cells. Cancer Res 1999;59:886-94.

[15] Takeuchi H, Kondo Y, Fujiwara K, et al. Synergistic augmentation of rapamycin-induced autophagy in malignant glioma cells by phosphatidylinositol 3-kinase/protein kinase B inhibitors. Cancer Res 2005;65:3336-46.

[16] Guba M, von Breitenbuch P, Steinbauer M, et al. Rapamycin inhibits primary and metastatic tumor growth by antiangiogenesis: involvement of vascular endothelial growth factor. Nat Med 2002;8:128-35.

[17] Guba M, Yezhelyev M, Eichhorn ME, et al. Rapamycin induces tumor-specific thrombosis via tissue factor in the presence of VEGF. Blood 2005;105:4463-9.

[18] Shinohara ET, Cao C, Niermann K, et al. Enhanced radiation damage of tumor vasculature by mTOR inhibitors. Oncogene 2005;24:5414-22.

[19] Eshleman JS, Carlson BL, Mladek AC, Kastner BD, Shide KL, Sarkaria JN. Inhibition of the mammalian target of rapamycin sensitizes U87 xenografts to fractionated radiation therapy. Cancer Res 2002;62:7291-7.

[20] Albert JM, Kim KW, Cao C, Lu B. Targeting the Akt/mammalian target of rapamycin pathway for radiosensitization of breast cancer. Mol Cancer Ther 2006;5:1183-9.

[21] Toulany M, Dittmann K, Baumann M, Rodemann HP. Radiosensitization of Ras-mutated human tumor cells in vitro by the specific EGF receptor antagonist BIBX1382BS. Radiother Oncol 2005;74:117-29.

[22] Gottschalk AR, Doan A, Nakamura JL, Haas-Kogan DA, Stokoe D. Inhibition of phosphatidylinositol-3-kinase causes cell death through a protein kinase B (PKB)-dependent mechanism and growth arrest through a PKB-independent mechanism. Int J Radiat Oncol Biol Phys 2005;61:1183-8.

[23] Taghian A, DuBois W, Budach W, Baumann M, Freeman J, Suit $H$. In vivo radiation sensitivity of glioblastoma multiforme. Int J Radiat Oncol Biol Phys 1995;32:99-104.

[24] Walker AM, Suit HD. Assessment of local tumor control using censored tumor response data. Int J Radiat Oncol Biol Phys 1983;9:383-6. 
[25] Krause M, Schutze C, Petersen C, et al. Different classes of EGFR inhibitors may have different potential to improve local tumour control after fractionated irradiation: a study on C225 in FaDu hSCC. Radiother Oncol 2005;74:109-15.

[26] Edwards AWF. Likelihood. Expanded edition. Baltimore: Johns Hopkins University Press; 1992.

[27] Lendrum AC, Fraser DS, Slidders W, Henderson R. Studies on the character and staining of fibrin. J Clin Pathol 1962;15:401-13.

[28] Sachs L. Angewandte statistik. Berlin: Springer; 1992.

[29] Kenerson HL, Aicher LD, True LD, Yeung RS. Activated mammalian target of rapamycin pathway in the pathogenesis of tuberous sclerosis complex renal tumors. Cancer Res 2002;62:5645-50.

[30] Brat DJ, Van Meir EG. Vaso-occlusive and prothrombotic mechanisms associated with tumor hypoxia, necrosis, and accelerated growth in glioblastoma. Lab Invest 2004;84:397405.

[31] Chan S, Scheulen ME, Johnston S, et al. Phase II study of temsirolimus (CCl-779), a novel inhibitor of $\mathrm{mTOR}$, in heavily pretreated patients with locally advanced or metastatic breast cancer. J Clin Oncol 2005;23:5314-22.

[32] Atkins MB, Hidalgo M, Stadler WM, et al. Randomized phase II study of multiple dose levels of CCl-779, a novel mammalian target of rapamycin kinase inhibitor, in patients with advanced refractory renal cell carcinoma. J Clin Oncol 2004;22:909-18.

[33] Beuvink I, Boulay A, Fumagalli S, et al. The mTOR inhibitor RAD001 sensitizes tumor cells to DNA-damaged induced apoptosis through inhibition of p21 translation. Cell 2005;120:747-59.

[34] Mondesire WH, Jian W, Zhang $\mathrm{H}$, et al. Targeting mammalian target of rapamycin synergistically enhances chemotherapyinduced cytotoxicity in breast cancer cells. Clin Cancer Res 2004;10:7031-42.

[35] Ito D, Fujimoto K, Mori T, et al. In vivo antitumor effect of the mTOR inhibitor $\mathrm{CCl}-779$ and gemcitabine in xenograft models of human pancreatic cancer. Int J Cancer 2006;118:233743.

[36] Gallant-Haidner HL, Trepanier DJ, Freitag DG, Yatscoff RW. Pharmacokinetics and metabolism of sirolimus. Ther Drug Monit 2000;22:31-5.

[37] Hoang T, Huang S, Armstrong E, Eickhoff JC, Harari PM. Augmentation of radiation response with the vascular targeting agent ZD6126. Int $\mathrm{J}$ Radiat Oncol Biol Phys 2006;64:1458-65.

[38] Murata R, Siemann DW, Overgaard J, Horsman MR. Interaction between combretastatin A4 disodium phosphate and radiation in murine tumors. Radiother Oncol 2001;60:155-61.

[39] Bruns CJ, Koehl GE, Guba M, et al. Rapamycin-induced endothelial cell death and tumor vessel thrombosis potentiate cytotoxic therapy against pancreatic cancer. Clin Cancer Res 2004;10:2109-19.

[40] Evans SM, Jenkins WT, Joiner B, Lord EM, Koch CJ. 2- Nitroimidazole (EF5) binding predicts radiation resistance in individual 9L s.c. tumors. Cancer Res 1996;56:405-11.

[41] Liu L, Cash TP, Jones RG, Keith B, Thompson CB, Simon MC. Hypoxia-induced energy stress regulates mRNA translation and cell growth. Mol Cell 2006;21:521-31.

[42] Brugarolas J, Lei K, Hurley RL, et al. Regulation of mTOR function in response to hypoxia by REDD1 and the TSC1/TSC2 tumor suppressor complex. Genes Dev 2004;18:2893-904.

[43] Kaper F, Dornhoefer N, Giaccia AJ. Mutations in the PI3K/PTEN/TSC2 pathway contribute to mammalian target of rapamycin activity and increased translation under hypoxic conditions. Cancer Res 2006;66:1561-9. 



\section{CHAPTER 6}

\section{Inhibition of 4E-BP1 phosphorylation and MRNA translation requires simultaneous blockade of mTORC1 and PI3K/Akt signaling}

Manuscript submitted

SA Weppler, M Koritzinsky, JW Voncken, P Lambin, and BG Wouters. 


\title{
Chapter 6
}

\begin{abstract}
The mammalian target of rapamycin (mTOR) kinase is a central regulator of cell metabolism and growth whose activity is often altered in cancer. An important consequence of mTOR activation is stimulation of cap-dependent translation, which is mediated by phosphorylation and inactivation of the eukaryotic initiation factor 4E-binding protein 1 (4E-BP1). Here, we demonstrate that short exposures to rapamycin, a specific inhibitor of mTOR complex 1 (mTORC1), has only a modest inhibitory effect on 4E-BP1 phosphorylation and mRNA translation despite completely blocking phosphorylation of another mTORC1 substrate p70S6K. We describe a synergistic effect of combined mTORC1 and phosphatidylinositol 3-kinase (PI3K) inhibition that is specific for dephosphorylation of 4E-BP1 at both Thr70 and Ser65, and which leads to a rapid suppression of translation in a 4E-BP1 dependent manner. Similar results are observed using rapamycin in combination with an inhibitor of protein kinase $B(P K B$, also termed Akt), suggesting the existence of a PI3K/Akt-dependent signaling pathway sufficient to maintain 4E-BP1 phosphorylation in the presence of $\mathrm{mTORC} 1$ inhibition. In addition, the differential sensitivity of mTORC1 targets to inhibition of PI3K/Akt alone implies that mTORC1 complexes may exhibit substrate specificity dependent upon activation of specific upstream signaling pathways to mTOR. Together these results suggest that targeting deregulated translation in cancer may be improved by strategies that block both $\mathrm{mTORC} 1$ dependent and independent signals regulating 4E-BP1.
\end{abstract}




\section{Introduction}

The mammalian target of rapamycin (mTOR) kinase exists in at least two distinct complexes with independent functions and regulation (1). mTOR complex 1 (mTORC1) consists of the mTOR kinase, LST8 (also known as $\mathrm{G} \beta \mathrm{L}$ ) and raptor, a scaffolding protein that serves to bring mTORC1 substrates in close proximity to mTOR's catalytic domain (2). The eukaryotic initiation factor 4E (elF4E) binding protein (4E-BP1) and p70S6K, both regulators of mRNA translation, are the best characterized targets of mTORC1. mTOR complex 2 (TORC2) also contains LST8, but instead of raptor associates with rictor (3). TORC2 has been shown to phosphorylate Akt at Ser473 and protein kinase $\mathrm{Ca}$, but to date no evidence of $4 \mathrm{E}-\mathrm{BP} 1$ or $\mathrm{p} 70 \mathrm{~S} 6 \mathrm{~K}$ phosphorylation has been demonstrated $(4,5)$.

mTOR regulates several processes relevant to cancer including mRNA translation, ribosome biogenesis, autophagy and metabolism (1). A direct link between mTOR and cancer was established following discovery that the tuberous sclerosis complex (TSC) functions as a negative regulator of mTORC1. Mutations in tsc1 or tsc2 genes thus activate mTOR and are responsible for the development of harmatomas in TSC patients. The TSC1/2 complex regulates mTORC1 in response to many upstream signals including amino acid and oxygen availability, energy status, insulin and other growth factors (6). These signals influence mTOR via TSC $1 / 2$ through signaling pathways that are also frequently altered in cancer, including the PI3K/Akt pathway. In response to insulin and other growth factors, PI3K/Akt signaling activates mTORC1 by phosphorylation and inhibition of TSC2 (7). PI3K activation is antagonized by the tumor suppressor PTEN, and its importance in cancer has been directly linked to its ability to control mTORC1 activity (8).

Regulation of translation is a critical function of mTOR that when deregulated contributes to cancer development. This is evidenced by the fact that both mTORC1 targets, 4E-BP1 and p70S6K, are involved in regulation of translation. 4E-BP1 functions as a negative regulator of translation by competing with elF4G for binding to the rate limiting translation initiation factor elF4E (9). Growth promoting signals that stimulate mTOR lead to phosphorylation of 4E-BP1, which prevents it from binding to elF4E and therefore stimulates translation. The importance of this mTOR effector has been demonstrated in a mouse model for cancer in which overexpression of elF4E can bypass the requirement for $\mathrm{mTOR}$ activation (8). In addition to its general role in protein synthesis, deregulation of translational control by elF4E and 4E-BP1 is thought to differentially alter the expression of cancer related genes in a manner that promotes malignant conversion (10). elF4E is often found to be 
overexpressed in cancer, and its expression is sufficient to transform cells (11). 4E-BP1 also has a demonstrated role in regulating gene expression and functions as a potential biomarker of malignant progression and adverse prognosis in breast, ovary, and prostate tumors $(12,13)$.

The binding of 4E-BP1 to elF4E is regulated by phosphorylation at multiple sites. Non-phosphorylated or hypo-phosphorylated 4E-BP1 binds strongly to elF4E and prevents cap-dependent translation, whereas hyperphosphorylated 4E-BP1 dissociates from elF4E, allowing translation to initiate (14). The phosphorylation of 4E-BP1 is complex involving at least six phosphoresidues. Four of these sites have been linked to mTOR signaling and are phosphorylated in a hierarchical manner, so that phosphorylation at Thr37/Thr46 is required for subsequent phosphorylation of Thr70, which in turn is required for Ser65 phosphorylation (14-16). Although these sites all show dependency on mTOR, their sensitivity to changes in phosphorylation by different signals that regulate mTOR are distinct. For example, phosphorylation of Thr37/Thr46 is affected significantly by amino acid availability, but not by insulin which preferentially stimulates Ser65 phosphorylation (6). The ability of 4E-BP1 to bind elF4E and thus inhibit translation correlates best with the phosphorylation status of Ser65, although this is somewhat controversial $(6,9,17)$. It remains unclear as to which, if any, of the 4E-BP1 phospho-sites are directly phosphorylated by mTOR and it is likely that other kinases are also involved $(9,18)$.

The importance of mTOR in regulation of mRNA translation, cell growth and metabolism coupled with its deregulation in cancer has made it an attractive therapeutic target. Rapamycin is a macrolide antibiotic that inhibits mTOR with high selectivity (19). Rapamycin interacts with the immunophilin FKBP12, which then binds to the FRB-domain of mTOR and in doing so, weakens its interaction with raptor. As a consequence, rapamycin prevents phosphorylation of the raptor dependent mTORC1 substrates, p70S6K and 4E-BP1 $(20,21)$, but not rictor dependent TORC2 substrates like Akt (22) although longer treatments may indirectly effect mTORC2 activity by interfering with assembly of mTOR into new TORC2 complexes (23).

The ability of rapamycin to inhibit proliferation or other cancer associated phenotypes is highly variable between tumors and dependent on their genetic background $(24,25)$. For example, loss of PTEN or activation of Akt leads to constitutive mTOR activation and can significantly sensitize cells to the effects of mTOR inhibitors $(26,27)$. Combinations of rapamycin with other small-molecule inhibitors or cytotoxic agents have also shown promising results, and found to provide better inhibition of targets downstream of 
mTORC1 (28-30). However, it is unclear whether this beneficial effect results from a more complete inhibition of $\mathrm{mTORC} 1$, or via mTORC1 independent regulation of its targets. Our objective was to examine the ability of mTORC1 and/or PI3K inhibition to regulate phosphorylation and function of 4E-BP1. Surprisingly, our data indicate that 4E-BP1 Ser65 and Ser70 phosphorylation and translation initiation is largely resistant to inhibition of either mTORC1 or PI3K. However, a strong synergistic effect restricted to the mTORC1 target 4E-BP1 is observed when these two targets are inhibited in combination. These data implicate PI3K/Akt in the regulation of 4E-BP1 and translation in an MTORC1 independent pathway and suggest a more effective way of targeting deregulated translation in cancer.

\section{Materials and methods}

\section{Cell lines}

HT29 and HCT116 colorectal carcinomas, A549 lung carcinoma, and HeLa cervix carcinoma were from the American Type Culture Collection, Tig3 human fibroblasts were a gift from J.Fukami (31), and U87 glioblastoma cells were a gift from J. Sarkaria (Mayo Clinic, MN, USA). All the above cell lines were maintained in Dulbecco's modified Eagle's medium (DMEM) (SigmaAldrich, Zwijndrecht, NL) supplemented with 10\% fetal calf serum (FCS) (HyClone, Logan UT, USA). DU145 prostate carcinoma cells were maintained in McCoy's 5A medium (Invitrogen, Breda, NL) with 10\% FCS. U373 glioma cells were cultured as described (32). U87 cells containing an ecdysone inducible-PTEN construct were generated and validated previously (33).

\section{Reagents and antibodies}

Rapamycin, LY294002, wortmannin, and Akti-1/2 were purchased from Calbiochem (Darmstadt, DE). Ponasterone A was from Sigma-Aldrich (Zwijndrecht, NL). The following antibodies were purchased from Cell Signaling Technology (Danvers, MA): Phospho-p70S6K (Thr389), Phospho-4E-BP1 (Ser65), Phospho-4E-BP1 (Thr70), Phospho-4E-BP1 (Thr37/46), PhosphoAkt (Ser473), Akt, PTEN, Raptor, and mTOR. The $\beta$-actin monoclonal antibody (Clone C4) was purchased from MP Biomedicals (Amsterdam, NL). The elF4E monoclonal antibody (Clone 87) was supplied by BD Biosciences (Breda, NL), and the elF4GI antibody was purchased from Abcam (Cambridgeshire, UK). Secondary antibodies were purchased from Sigma-Aldrich (goat-anti-mouse) and Cell Signaling Technology (goat-anti-rabbit). 


\section{Western blot analysis}

Cell extracts were prepared, resolved by SDS-PAGE and transferred to a nitrocellulose membrane as described previously (32). The membrane was blocked with $5 \%$ milk-TBST $(20 \mathrm{mM}$ Tris- $\mathrm{HCl}, \mathrm{pH} 7.6,140 \mathrm{mM} \mathrm{NaCl}, 0.1 \%$ Tween 20) and incubated overnight with the appropriate primary antibody. The membrane was washed with TBST and incubated for $1 \mathrm{~h}$ with a horseradish peroxidase-linked secondary antibody. Chemiluminescence detection was carried out using SuperSignal West Pico from Perbio (Etten-Leur, NL).

\section{$m^{7}$ GTP-agarose affinity chromatography}

elF4E and associated proteins were isolated as described (34) but with the following amendments. $300 \mu \mathrm{g}$ of cytoplasmic extract was incubated with 50 $\mu \mathrm{l}$ of $\mathrm{m}^{7}$ GTP-Sepharose 4B resin (GE Healthcare Life Sciences) overnight at $4^{\circ} \mathrm{C}$. The resin was washed, boiled in Laemmli sample buffer and the isolated proteins were resolved by SDS-PAGE and detected by immunoblotting.

\section{Polysome analysis}

Polysome-associated mRNA was isolated by sucrose gradient centrifugation as described previously (35). The absorbance at $254 \mathrm{~nm}$ was recorded continuously as the gradient was fractionated.

\section{RNA interference}

4E-BP1 expression was modulated by stably transfecting U87 cells with pRetroSuper (36) containing a short hairpin RNA with the targeting sequence gtttgagatggacatttaa. The empty pRetroSuper vector was used as a control. Effective reduction of $4 \mathrm{E}-\mathrm{BP} 1$ protein levels using this vector has been validated previously (37). Pre-designed siRNA against raptor, as well as a nontargeting negative control siRNA, were purchased from Applied Biosystems (Nieuwerkerk a/d ljssel, NL). Raptor siRNA had the sequence ggattatgaggtcgtataatt and was used at a concentration of $20 \mathrm{nM}$. A SignalSilence siRNA kit for mTOR was purchased from Cell Signaling Technology. mTOR siRNA was transfected at a concentration of $50 \mathrm{nM}$. For all siRNA transfections, cells were transfected in 6-well plates using $12 \mu$ l Oligofectamine (Invitrogen) in a total volume of $2 \mathrm{ml}$ growth medium according to the manufacturer's directions. Cell lysates were analyzed $72 \mathrm{~h}$ after transfection.

\section{Clonogenic survival assay}

$24 \mathrm{hr}$ after treatment with rapamycin and LY294002, cells were trypsinized and counted using a Coulter Z Series particle counter (Beckman Coulter, Mij- 
drecht, NL). Cells were seeded in triplicate $6 \mathrm{~cm}$ dishes at two different densities in complete growth medium. The dishes were incubated under standard culture conditions for a period of 12 days for colony formation. Colonies were fixed and stained with $2 \%$ bromophenol blue in $70 \%$ ethanol. Plating efficiency was determined by counting colonies consisting of $\geq 50$ cells and correcting for the number of cells seeded.

\section{Statistics}

A two-tailed Student's $t$-test was used to assess differences in translation inhibition and clonogenic survival. $P$ values less than 0.05 were considered to be significant.

\section{Results}

\section{E-BP1 phosphorylation is independently maintained by mTORC1 and PI3K}

Given the demonstrated influence of mTOR and PI3K signaling on 4E-BP1 phosphorylation and mRNA translation, we evaluated the consequences of inhibiting either or both of these pathways using the mTORC1 inhibitor rapamycin and the PI3K inhibitor LY294002. Two glioma cell lines were treated with these inhibitors, either alone or in combination, for a period of $2 \mathrm{~h}$ at which time we examined phosphorylation of 4E-BP1 and p70S6K (Figure 1a). In both U87 and U373 cell lines, treatment with rapamycin alone resulted in a complete loss of p70S6K phosphorylation. Consistent with its reported role in signaling to mTOR via TSC1/2, inhibition of PI3K with LY294002 was also sufficient to block phosphorylation of p70S6K. Despite this clear inhibition of mTORC1 activity with either inhibitor, phosphorylation of 4E-BP1 at Ser65 was only marginally reduced following either of these treatments alone. However, a strong synergistic effect resulting in near complete loss of 4E-BP1 Ser65 phosphorylation was observed when the two inhibitors were used in combination (Figure 1a, lanes 4 and 8).

No decrease in 4E-BP1 Ser65 phosphorylation similar to that observed with the combination treatment was found by increasing the concentration of rapamycin alone from 10nM to $100 \mathrm{nM}$ or the concentration of LY294002 alone from $5 \mu \mathrm{M}$ to $10 \mu \mathrm{M}$ (Supplementary Figure S1). This suggests that the differential outcome of mTORC1 and PI3K inhibition on 4E-BP1 and p70S6K does not result from dissimilar sensitivities to any residual kinase activity present after treatment with the inhibitors (at least not at the concentrations used in these experiments). In contrast, a clear dose-dependent decrease in 4E-BP1 
phosphorylation was observed using LY294002 concentrations ranging from 1 to $10 \mu \mathrm{M}$ in combination with $10 \mathrm{nM}$ rapamycin. Together these results indicate that unlike p70S6K, 4E-BP1 phosphorylation on Ser65 is maintained unless both PI3K and mTORC1 are inhibited.

Because phosphorylation of 4E-BP1 occurs on multiple sites and in a hierarchical fashion (15), we further assessed the effects of mTORC1 and/or PI3K inhibition on Thr37/46 and Thr70 phosphorylation (Figure 1b). Similar to Ser65, treatment with either inhibitor alone showed no effect on Thr70 phosphorylation whereas the combination resulted in a near complete loss of phosphorylation. In contrast, total levels of Thr37/46 phosphorylation after combination treatment were similar to treatment with either inhibitor alone. Rapamycin or LY294002 caused an apparent shift to the faster migrating hypo-phosphorylated bands of 4E-BP1 which was further enhanced by combining both inhibitors. Therefore, Thr37/46 appear not to be affected directly by the combination of mTORC1 and PI3K inhibition and the change in migration is likely due to the dephosphorylation of Thr70 and Ser65. Assuming the reported hierarchy of 4E-BP1 phosphorylation is correct, with phosphorylation of Thr70 preceding Ser65, then the synergistic effect of PI3K and mTORC1 inhibition appears to occur at the point of Thr70 phosphorylation.

Figure 1. Combined PI3K and mTOR inhibition has a co-operative effect on 4E-BP1 phosphorylation and global translation. (a) U87 and U373 cells were treated with 10nM rapamycin and/or 10uM LY294002 for $2 \mathrm{~h}$ in complete DMEM. Cells were harvested for protein and Western blot analysis was performed using antibodies against phospho-p70S6K (Thr389), phospho-4EBP1 (Ser65) and actin as a loading control. (b) 4E-BP1 phosphorylation at Ser65, Thr70, and Thr37/46 was investigated in U87 cell lysates treated as described in (a). (c) elF4E was purified from U87 lysates treated with rapamycin and/or LY294002 using $m^{7}$ GTP-agarose affinity chromatography. The association of 4E-BP1 and elF4G with elF4E was detected by subsequent immunoblotting. (d) Polysomal mRNA was isolated from U87 lysates by centrifugation through sucrose gradients. The absorbance at $254 \mathrm{~nm}$ was recorded as the gradient was fractionated and plotted as a function of gradient depth. Arrows indicate the peaks corresponding to the position of $40 \mathrm{~S}, 60 \mathrm{~S}$, and $80 \mathrm{~S}$ ribosomal complexes as well as the location of polysomes. (e) Translation inhibition was calculated by comparing the fractional area under the polysome peaks for each treatment condition with that of the control. 
A

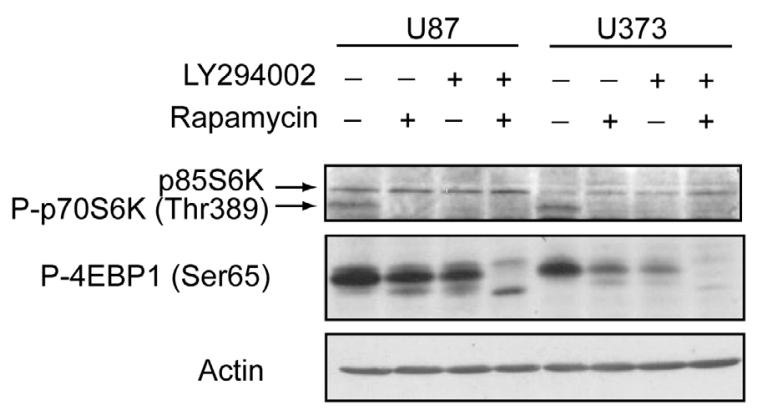

B

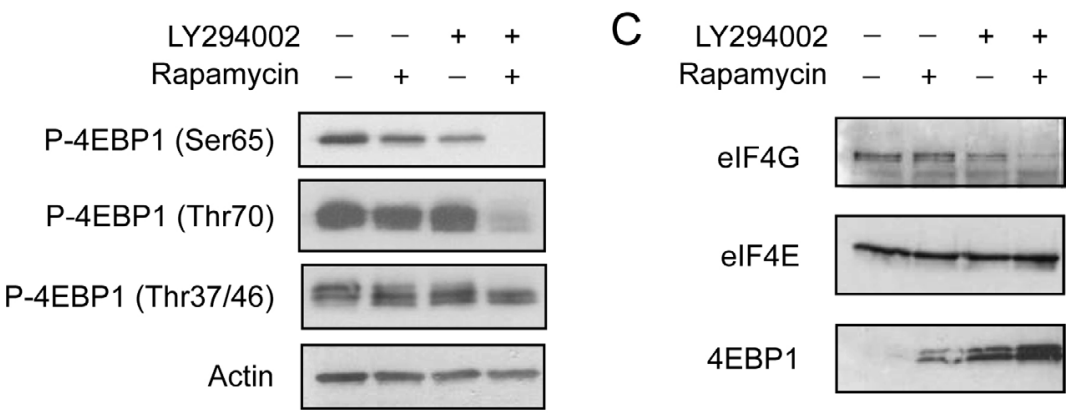

D

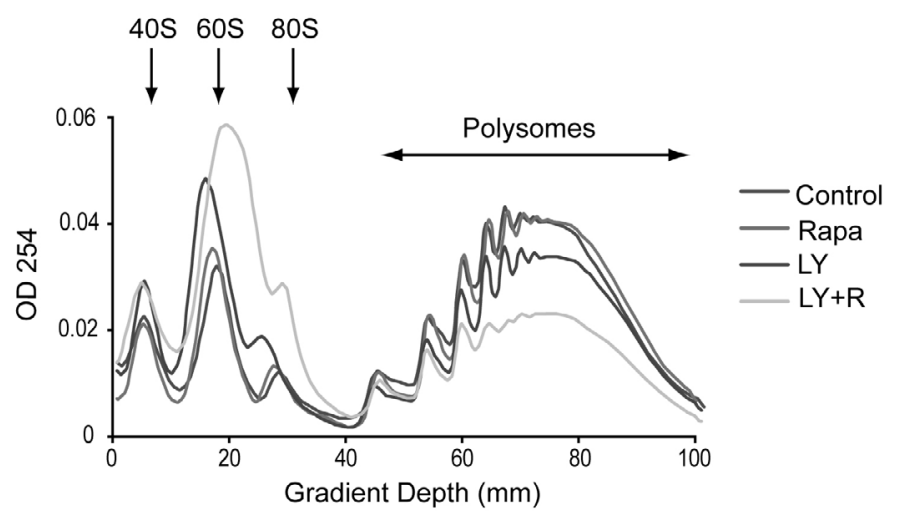

E

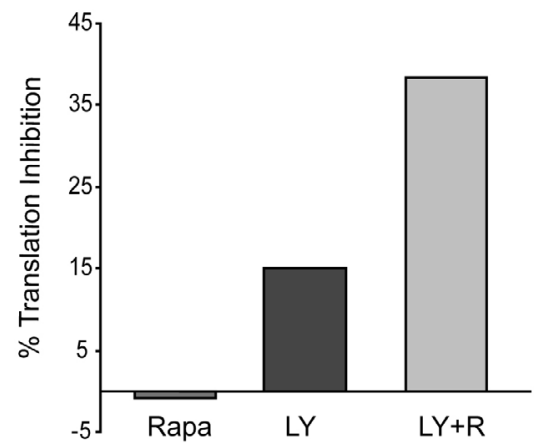




\section{Rapamycin and LY294002 inhibit translation initiation in a 4E-BP1 dependent manner}

The phosphorylation of 4E-BP1 at Ser65 and Thr70 has been demonstrated to correlate with release of its binding partner elF4E (14), and thus its functional ability to regulate mRNA translation initiation. Consistent with these data, we found that treatment with rapamycin and LY294002 resulted in a greater increase in the amount of 4E-BP1 associated with affinity-purified elF4E when compared to treatment with either inhibitor alone (Figure 1c). At the same time, a similar decrease in the binding of elF4GI to elF4E was observed, suggesting that translation initiation could be more effectively inhibited after combined treatment with both inhibitors.

The functional importance of changes in 4E-BP1 phosphorylation and elF4E association to mRNA translation was investigated by analyzing changes in polysome distributions after inhibition of mTORC1 and/or PI3K (Figure 1d and e). Despite its clear ability to inhibit mTORC1 and block p70S6K phosphorylation, treatment with rapamycin for $2 \mathrm{~h}$ caused no significant change in the amount of polysomal RNA or the distribution of $40 \mathrm{~S}, 60 \mathrm{~S}$ or $80 \mathrm{~S}$ ribosome subunits. LY294002 alone caused a small (15\%) decrease in polysome-associated RNA, with a concomitant increase in free ribosome subunits. However, the combination of rapamycin and LY294002 resulted in a large drop in mRNA translation (a $38 \%$ decrease in the area under the polysome region of the curve).

Although changes in mRNA translation correlated well with 4E-BP1 Ser65 and Thr70 phosphorylation upon inhibition of both mTORC1 and PI3K, these data do not definitely demonstrate that 4E-BP1 is responsible for this effect. The drop in translation was not due to toxicity, since rapamycin and LY294002 caused no significant change in clonogenic survival even after a $24 \mathrm{~h}$ treatment (Figure S2). To more directly assess the requirement for 4E$\mathrm{BP} 1$ in the inhibition of translation we created a stable knock-down of 4E-BP1 in U87 cells using RNA interference. U87-sh4E-BP1 cells showed no significant difference in their polysome profiles compared to U87 cells carrying the empty vector (pRS) when grown under normal conditions (Figure 2a and b). However when treated with rapamycin and LY294002, we observed a significantly smaller decrease (21\%) of polysomal RNA in U87-sh4EBP1 cells compared with the U87-pRS cells (36\%) (Figure 2c). These data indicate that translation inhibition caused by rapamycin and LY294002 is largely dependent upon the functional activation of 4E-BP1. 

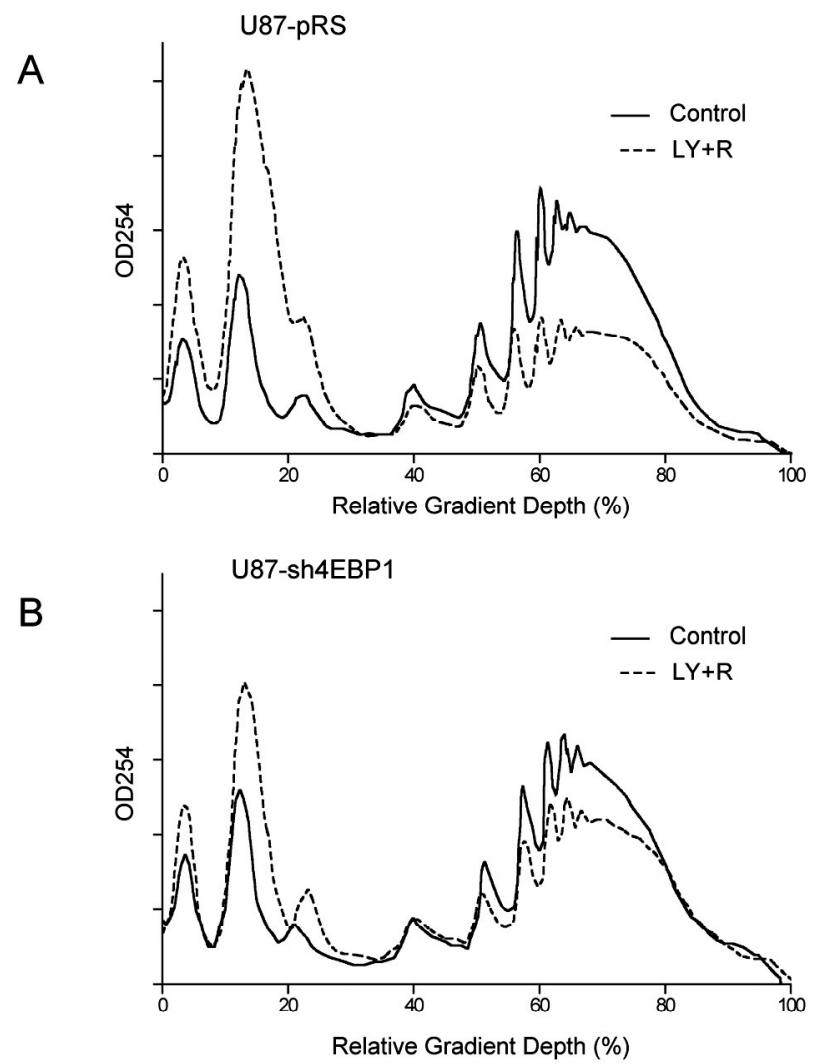

C

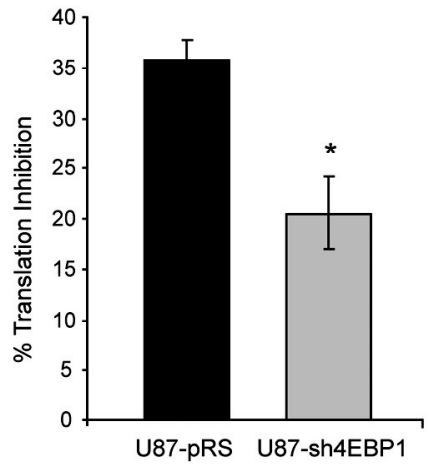

Figure 2. The combination of LY294002 and rapamycin inhibits translation in a 4E-BP1 dependent manner. U87 cells expressing either a stable short-hairpin RNA against 4E-BP1 (U87sh4EBP1) (b) or the empty pRetroSuper vector (U87-pRS) (a) were treated for $2 \mathrm{~h}$ with 10uM LY294002 and 10nM rapamycin and subjected to polysome analysis. (c) Translation inhibition was calculated as described in figure $1 \mathrm{e}$ and is presented as the mean of 4 independent experiments \pm standard error. ${ }^{*} P=0.01$. 


\section{The response of 4E-BP1 phosphorylation to mTORC1 and PI3K inhibition is PTEN independent}

A frequent characteristic of glioblastoma cell lines, including U87, is the loss of PTEN expression (38). Since this can lead to upregulation of signaling downstream of PI3K, including mTOR activation, we determined whether loss of PTEN altered the regulation of 4E-BP1 in this cell line. We assessed changes in 4E-BP1 phosphorylation after short treatments with rapamycin and LY294002 in U87 cells containing an inducible-PTEN construct. PTEN expression could clearly be detected in these cells after $24 \mathrm{~h}$ incubation with ponasterone A (Figure 3). However, the presence of PTEN did not lead to any changes in the response of 4E-BP1 phosphorylation to rapamycin and/or LY294002 (Figure 3).

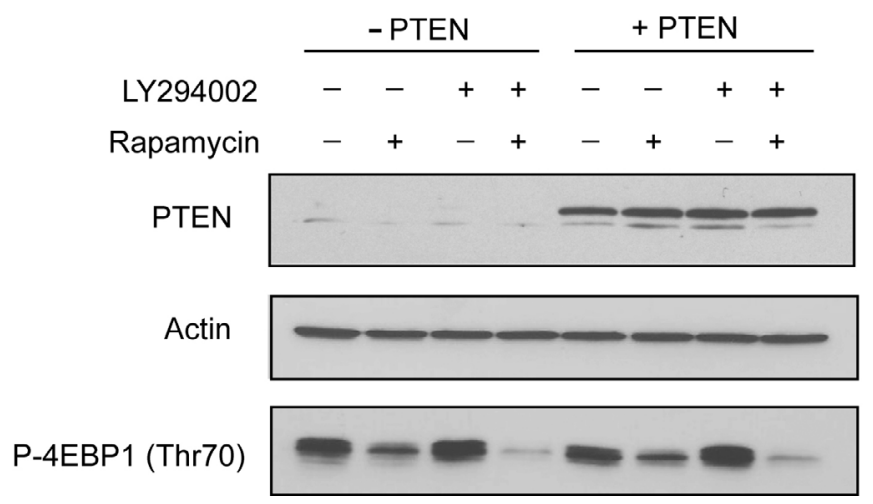

Figure 3. PTEN expression does not influence the change in 4E-BP1 phosphorylation elicited by LY294002 and rapamycin. U87 cells containing an ecdysone-inducible PTEN expression vector were treated with $500 \mathrm{nM}$ ponasterone A to initiate PTEN expression. $24 \mathrm{~h}$ later, the cells were treated with $10 \mathrm{nM}$ rapamycin and/or $10 \mu \mathrm{M}$ LY294002 for an additional $2 \mathrm{~h}$. Cell extracts were verified for induction of PTEN and analyzed for 4E-BP1 phosphorylation at Thr70.

We also examined a number of other cell lines from a variety of different tissue types to determine if the cooperative effect of rapamycin and LY294002 was a common phenomenon. Six out of eight cell lines tested showed an additional antagonistic effect on 4E-BP1 phosphorylation when LY294002 was added to rapamycin (Table 1). 4E-BP1 phosphorylation in DU145 prostate carcinoma and HCT116 colon carcinoma was sensitive to either inhibitor alone, and thus the combination had no further effect. The enhanced effectiveness of rapamycin and LY294002 does not seem to be restricted to transformed cells, as it was also observed in diploid Tig3-hTERT fibroblasts (Table 1). There was no correlation between the presence of PTEN and the co- 
operative effect of rapamycin and LY294002 in the panel of cell lines that we examined. Therefore, the synergistic response of 4E-BP1 to mTORC1 and $\mathrm{PI} 3 \mathrm{~K}$ inhibition is present in normal cells as well as the majority of tumor cell lines investigated, and is not determined by PTEN status.

Table 1.

Response of 4E-BP1 Ser65 phosphorylation to rapamycin and LY294002 in various cell lines.

\begin{tabular}{|l|l|l|l|l|}
\hline Cell Line & Tissue Type & $\begin{array}{l}\text { PTEN } \\
\text { status }\end{array}$ & $\begin{array}{l}\text { Inhibition of 4E-BP1 } \\
\text { Phosphorylation in } \\
\text { Response to Rapamy- } \\
\text { cin Alone }\end{array}$ & $\begin{array}{l}\text { Additional } \\
\text { Effect of Ra- } \\
\text { pamycin + } \\
\text { LY294002 } \\
\text { Combination }\end{array}$ \\
\hline U87 & Glioblastoma & Negative & partial & Yes \\
\hline U373 & Glioma & Negative & partial & Yes \\
\hline DU145 & Prostate Carcinoma & Positive & complete & No \\
\hline HeLa & $\begin{array}{l}\text { Cervix Adenocarci- } \\
\text { noma }\end{array}$ & Positive & partial & Yes \\
\hline A549 & Lung Carcinoma & Positive & partial & Yes \\
\hline HT29 & $\begin{array}{l}\text { Colorectal Adenocar- } \\
\text { cinoma }\end{array}$ & Positive & partial & Yes \\
\hline HCT116 & $\begin{array}{l}\text { Colorectal Carcinoma } \\
\text { blasts }\end{array}$ & Positive & complete & No \\
\hline
\end{tabular}

\section{Specificity of LY294002 and rapamycin as inhibitors of mTORC1 and PI3K}

LY294002 binds the ATP-binding pocket of PI3K and is known to partially inhibit other kinases with a similar catalytic domain such as DNA-PK and even mTOR (39). To obtain independent pharmacological proof that the PI3K pathway is involved in the observed synergistic inhibition of 4E-BP1 phosphorylation, we used rapamycin in combination with other structurally unrelated inhibitors of the PI3K/Akt pathway. The PI3K inhibitor wortmannin produced results similar to LY294002, causing only marginal inhibition of 4EBP1 phosphorylation on its own, but complete inhibition in combination with rapamycin (Figure 4a). The concentrations of both LY294002 and wortmannin that were used in this experiment were sufficient to inhibit phosphorylation 
of Akt. Rapamycin on the other hand, did not have any appreciable effect on Akt phosphorylation at Ser473. More importantly, inhibition of Akt in U87 cells with the Akt1/2 inhibitor (Akti-1/2) also resulted in only a small inhibition of 4E-BP1 phosphorylation on its own, but a near complete attenuation of Ser65 phosphorylation when given in combination with rapamycin (Figure 4b). Taken together, these results reinforce the existence of a PI3K/Akt dependent pathway that signals to $4 \mathrm{E}-\mathrm{BP} 1$ in an mTORC1 independent manner.

Rapamycin is considered to be one of the most specific small molecule inhibitors known due to its formation of a stable complex with both FKBP12 and mTOR. The biological consequences of rapamycin are largely assumed to result from inhibition of mTORC1, since it us unable to block mTOR activity of the TORC2 complex. However, it remains possible that rapamycin affects mTOR activities that are separate from that associated with mTORC1. In order to assess the contribution of combined mTORC1 and PI3K inhibition on 4E-BP1 regulation independently of rapamycin, we used a genetic approach to inhibit the mTORC1 specific protein raptor. Figure 4c shows that we were able to attain near complete loss of detectable raptor protein using siRNA. Inhibition of raptor reduced the basal levels of 4E-BP1 phosphorylation at Ser65 to levels similar to those caused by treatment of the parental cells with rapamycin or LY294002 alone (Figure 4c). Importantly, treatment of the raptor knockdown cells with LY294002 resulted in complete loss of 4E-BP1 Ser65 phosphorylation. These data support mTORC1 as the target of rapamycin in the synergistic effect observed on 4E-BP1 phosphorylation in combination with $\mathrm{PI} 3 \mathrm{~K}$ inhibition. Knockdown of raptor also led to a small decrease in mTOR protein, possibly due to destabilization of the mTORC1 complex. However, this is unlikely to have influenced 4E-BP1 phosphorylation since knockdown of mTOR to $\sim 50 \%$ of control levels had no significant effect on the basal or inhibitor treated levels of 4EBP1 Ser65 phosphorylation (Figure S3). Consequently mTOR protein levels do not seem to be rate limiting for mTORC1 activity. As expected, rictor siRNA also did not promote 4EBP1 dephosphorylation either basally or after treatment with rapamycin (data not shown). 
A
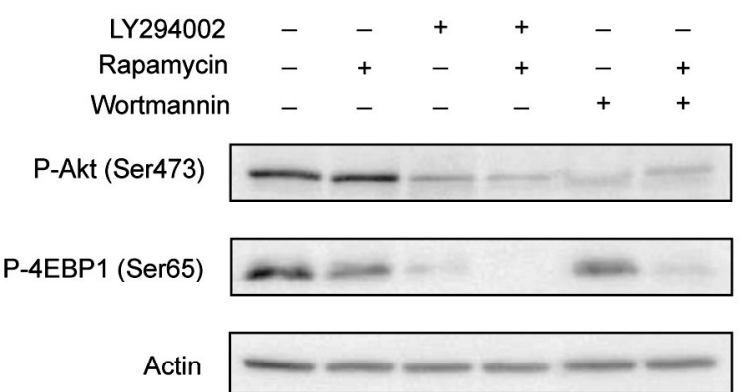

B

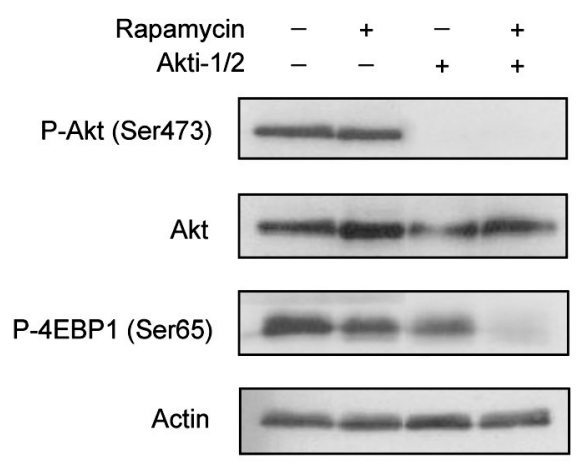

C

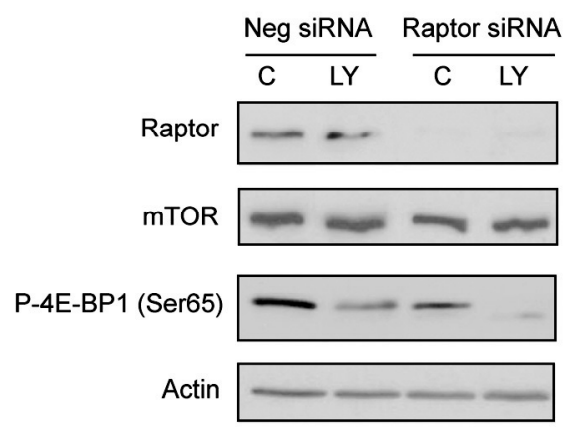

Figure 4. Multiple inhibitors of the PI3K pathway act synergistically with mTORC1 inhibition to decrease 4E-BP1 phosphorylation. (a) U87 cells were treated for $2 \mathrm{~h}$ with $10 \mathrm{nM}$ rapamycin in combination with 10uM LY294002 or 200nM wortmannin. Western blotting was performed using antibodies against phospho-Akt (Ser 473), phospho-4EBP1 (Ser65) and actin. (b) U87 cells were treated for $2 \mathrm{~h}$ with $10 \mathrm{nM}$ rapamycin and/or $25 \mathrm{uM}$ of an isoform specific Akt inhibitor (Akti-1/2). (c) U87 cells were transfected with siRNA against raptor or a non-targeting negative control siRNA. $72 \mathrm{~h}$ after transfection cells were treated for an additional $2 \mathrm{~h}$ with 10uM LY294002. Expression of raptor, mTOR, and actin protein was detected by Western blot, as well as phosphorylation of 4E-BP1 at Ser65. 


\section{Discussion}

Our data demonstrate differential sensitivity of the mTOR targets p70S6K and 4EBP1 to inhibition of the mTORC1 and PI3K signaling pathways. Whereas inhibition of PI3K or mTORC1 was sufficient to rapidly block p70S6K phosphorylation, inhibition of both was necessary to cause complete dephosphorylation of 4E-BP1 at Thr70 and Ser65. Inhibition of both targets also resulted in a clear functional effect as evidenced by a rapid decrease in translation initiation that was largely dependent upon 4E-BP1 expression. These data suggest that the phosphorylation and inactivation of 4E-BP1 binding to elF4E is maintained so long as either of these signaling pathways is activated. This cooperative interaction of PI3K and mTORC1 signaling was observed in the majority of cell types investigated, including normal human fibroblasts. However, rapamycin was effective as a single agent in two tumor types (see table 1) indicating that cancer associated changes may lead to defects that can be exploited by single agent treatment. Nonetheless, our results suggest that dual inhibition of $\mathrm{MTORC} 1$ and PI3K is a far more effective approach to activate 4E-BP1 and inhibit mRNA translation initiation compared with rapamycin alone. Furthermore, we could reproduce these results using various combinations of inhibitors or siRNAs that selectively targeted the PI3K or mTORC1 pathways, demonstrating the specificity of the interaction. The fact that phosphorylation of 4EBP1 at Thr70 and Ser65 is maintained in cells treated with rapamycin or PI3K inhibitors alone, may explain previously reported results demonstrating the requirement for inhibition of both PI3K and mTOR to suppress the translational changes mediated by oncogenic Ras and Akt (40).

Based on our observations, we propose a model whereby 4E-BP1 phosphorylation is mediated independently through both mTORC1 and PI3K/Akt pathways (Figure 5). In this model, PI3K/Akt signaling is playing substantially different roles in maintenance of the phosphorylation status of individual mTORC1 targets. In the case of p70S6K (Thr389), PI3K/Akt signaling functions via its well-described ability to regulate $\mathrm{mTORC} 1$, presumably through negative regulation of the TSC1/2 complex (Figure 5a). Consequently, inhibition of either PI3K or mTORC1 is sufficient to block phosphorylation of this target. In the case of 4E-BP1 phosphorylation, PI3K/Akt is playing a different role that, to a large extent, occurs independently of mTOR. mTORC1 activity on 4E-BP1 also appears much less dependent on PI3K signaling compared to p70S6K. Although we cannot rule out that some of the effects of PI3K or Akt inhibition may be mTORC1 dependent, an important mTORC1 activity on 4EBP1 remains in cells treated with PI3K or Akt inhibitors. This is evidenced by the requirement for rapamycin or raptor knockdown in combination with 
PI3K inhibition to cause significant changes in phosphorylation and activity of 4E-BP1. The fact that PI3K inhibition blocks mTORC1 activity against p70S6K but not 4E-BP1 suggests that mTORC1 complexes may display some degree of substrate specificity that is dependent on the activation status of upstream signaling pathways. The activation of pathways regulating mTORC1 other than PI3K, such as AMPK or GSK3 (41) may help to explain why PI3K inhibitors are ineffective as single agents to block 4E-BP1 phosphorylation.

a)

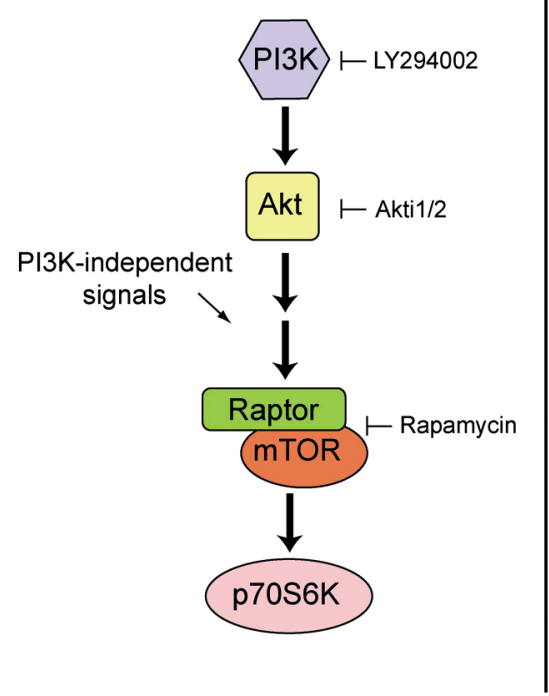

b)

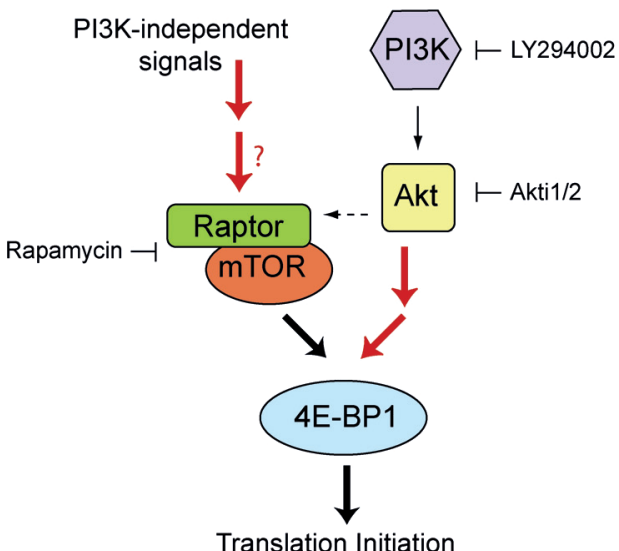

Translation Initiation

Figure 5. Model of the pathways responsible for differential phosphorylation sensitivity of the mTORC1 targets p70S6K and 4E-BP1. p70S6K and 4E-BP1 are both phosphorylated by mTORC1 dependent activity that is regulated upstream by signaling from PI3K as well as other non-PI3K signals. a) In the case of p70S6K, phosphorylation is dependent on both PI3K and mTORC1 signaling and is suppressed upon inhibition of either pathway alone. b) 4E-BP1 phosphorylation is additionally regulated by PI3K/Akt dependent inputs that do not require mTORC1. Phosphorylation of 4E-BP1 on Thr70 and Ser65 is maintained unless both PI3K or Akt and mTORC1 are inhibited (new pathway shown in red). The requirement for rapamycin or raptor knockdown for inhibition of 4E-BP1 phosphorylation in cells treated with PI3K or Akt inhibitors also implies that unlike p70S6K, mTORC1 dependent phosphorylation of 4E-BP1 is not sensitive to PI3K inhibition. We speculate that additional upstream regulatory pathways are important for this activity (pathway in red arrows).

Although the exact mechanisms responsible for the synergistic effects of mTORC1 and PI3K inhibition on 4E-BP1 remain to be elucidated, we envisage several possibilities. First, it is possible that both pathways independently regulate kinase activity on Thr70 or Ser65 and thus inhibition of either is insufficient to prevent phosphorylation on these sites. Although, there is little 
evidence that these sites on 4E-BP1 are direct targets of either mTOR or Akt, these pathways may regulate an additional kinase that has specificity for $4 \mathrm{E}$ $\mathrm{BP} 1$. Second, it is equally possible that the PI3K and mTORC1 pathways regulate a phosphatase complex that acts on Thr70 and/or Ser65. In this case, the phosphatase complex would have to be negatively regulated independently by these two pathways. The fact that we observed rapid loss in phosphorylation without noticeable changes in Thr37/46 phosphorylation would support this possibility. Unfortunately, the process of 4E-BP1 dephosphorylation is much more poorly understood than its phosphorylation. Third, the process of 4E-BP1 phosphorylation occurs in a hierarchical fashion and is likely mediated by several independent protein kinases that may or may not be associated with mTORC1. The requirement for kinases other than mTOR at particular steps during the phosphorylation sequence may also explain the requirement for dual inhibition of both pathways. Several publications have alluded to an mTOR-associated kinase responsible for phosphorylation of 4E-BP1 C-terminal residues that can influence the phosphorylation of other sites $(6,42)$.

Recently, it has been reported that silencing or inactivating mTOR can paradoxically enhance the inhibitory effect of rapamycin $(43,44)$. This suggests yet another possibility, that LY294002, by inhibiting mTOR catalytic activity (rather than PI3K), could sensitize cells to rapamycin. While we cannot rule out direct effects of LY294002 on mTOR activity, this effect is unlikely to explain the general cooperative outcome on 4E-BP1 observed in our studies since we also found a synergistic interaction with rapamycin and an Akt inhibitor. Since Akt1/2 targets the plekstrin homology domain/hinge region of Akt and mTOR does not contain any structurally similar domains, we do not expect that this inhibitor would bind or inactivate mTOR. Furthermore, targeting the mTORC1 complex by knockdown of raptor with siRNA also showed co-operativity with PI3K inhibition whereas moderate knockdown of mTOR itself did not.

Independent arguments for combining mTORC1 and Akt inhibitors follow from previous data demonstrating the existence of a negative-feedback pathway from mTORC1 via IRS-1 that regulates Akt activation (45). This feedback mechanism can be activated by rapamycin in some cell types and can stimulate the phosphorylation of Akt. Although rapamycin has been shown to induce Akt activation in U87 cells (46), no increase in Ser473 phosphorylation was observed after the relatively short $2 \mathrm{~h}$ incubation period used throughout our study (Figure $4 \mathrm{a}$ and $4 \mathrm{~b}$ ). Therefore, it is unlikely that this negative-feedback pathway contributes in any significant way to the synergistic effects on 4E-BP1 reported in this study. However, these data suggest 
that combining rapamycin with a $\mathrm{PI} 3 \mathrm{~K}$ or Akt inhibitor may not only cooperate in blocking 4E-BP1 phosphorylation, but also on blockade of compensatory Akt activation.

The relative importance of different mTOR effectors as determinants or targets of cancer treatment is not well understood, although 4E-BP1 and its ability to regulate mRNA translation initiation has been implicated in some situations (8). Our data demonstrate that combined treatment with rapamycin and a PI3K inhibitor results in a rapid inhibition of 4E-BP1 phosphorylation and a corresponding inhibition of cap-dependent translation. Rapamycin alone led to virtually no change in mRNA translation at this time point, even though p70S6K phosphorylation was clearly inhibited. We propose that treatment with rapamycin or its analogues may be substantially more clinically effective when phosphorylation of 4E-BP1 and thus translation initiation, can be inhibited. In this regards, it would be interesting to determine if changes in 4E-BP1 phosphorylation at short times after treatment might have predictive value for rapamycin efficacy. In view of the fact that deregulation of mRNA translation is a common feature of many cancers and represents a critical function downstream of commonly mutated oncogenes and tumor suppressor genes (47), targeting mTORC1 together with PI3K/Akt represents a promising therapeutic strategy.

\section{Supplementary figures}

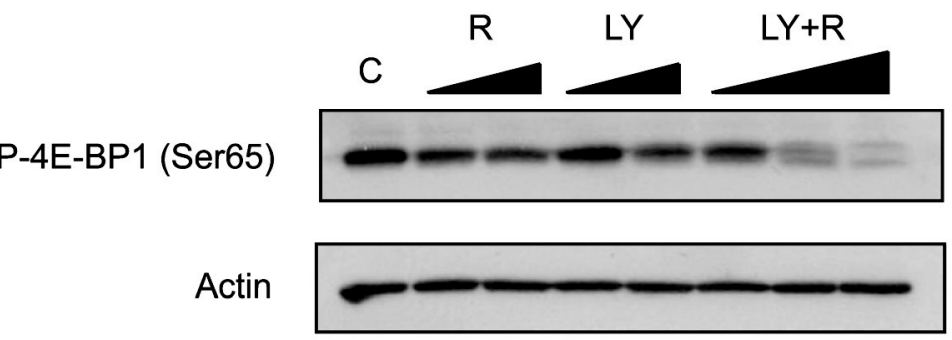

Figure S1. Dose response of 4E-BP1 Ser65 phosphorylation to rapamaycin and LY294002. U87 cells were treated with increasing concentrations of rapamycin (R) or LY294002 (LY) or with the two inhibitors in combination $(L Y+R)$ for a period of $2 \mathrm{~h}$. Lanes from left to right are: untreated cells (C), $10 \mathrm{nM}$ R, $100 \mathrm{nM} \mathrm{R}, 5 \mu \mathrm{M} L Y, 10 \mu \mathrm{M} \mathrm{LY}, 10 \mathrm{nM} \mathrm{R}+1 \mu \mathrm{M} \mathrm{LY}, 10 \mathrm{nM} \mathrm{R}+5 \mu \mathrm{M}$ LY, and $10 \mathrm{nM} R+10 \mu \mathrm{M} L Y$. 


\section{Chapter 6}

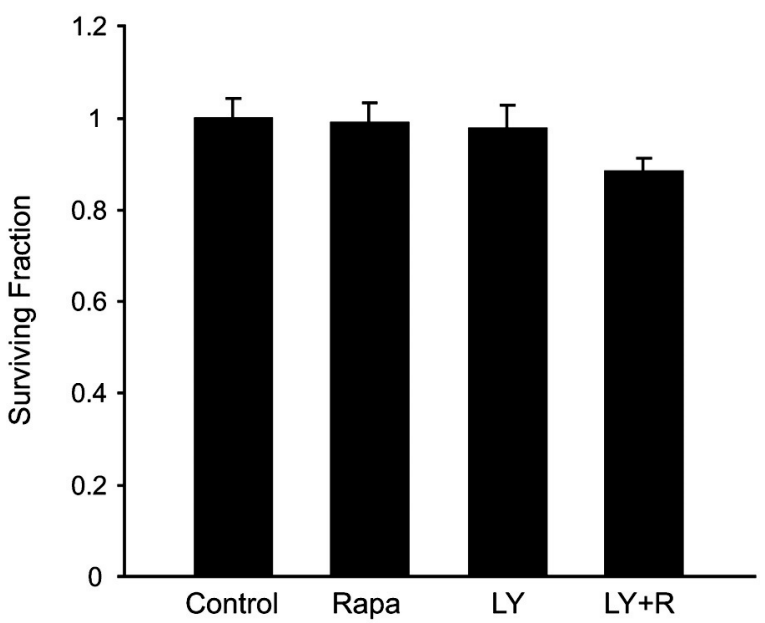

Figure S2. The combination of $\mathrm{mTOR}$ and PI3K inhibition yields insignificant toxicity. A549 cells were treated for $24 \mathrm{~h}$ with $10 \mathrm{nM}$ rapamycin and/or $10 \mu \mathrm{M}$ LY294002 at which times cells were seeded for clonogenic survival. Colonies were counted 12 days later and the surviving fraction was normalized to the plating efficiency of untreated cells. The mean surviving fraction \pm standard error $(n=6)$ is depicted. Survival of Control compared to $L Y+R$ is not significantly different; $P$ $=0.06$.

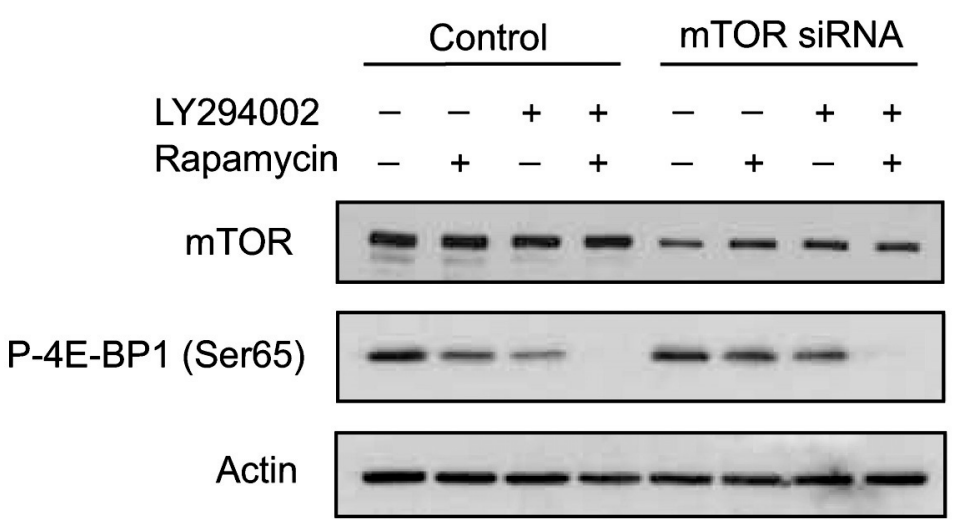

Figure S3. Partial silencing of mTOR expression does not influence 4E-BP1 Ser65 phosphorylation. U87 cells were transfected with siRNA targeting mTOR. $72 \mathrm{~h}$ later, cells were treated with $10 \mathrm{nM}$ rapamycin and/or $10 \mu \mathrm{M}$ LY294002. Western blots were performed to validate the knock-down of mTOR protein levels, as well as to investigate the phosphorylation of $4 \mathrm{E}$ BP1 at Ser65. 


\section{References}

1. Guertin, D. A. and Sabatini, D. M. Defining the role of mTOR in cancer. Cancer Cell, 12: 922, 2007.

2. Hara, K., Maruki, Y., Long, X., Yoshino, K., Oshiro, N., Hidayat, S., Tokunaga, C., Avruch, J., and Yonezawa, K. Raptor, a binding partner of target of rapamycin (TOR), mediates TOR action. Cell, 110: 177-189, 2002.

3. Sabatini, D. M. mTOR and cancer: insights into a complex relationship. Nat Rev Cancer, 6: 729-734, 2006.

4. Jacinto, E., Loewith, R., Schmidt, A., Lin, S., Ruegg, M. A., Hall, A., and Hall, M. N. Mammalian TOR complex 2 controls the actin cytoskeleton and is rapamycin insensitive. Nat Cell Biol, 6: 1122-1128, 2004.

5. Sarbassov, D. D., Guertin, D. A., Ali, S. M., and Sabatini, D. M. Phosphorylation and regulation of Akt/PKB by the rictor-mTOR complex. Science, 307: 1098-1101, 2005.

6. Wang, X., Beugnet, A., Murakami, M., Yamanaka, S., and Proud, C. G. Distinct signaling events downstream of mTOR cooperate to mediate the effects of amino acids and insulin on initiation factor 4E-binding proteins. Mol Cell Biol, 25: 2558-2572, 2005.

7. Cai, S. L., Tee, A. R., Short, J. D., Bergeron, J. M., Kim, J., Shen, J., Guo, R., Johnson, C. L., Kiguchi, K., and Walker, C. L. Activity of TSC2 is inhibited by AKT-mediated phosphorylation and membrane partitioning. J Cell Biol, 173: 279-289, 2006.

8. Wendel, H. G., De Stanchina, E., Fridman, J. S., Malina, A., Ray, S., Kogan, S., CordonCardo, C., Pelletier, J., and Lowe, S. W. Survival signalling by Akt and elF4E in oncogenesis and cancer therapy. Nature, 428: 332-337, 2004.

9. Hay, N. and Sonenberg, N. Upstream and downstream of mTOR. Genes Dev, 18: 19261945, 2004.

10. Larsson, O., Li, S., Issaenko, O. A., Avdulov, S., Peterson, M., Smith, K., Bitterman, P. B., and Polunovsky, V. A. Eukaryotic translation initiation factor $4 \mathrm{E}$ induced progression of primary human mammary epithelial cells along the cancer pathway is associated with targeted translational deregulation of oncogenic drivers and inhibitors. Cancer Res, 67: 6814-6824, 2007.

11. Richter, J. D. and Sonenberg, N. Regulation of cap-dependent translation by elF4E inhibitory proteins. Nature, 433: 477-480, 2005.

12. Armengol, G., Rojo, F., Castellvi, J., Iglesias, C., Cuatrecasas, M., Pons, B., Baselga, J., and Ramon, Y. C. S. 4E-Binding Protein 1: A Key Molecular "Funnel Factor" in Human Cancer with Clinical Implications. Cancer Res, 67: 7551-7555, 2007.

13. Zhou, X., Tan, M., Stone Hawthorne, V., Klos, K. S., Lan, K. H., Yang, Y., Yang, W., Smith, T. L., Shi, D., and Yu, D. Activation of the Akt/mammalian target of rapamycin/4E-BP1 pathway by ErbB2 overexpression predicts tumor progression in breast cancers. Clin Cancer Res, 10: 6779-6788, 2004.

14. Gingras, A. C., Gygi, S. P., Raught, B., Polakiewicz, R. D., Abraham, R. T., Hoekstra, M. F., Aebersold, R., and Sonenberg, N. Regulation of 4E-BP1 phosphorylation: a novel two-step mechanism. Genes Dev, 13: 1422-1437, 1999.

15. Gingras, A. C., Raught, B., Gygi, S. P., Niedzwiecka, A., Miron, M., Burley, S. K., Polakiewicz, R. D., Wyslouch-Cieszynska, A., Aebersold, R., and Sonenberg, N. Hierarchical phosphorylation of the translation inhibitor 4E-BP1. Genes Dev, 15: 2852-2864, 2001.

16. Mothe-Satney, I., Brunn, G. J., McMahon, L. P., Capaldo, C. T., Abraham, R. T., and Lawrence, J. C., Jr. Mammalian target of rapamycin-dependent phosphorylation of PHAS-I in four (S/T)P sites detected by phospho-specific antibodies. J Biol Chem, 275: 33836-33843, 2000.

17. Wang, X., Li, W., Parra, J. L., Beugnet, A., and Proud, C. G. The C terminus of initiation factor 4E-binding protein 1 contains multiple regulatory features that influence its function and phosphorylation. Mol Cell Biol, 23: 1546-1557, 2003.

18. Averous, J. and Proud, C. G. When translation meets transformation: the mTOR story. Oncogene, 25: 6423-6435, 2006.

19. Huang, S., Bjornsti, M. A., and Houghton, P. J. Rapamycins: mechanism of action and cellular resistance. Cancer Biol Ther, 2: 222-232, 2003.

20. Kim, D. H., Sarbassov, D. D., Ali, S. M., King, J. E., Latek, R. R., Erdjument-Bromage, H., Tempst, P., and Sabatini, D. M. mTOR interacts with raptor to form a nutrient-sensitive complex that signals to the cell growth machinery. Cell, 110: 163-175, 2002. 
21. Oshiro, N., Yoshino, K., Hidayat, S., Tokunaga, C., Hara, K., Eguchi, S., Avruch, J., and Yonezawa, K. Dissociation of raptor from mTOR is a mechanism of rapamycin-induced inhibition of mTOR function. Genes Cells, 9: 359-366, 2004.

22. Sarbassov, D. D., Ali, S. M., Kim, D. H., Guertin, D. A., Latek, R. R., Erdjument-Bromage, H., Tempst, P., and Sabatini, D. M. Rictor, a novel binding partner of mTOR, defines a rapamycin-insensitive and raptor-independent pathway that regulates the cytoskeleton. Curr Biol, 14: 1296-1302, 2004.

23. Sarbassov, D. D., Ali, S. M., Sengupta, S., Sheen, J. H., Hsu, P. P., Bagley, A. F., Markhard, A. L., and Sabatini, D. M. Prolonged rapamycin treatment inhibits mTORC2 assembly and Akt/PKB. Mol Cell, 22: 159-168, 2006.

24. Noh, W. C., Mondesire, W. H., Peng, J., Jian, W., Zhang, H., Dong, J., Mills, G. B., Hung, M. C., and Meric-Bernstam, F. Determinants of rapamycin sensitivity in breast cancer cells. Clin Cancer Res, 10: 1013-1023, 2004.

25. Yu, K., Toral-Barza, L., Discafani, C., Zhang, W. G., Skotnicki, J., Frost, P., and Gibbons, J. J. mTOR, a novel target in breast cancer: the effect of CCl-779, an mTOR inhibitor, in preclinical models of breast cancer. Endocr Relat Cancer, 8: 249-258, 2001.

26. Aoki, M., Blazek, E., and Vogt, P. K. A role of the kinase mTOR in cellular transformation induced by the oncoproteins P3k and Akt. Proc Natl Acad Sci U S A, 98: 136-141, 2001.

27. Neshat, M. S., Mellinghoff, I. K., Tran, C., Stiles, B., Thomas, G., Petersen, R., Frost, P., Gibbons, J. J., Wu, H., and Sawyers, C. L. Enhanced sensitivity of PTEN-deficient tumors to inhibition of FRAP/mTOR. Proc Natl Acad Sci U S A, 98: 10314-10319, 2001.

28. Buck, E., Eyzaguirre, A., Brown, E., Petti, F., McCormack, S., Haley, J. D., Iwata, K. K., Gibson, N. W., and Griffin, G. Rapamycin synergizes with the epidermal growth factor receptor inhibitor erlotinib in non-small-cell lung, pancreatic, colon, and breast tumors. Mol Cancer Ther, 5: 2676-2684, 2006.

29. Mabuchi, S., Altomare, D. A., Cheung, M., Zhang, L., Poulikakos, P. I., Hensley, H. H., Schilder, R. J., Ozols, R. F., and Testa, J. R. RAD001 inhibits human ovarian cancer cell proliferation, enhances cisplatin-induced apoptosis, and prolongs survival in an ovarian cancer model. Clin Cancer Res, 13: 4261-4270, 2007.

30. Takeuchi, H., Kondo, Y., Fujiwara, K., Kanzawa, T., Aoki, H., Mills, G. B., and Kondo, S. Synergistic augmentation of rapamycin-induced autophagy in malignant glioma cells by phosphatidylinositol 3-kinase/protein kinase B inhibitors. Cancer Res, 65: 3336-3346, 2005.

31. Fukami, J., Anno, K., Ueda, K., Takahashi, T., and Ide, T. Enhanced expression of cyclin D1 in senescent human fibroblasts. Mech Ageing Dev, 81: 139-157, 1995.

32. Weppler, S. A., Li, Y., Dubois, L., Lieuwes, N., Jutten, B., Lambin, P., Wouters, B. G., and Lammering, G. Expression of EGFR variant vlll promotes both radiation resistance and hypoxia tolerance. Radiother Oncol, 83: 333-339, 2007.

33. Stolarov, J., Chang, K., Reiner, A., Rodgers, L., Hannon, G. J., Wigler, M. H., and Mittal, V. Design of a retroviral-mediated ecdysone-inducible system and its application to the expression profiling of the PTEN tumor suppressor. Proc Natl Acad Sci U S A, 98: 1304313048, 2001.

34. Constantinou, C. and Clemens, M. J. Regulation of translation factors elF4GI and 4E-BP1 during recovery of protein synthesis from inhibition by p53. Cell Death Differ, 14: 576-585, 2007.

35. Koritzinsky, M., Magagnin, M. G., van den Beucken, T., Seigneuric, R., Savelkouls, K., Dostie, J., Pyronnet, S., Kaufman, R. J., Weppler, S. A., Voncken, J. W., Lambin, P., Koumenis, C., Sonenberg, N., and Wouters, B. G. Gene expression during acute and prolonged hypoxia is regulated by distinct mechanisms of translational control. Embo J, 25: 1114-1125, 2006.

36. Brummelkamp, T. R., Bernards, R., and Agami, R. Stable suppression of tumorigenicity by virus-mediated RNA interference. Cancer Cell, 2: 243-247, 2002.

37. Koritzinsky, M., Rouschop, K. M., van den Beucken, T., Magagnin, M. G., Savelkouls, K., Lambin, P., and Wouters, B. G. Phosphorylation of elF2alpha is required for mRNA translation inhibition and survival during moderate hypoxia. Radiother Oncol, 83: 353-361, 2007.

38. Ohgaki, H. and Kleihues, P. Genetic pathways to primary and secondary glioblastoma. Am J Pathol, 170: 1445-1453, 2007.

39. Brunn, G. J., Williams, J., Sabers, C., Wiederrecht, G., Lawrence, J. C., Jr., and Abraham, R. T. Direct inhibition of the signaling functions of the mammalian target of rapamycin by the phosphoinositide 3-kinase inhibitors, wortmannin and LY294002. Embo J, 15: 52565267, 1996. 
40. Rajasekhar, V. K., Viale, A., Socci, N. D., Wiedmann, M., Hu, X., and Holland, E. C. Oncogenic Ras and Akt signaling contribute to glioblastoma formation by differential recruitment of existing mRNAs to polysomes. Mol Cell, 12: 889-901, 2003.

41. Inoki, K., Ouyang, H., Zhu, T., Lindvall, C., Wang, Y., Zhang, X., Yang, Q., Bennett, C., Harada, Y., Stankunas, K., Wang, C. Y., He, X., MacDougald, O. A., You, M., Williams, B. O., and Guan, K. L. TSC2 integrates Wnt and energy signals via a coordinated phosphorylation by AMPK and GSK3 to regulate cell growth. Cell, 126: 955-968, 2006.

42. Heesom, K. J. and Denton, R. M. Dissociation of the eukaryotic initiation factor-4E/4E-BP1 complex involves phosphorylation of 4E-BP1 by an mTOR-associated kinase. FEBS Lett, 457: 489-493, 1999.

43. Edinger, A. L., Linardic, C. M., Chiang, G. G., Thompson, C. B., and Abraham, R. T. Differential effects of rapamycin on mammalian target of rapamycin signaling functions in mammalian cells. Cancer Res, 63: 8451-8460, 2003.

44. Iwamaru, A., Kondo, Y., Iwado, E., Aoki, H., Fujiwara, K., Yokoyama, T., Mills, G. B., and Kondo, S. Silencing mammalian target of rapamycin signaling by small interfering RNA enhances rapamycin-induced autophagy in malignant glioma cells. Oncogene, 26: 1840-1851, 2007.

45. Harrington, L. S., Findlay, G. M., Gray, A., Tolkacheva, T., Wigfield, S., Rebholz, H., Barnett, J., Leslie, N. R., Cheng, S., Shepherd, P. R., Gout, I., Downes, C. P., and Lamb, R. F. The TSC1-2 tumor suppressor controls insulin-PI3K signaling via regulation of IRS proteins. J Cell Biol, 166: 213-223, 2004.

46. Fan, Q. W., Knight, Z. A., Goldenberg, D. D., Yu, W., Mostov, K. E., Stokoe, D., Shokat, K. M., and Weiss, W. A. A dual PI3 kinase/mTOR inhibitor reveals emergent efficacy in glioma. Cancer Cell, 9: 341-349, 2006.

47. Bilanges, B. and Stokoe, D. Mechanisms of translational deregulation in human tumors and therapeutic intervention strategies. Oncogene, 26: 5973-5990, 2007. 



\section{CHAPTER 7}

Neuroendocrine carcinoma in BirtHogg-Dubé syndrome

Manuscript submitted

S.A. Weppler, T. Claessens, M. van Geel, D. Creytons, M. Vreeburg, B.G. Wouters, M.A.M. van Steensel. 


\title{
Chapter 7
}

\begin{abstract}
Birt-Hogg-Dubé syndrome (BHD) is a dominantly inherited disorder characterized by an increased risk of developing kidney cancer, pneumothorax as a consequence of lung cysts and benign hair follicle tumors called fibrofolliculomas. It is caused by mutations in the BHD gene, coding for folliculin (FLCN), a protein possibly involved in mTOR signaling. BHD syndrome is generally considered to be a relatively benign condition for which annual follow-up suffices. However, the possibility that the pre-existing gene defect might act to modify the behavior of other cancers that arise in patients with BHD syndrome has so far not been considered.
\end{abstract}

We describe a patient with BHD who succumbed to a malignant neuroendocrine tumor of prostatic or bladder origin within 6 months of its discovery. He also had a papillary renal cell carcinoma. We propose that the behavior of our patient's cancer might have been modulated by absence of the BHD gene. We demonstrate loss of FLCN in the tumor and show that it does not cause mTOR upregulation, contrary to previous findings in a mouse model. Our observation could possibly lead to a different approach towards BHD patient surveillance and treatment in the future. 


\section{Introduction}

Birt-Hogg-Dubé syndrome (BHD, MIM \#135150) is an autosomal-dominantly inherited cancer syndrome characterized by fibrofolliculomas, lung cysts leading to pneumothorax, and mainly chromophobic/oncocytic renal cell carcinoma (1). The disease is caused by heterozygous mutations in the BHD gene encoding folliculin (FLCN). Almost all human mutations reported so far lead to putative protein truncation (2). A conditional kidney-specific BHD knockout mouse displays activation of mTOR signaling (3). Thus, loss of FLCN may result in inappropriate mTOR activity. Considering that mTOR signaling is increasingly implicated in tumor progression (4) the spectrum of malignancies associated thus far with BHD syndrome seems limited. Studies of multiple extended pedigrees have so far not yielded any firm evidence to the contrary. We present a patient with BHD syndrome who developed a neuroendocrine carcinoma of prostate or bladder origin that behaved in a highly malignant fashion, causing our patient's demise within 6 months after his initial diagnosis. He also had fibrofolliculomas, lung cysts and a papillary renal cell carcinoma. We find loss of FLCN in the tumor and suggest that this may have contributed to tumorigenesis, although we find no evidence for mTOR deregulation in our patient's tissues.

\section{Materials and methods}

Immunohistochemical stainings were performed on frozen sections according to a standard protocol. Briefly, tissue samples were flash frozen in liquid nitrogen and transferred to $-80^{\circ} \mathrm{C}$ within one hour after sampling. $5 \mu \mathrm{m}$ sections were cut with a microtome at $-20^{\circ} \mathrm{C}$. For staining, slides were fixed in acetone for 10 minutes at $-20^{\circ} \mathrm{C}$ and washed twice in TBS, followed by an incubation with $\mathrm{H}_{2} \mathrm{O}_{2}(3 \%)$ in methanol for 10 minutes. After another washing step, slides were blocked (TBS/Triton X-100 0.3\%/goat serum 5\%) and primary antibody was added in a $1: 50$ dilution to be incubated overnight at $4^{\circ} \mathrm{C}$. Next, secondary antibody (goat anti-rabbit, 1:200) was added and incubated at room temperature for 30 minutes. The slides were then washed ( $3 \times 5$ minutes) in washing buffer. $A B C$ reagent was then added and incubated at room temperature for 30 minutes, followed by three wash steps with washing buffer. DAB was then added in $10 \mathrm{ml}$ washing buffer with $0.1 \% \mathrm{H}_{2} \mathrm{O}_{2}$ followed by rinsing in demineralized water during development of the stain. H\&E stained slides were used for orientation and histological examination. Photographs were taken using a Leica DM-4000 microscope with the Leica Application Suite software. 


\section{Case report}

The patient, a 50 year-old man of Dutch origin, was originally diagnosed with Birt-Hogg-Dubé syndrome in 2005 when he visited the outpatient clinic of the department of dermatology. Several family members were also found to be affected. Our findings in the family are described elsewhere (5). Using direct sequencing, we found a novel heterozygous insertion mutation 1408_1418delGGGAGCCCTGT in the BHD gene in all affected family members, including the present patient. Following local guidelines in place at the time, we performed abdominal CT imaging and found a homogeneous hypodense mass in the upper pole of the left kidney that the radiologist judged to be benign, possibly an oncocytoma. A wait-and-see policy was thus adopted, as the patient seemed otherwise healthy.

A year later, he visited the outpatient clinic of the department of urology because of visible hematuria since six months, particularly after exercise. There were no other complaints, with the exception of incidental hematospermia. Physical examination at the time showed no abnormalities. Rectal examination in particular was unremarkable. Routine lab examination showed the following normal results: ESR $11, \mathrm{Hb} 8.3 \mathrm{mmol} / \mathrm{l}$, Creatinine $74 \mu \mathrm{mol} / \mathrm{l}$, alkaline phosphatase $83 \mathrm{U} / \mathrm{l}$, gammaGT $23 \mathrm{U} / \mathrm{l}$ and PSA 1.0. Routine urinalysis was also normal. An abdominal CT-scan was performed and showed the previously found lesion in the left kidney, in addition to a hypodense mass in the left prostate lobe (figure 1a). An MRI likewise demonstrated the presence of a mass in the left prostate with extension underneath the bladder and into the mesorectal fat (figure 1b). At the time, it was interpreted as inflammatory. In an attempt to further characterize the process, a transrectal prostate biopsy was taken, which revealed only inflammatory changes. A malignancy was considered unlikely and the patient was discharged. About five months later, he developed acute urinary retention for which he was treated with alpha-sympathicolytic agents and a trans-urethral catheter. A trans-urethral prostate resection was attempted a month after the initial presentation. During surgery, a mass was seen on the posterior bladder wall, blocking the ureteric ostia. Tissue samples were taken and a suprapubic catheter was placed. A post-operative MRI of the abdomen showed a large pelvic mass and extensive lymphadenopathy (figure 2). The tumor invaded pelvic wall muscles, prostate, seminal vesicles and bladder. A second large tumor was seen that impinged upon the rectum. In addition, extensive lymphadenopathy was now present, in particular on the left para-iliacal side. A thoracic CT-scan did not show any evidence for intrathoracic metastases. Histopathological examination of the tissue samples obtained during surgery was consistent with a neuroendocrine carcinoma of unknown origin. Two weeks after surgery, the patient developed deep venous thrombosis of the left 
leg. Venous duplex ultrasound examination showed a thrombus in the left deep femoral vein. An abdominal CT scan, which was subsequently performed, demonstrated the presence of a mass in the left common iliac vein extending to the left renal vein. The patient was treated with LMW heparin for his thrombosis. The oncology department was consulted for chemotherapy, but a day after his CT scan the patient collapsed and passed away suddenly. Post-mortem examination was performed after the family gave their permission.
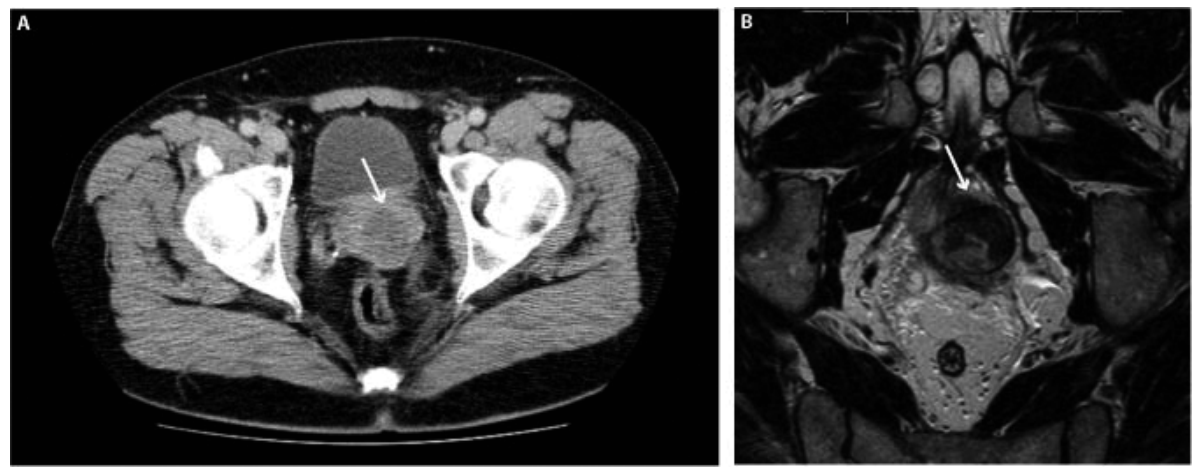

Figure 1. (a) CT scan made at initial presentation showing hypodense mass in the left prostate lobe (arrow). Contrast was enhanced to better demonstrate the lesion. (b) MRI (T1-weighted) at approximately the same anatomical level demonstrating a mass in the left prostate lobe that seems to invade the perirectal fat (arrow).

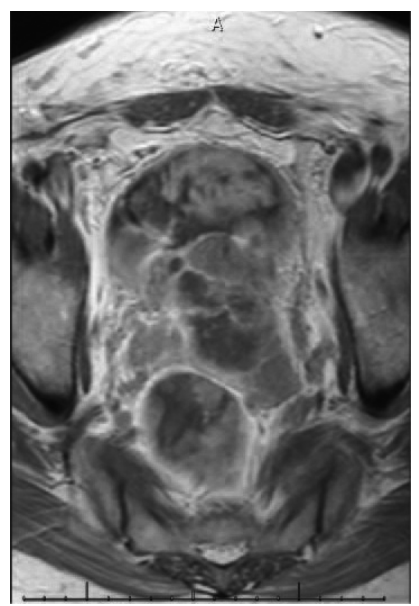

Figure 2. MRI (T1 weighted, contrast) made 5.5 months later illustrating dramatic progression of tumor growth (more cranial slice with respect to $1 \mathrm{~b}$ ). Note that the bladder is almost replaced by tumor. 


\section{Results}

During autopsy, the pulmonary arteries were found to contain multiple blood clots in addition to CD56 positive tumor cells. The upper pole of the left kidney contained a white-grey solid tumor with a diameter of $1.5 \mathrm{~cm}$. Histopathological examination was consistent with a diagnosis of papillary renal cell carcinoma (figure 3a). Examination of the pelvic basin revealed a large mostly necrotic tumor that almost replaced bladder and prostate with extension into the pelvis on the left, probably originating from within the left prostatic lobe. Microscopic examination showed a highly cellular tumor process with partly nodular growth. The cells had large nuclei of irregular shape and with a sometimes recognizable salt-and-pepper pattern (figure $3 b$ ). There were considerable mitotic activity and a large number of apoptotic cells. Extensive angio-invasive growth was seen. Immunohistochemical examination of material obtained during the postmortem showed the cells to be weakly positive for the neuroendocrine markers CD56 and NSE. Some positive vimentin staining was also observed. All other markers including MNF116, keratin 7, keratin 20, 34BE12, EMA, PSA, synaptofysin and TTF1 were negative (not shown). Although uncertain, a prostatic origin of this apparently highly malignant neuroendocrine tumor was considered likely. We next examined the patient's tumors and unaffected tissues for evidence of FLCN absence and mTOR activation. Not all samples were of sufficient quality to allow for adequate staining, possibly due to post-mortem degradation. Frozen sections from the neuroendocrine carcinoma showed absence of FLCN staining in the tumor tissue (figure 4a), while there was clear staining of infiltrating lymphocytes, which express FLCN (6). The tumor tissue did not stain significantly with an antibody directed against phosphorylated S6, a known target of mTOR complex 1 (mTORC1) (7) (figure 4b). We also examined unaffected patient and control skin, a fibrofolliculoma, unaffected kidney and the papillary renal cell carcinoma for evidence of mTOR activity. The renal carcinoma stained for phosphorylated mTOR (serine 2448), but so did unaffected kidney from the patient (figure $4 \mathrm{c}$, d). Skin gave the same results: basal keratinocytes stained in both the patient and a healthy control (not shown). 


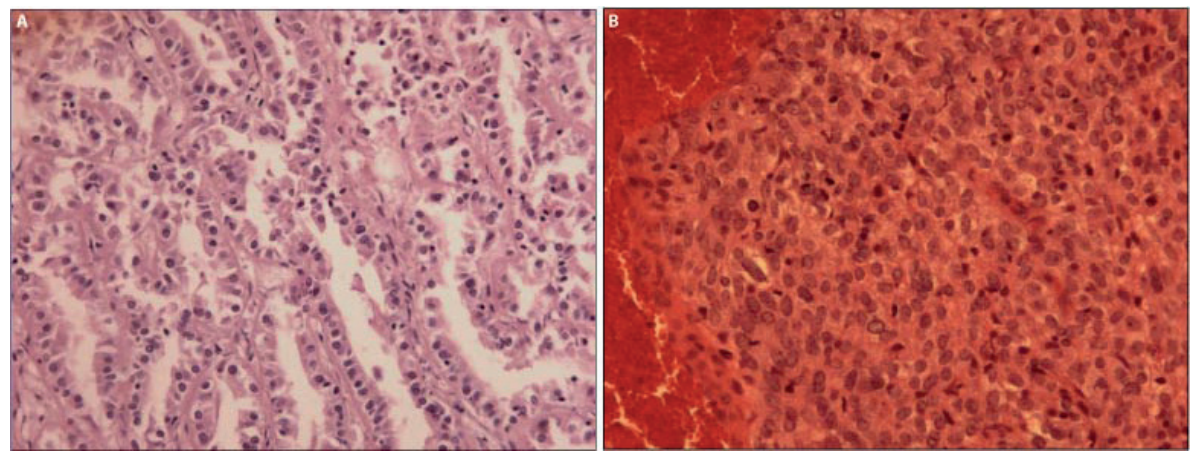

Figure 3. (a) H\&E staining of the kidney lesion consistent with papillary renal cell carcinoma (x100). (b) Histopathology of the neuroendocrine carcinoma. Highly cellular process with large nuclei (x100).

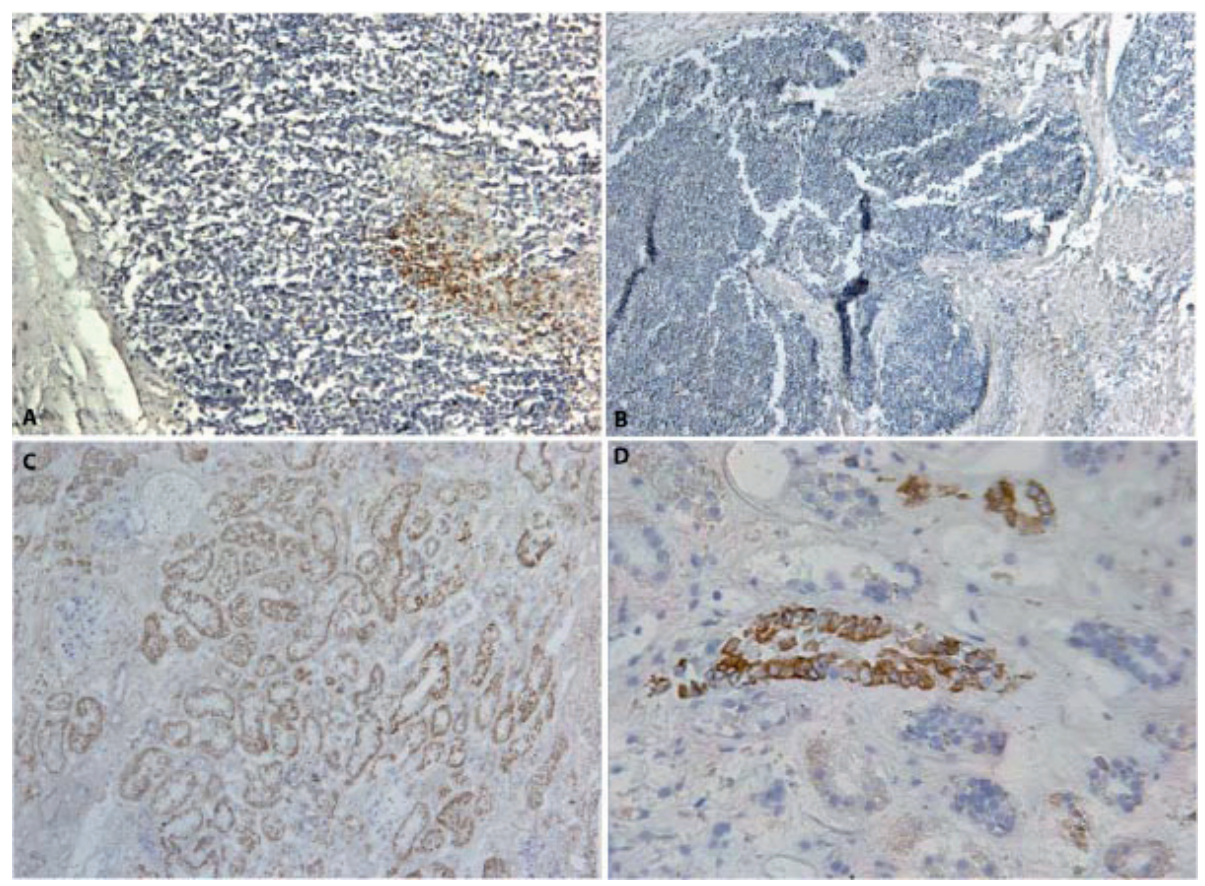

Figure 4. (a) Absence of FLCN staining in neuroendocrine carcinoma (blue nuclei), but presence in the lymphocytic infiltrate (x100). (b) Absence of phospho-S6 staining in neuroendocrine carcinoma. Staining cells are leucocytes (x50). (c) Phospho-mTOR (Ser2448) staining in affected kidney (x50). (d) Phospho-mTOR (Ser2448) staining of a tubule in the clinically healthy kidney of the patient $(x 100)$. 


\section{Discussion}

We report a patient with Birt-Hogg-Dubé syndrome who died with a poorly differentiated neuroendocrine carcinoma of either prostatic or bladder origin. Based on the post-mortem findings and the CT scan that showed the mass at a relatively early stage, a prostatic origin seems most likely. Small-cell neuroendocrine carcinoma of prostate or bladder is very rare but highly malignant as evidenced by its rapid growth and metastasis in the present case. Its occurrence in the context of Birt-Hogg-Dubé syndrome is intriguing and we hypothesized that loss of FLCN may have contributed to the aggressive behavior of the cancer. Birt-Hogg-Dube syndrome is caused by heterozygous truncating mutations in the BHD gene. Its strong evolutionary conservation hints at an important function of FLCN in cellular physiology. It has been hypothesized that activation of mTOR signaling is a common event that contributes to tumor development in disorders such as tuberous sclerosis, Peutz-Jeghers syndrome or Cowden's disease (4). Given the strong similarities between the clinical phenotypes of BHD and these hamartoma syndromes, it is not surprising that FLCN is thought to be involved in mTOR signaling. However, FLCN's exact function remains to be determined. The recently published conditional BHD knockout in mice shows inappropriate mTOR and Akt activity, suggesting that FLCN is a negative regulator of mTOR. There are also indications of an interaction with AMPK (3).

One of the important pathways regulating mTOR activity is the PI3K/Akt pathway, which is frequently upregulated by mutation or gene amplification in tumors, leading to mitogen-independent proliferation. Activating mutations within the PI3K/Akt/mTOR pathway have been found to occur in $30-50 \%$ of all human tumors (4). Neuroendocrine differentiation in prostate cancer requires Akt-mTOR signaling and is Akt-dependent (8). Therefore, we hypothesized that increased mTOR signaling caused by FLCN deficiency might have contributed to the cancer phenotype that we observed. However, our results suggest that absence of FLCN does not coincide with increased phosphorylation of S6, an established marker of mTORC1 activity (7). Neither does the heterozygous state seem to be associated with increased mTOR phosphorylation in this patient. Thus, FLCN's exact role in the regulation of mTOR activity remains to be determined. Our results contradict earlier findings, but it should be noted in this context that rodent models of BHD are not completely congruent with the human phenotype. Thus, FLCN may have different functions in humans and rodents, in particular with regard to mTOR regulation. 
In conclusion, we suggest that our patient's FLCN mutation may have contributed to the pathogenesis of his small-cell neuroendocrine carcinoma. We further propose that follow-up of BHD patients should perhaps be more aggressive than currently recommended because, conceivably, loss of FLCN may predispose to more tumor types than renal cell carcinoma alone, or alternatively may render other tumors more malignant. The apparent absence of mTOR deregulation in our patient's tumors might suggest that therapies targeting mTORC1 may not be useful for BHD-associated malignancies.

\section{Acknowledgements}

MvS is supported by grants from the university Hospital Maastricht, the GROW research institute for oncology and developmental biology and the Netherlands Organization for Scientific Research ZONMW (907-00-202).

SW is supported by a grant from the university Hospital Maastricht. This work is supported by the Myrovlytis Trust. SW, TC and MvS are members of the European Birt-Hogg-Dubé Consortium.

\section{References}

1. Schulz, T. and Hartschuh, W. Characteristics of the Birt-Hogg-Dube/Hornstein-Knickenberg syndrome. Am J Dermatopathol, 22: 293-294, 2000.

2. Schmidt, L. S., Nickerson, M. L., Warren, M. B., Glenn, G. M., Toro, J. R., Merino, M. J., Turner, M. L., Choyke, P. L., Sharma, N., Peterson, J., Morrison, P., Maher, E. R., Walther, M. M., Zbar, B., and Linehan, W. M. Germline BHD-mutation spectrum and phenotype analysis of a large cohort of families with Birt-Hogg-Dube syndrome. Am J Hum Genet, 76: 1023-1033, 2005.

3. Hasumi, H., Baba, M., Hong, S. B., Hasumi, Y., Huang, Y., Yao, M., Valera, V. A., Linehan, W. M., and Schmidt, L. S. Identification and characterization of a novel folliculin-interacting protein FNIP2. Gene, 415: 60-67, 2008.

4. Shaw, R. and Cantley, L. Ras, $\mathrm{PI}(3) \mathrm{K}$ and mTOR signalling controls tumour cell growth. Nature, 441: 424-430, 2006.

5. van Steensel, M. A., Verstraeten, V. L., Frank, J., Kelleners-Smeets, N. W., PobleteGutierrez, P., Marcus-Soekarman, D., Bladergroen, R. S., Steijlen, P. M., and van Geel, M. Novel mutations in the BHD gene and absence of loss of heterozygosity in fibrofolliculomas of Birt-Hogg-Dube patients. J Invest Dermatol, 127: 588-593, 2007.

6. Takagi, Y., Kobayashi, T., Shiono, M., Wang, L., Piao, X., Sun, G., Zhang, D., Abe, M., Hagiwara, Y., Takahashi, K., and Hino, O. Interaction of folliculin (Birt-Hogg-Dube gene product) with a novel Fnip1-like (FnipL/Fnip2) protein. Oncogene, 27: 5339-5347, 2008.

7. Ruvinsky, I. and Meyuhas, O. Ribosomal protein S6 phosphorylation: from protein synthesis to cell size. Trends Biochem Sci, 31: 342-348, 2006.

8. Wu, C. and Huang, J. Phosphatidylinositol 3-kinase-AKT-mammalian target of rapamycin pathway is essential for neuroendocrine differentiation of prostate cancer. $\mathrm{J}$ Biol Chem, 282: 3571-3583, 2007. 

CHAPTER 8

General discussion 


\section{Discussion}

Tumorigenesis in humans is often a slow and multistep process characterized by changes in cell physiology that overcome the inherent defense mechanisms that limit tissue growth. Such changes have been defined as the 'hallmarks of cancer' and are thought to be essential steps in the development and progression of all solid tumors (1). A number of these hallmarks, such as self-sufficiency in growth signals, evading apoptosis, and sustained angiogenesis can be achieved through changes in pathways that influence signaling to mTOR. As a benign proliferative lesion grows, areas of hypoxia develop when tissue demand for oxygen and nutrients exceeds the vascular supply. The cellular response and eventual adaptation to hypoxia allows tumor cells to remain viable during long periods with little or fluctuating oxygen, and on a tissue-level activates the "angiogenic switch". Thus hypoxia tolerance is also an acquired characteristic of solid tumors that may be necessary for tumor progression and could be considered an additional hallmark of cancer.

\section{Regulation of mRNA translation is a biological response to hy- poxia}

Chapter 2 outlines the clinical importance of tumor hypoxia as a prognostic indicator of poor outcome and discusses several ways of targeting hypoxia in order to improve cancer therapy. Hypoxia not only impedes the effectiveness of radiation or chemotherapy but also promotes a more malignant phenotype by stimulating angiogenesis, metastasis, and by selecting for cells with reduced apoptotic potential. One way to combat hypoxia in tumors is to interfere with the biological response that is initiated when reduced oxygen levels are encountered.

In chapter 3 we investigated one of the main biological responses to hypoxia, the control of mRNA translation. We have shown that the inhibition of translation under hypoxia occurs via two distinct mechanisms, the first involving elF2 $\alpha$ which occurs rapidly during the first 4 hours of hypoxia and the second involving elF4E which maintains repression of translation during prolonged hypoxic exposure. Different patterns of gene-specific translation efficiency were characterized during acute and prolonged hypoxia. For example, actin and CAIX are efficiently translated under control conditions but show a rapid decrease in the average number of ribosomes per transcript during acute hypoxia that partially recovers during prolonged hypoxia. The rapid decrease in translation efficiency of these genes was dependent on elF2 $\alpha$. In contrast, ATF4, a transcription factor activated upon ER stress, displays increased 
translation under hypoxia therefore illustrating that specific genes are able to overcome the general repression in global translation under hypoxia in order to increase their expression levels. Microarray studies utilizing polysomeassociated RNA have revealed a number of genes that are preferentially translated under hypoxia $(2,3)$. The exact mechanisms responsible for increased translation under hypoxia are still being investigated but seem to depend upon gene-specific sequences or secondary structure of the 5' and 3' UTRs. ATF4 harbors upstream open reading frames (ORFs) in its 5'UTR which prevent ribosome initiation at the proper start codon under normal conditions; however under ER stress the phosphorylation of elF2 $\alpha$ impairs ribosome initiation increasing the probability that ribosomes will read through the upstream ORFs and initiate translation at the correct ATF4 start site (4). It is probable that the same mechanism regulates ATF4 expression under hypoxia. Other genes may rely upon internal ribosome entry sites (IRES) to initiate cap-independent translation under conditions where the elF4F initiation complex is limiting. A majority of advanced breast cancers overexpress both 4E-BP1 and elF4G which facilitates a hypoxia-mediated switch between capdependent to cap-independent mRNA translation (5). This increase in 4EBP1 expression enables the inhibition of cap-dependent translation under higher oxygen levels while high elF4G expression allows the selective translation of IRES-harbouring mRNAs under hypoxia. However the existence of IRES mediated translation of endogenous genes remains controversial and there is yet no irrefutable evidence that it contributes significantly to the selective translation of particular genes under hypoxia $(6,7)$. A recent report by Zimmer et al. has described a mechanism that increases the translation of HIF2 $\alpha$ under hypoxia that involves binding of iron regulatory protein 1 (IRP1) to an iron-responsive element (IRE) in the HIF2 $\alpha$ 5'UTR (8). The IRP1/IRE association represses translation under normoxic conditions; however hypoxia impairs IRP1 binding therefore allowing efficient translation of HIF2 $\alpha$ under low oxygen.

\section{EGFRvIII promotes resistance to hypoxia}

In chapter 4 we investigated a constitutively active tyrosine kinase receptor that signals to mTORC1 via the PI3K-Akt pathway, EGFRvIll. We generated a glioma cell line that stably expresses EGFRvIll which we used to determine the effect of EGFRvIll expression on radiation sensitivity, tumor growth and hypoxia tolerance. Despite having no effect on the growth rate of cells grown under optimal culture conditions, EGFRvlll stimulated the growth of xenograft tumors in mice. This result suggests that EGFRvIII is able to promote proliferation and/or survival under conditions specific to the tumor microenvironment. Indeed, when cultured under hypoxia, EGFRvIll expressing cells had 
an increased growth rate and were less susceptible to hypoxia-induced cell death. Although the mechanism involved has yet to be investigated, it is interesting to speculate that mTOR might play a role. EGFR activation of the PI3K-mTOR pathway has been shown to upregulate HIF-1a expression leading to increased survivin expression and subsequent resistance to apoptosis (9). Based on our results, we reason that EGFR over-expressing or EGFRvIII positive cells would accumulate in hypoxic regions due to the selective advantage that increased proliferation and survival under hypoxia imparts to these cells. Indeed, a correlation between EGFR expression and regions of tumor hypoxia has been reported (10). Treatment of tumors with EGFR inhibitors also leads to a decrease in hypoxic fraction $(11,12)$. Increased cell viability within hypoxic regions of tumors would also promote resistance to radiation therapy since hypoxic cells require a 3 fold higher radiation dose in order to achieve an equivalent amount of toxicity as oxygenated tissue (13). Thus, in addition to the effect of EGFRvIll that we found on intrinsic radiosensitivity (as seen by a nearly two-fold increase in survival after irradiation with 4 Gy in vitro), increased hypoxia in EGFRvlll expressing tumors can significantly impair tumor response to radiation therapy.

The relationship between EGFR and hypoxia also works in the reverse direction with hypoxia stimulating translation of EGFR mRNA (14). Since EGFRvIII and wild-type EGFR share the same UTR sequences, it is likely that the same regulation would apply to our model. Targeting of mTOR in this situation could be advantageous if it would block the hypoxia-induced expression of EGFR. A number of recent studies have examined the combination of mTOR and EGFR inhibitors and have shown promising results (15-17).

\section{Targeting $\mathrm{mTOR}$ in combination with radiotherapy}

In chapter 5 we focused our interest on mTOR as a therapeutic target by investigating the combination of rapamycin with radiation therapy in a mouse tumor xenograft model. We demonstrated that rapamycin was effective both in vitro and in vivo to reduce the proliferation of tumor cells. When given in combination with fractionated radiotherapy, there was however no additional effect of rapamycin on tumor cure or on tumor growth delay. This finding is in contrast to two other reports that mTOR inhibitors can enhance the growth delay achieved by fractionated radiation $(18,19)$. However, several key differences exist in the design of our study which may explain the conflicting results. In our experiment, we delivered the rapamycin treatment over a short period of 6 days to look specifically at the interaction with radiation. This limited the anti-proliferative effect that rapamycin would have on tumor cell repopulation between radiation fractions or on the growth rate of tumor cells 
surviving radiotherapy. We also used higher radiation doses per fraction than the other studies as our primary goal was to measure tumor cure rate. In the other studies, rapamycin or RAD001 was given over a prolonged period (> 18 days). Given the fast doubling time of U87 xenografts ( 4 days), overall treatment time will play a significant role in the outcome of such a growth delay assay. It still remains to be determined if rapamycin would be beneficial with respect to local tumor control and survival in a typical clinical setting where radiation is delivered over a 4-6 week period in 2 Gy fractions.

We found a high degree of heterogeneity in the response of individual animals receiving the combination of rapamycin and radiation which suggested that a subset of tumors may have benefited although the group as a whole did not. Upon ex vivo examination of tumors we found that rapamycin treatment increased the presence of hypoxia in tumor sections. This may be due to an increasing trend in the amount of thrombotic vessels within the tumor tissue which could limit perfusion. Alternatively, this may be a result of metabolic effects of mTOR inhibition. Ronellenfitsch et al. show that rapamycin can protect glioma cells against hypoxia-induced cell death by maintaining ATP levels and thus preserving cell viability (20). Sustaining energy homeostasis by limiting translation may allow tumor cells to better tolerate hypoxic stress. This is supported by evidence that the inhibition of translation via 4EBP1 is important in order for tumor cells to survive chronic hypoxia (21).

We speculate that these microenvironmental effects of rapamycin may have limited any additional increase in cytotoxicity that may have resulted from the combination with radiotherapy. Different scheduling of rapamycin and radiation may be useful to alleviate any complications of rapamycin-induced hypoxia (ie sequential versus concurrent treatment) as has been demonstrated with anti-angiogenic agents (22).

\section{Differential effects of mTOR inhibition on downstream targets}

In chapter 6, we conducted an in-depth examination of the effects of rapamycin on the downstream targets of mTORC1. We found that p70S6K and 4E$\mathrm{BP} 1$ responded differently to rapamycin treatment as seen by a more effective inhibition of p70S6K phosphorylation than of 4E-BP1. Curiously, by combining rapamycin with LY294002, a PI3K inhibitor, 4E-BP1 phosphorylation could be blocked more effectively than by either inhibitor alone and there was also a greater repression on the biological consequences of mTOR regulation as revealed by changes in global translation. This was unexpected given what is currently known about the mTOR signaling pathway and the specificities of these two kinase inhibitors. Previous studies have described both ra- 
pamycin-sensitive and insensitive functions of mTORC1 towards 4E-BP1 and have shown that expression of a kinase-inactive mTOR mutant can enhance the inhibitory effect of rapamycin towards 4E-BP1 phosphorylation (23). These results indicate that rapamycin is not able to block all aspects of mTORC1 function in some cell lines. Dose-dependent effects of mTOR inhibition have also been described, with $\mathrm{CCl}-779$ displaying an FKBP12independent inhibition of mTOR kinase activity at high micromolar concentrations (24). This suggests that high-dose rapamycin may be more effective to inhibit signaling from both mTOR complexes and could overcome the resistance of some cell lines to low-dose rapamycin treatment.

We also saw an enhanced inhibition of 4E-BP1 phosphorylation when using rapamycin in combination with an Akt inhibitor, suggesting that there is a $\mathrm{PI} 3 \mathrm{~K} /$ Akt-dependent stimulation of 4E-BP1 phosphorylation that is independent of mTORC1. This parallel pathway does not influence the phosphorylation of p70S6K but can maintain phosphorylation of 4E-BP1 and global translation when mTORC1 is inactive. This parallel pathway may be similar to one described by Pore et al. which concerns a PI3K/Akt- dependent regulation of HIF-1 $\alpha$ translation that does not require mTOR (25).

In conclusion, our results suggest that a more effective inhibition of all mTORC1 downstream targets will lead to a better inhibition of translation and perhaps a more robust anticancer activity.

\section{Folliculin dependent regulation of mTOR}

Upregulation of mTOR signaling has been described as a common feature in a number of genetic disorders that are associated with the development of both benign and malignant tumors referred to as hamartoma syndromes (26). The genes which are mutated in these syndromes are tumor suppressors such as PTEN, TSC1/2, or LKB1 that all act as negative regulators of the various signaling pathways that activate $\mathrm{mTOR}$. The clinical manifestation of Birt-Hogg-Dubé syndrome is similar to the phenotypes of the hamartoma family of diseases, and mouse models of BHD have established a connection between loss of folliculin expression and upregulation of mTOR and MAPK signaling $(27,28)$. Thus, these findings point to a potential function of folliculin in suppressing tumor formation by downregulating mTOR signaling by an unknown mechanism.

In the case report presented in chapter 7 , we describe a BHD patient who died as a result of an aggressive neuroendocrine carcinoma of the prostate. This was an unusual case since BHD is not commonly associated with this 
type of tumor. We hypothesized that increased mTORC1 activity as a consequence of lost folliculin expression in the tumor may have contributed to the aggressiveness of this patient's cancer. However, despite observing loss of folliculin expression in the prostate tumor we found no evidence of S6 phosphorylation, a target downstream of mTORC1. Interestingly, this finding is consistent with recently published results from Hartman et al. who also reported downregulation of S6 phosphorylation in human cell lines expressing BHD siRNA (29). Therefore it appears that loss of folliculin does not correlate with increased mTORC1 activity in humans, unlike what is observed in various mouse models of the disease. This discrepancy may be due to species specific differences or may be related to the time during development during which folliculin expression is lost (i.e. during embryonic development in the conditional knock-out mice or after tissue specific differentiation has occurred as in the human situation).

We have continued to explore the mechanistic basis behind these surprising observations and have recently obtained preliminary data suggesting that mTORC2 may be more relevant for BHD than mTORC1 (figure 1). We have expressed either wild-type folliculin or a series of patient-derived folliculin mutants in HEK293 cells. Expression of the wild-type folliculin protein leads to reduced phosphorylation of Akt at Ser473 (the site which is phosphorylated by mTORC2 (30)). In contrast, expression of mutant folliculin constructs which result in the expression of truncated proteins (c.1733insC or Y463X) resulted in increased phosphorylation of Akt at the same site. The truncated mutants also appear to elevate Akt activity as seen by enhanced FoxO3a phosphorylation, a downstream target of Akt. In comparison to these truncating mutations, the folliculin K508R missense mutant did not have the same stimulatory effect on Akt phosphorylation. These new data suggest that the C-terminus of folliculin functions as a negative regulator of mTORC2 and that these truncating mutations cause activation of mTORC2 and Akt. 
c. 1733

Ctrl WT insC Y463X K508R

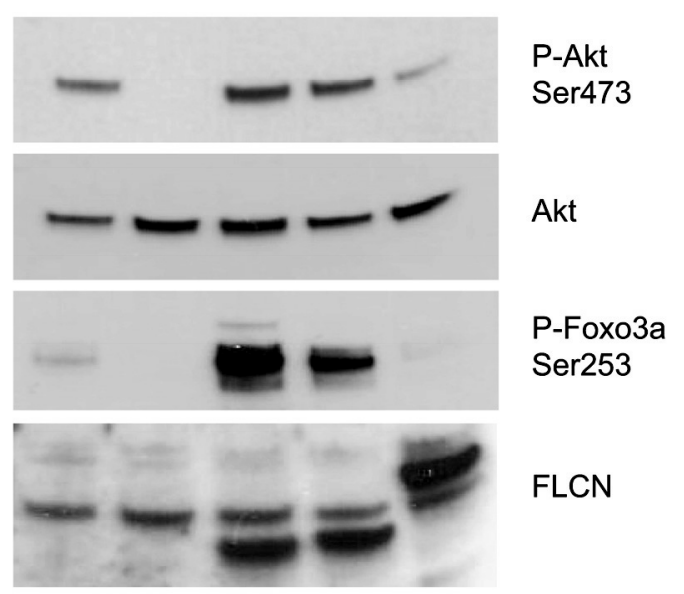

Figure 1. FLCN dependent regulation of Akt. HEK293 cells stably expressing empty vector (Ctrl), wildtype (WT), or mutant FLCN constructs (c.1733insC, Y463X, or $\mathrm{K} 508 \mathrm{R}$ ) were lysed and subjected to Western blotting for phospho-Akt Ser473 and phospho-FoxO3a Ser253. Total Akt serves as a protein loading control. Expression of the constructs is confirmed by the FLCN blot.

\section{Future prospectives}

The development of specific mTOR kinase domain inhibitors (TORKinibs) is currently an area of great enthusiasm. New data describing the effectiveness of two such inhibitors (PP242 and PP30) in blocking signaling downstream of both mTOR complexes has recently been published (31). PP242 has enhanced anti-proliferative activity compared to rapamycin, which is due to more effective inhibition of mTORC1 and cap-dependent translation rather than from additional effects of mTORC2 inhibition on proliferation. This finding also supports our data in chapter 6 which show that the rapamycinresistant outputs of mTORC1 are important for the regulation of translation. These new agents are yet another tool to improve our understanding of the mTOR signaling pathway but furthermore, it will be exciting to follow TORKinibs on their journey to the clinic to see if they can indeed improve the efficacy of cancer treatment. Cancers displaying upregulation of either mTORC1 or mTORC2 activity, and in particular cancers associated with Birt-HoggDubé syndrome will be excellent candidates for future testing of these new agents in the clinic. Nevertheless, attention should be given to potential vasculature effects and metabolic consequences of mTOR inhibition as these new agents are investigated further in tumor models. 


\section{References}

1. Hanahan, D. and Weinberg, R. A. The hallmarks of cancer. Cell, 100: 57-70, 2000.

2. Blais, J. D., Filipenko, V., Bi, M., Harding, H. P., Ron, D., Koumenis, C., Wouters, B. G., and Bell, J. C. Activating transcription factor 4 is translationally regulated by hypoxic stress. Mol Cell Biol, 24: 7469-7482, 2004.

3. Koritzinsky, M., Seigneuric, R., Magagnin, M. G., van den Beucken, T., Lambin, P., and Wouters, B. G. The hypoxic proteome is influenced by gene-specific changes in mRNA translation. Radiother Oncol, 76: 177-186, 2005.

4. Harding, H. P., Novoa, I., Zhang, Y., Zeng, H., Wek, R., Schapira, M., and Ron, D. Regulated translation initiation controls stress-induced gene expression in mammalian cells. Mol Cell, 6: 1099-1108, 2000.

5. Braunstein, S., Karpisheva, K., Pola, C., Goldberg, J., Hochman, T., Yee, H., Cangiarella, J., Arju, R., Formenti, S. C., and Schneider, R. J. A hypoxia-controlled cap-dependent to cap-independent translation switch in breast cancer. Mol Cell, 28: 501-512, 2007.

6. Young, R. M., Wang, S. J., Gordan, J. D., Ji, X., Liebhaber, S. A., and Simon, M. C. Hypoxia-mediated selective mRNA translation by an internal ribosome entry site-independent mechanism. J Biol Chem, 283: 16309-16319, 2008.

7. Kozak, M. A second look at cellular mRNA sequences said to function as internal ribosome entry sites. Nucleic Acids Res, 33: 6593-6602, 2005.

8. Zimmer, M., Ebert, B. L., Neil, C., Brenner, K., Papaioannou, I., Melas, A., Tolliday, N., Lamb, J., Pantopoulos, K., Golub, T., and Iliopoulos, O. Small-molecule inhibitors of HIF-2a translation link its 5'UTR iron-responsive element to oxygen sensing. Mol Cell, 32: 838-848, 2008.

9. Peng, X. H., Karna, P., Cao, Z., Jiang, B. H., Zhou, M., and Yang, L. Cross-talk between epidermal growth factor receptor and hypoxia-inducible factor-1alpha signal pathways increases resistance to apoptosis by up-regulating survivin gene expression. J Biol Chem, 281: 25903-25914, 2006.

10. Swinson, D. E. and O'Byrne, K. J. Interactions between hypoxia and epidermal growth factor receptor in non-small-cell lung cancer. Clin Lung Cancer, 7: 250-256, 2006.

11. Krause, M., Ostermann, G., Petersen, C., Yaromina, A., Hessel, F., Harstrick, A., van der Kogel, A. J., Thames, H. D., and Baumann, M. Decreased repopulation as well as increased reoxygenation contribute to the improvement in local control after targeting of the EGFR by C225 during fractionated irradiation. Radiother Oncol, 76: 162-167, 2005.

12. Solomon, B., Binns, D., Roselt, P., Weibe, L. I., McArthur, G. A., Cullinane, C., and Hicks, R. J. Modulation of intratumoral hypoxia by the epidermal growth factor receptor inhibitor gefitinib detected using small animal PET imaging. Mol Cancer Ther, 4: 1417-1422, 2005.

13. Basic Clinical Radiobiology, second edition, p. 254. London: Arnold, 1997.

14. Franovic, A., Gunaratnam, L., Smith, K., Robert, I., Patten, D., and Lee, S. Translational upregulation of the EGFR by tumor hypoxia provides a nonmutational explanation for its overexpression in human cancer. Proc Natl Acad Sci U S A, 104: 13092-13097, 2007.

15. Jimeno, A., Kulesza, P., Wheelhouse, J., Chan, A., Zhang, X., Kincaid, E., Chen, R., Clark, D. P., Forastiere, A., and Hidalgo, M. Dual EGFR and mTOR targeting in squamous cell carcinoma models, and development of early markers of efficacy. $\mathrm{Br} \mathrm{J}$ Cancer, 96: 952959, 2007.

16. Buck, E., Eyzaguirre, A., Brown, E., Petti, F., McCormack, S., Haley, J. D., Iwata, K. K., Gibson, N. W., and Griffin, G. Rapamycin synergizes with the epidermal growth factor receptor inhibitor erlotinib in non-small-cell lung, pancreatic, colon, and breast tumors. Mol Cancer Ther, 5: 2676-2684, 2006.

17. Wang, M. Y., Lu, K. V., Zhu, S., Dia, E. Q., Vivanco, I., Shackleford, G. M., Cavenee, W. K., Mellinghoff, I. K., Cloughesy, T. F., Sawyers, C. L., and Mischel, P. S. Mammalian target of rapamycin inhibition promotes response to epidermal growth factor receptor kinase inhibitors in PTEN-deficient and PTEN-intact glioblastoma cells. Cancer Res, 66: 7864-7869, 2006.

18. Eshleman, J. S., Carlson, B. L., Mladek, A. C., Kastner, B. D., Shide, K. L., and Sarkaria, J. $\mathrm{N}$. Inhibition of the mammalian target of rapamycin sensitizes U87 xenografts to fractionated radiation therapy. Cancer Res, 62: 7291-7297, 2002. 
19. Manegold, P. C., Paringer, C., Kulka, U., Krimmel, K., Eichhorn, M. E., Wilkowski, R., Jauch, K. W., Guba, M., and Bruns, C. J. Antiangiogenic therapy with mammalian target of rapamycin inhibitor RAD001 (Everolimus) increases radiosensitivity in solid cancer. Clin Cancer Res, 14: 892-900, 2008.

20. Ronellenfitsch, M. W., Brucker, D. P., Burger, M. C., Wolking, S., Tritschler, F., Rieger, J., Wick, W., Weller, M., and Steinbach, J. P. Antagonism of the mammalian target of rapamycin selectively mediates metabolic effects of epidermal growth factor receptor inhibition and protects human malignant glioma cells from hypoxia-induced cell death. Brain, 132: 15091522, 2009.

21. Dubois, L., Magagnin, M. G., Cleven, A. H., Weppler, S. A., Grenacher, B., Landuyt, W., Lieuwes, N., Lambin, P., Gorr, T. A., Koritzinsky, M., and Wouters, B. G. Inhibition of 4EBP1 sensitizes U87 glioblastoma xenograft tumors to irradiation by decreasing hypoxia tolerance. Int J Radiat Oncol Biol Phys, 73: 1219-1227, 2009.

22. Williams, K. J., Telfer, B. A., Brave, S., Kendrew, J., Whittaker, L., Stratford, I. J., and Wedge, S. R. ZD6474, a potent inhibitor of vascular endothelial growth factor signaling, combined with radiotherapy: schedule-dependent enhancement of antitumor activity. Clin Cancer Res, 10: 8587-8593, 2004.

23. Edinger, A. L., Linardic, C. M., Chiang, G. G., Thompson, C. B., and Abraham, R. T. Differential effects of rapamycin on mammalian target of rapamycin signaling functions in mammalian cells. Cancer Res, 63: 8451-8460, 2003.

24. Shor, B., Zhang, W. G., Toral-Barza, L., Lucas, J., Abraham, R. T., Gibbons, J. J., and Yu, K. A new pharmacologic action of CCl-779 involves FKBP12-independent inhibition of mTOR kinase activity and profound repression of global protein synthesis. Cancer Res, 68: 2934-2943, 2008.

25. Pore, N., Jiang, Z., Shu, H. K., Bernhard, E., Kao, G. D., and Maity, A. Akt1 activation can augment hypoxia-inducible factor-1alpha expression by increasing protein translation through a mammalian target of rapamycin-independent pathway. Mol Cancer Res, 4: 471479, 2006.

26. Inoki, K., Corradetti, M. N., and Guan, K. L. Dysregulation of the TSC-mTOR pathway in human disease. Nat Genet, 37: 19-24, 2005.

27. Baba, M., Furihata, M., Hong, S. B., Tessarollo, L., Haines, D. C., Southon, E., Patel, V., Igarashi, P., Alvord, W. G., Leighty, R., Yao, M., Bernardo, M., Ileva, L., Choyke, P., Warren, M. B., Zbar, B., Linehan, W. M., and Schmidt, L. S. Kidney-targeted Birt-Hogg-Dube gene inactivation in a mouse model: Erk1/2 and Akt-mTOR activation, cell hyperproliferation, and polycystic kidneys. J Natl Cancer Inst, 100: 140-154, 2008.

28. Chen, J., Futami, K., Petillo, D., Peng, J., Wang, P., Knol, J., Li, Y., Khoo, S. K., Huang, D., Qian, C. N., Zhao, P., Dykyma, K., Zhang, R., Cao, B., Yang, X. J., Furge, K., Williams, B. O., and Teh, B. T. Deficiency of FLCN in mouse kidney led to development of polycystic kidneys and renal neoplasia. PLoS ONE, 3: e3581, 2008.

29. Hartman, T. R., Nicolas, E., Klein-Szanto, A., Al-Saleem, T., Cash, T. P., Simon, M. C., and Henske, E. P. The role of the Birt-Hogg-Dube protein in mTOR activation and renal tumorigenesis. Oncogene, 28: 1594-1604, 2009.

30. Sarbassov, D. D., Guertin, D. A., Ali, S. M., and Sabatini, D. M. Phosphorylation and regulation of Akt/PKB by the rictor-mTOR complex. Science, 307: 1098-1101, 2005.

31. Feldman, M. E., Apsel, B., Uotila, A., Loewith, R., Knight, Z. A., Ruggero, D., and Shokat, K. M. Active-site inhibitors of mTOR target rapamycin-resistant outputs of mTORC1 and mTORC2. PLoS Biol, 7: e38, 2009. 
Summary

Samenvatting

Acknowledgements

Curriculum vitae

List of publications 


\section{SUMMARY}

The mTOR kinase, as a central integration point for sensors of growth factors, nutrients and energy sources, plays a key role in tumor biology. In the cell, mTOR is a part of two different multi-protein complexes, mTORC1 and mTORC2. The main function of mTORC1 is to regulate the production of new proteins within the cell. In this dissertation I have investigated several key aspects of mTOR signaling in cancer with a focus on its role in the tumor microenvironment.

During the process of tumor development, the normally tight regulation of mTOR and protein synthesis is often lost, leading to increased proliferation and survival, and alteration of the microenvironment (this thesis). This is illustrated in chapter 4 where we show that EGFRvIll, a constitutively active kinase receptor that signals through the PI3K/Akt/mTOR pathway, stimulates tumor growth and promotes survival after irradiation or under low-oxygen conditions (hypoxia). Hypoxia is a common feature of solid tumors and an important determinant of poor treatment outcome, thus strategies that can reduce or eliminate hypoxic tumor cells are highly desirable (reviewed in chapter 2). The ability of cells to repress mTOR activity and protein synthesis is an important part of the cellular response to hypoxia. In chapter 3 we show that hypoxia inhibits protein synthesis in two separate phases by using two distinct mechanisms, one of which requires 4E-BP1, an mTOR substrate.

The ability of 4E-BP1 to inhibit protein synthesis is determined by its level of phosphorylation. This prompted us to conduct an indepth study of 4E-BP1 regulation in chapter 6 . We provide evidence to suggest that in addition to mTORC1, there is a PI3K/Akt-dependent but mTORC1-independent signal to 4E-BP1 that must be blocked in order to effectively inhibit protein synthesis via this mechanism. Thus, targeting protein synthesis in cancer might be improved by strategies that block 4E-BP1 more effectively.

Due to the attractiveness of mTOR as a therapeutic target in cancer, a number of mTOR inhibitors are currently being tested, many of which are analogs based upon the structure of the original mTOR inhibitor, rapamycin. Previous studies have shown that rapamycin can inhibit tumor regrowth when used in combination with radiation. However, in chapter 5 , we saw no additional effect of rapamycin to limit local tumor control by radiation, although we did observe heterogeneity in the response of individual tumors that may have been influenced by increased areas of hypoxia and intravascular thrombosis after rapamycin treatment. 
Our knowledge of the mTOR signaling pathway continues to evolve as we learn more about the intricacies of its regulatory proteins and feedback pathways. Human genetics can be a valuable tool in helping us to dissect the interactions between signaling proteins within a pathway. In chapter 8 , we describe a patient with Birt-Hogg-Dubé syndrome (a familial cancer disease) in which the mutant folliculin protein is suspected to promote tumor formation by upregulation of mTOR activity through an unknown mechanism. We show that tumors associated with this syndrome do not express common markers of increased mTORC1 activity, but rather that activation of mTORC2 may be more relevant to this disease.

In conclusion, mTOR and protein synthesis are attractive targets for cancer therapy. However, the future success of these strategies will depend upon both basic and translational research to understand how best to inhibit these processes for maximum gain of anti-tumor effect without undesirable activation of feedback loops or normal tissue side-effects. 


\section{SAMENVATTING}

mTOR fungeert als centraal integratiepunt voor sensoren van groeifactoren, voedingsstoffen en energiebronnen. Op die manier heeft mTOR een erg belangrijke rol in tumorbiologie. In de cel kan mTOR deel uitmaken van twee verschillende multi-eiwit complexen, mTORC1 en mTORC2. De hoofdfunctie van mTORC1 is het reguleren van de productie van nieuwe eiwitten binnen de cel. In dit proefschrift heb ik een aantal sleutelaspecten van mTORsignalering in kanker onderzocht. De focus lag daarbij op de rol die mTOR speelt in de tumor micro-omgeving.

Gedurende het ontwikkelingsproces van een tumor gaat de strikte regulering van mTOR en eiwitsynthese vaak verloren. Dit leidt tot toegenomen proliferatie en overleving van tumorcellen, en tot een verandering van de tumor micro-omgeving (dit proefschrift). Dit wordt beschreven in hoofdstuk 4 waar we laten zien dat EGFRvIII, een constitutief geactiveerde kinase receptor die signaleert via de PI3K/Akt/mTOR-route, tumorgroei stimuleert. Expressie van EGFRvIll verbetert ook het overleven van tumoren na bestraling of bij blootstelling aan verlaagde zuurstofconcentraties (hypoxie). Hypoxie komt veelvuldig voor in vaste tumoren en is een belangrijke determinerende factor voor een slechte behandelingsuitkomst. Het is dan ook zeer wenselijk dat strategieën ontwikkeld worden die het aantal hypoxische cellen in tumoren kunnen verminderen of elimineren (zoals beschreven in hoofdstuk 2). Het vermogen van cellen om mTOR-activiteit en eiwitsynthese te onderdrukken vormt een belangrijk onderdeel van de cellulaire respons tegenover hypoxie. In hoofdstuk 3 tonen we aan dat hypoxie de eiwitsynthese remt in twee verschillende fases, door gebruik te maken van twee verschillende mechanismen. Eén van deze mechanismen vereist het mTOR-substraat 4E-BP1.

De mogelijkheid van 4E-BP1 om eiwitsynthese te remmen hangt af van de mate waarin het is gefosforyleerd. Dit zette ons aan om de regulatie van $4 \mathrm{E}-$ BP1 in detail te onderzoeken (hoofdstuk 6). Onze data suggereren dat naast het mTORC1 signaal wellicht een PI3K/Akt-afhankelijk maar mTORC1onafhankelijk signaal naar 4E-BP1 gaat, dat geblokkeerd moet worden om via dit mechanisme de eiwitsynthese te kunnen remmen. Zodoende zou het aangrijpen op de eiwitsynthese bij kanker mogelijk verbeterd kunnen worden met behulp van strategieën die 4E-BP1 effectiever blokkeren.

Omwille van het feit dat mTOR aantrekkelijk is als een therapeutisch doelwit bij kanker, worden momenteel een aantal mTOR-inhibitoren getest. Vele van deze remmers zijn analogen die gebaseerd zijn op de structuur van de originele mTOR-remmer, rapamycine. Eerdere studies hebben laten zien dat ra- 
pamycine, in combinatie met bestraling, de hergroei van tumoren kan remmen. Echter, in hoofdstuk 5 hebben we geen additioneel effect van rapamycine op lokale tumorcontrole door bestraling gevonden. Wat we wel duidelijk observeerden, was een heterogeniteit in respons van individuele tumoren. Dit kan mogelijk verklaard worden door een toename van hypoxie en intravasculaire thrombose na behandeling met rapamycine.

Onze kennis van de mTOR-signaleringsroute blijt zich verder ontwikkelen doordat we steeds meer te weten komen over de gecompliceerdheid van de verschillende mTOR-regulatorische eiwitten en de feedback mechanismen. Humane genetische informatie kan een waardevol instrument zijn om de interacties tussen verschillende signaleringseiwitten binnen een transductieweg in een cel te ontleden. In hoofdstuk 8 beschrijven we een patiënt met het Birt-Hogg-Dubé syndroom (een familiale kankeraandoening) waarbij vermoed wordt dat het gemuteerd folliculin-eiwit tumorvorming promoot door verhoging van de mTOR-activiteit via een nog onbekend mechanisme. Wij tonen aan dat tumoren die met dit syndroom geassocieerd zijn, geen merkers van verhoogde mTORC1-activiteit tot expressie brengen, maar dat eerder activering van mTORC2 relevanter is voor deze ziekte.

Tot besluit kunnen we stellen dat mTOR en eiwitsynthese aantrekkelijke doelen zijn voor kankertherapie. Het toekomstige succes van deze strategieën zal afhankelijk zijn van zowel basaal en translationeel onderzoek, dat ons in staat moet stellen om te begrijpen hoe we deze processen het best inhiberen, zodat we een maximaal anti-tumor effect kunnen verkrijgen zonder ongewenste activering van feedbackmechanismen of neveneffecten op gezond weefsel. 


\section{ACKNOWLEDGEMENTS}

According to a well-known African proverb, "it takes a village to raise a child". In the same way, it takes many people to bring a Ph.D. thesis to fruition. Therefore, I would like to offer my thanks and gratitude to the following people.

I would like to begin by thanking my supervisors Brad Wouters and Philippe Lambin for giving me the opportunity to come to Maastricht and be involved in the start-up of the MAASTRO lab. I also appreciate the many opportunities that I had to travel to conferences in such exotic locations as Puerto Rico, Australia, the USA, as well as within Europe. Brad, l've learned a tremendous amount from you and am sure that it will serve me well in the future.

I would also like to thank Guido Lammering and Willem Voncken for serving as members of my Ph.D. portfolio committee. Your comments and criticisms were always very helpful, and I now know to plan at least 1 hour of discussion per committee member present! Also thanks to Guido and Maurice van Steensel for serving as co-promoters.

Over the years, I have had many colleagues at the MAASTRO lab (unfortunately too many to name everyone individually), so a big thanks to all past and present lab members. A special thanks to all the technicians who really do a great job of keeping the lab running in spite of the efforts of all those pesky Ph.D. students.

Jan, Kim, and Roland-you were my trusted coffee companions over the years. Thanks to you guys I got the 'Belgian perspective' on everything from politics to football to beer. Roland, my fellow Canuck, it seems like a lifetime ago that we made the decision to pack-up everything in Ottawa and move to Maastricht. You have been the one constant element through this whole journey from beginning to end. Thanks for everything man...I'm sure I still owe you a Duvel.

More recently I began working at the department of Dermatology, so I would like to thank everyone who has made me feel welcome there, especially Tijs Claessens with whom I worked most closely. Good luck with your future Ph.D. research Tijs, and with climbing mountains both on your bike and in the lab.

During my studies I had the wonderful experience to spend several months in Dresden, Germany at the lab of Prof. dr. Michael Baumann to conduct the 
rapamycin and radiotherapy study. I would like to thank Mechthild Krause who helped to design and carry out the experiments and Dorothy Pfitzmann for teaching me the technical aspects of working with mice. Also thanks to Agnieska Zyromska for her contribution to the follow-up study. Hopefully we will have the opportunity to meet in person one day in the future.

Thanks again to Willem Voncken (this time for his contagious and unquenchable enthusiasm for good science) and to his research group for all of the interesting discussions and for making journal club, pizza meetings, etc. more enjoyable and thought provoking. Especially to Hanneke, Frank, and Peggy who commiserated with me throughout the Ph.D. process.

Thanks also to Ramon Langen and the others from the Pulmonology department who participate in our weekly lab meetings. Your comments and feedback are always appreciated.

During my time in Maastricht, I established a strong "French connection" through the friendships I made with Florence, Celine \& Vincent. As foreigners in a strange land we flocked together, even if only to avoid Dutch 'food' or for shopping trips across the border. Thanks for the memories and I hope we will continue to stay in touch.

The ProTones band provided me with a welcome musical interlude away from the lab. Thanks to everyone for letting me 'meeblazen'. Maybe next year we'll go on tour?

Also thanks to Kim \& Jos for worrying about me, so that I would be guilted into writing more quickly. I like to think that you guys contributed to my education through our frequent trips to John Mullins for quiz night.

Een heel groot "merci" aan de familie Willems, mijn nieuwe schoonfamilie. Ik heb van jullie alle limburgse dingen geleerd te waarderen. Nu alleen nog maar praten in het plat.....maar ik kan wel zeggen dat ik toch een beetje ingeburgerd ben door jullie.

Mom and Dad, thanks for all the years of patience and support. Even though most of this book is nothing more than Greek to you, I know that you can see all the hard work, the trials and tribulations that are behind the words on every page. And to the rest of my family, Dianne \& Dave, Dale \& Emily, Jessie \& Sarah, I hope that you can be proud and enjoy bragging that there is now a doctor in the family. 
And last, but most importantly, my heartfelt thanks to Jodil, for always starting dinner and taking care of the home-front when I was delayed at the lab. I love that we can discuss experiments over breakfast (usually in 'du-nglish', our own special language), and that you sympathize whole-heartedly when I have Western blot issues. Infinite thanks for the emotional support you've given me during the tough times and for the welcome distractions you provide from work. I look forward to many more years of scientific discovery by your side. 


\section{CURRICULUM VITAE}

Sherry Weppler was born on August 15, 1975 in Hanover, Canada. She was awarded her Ontario Secondary School Diploma from John Diefenbaker Secondary School in 1994. At this time she enrolled in an Honours Bachelor of Science program specializing in Microbiology and Immunology at the University of Western Ontario in London, Canada. Her graduation project was under the supervision of Dr. Katherine Dobinson and involved the molecular characterization of a trypsin-like protease from the plant pathogenic fungus Verticillium dahliae. In 1998 she was awarded her bachelors degree with distinction (cum laude), and moved to the University of Ottawa where she began a Master of Science in the department of Microbiology and Immunology. Under the supervision of Dr. Chaim Birnboim, she conducted research describing spontaneous and nitrous oxide-induced mutations in a murine tumor model. After completion of her M.Sc. in 2001, she moved to the Netherlands in order to pursue her doctorate at Maastricht University under the guidance of Prof. Brad Wouters and Prof. Philippe Lambin in the newly established Maastricht Radiation Oncology (MAASTRO) laboratory. She is currently working at Maastricht University as a post-doctoral fellow under the supervision of Dr. Maurice van Steensel on a collaborative project between MAASTRO and the department of Dermatology that is investigating the involvement of mTOR and HIF in Birt-Hogg-Dubé syndrome. 


\section{LIST OF PUBLICATIONS}

Wouters, B.G., Weppler, S.A., Koritzinsky, M., Landuyt, W., Nuyts, S., Theys, J., Chiu, R.K., Lambin, P. Hypoxia as a target for combined modality treatments. Eur J Cancer 2002, 38 (2): 240-257.

Koritzinsky, M., Magagnin, M.G., van den Beucken, T., Seigneuric, R., Savelkouls, K., Dostie, J., Pyronnet, S., Kaufman, R.J., Weppler, S.A., Voncken, J.W., Lambin, P., Koumenis, C., Sonenberg, N., Wouters, B.G. Gene expression during acute and prolonged hypoxia is regulated by distinct mechanisms of translational control. EMBO J 2006, 25 (5): 1114-25.

Weppler, S.A., Krause, M., Zyromska, A., Lambin, P., Baumann, M., Wouters, B.G. Response of U87 glioma xenografts treated with concurrent rapamycin and fractionated radiotherapy: possible role for thrombosis. Radiother Oncol 2007, 82 (1): 96-104.

Aerts, H.J.W.L., Dubois, L., Hackeng, T.M., Straathof, R., Chiu, R.K., Lieuwes, N.G., Jutten, B., Weppler, S.A., Lammering, G., Wouters, B.G., Lambin, $P$. Development and evaluation of a Cetuximab-based imaging probe to target EGFR and EGFRvIII. Radiother Oncol 2007, 83 (3): 326-332.

Weppler, S.A.*, Li, Y.*, Dubois, L., Lieuwes, N., Jutten, B., Lambin, P., Wouters, B.G., Lammering, G. Expression of EGFR variant vlll promotes both radiation resistance and hypoxia tolerance. Radiother Oncol 2007, 83 (3): 333-339.

( ${ }^{*}$ These authors contributed equally to this work).

Dubois, L.*, Magagnin, M.G.*, Cleven, A.H., Weppler, S.A., Grenacher, B., Landuyt, W., Lieuwes, N., Lambin, P., Gorr, T.A., Koritzinsky, M., Wouters., B.G. Inhibition of 4E-BP1 sensitizes U87 glioblastoma xenograft tumors to irradiation by decreasing hypoxia tolerance. Int $\mathrm{J}$ Radiat Oncol Biol Phys 2009, 73 (4): 1219-27.

Weppler, S.A., Koritzinsky, M., Voncken, J.W., Lambin, P., Wouters, B.G. Inhibition of 4E-BP1 phosphorylation and mRNA translation requires simultaneous blockade of mTORC1 and PI3K/Akt signaling. (manuscript submitted).

Weppler, S.A., Claessens, T., van Geel, M., Creytons, D., Vreeburg, M., Wouters, B.G., van Steensel, M.A.M. Neuroendocrine carcinoma in BirtHogg-Dubé syndrome. (manuscript submitted). 